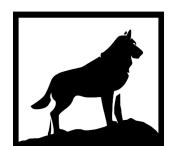

Michigan Technological

18.5 University
Michigan Technological University Digital Commons @ Michigan Tech

CAVE DETECTION USING SEISMIC METHODS AT MADISON BLUE SPRING STATE PARK, MADISON COUNTY, FLORIDA

Charles Breithaupt

Michigan Technological University, cibreith@mtu.edu

Copyright 2016 Charles Breithaupt

Recommended Citation

Breithaupt, Charles, "CAVE DETECTION USING SEISMIC METHODS AT MADISON BLUE SPRING STATE PARK, MADISON COUNTY, FLORIDA", Open Access Master's Thesis, Michigan Technological University, 2016.

https://doi.org/10.37099/mtu.dc.etdr/152

Follow this and additional works at: https://digitalcommons.mtu.edu/etdr

Part of the Geophysics and Seismology Commons 


\title{
CAVE DETECTION USING SEISMIC METHODS AT MADISON BLUE SPRING STATE PARK, MADISON COUNTY, FLORIDA
}

By

Charles Breithaupt

\begin{abstract}
A THESIS
Submitted in partial fulfillment of the requirements for the degree of

MASTER OF SCIENCE

In Geophysics
\end{abstract}

MICHIGAN TECHNOLOGICAL UNIVERSITY

2016

(C) 2016 Charles Breithaupt 
This thesis has been approved in partial fulfillment of the requirements for the Degree of MASTER OF SCIENCE in Geophysics.

Department of Geological and Mining Engineering and Sciences

Thesis Advisor: $\quad$ Prof. Jason D. Gulley

Committee Member: $\quad$ Prof. Wayne D. Pennington

Committee Member: $\quad$ Prof. Roger Turpening

Department Chair: $\quad$ Prof. John S. Gierke 


\section{Table of Contents}

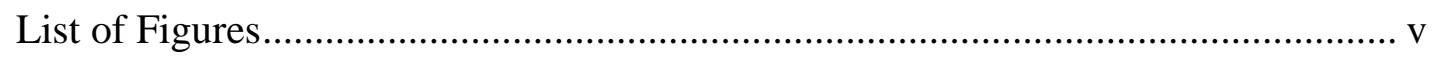

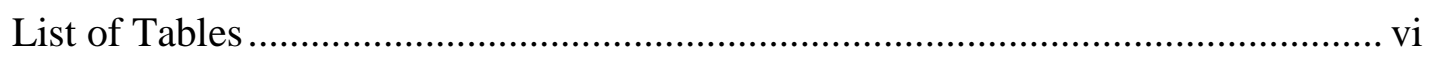

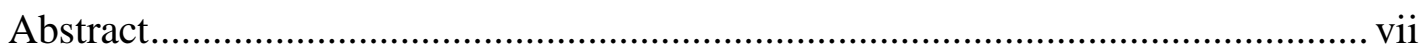

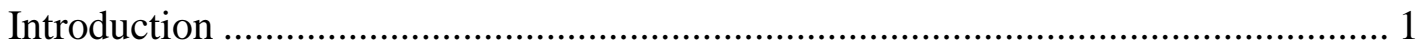

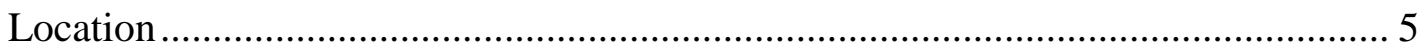

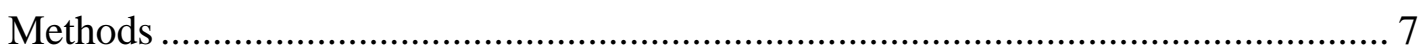

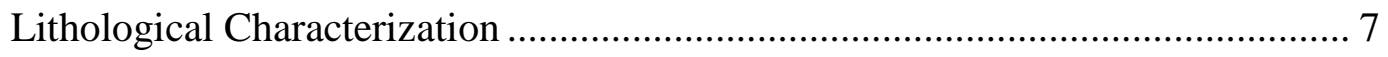

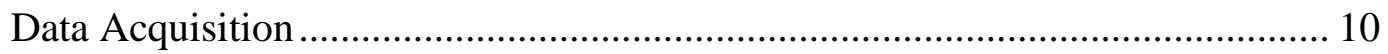

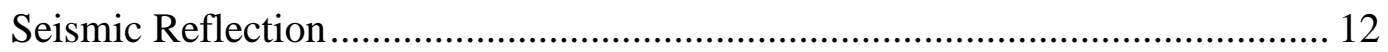

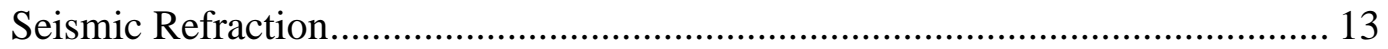

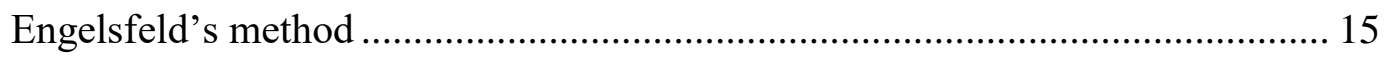

Multichannel Analysis of Surface Waves (MASW) ........................................ 17

Attenuation Analysis of Rayleigh Waves (AARW) .......................................... 19

Numerical Modeling of Seismic Wave Propogation.......................................... 21

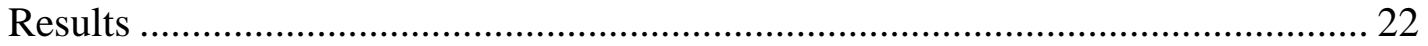

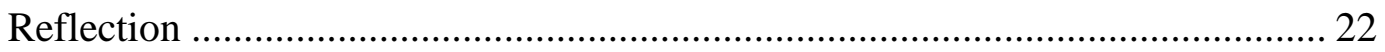

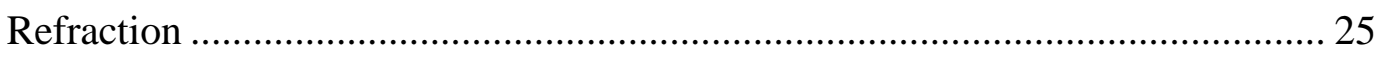

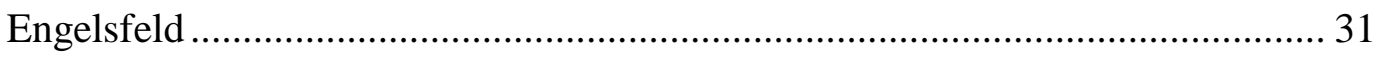

Attenuation Analysis of Rayleigh Waves (AARW) ......................................... 31

Multichannel Analysis of Surface Waves (MASW) ........................................... 36

Numerical Modeling of Seismic Wave Propagation .......................................... 39

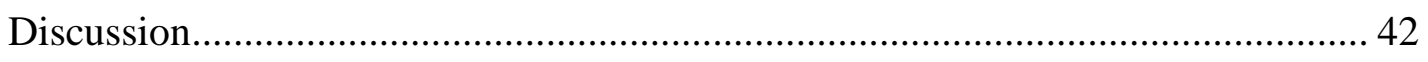

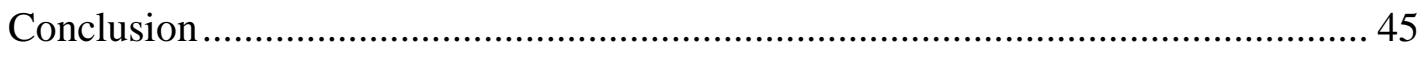

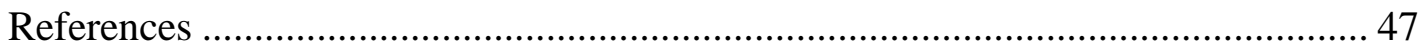

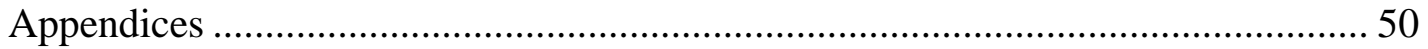

Appendix A: Survey Line Elevations \& Coordinates ......................................... 51

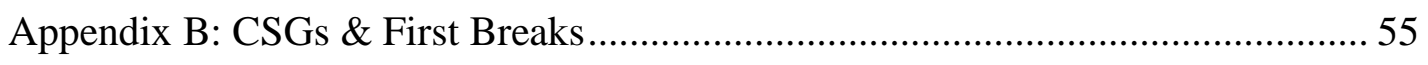

Appendix C: First Break Tables ..................................................................... 75 


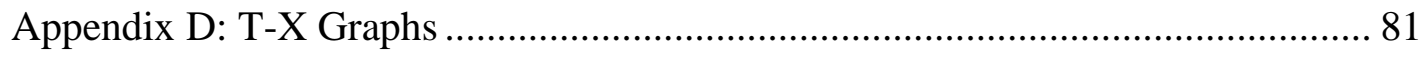

Appendix E: Processed \& Filtered Images .......................................................... 90

Appendix F: 3D Frequency Images...................................................................... 111

Appendix G: Frequency Contour Plots ............................................................ 123

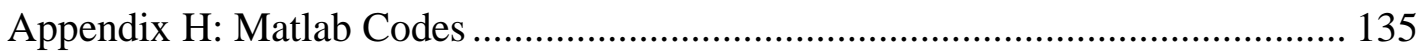




\section{List of Figures}

Figure 1: Location map of Madison Blue Spring State Park. ................................ 6

Figure 2: Map showing water wells near Madison Blue Spring State Park............. 8

Figure 3: Stratigraphic column of well number 78270 ......................................... 9

Figure 4: Conduit map with various seismic lines plotted in A through D............. 11

Figure 4A, B and C: Profiles perpendicular to conduit strike. ............................. 11

Figure 4D: Varying azimuth survey............................................................ 11

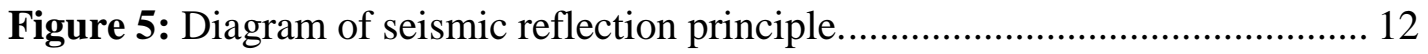

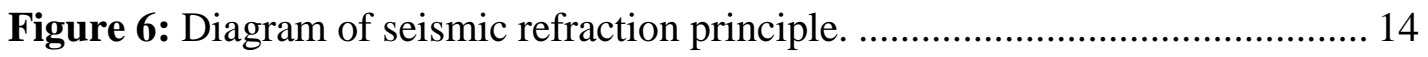

Figure 7: Example of first break picks from raw data ........................................ 14

Figure 8: Application of Engelsfeld method form the time vs distance graph........ 16

Figure 9: Diagram illustrating the concept of backscatter. ..................................... 18

Figure 10: Diagram of amplitude attenuation and concentration......................... 20

Figure 11: Acoustic finite difference model..................................................... 22

Figure 12: Incident reflection model....................................................... 23

Figure 13: Split shots displaying incident reflections in field data. Notice that ..... 24

Figure 14: Roll along line common shot gathers. ............................................... 26

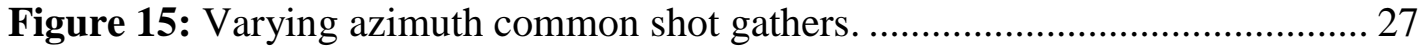

Figure 16: Roll along travel time curves ............................................................. 28

Figure 17: Varying Azimuth T-X curves. ..................................................... 29

Figure 19: 3D common shot gathers displayed in the frequency domain............... 34

Figure 20: 2D common shot gathers in the frequency domain. .......................... 35

Figure 21: Roll along processed common shot gathers................................... 37

Figure 22: Varying Azimuth processed common shot gathers ............................. 38

Figure 23: Comparison of real data to synthetic data........................................... 40

Figure 24: Data and Synthetic traces overlay.................................................... 41

Figure 25: Cave detection workflow ........................................................ 44

Figure 26 A-R: Complete set of common shot gathers with first breaks selected. . 74

Figure 28 A-S: Complete set of filtered common shot gathers.......................... 89

Figure 28 A-S: Complete set of filtered common shot gathers......................... 110

Figure 29 A-S: Complete set of frequency vs offset plots. .............................. 122

Figure 30 A-S: Complete set of frequency vs offset plots. ................................ 134 


\section{List of Tables}

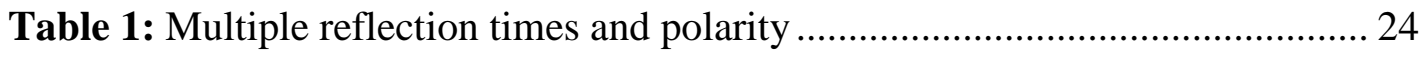

Table 2: Velocities and intercept times from all shots. ........................................ 30

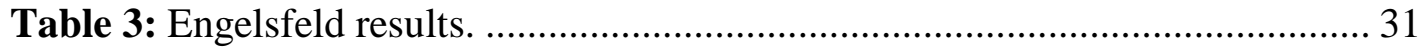

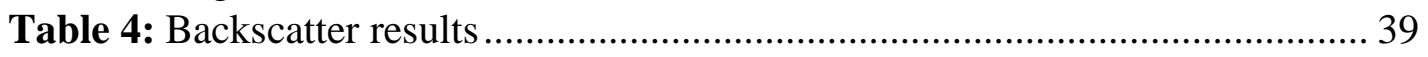

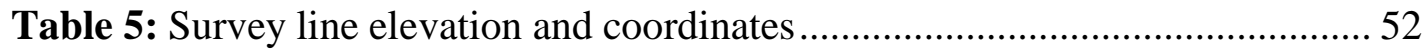

Table 6: Complete set of first break times vs offset ............................................ 76 


\section{Abstract}

Locating caves and quantifying their geometries has significant importance in aquifer characterization, sinkhole mitigation, and contaminant transport

monitoring. Several geophysical methods have been used for cave detection with limited success, but no reliable solution has been found. New developments in seismic techniques, however, show promising results indicating that cave voids may be more accurately detected.

We evaluated the capability of several seismic techniques to detect caves by collecting new seismic data over a known conduit connected to Madison Blue Spring, in northern Florida. These analyses validated the abilities of diffracted surface waves to detect water-filled caves by viewing these data in the time and frequency domain. We also used refracted and reflected P-waves to model multiple incident reflections for the conduit roof. Delay times in the refracted wave were present at the conduit offset but depth calculations using these delays proved unsuccessful. We were, however, able to demonstrate that surface wave diffractions can be synthetically modeled to verify field results. The combination of these seismic techniques was ultimately successful in determining the location, depth and approximate diameter of the conduit at Madison Blue Spring. 


\section{Introduction}

Karst is a landscape formed by the dissolution of soluble rocks and is characterized by sinkholes, caves, and complex networks of subsurface drainage conduits (Palmer 1991). Approximately 10-20 percent of the Earth's surface is karst, with the primary geomorphic mechanism being the collapse of underlying cave networks. Most of these caves result from the enlargement of prominent fracture networks and bedding planes by sinking streams (Palmer 1991).

Caves present several difficulties in construction projects and water resource management. A large cave failure can cost millions in property damage and threaten the safety of those near the collapse (Wilson and Beck 1992). Smaller cave collapses happen more frequently and render parking lots, roads and buildings unsafe. In karst systems, caves cause unique aquifer characteristics like anisotropy and rapid water table fluctuations (Ford and Williams 2007). Both point and diffuse recharge can occur from allogenic or autogenic sources making water budgets sensitive to local and regional precipitation levels. These aquifers are also at additional risk for contamination because they offer little filtration and provide pathways for accelerated transport through open fractures and sinking streams (Vesper., et al 2001). Detecting caves is important to both sinkhole mitigation and understanding karst aquifers, which currently supply as much as 25 percent of the world's population with drinking water (Ford and Williams 2007). 
While important to water resources and construction planning, caves are notoriously difficult to locate. Caves often go undetected when no entrance or surface expression is present. Even when entrances are present, caves can seldom be mapped to their entire extent. Dye tracing, geochemical studies and hydrograph analysis provide some information about cave systems but do not give indication of cave locations. However, several geophysical techniques are being applied in cave detection. Methods such as ground penetrating radar (GPR), and electrical resistivity (ER) have been widely employed for cave detection (Burger et al., 1992). While both methods have been successfully used to locate caves (Chalikakis et al., 2011), their use is subject to some limitations in many karst environments. The penetration depth of GPR is greatly variable depending on the overburden composition and thickness, and does not work where there is high clay content or salt water present (Chalikakis et al., 2011). Electrical resistivity is less sensitive to clay content and the presence of saline water, but it is greatly affected by anthropogenic noise such as well casing and water pipelines (Burger et al., 1992).

Shallow seismic surveys are another geophysical method that can be used to locate caves. Seismic methods utilize changes in density and elastic properties to infer subsurface geometries by interpretation of arrival times from various wave fronts (Burger et al., 1992). Seismic surveys tend not to be as limited by the site conditions as other techniques such as GPR or ER. This is because seismic signals attenuate more slowly and are insensitive to soil properties like conductivity which diminish other types of signals. Seismic methods, however, have not been as widely used as GPR or ER in cave detection because the seismic behavior tends to be different in each specific case (Grandjean and Leparoux 2004). Detection can be complicated depending on the nature of the interacting 
wave, void to wavelength ratio, and complexity of near surface layers. Diffracted compressional waves (P-waves) can be used to locate shallow voids but are often overlooked because of the overwhelming amplitudes of the surface waves (Rayleigh waves and Love waves) (Grandjean and Leparoux 2004). Deeper or smaller caves will be harder to detect because higher frequencies will attenuate with increasing depth. This means that the wavelengths will be longer and the resolution of these data will generally be limited to one quarter of the wavelength (Park and Miller 1999). The material properties and thickness of the overburden will dictate the amplitude and penetration depth of the surface waves in the second layer (Moghaddam 2006).

Progress in the field of void detection since the early 1990's resulting from development of new field procedures, and technological advancements, has led to the use of seismic techniques to locate caves to become more common (Chalikakis et al., 2011). These techniques utilize discrete wave types or combinations of the seismic wave field with both passive and active source acquisition.

Guided P-waves have long been utilized for determining near surface layer geometries, and several attempts have been made to incorporate them into void detection with varying success. Delay times have been generated in the head wave using a two layer synthetic model and a void diameter and embedment depth were calculated (Engelsfeld et al., 2008). These results were subsequently validated using a buried cylinder at a test site. More qualitative approaches have shown that attenuation and delay effects occur in the direct and diffracted P-wave arrivals near a buried cylinder (Grandjean and Leparoux 2004). 
Newer and more sophisticated P-wave methods such as refraction tomography have been used to delineate voids with mixed results in both synthetic and field tests. Synthetic tomography models have shown that both acquisition and subsurface geometries have profound influences on the inverted data (Sheehan et al., 2005). Even with substantial differences in velocity and density between voids and the surrounding materials, the measured velocity contrast tends to be less extensive due to the diffuse nature of the P-wave interactions; thus, refraction tomography can only be applied with limited reliability (Hickey 2009).

Surface waves have also been used to create shallow shear wave (S-wave) velocity profiles that would in theory be sensitive to voids (Xia et al., 1999). However, even with the high density and velocity contrast, the inverted S-wave profiles may not be of sufficiently high resolution to locate voids because they are created from surface wave measurements (Xia, et al., 2005). By using backscatter, however, voids could not only be detected, but it was also possible to calculate their embedment depth using the diffraction hyperbolas in the common shot gathers (CSGs). This method has been successfully used for karst void (Xia, et al., 2007), and tunnel detection (Sloan et al., 2013). There is also evidence that passive methods can be used to infer near surface heterogeneities using controlled source seismic interferometry and ghost scattered surface and body waves (Harmankaya et al., 2013).

Techniques that rely on scattering of waves to identify conduits have not proven to be as useful in detecting caves as hoped because caves are not the only scattering features in karst systems. Any rapidly changing lateral variation in density or elastic moduli can become a scatterer. Faults, buried sinkholes, and slot and block features can 
all be present in karst systems (Sowers 1996), and contribute to scattering. Consequently, it is often difficult to determine the degree to which scatter results from caves or these other features.

Attenuation analysis of Rayleigh waves (AARW) has shown potential for uniquely identifying caves by examining the energy distribution in the frequency domain across a common shot gather (Moghaddam 2006). This technique has been successfully applied to drainage culverts where surface wave diffractions and energy from the oscillating culvert appear as energy anomalies in the frequency domain (Putnam et al., 2008). The advantage of the AARW method over other types of seismic analysis is that the additional energy generated requires an enclosed boundary to trap waves, making it unique to voids (Moghaddam 2006).

In this study, we determine the effectiveness of seismic refraction, reflection, MASW, AARW and the Engelsfeld method for detecting water-filled karst features up to 30 feet below the surface. We accomplished this by testing these methods over a known conduit at Madison Blue Springs State Park in north central Florida. We will couple our field analysis with a modeling study to further validate our findings.

\section{Location}

Madison Blue Spring is located in north central Florida (Fig. 1). The regional geology consists of an early Oligocene formation called the Suwannee Limestone, which is overlain by 3 to 5 meters of sands and clays (Fig. 3). The Suwannee Limestone is underlain by the Ocala limestone, which is nearly indistinguishable from the Suwanee Limestone (Miller 1982). The Suwannee and Ocala limestones contain a number of 
springs discharging water from the upper Floridian aquifer. These springs include nine first magnitude defined as having discharge rates greater than $2.8 \mathrm{~m}^{3} / \mathrm{s}$ (Meinzer 1927). Madison Blue Spring discharges water at a rate of 2.0 to $3.9 \mathrm{~m}^{3} / \mathrm{s}$ from an extensive conduit network to the Withlacoochee River by way of a spring run (Gulley, et al. 2011).

Cave divers have mapped more than $8 \mathrm{~km}$ of passages that are connected to Madison Blue Spring (Gulley et al., 2011). Within 100 meters of the spring vent, where we focused our investigation, the mapped passage is approximately 18 meters below the water table, and has a width of 25 feet ( 7.6 meters), and height of 9 feet ( 2.75 meters) (Fig. 4).

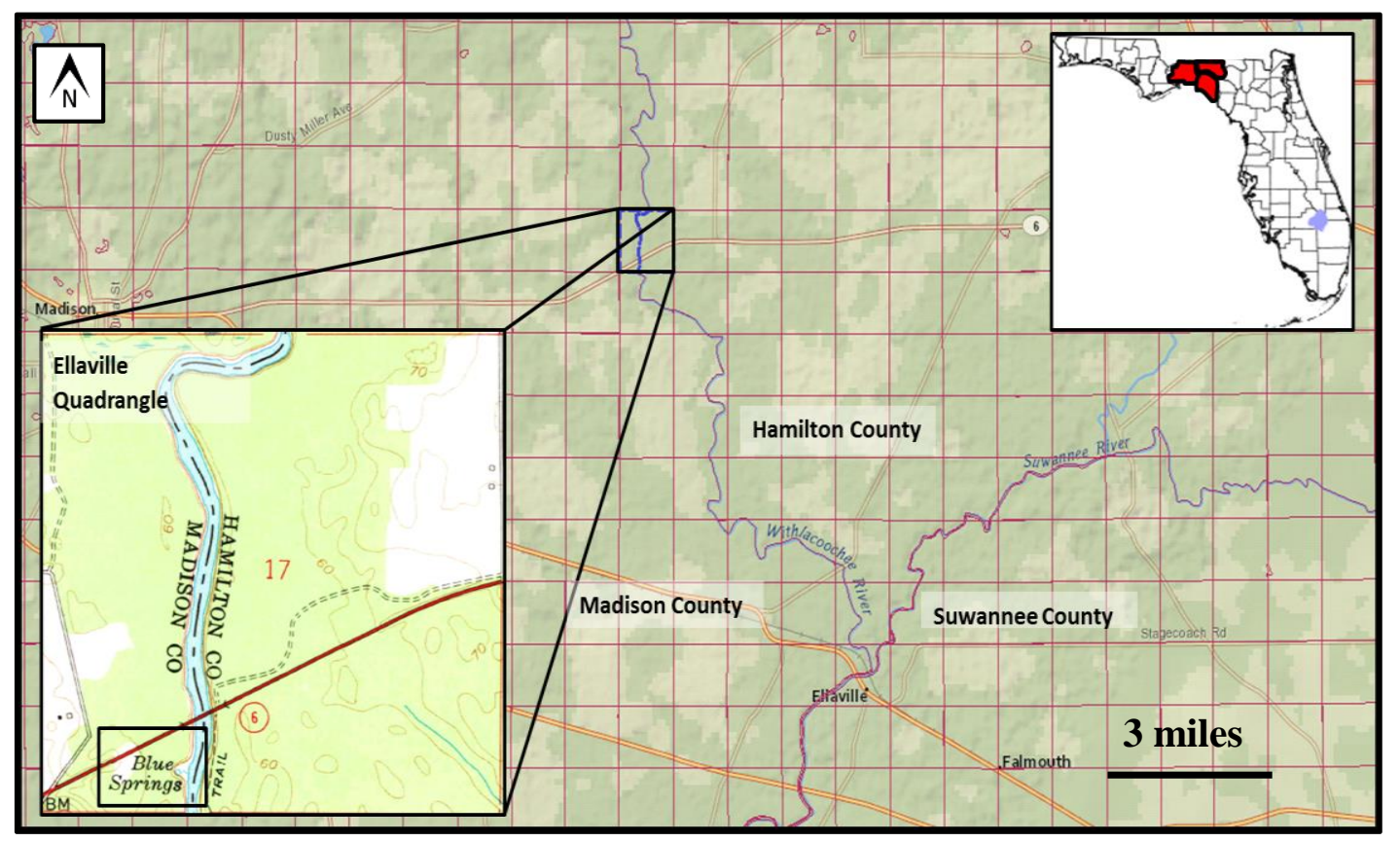

Figure 1: Location map of Madison Blue Spring State Park. The three counties highlighted in red in the Florida state index map are Madison, Hamilton, and Suwannee County. The county boundaries are defined by the intersection of the Withlacoochee and Suwannee rivers. The Ellaville quadrangle is approximately 7 miles north of the intersection of the rivers. Madison Blue Springs state park can be seen in the Southwestern corner of the Ellaville quadrangle. 


\section{Methods}

\section{Lithological Characterization}

We used drilling logs from water wells to determine the depth to water table and elevation of lithological contacts. These data were used as control points for the interpretation of seismic data collected in the field and the generation of a synthetic computer model which was used to validate interpretation of field data (see synthetic data modeling results). Data were acquired from the Saint Johns River Water Management District (SJRWMD) Hydrogeologic information system (www.sjrwmd.com). Wells with lithological logs were sparse but analysis of six wells available within 1.5 kilometers of Madison Blue Spring indicate a relatively flat bedrock surface (Fig. 2). Well number 78270 is closest to Madison Blue Spring and is used to approximate the elevation of the water table and bedrock. An image generated from this well indicates the water table elevation at approximately 15 meters above sea level (Fig. 3). Using a handheld GPS and Google Earth, we estimated both the elevation of the ground surface above the conduit and the nearby river surface. The ground surface elevation was 58 feet (17.68 meters) above sea level while the river surface was 40 feet (12.2 meters) above sea level. The water table in the nearby well is slightly above the river surface elevation. We will use the elevation of the river surface in our calculation due to its proximity to the survey location. Given a conduit depth of 18 meters below the water table, and a difference in elevation of the ground and water surface of 5.48 meters the approximated conduit depth is 23.5 meters below the ground surface. 


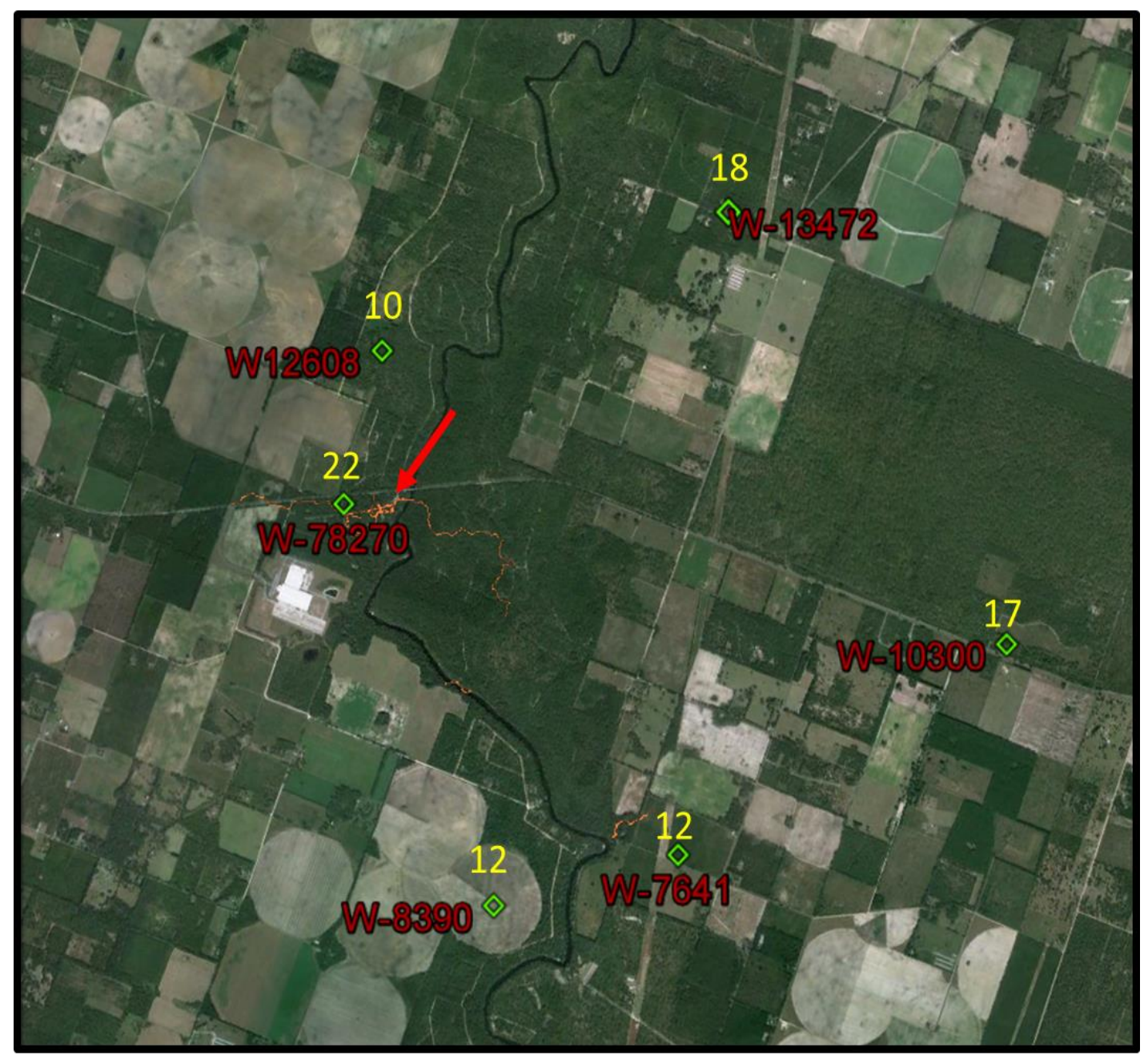

$2000 \mathrm{~m}$

Figure 2: Map showing water wells near Madison Blue Spring State Park. The red numbers are the well identification number and the yellow numbers indicate the bedrock elevation in each well. These wells show that regionally the bedrock is practically flat having a maximum dip of 1.3 degrees between wells 78270 and 12608 . Well number 78270 also indicates a water table elevation of 15.5 meters which is useful in determining the proximity of the water table and bedrock at the nearby study location indicated by the red arrow. 


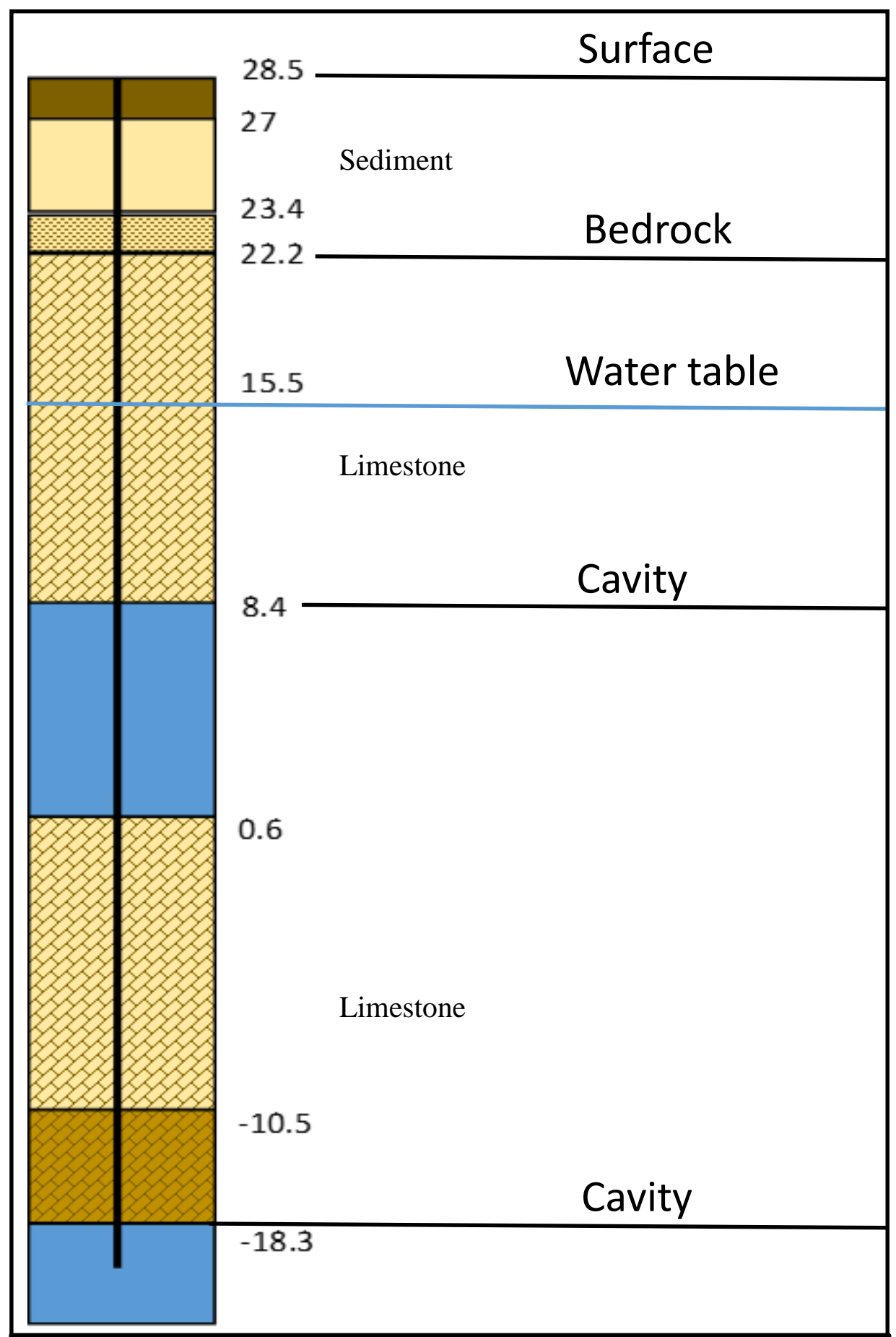

Figure 3: Stratigraphic column of well number 78270 . Notice the bedrock elevation is approximately 22.2 meters and the water table is indicated by the blue line at 15.5 meters in elevation above MSL. Two large voids are observed at elevations of 8.4 and -18.3 meters respectively. 


\section{Data Acquisition}

Seismic data were collected over the conduit using a Geometrics Geode 24channel exploration seismograph with 24 vertical component 4-hertz geophones. All common shot gathers (CSG) were collected by stacking 20 impacts from a 12-pound sledgehammer. We used two complementary survey techniques to infer the geometry of the conduit. A roll along seismic survey perpendicular to the conduit was used to define the lateral position and width of the conduit, and a varying azimuth survey to define the conduits strike. We used a 2-meter geophone spacing and 1 meter off end shot locations on all of the common shot gathers. The total geophone spread length was 46 meters, with the shot being moved to either end of the line to check for reciprocity and provide data to determine the bedrock dip, if necessary. We moved the line 12 meters and the procedure was repeated until the line had a total length of 71 meters with the first shot point at zero and the last at 71 . The varying azimuth lines were rotated about an offset of 36 meters on line 2 and were only a single spread length due to sight limitations (Fig. 4D). All of the lines were plotted using GPS coordinates collected in the field. An elevation base station was established at the beginning of the line by referencing quadrangle maps found on the Florida Geological Surveys website. The subsequent elevation points were collected relative to the beginning of the line using a standard auto leveling procedure. However, no elevation data were recorded for the seismic lines with the other two azimuths. Elevation and GPS data can be found in Appendix A. 

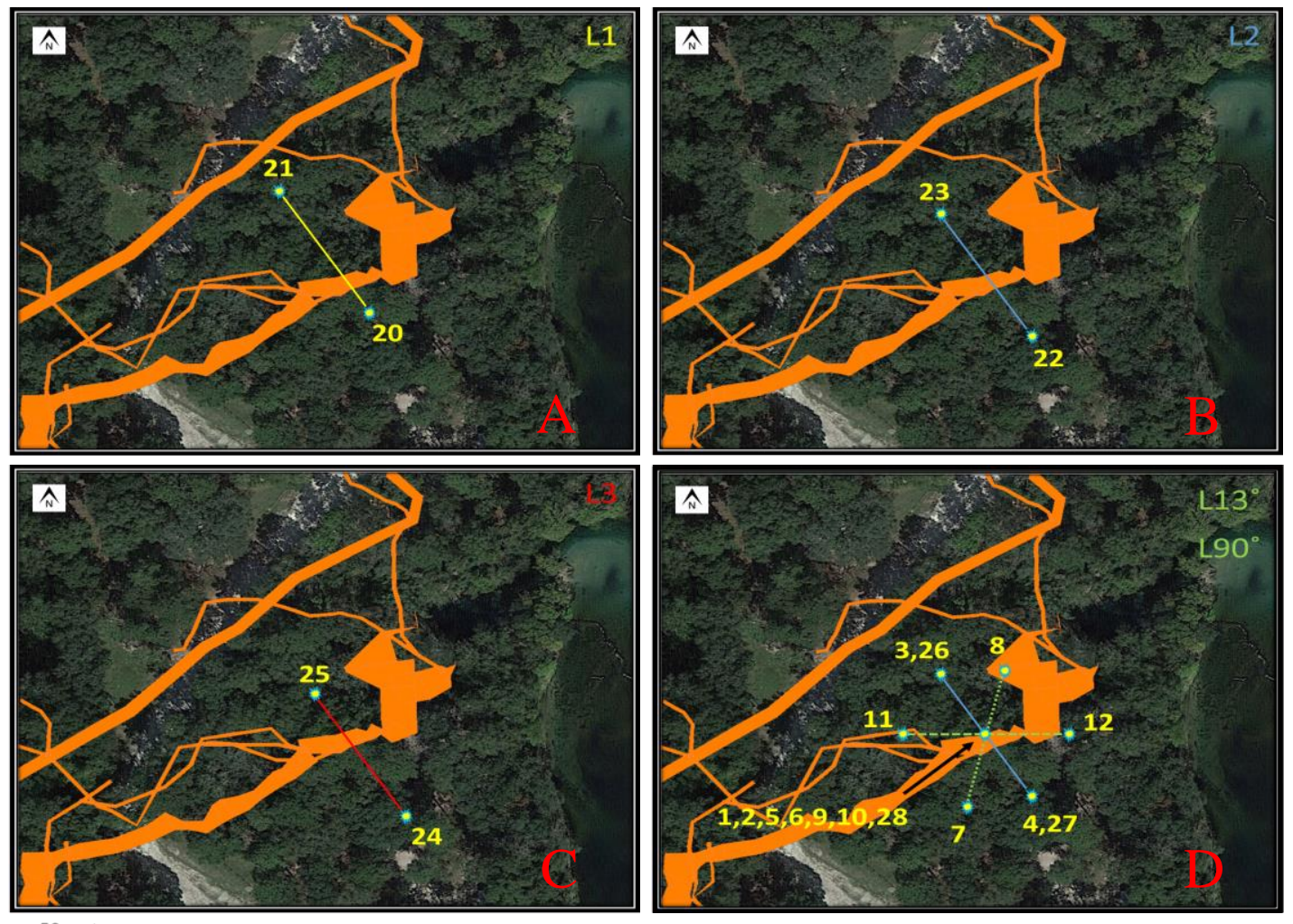

50 meters

Figure 4: Conduit map with various seismic lines plotted in A through D. The conduit is displayed in orange and has a known depth of 18 meters below the water level from hydrostatic measurements. The ground surface elevation directly above the conduit is 17.68 meters and the river level is 12.8 meters above sea level. This yields an approximate conduit depth of 23.5 meters. The conduit dimensions at the intersection of L1, L2, and L3 is approximately 3 meters in height and 7 meters wide.

Figure 4A, B and C: Profiles perpendicular to conduit strike. Shot locations are measured in 12 meter increments relative to shot number 20; thus shots 20,21,22,(1\&2),23,24, and 25 are located at offsets of $0,12,24,36,48,60$ and 72 meters respectively. Note that the conduit intersections this line at an offset of 39 meters from shot number 20 .

Figure 4D: Varying azimuth survey. This survey is composed of three lines at azimuths of 13, 90 and the orientation of L1, at 145 degrees. Note that several split shots are taken at an offset of 36 meters from shot number 20. The lines were rotated about this center point keeping their offset assignments from L1 for easier comparison of the varying azimuth shots. 


\section{Seismic Reflection}

Seismic methods take advantage of changes in velocity and density to infer subsurface geometries (Burger et al., 1992). The seismic reflection method (Fig. 5) utilizes energy reflected from a boundary across which there is a change in acoustic impedance (defined as the product of velocity and density) to infer depth to an object or interface (Ashcroft 2011). Seismic reflection is typically used for imaging continuous

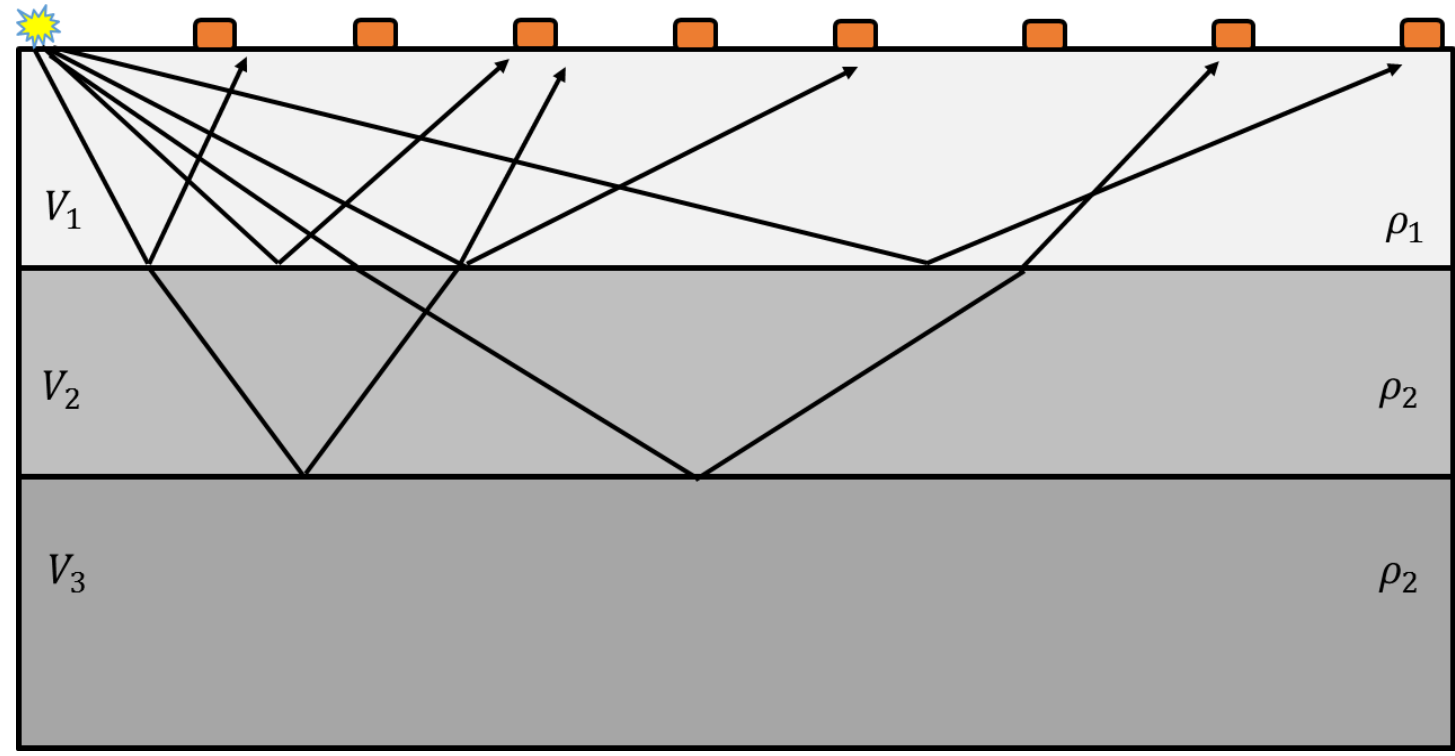

Figure 5: Diagram of seismic reflection principle. P-waves travel to a boundary in a layered half space and due to a change in velocity and/or density are reflected back to the surface. The time it takes for each reflection to travel from the source to a boundary and back to a geophone is recorded in two way travel time TWTT and can later be used to infer subsurface geometries.

reflectors (Ashcroft 2011). In this study, however, we apply the reflection method in an attempt to predict the two-way travel times of an incident wave and its multiples. A wave will travel from the source to the top of the conduit and back changing polarity each time it reflects from the conduit and the free surface (Ashcroft 2011). Because we knew the 
approximate location of the conduit when acquiring these data, we designed the array with the source above the conduit in an attempt to create an incident reflection from the conduit roof. The travel times of the incident reflection and its multiples were then recorded on the common shot gathers. Because we know that the conduit is embedded in limestone and water-filled we can obtain a reflection coefficient to determine the polarity of the reflection and multiples (Eq1). We then built a model using the layer velocities and thicknesses obtained from the refraction method and varied the depth of the void until the calculated travel times and polarities matched the data collected on the field records.

\section{Eq. 1.}

$$
R C=\left(\rho_{1} V_{1}-\rho_{2} V_{2}\right) /\left(\rho_{1} V_{1}+\rho_{2} V_{2}\right)
$$

where $V_{1}, V_{2}, \rho_{1}, \rho_{2}$ are in this casee densities of limestone and water

(Ashcroft 2011)

\section{Seismic Refraction}

Seismic refraction utilizes waves that are critically refracted or guided along a layer boundary to measure velocity, travel time, and infer depth (Burger et al., 1992) (Fig. 6). These waves are the first to arrive at the geophone from the source making them the "first breaks" of the head wave. These first break times are selected from the raw shot plotted on a time versus offset graph (T-X graph) to determine the velocity and intercept times of each layer (Fig. 7). This is known as the time intercept method (Burger et al., 1992) and we will use it in this study to determine layer velocities, depth to bedrock, and dip of the bedrock interface. 

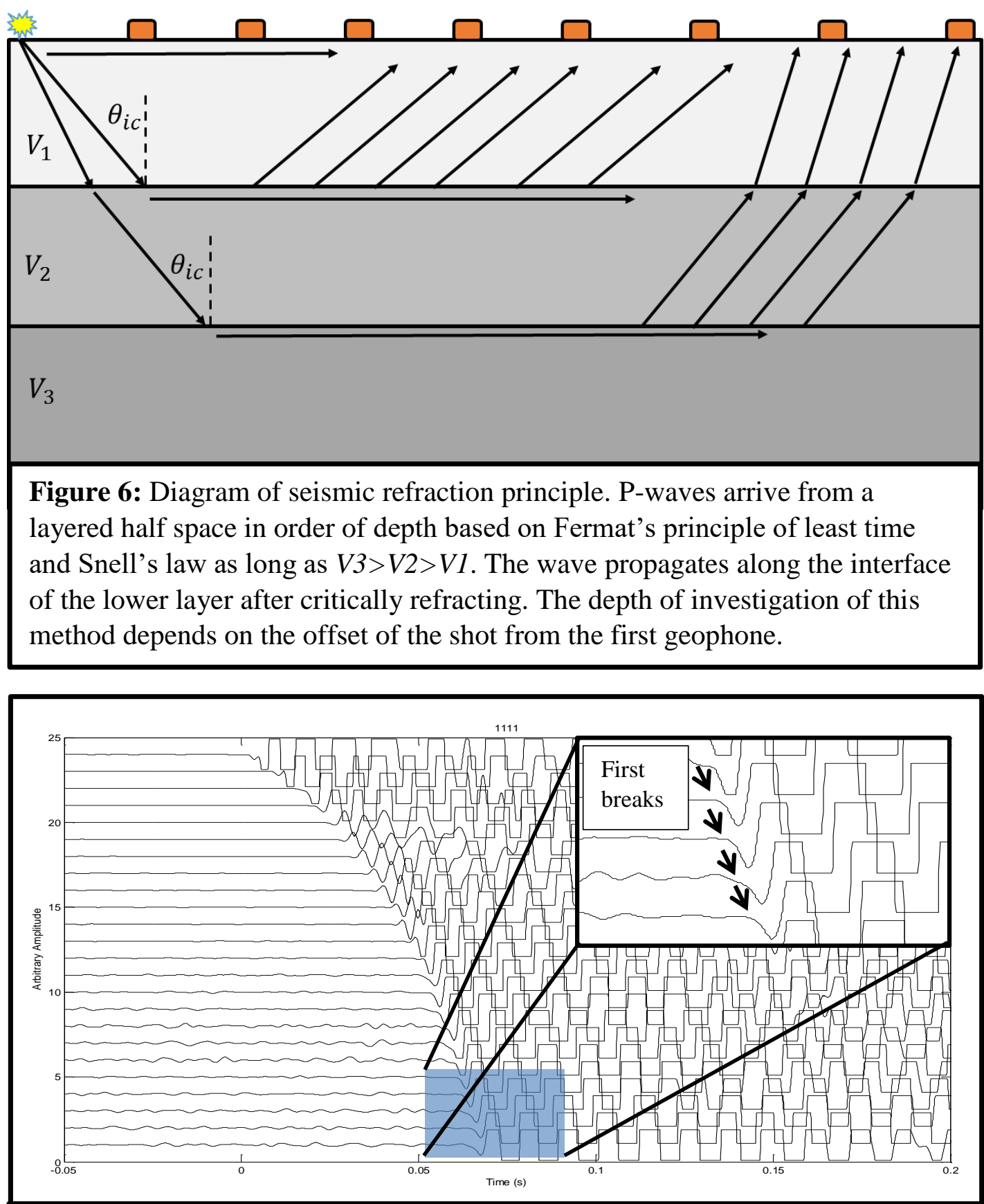

Figure 7: Example of first break picks from raw data. The first break is generated when the geophone first begins to experience ground displacement due to a wave arrival from a source. An example of first breaks is displayed in the small cut out in the upper right hand corner. By selecting the arrival times and plotting them against geophone offset a $\mathrm{T}-\mathrm{X}$ graph is generated and the velocity of the first break arrivals can be calculated. These velocities paired with the intercept times of each slope can be used to calculate depth and dip. 


\section{Engelsfeld's method}

The seismic velocity and density of fluid and sediment filled karst features differ greatly from the surrounding rock in which they are embedded (Chalikakis et al., 2011). For this reason, the seismic refraction method seems to be a likely candidate for void detection. Refraction however is inadequate in delineating voids when they are not embedded in horizontal layering (Sheehan et al., 2005). The requirement that velocity increases with depth to avoid near surface fast layers hiding structures also limits the effectiveness of refraction (Chalikakis et al., 2011). Despite its limitations, there are some refraction phenomena that can be used to detect and approximate the geometries of subsurface heterogeneities. One model suggests that when a critically refracted up-going wave field encounters a void it will act as a boundary to wave propagation due to the large contrast in elastic parameters (Engelsfeld et al., 2008). By invoking Huygen's principle, the interaction of the wave field with the boundary generates new sources and a new wave field propagates from the void interface with a delay due to the added length of the wave path (Engelsfeld et al., 2008). This delay time is dependent on the size and depth of the void as well as the depth of the refraction surface. The workflow and equations used to calculate conduit embedment depth and diameter can be seen below in Figure 8 and in equations 2, 3 and 4 taken from (Engelsfeld et al., 2008). 


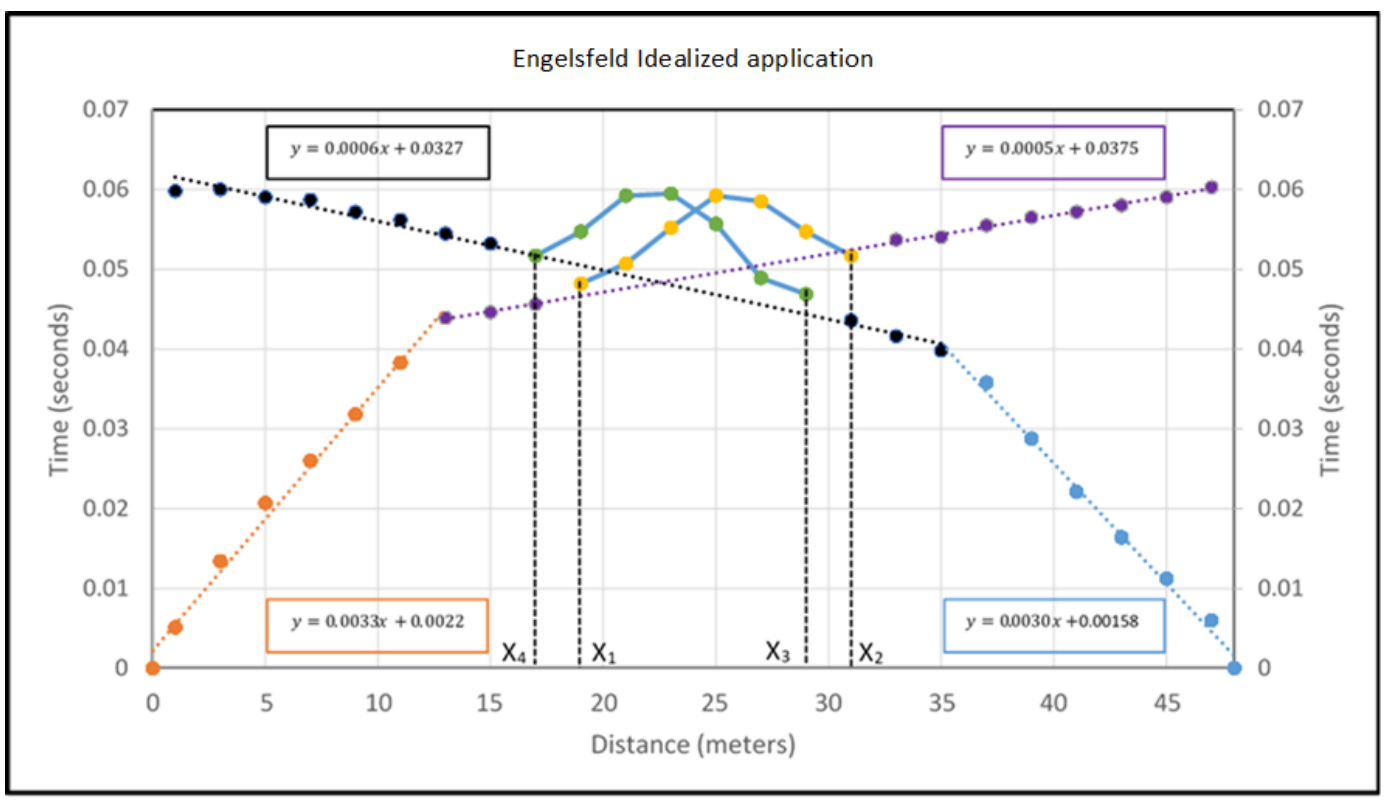

Figure 8: Application of Engelsfeld method form the time vs distance graph. The $\mathrm{x}$ locations indicate the beginning and end of delays from forward and reverse shots. The velocity of each layer is taken from the inverse of the slope of each line but excludes the delay times caused by the void.

Eq 2. Radius of the cavity

$$
2 r=\left(x_{2}-x_{1}\right) \cos (\theta)
$$

Eq 3. Location of the cavity

$$
x_{p}=\frac{\left(x_{1}+x_{3}\right)}{2}=\frac{\left(x_{2}+x_{4}\right)}{2}
$$

\section{Eq 4. Depth of the cavity}

$$
z=\frac{\left(x_{2}-x_{3}\right)}{2 \cos (\theta)}
$$

Where

$$
\theta=\text { critical angle }=\sin ^{-1}\left(\frac{v_{1}}{v_{2}}\right)
$$

And

$v_{1}$ and $v_{2}$ are layer 1 and 2 velocities calculated from the $T-X$ graph 
This particular model is designed for two layers where the conduit is in the first layer but may theoretically be applied as long as the object exists in a layer above an interface producing an up going head wave which generates a first break on the geophone array. However, it is also important to note that a phenomenon known as wave front healing may occur (Stein and Wysession 2003) where a reduction in delay times resulting from the bending of waves around the void or low velocity zone may occur. This would render some voids and conduits invisible in the first arrivals depending on their size, depth, and properties of the materials contained within their boundaries.

\section{Multichannel Analysis of Surface Waves (MASW)}

In the last 20 years, surface waves have been more frequently employed for obtaining near surface S-wave velocities for the detection of near surface heterogeneities (Xia et al., 2007). The dispersive nature of surface waves and the shear component of the Rayleigh waves makes detection of voids and low velocity zones easier and cheaper than with the traditional refraction and reflection methods (Grandjean and Leparoux 2004). In this study, we used a particular application of the MASW technique called backscatter analysis to estimate the location and depth of the conduit. An abridged version of the method is presented below. For the full method refer to (Xia et al., 2007).

Picture a forward traveling surface wave like the one illustrated in Figure 9. At a distance $\mathrm{X}$ this forward traveling wave, with a phase velocity $V_{R}$, intersects the cavity From the simple three term equation $\mathrm{D}=\mathrm{RT}$, the travel time $\mathrm{T}_{\mathrm{x}}$ is calculated when given 


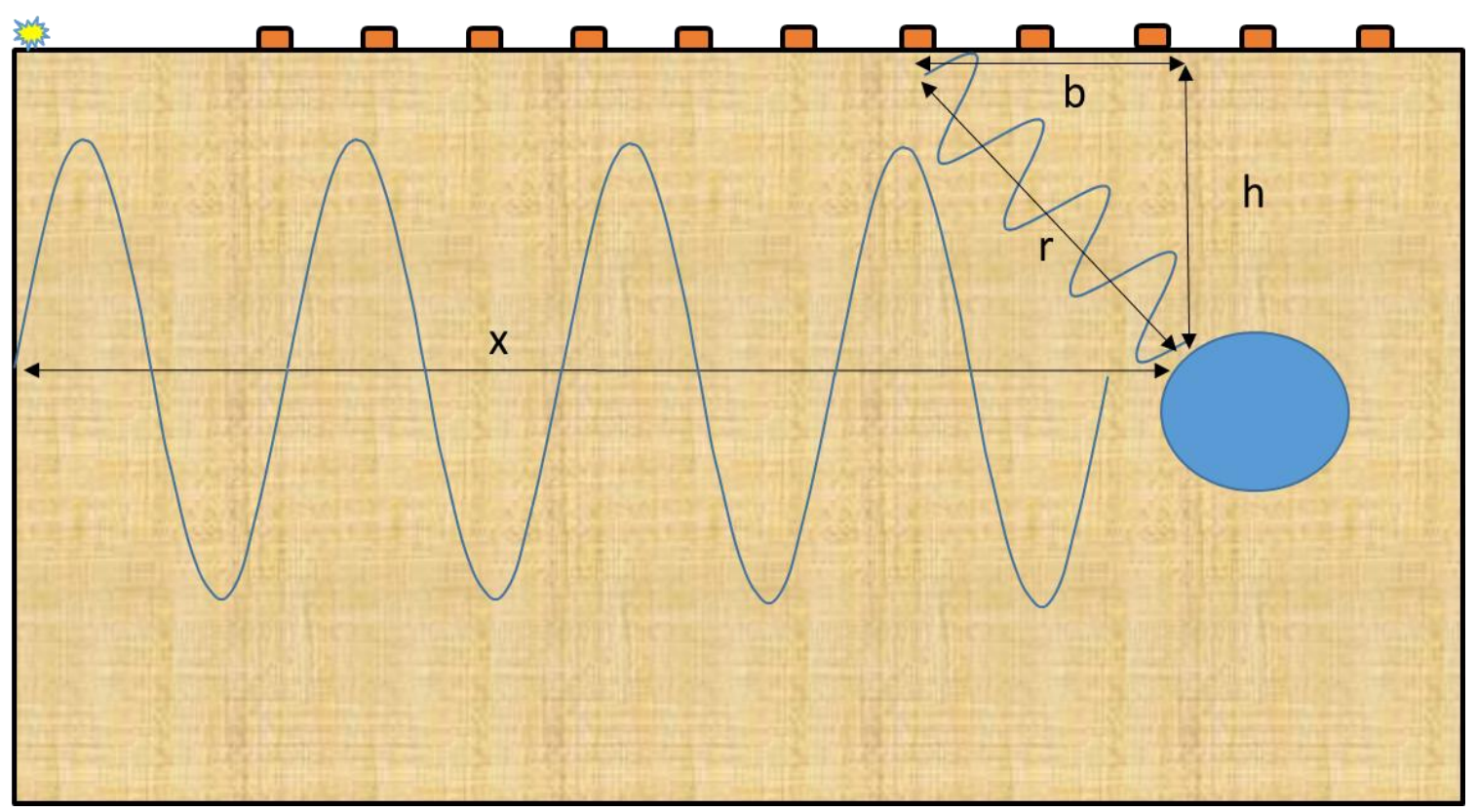

Figure 9: Diagram illustrating the concept of backscatter. A forward propagating wave travels distance $\mathrm{x}$ before reflecting off a subsurface body back to the surface. As $h$ increases, $b$ becomes negligible. However, the object will become harder to detect due to the exponential decay of surface waves with depth.

$V_{R}$ and $X$. Once reaching the cavity a component of the forward propagating wave is scattered back to the surface with the same phase velocity $V_{R}$. On the shot record the arrival of the scattered energy will appear as a hyperbola with the apex at the approximate offset of the void. The additional time for the wave to travel to the surface is the distance $r$ divided by the phase velocity $V_{R}$. Therefore, the travel time observed on the shot record for an event scattered from the conduit can be given by Eq. 5 .

Eq. 5

$$
\begin{gathered}
T_{t}=T_{x}+T_{r} \\
T_{x}=\frac{X}{V_{R}} \text { and } T_{r}=\frac{\sqrt{b^{2}+h^{2}}}{V_{R}}
\end{gathered}
$$


Since the arrival of backscattered energy can be read directly from the shot record, $\mathrm{T}_{\mathrm{r}}$ can be determined by the simple difference of $\mathrm{T}_{t}$ and $\mathrm{T}_{\mathrm{x}}$. After obtaining the value for $\mathrm{T}_{\mathrm{r}}$ we can solve for the depth to the top of the cavity (h) using Eq. 6.

Eq. 6

$$
h=\sqrt{\left(T_{r} V_{R}\right)^{2}+b^{2}}
$$

when $b$ approches 0

$$
h \approx T_{r} V_{R}
$$

This approach is dependent upon two key assumptions. The first of which is that the surface wave is traveling approximately horizontally from the source. This assumption becomes more valid with greater offsets between the source and void but its effectiveness diminishes when offsets become too large due to attenuation. A second assumption is that $\mathrm{b}$ becomes negligibly small. Given that the scatter is in all directions this hypothesis is valid since the shortest path would be approximately vertical. Some energy will be scattered forward from the object but those arrivals are difficult to detect as they will be mixed with the arrivals of other phase velocities in the surface wave packet.

\section{Attenuation Analysis of Rayleigh Waves (AARW)}

Another approach to locating voids and conduits is to look closely at the attenuation of surface waves in the frequency domain (attenuation analysis of Rayleigh waves AARW) (Moghaddam 2006). Due to Rayleigh wave excitation a subsurface void vibrates and wave partitioning occurs (Moghaddam 2006). Some of the incident energy is reflected in the form of backscatter as described in the previous section. Some of the 
energy is transferred into body waves and propagates in the medium surrounding the void. A third portion of energy is trapped inside the void reflecting from the void boundaries until attenuating (Moghaddam 2006). This partitioning of energy leaves the transferred portion of the Rayleigh wave more severely attenuated in the region just past the void. The receivers above the void, however, will receive additional energy from the backscattered Rayleigh waves and from the reverberation of the conduit due to the waves trapped inside (Fig. 10). These zones of additional and attenuated energy can be seen in

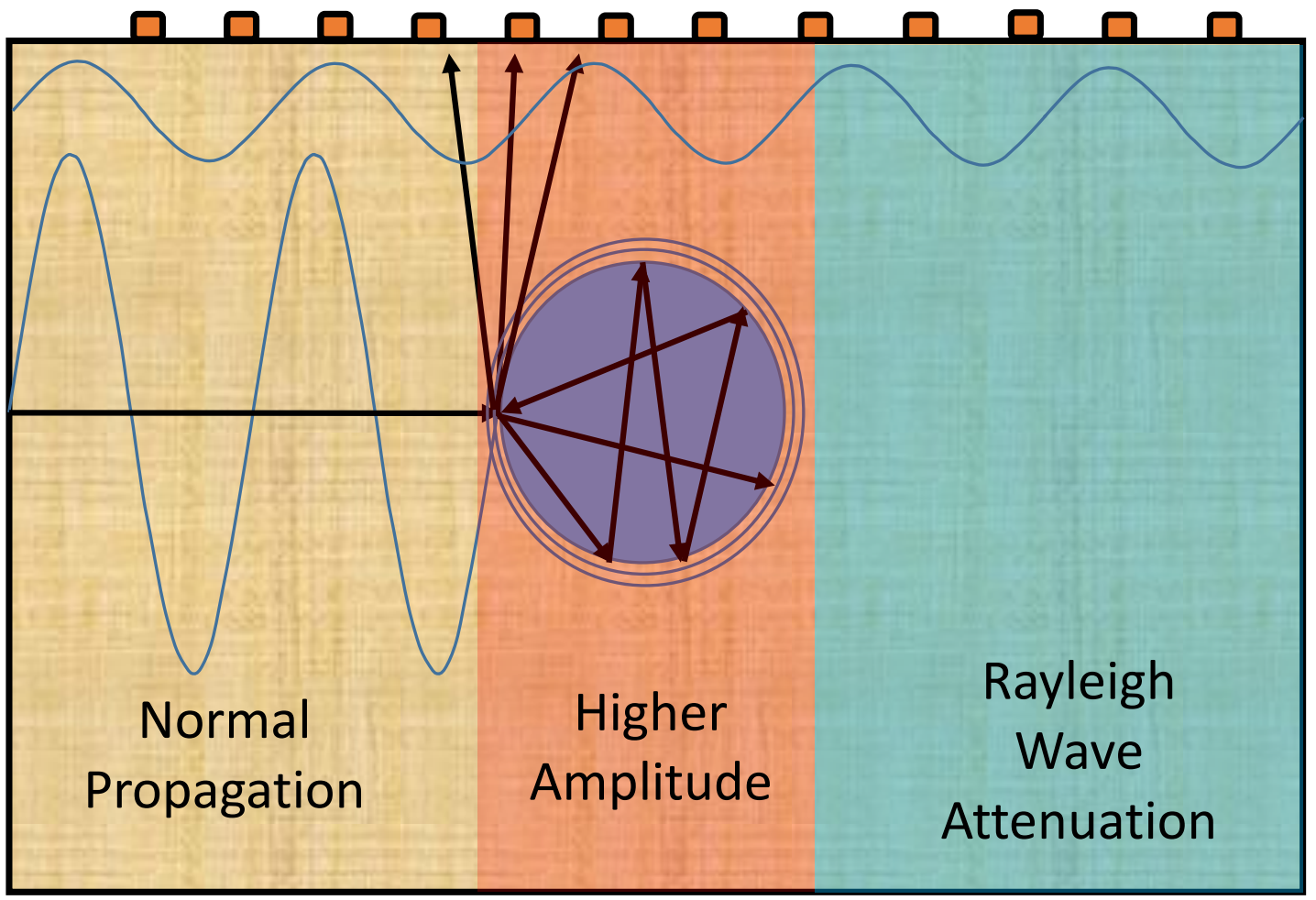

Figure 10: Diagram of amplitude attenuation and concentration. The area before the conduit contains Rayleigh waves traveling with normally attenuated amplitudes. In the zone around the conduit energy is scattered off the conduit, trapped inside it or converted to body waves. The receivers directly above the conduit exhibit elevated amplitudes while the receivers after the conduit contain reduced amplitudes. The size and shape of the conduit will determine the number of channels affected and the depth of the conduit will determine the extent to which the wave field is affected. Note that some of the surface waves will not be affected as they cannot penetrate deep enough to interact with the void. 
both the time and frequency domains. The time domain is simply displayed as a shot gather and the void location can be indicated by backscatter, low amplitudes, changes in the slopes of surface waves and diffraction patterns in other wave packets (Putnam et al., 2008). In the frequency domain energy appears in anomalously high concentrations even at offsets far from the source. These concentrations are localized to a few channels that are either directly above the conduit or at a location that is a function of the geometry of the conduit.

\section{Numerical Modeling of Seismic Wave Propagation}

We generated synthetic data using finite difference analysis to confirm results from the backscatter analysis. Using a model with the relative elevation profile of the site and a minimum phase wavelet that was statistically extracted from field data several iterations of acoustic and elastic finite difference models were produced using GeoTomo (Fig. 11). Because we are only interested in the nature of the diffraction off the conduit, an acoustic model is appropriate as long as we acknowledge that the input p-wave velocity is in reality the phase velocity of the diffracted Rayleigh wave. This model can be used to confirm the depth of the object responsible for the backscatter event but not for other parameters. We were limited to this model in part because GeoTomo does not include attenuation in their finite difference codes, which is important for interactions of waves both at the boundary and passing through the conduit. This model is however sensitive to the depth of the conduit and will produce diffraction hyperbolae with different apex times which can then be compared with the diffraction arrivals in real data. 


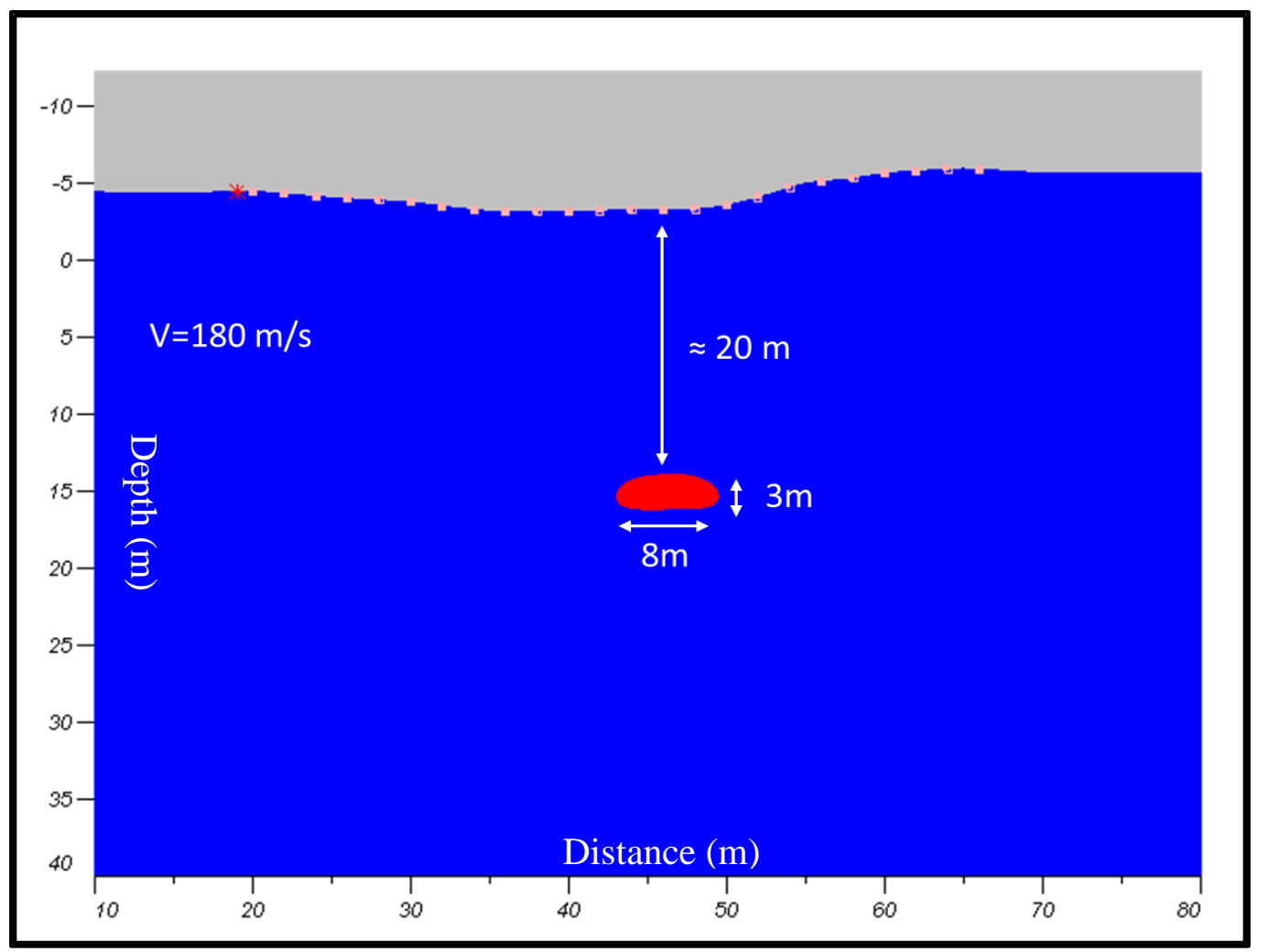

Figure 11: Acoustic finite difference model. The model was generated using a finite difference code from Geotomo. The model includes relative surface elevation and has a geophone spacing of 2 meters. Using a phase velocity of $180 \mathrm{~m} / \mathrm{s}$ to represent a forward traveling surface wave, this model is used to observe the nature of the diffraction a wave matching the phase velocity of the forward propagating surface wave. The object is at approximately 20 meters in depth from the ground surface and has dimensions of 8 meters wide and 3 meters high.

\section{Results}

\section{Reflection}

Using average layer velocities from the refraction method, a two-layer model was created (Fig. 12). The depth to the conduit was adjusted until a best fit of a properly polarized incident wave and its multiples was generated. The arrival times from the 
numerical model (Tab. 1) correlate well with shot 2 (Fig. 13). Shot number 5 has been band pass filtered $(10-60 \mathrm{~Hz})$ which will cause the phase of the wave to shift, hence the arrivals do not fit as well but the multiples are clearer (Fig. 13). Note that the multiple reflections will change polarity each time they are reflected from the free surface. Here we have only highlighted the negative reflections, which will include every other multiple for visual clarity. Using this model, we achieve a depth of 22 meters, which is comparable to our initial assumption of 23.5 meters below the ground surface.

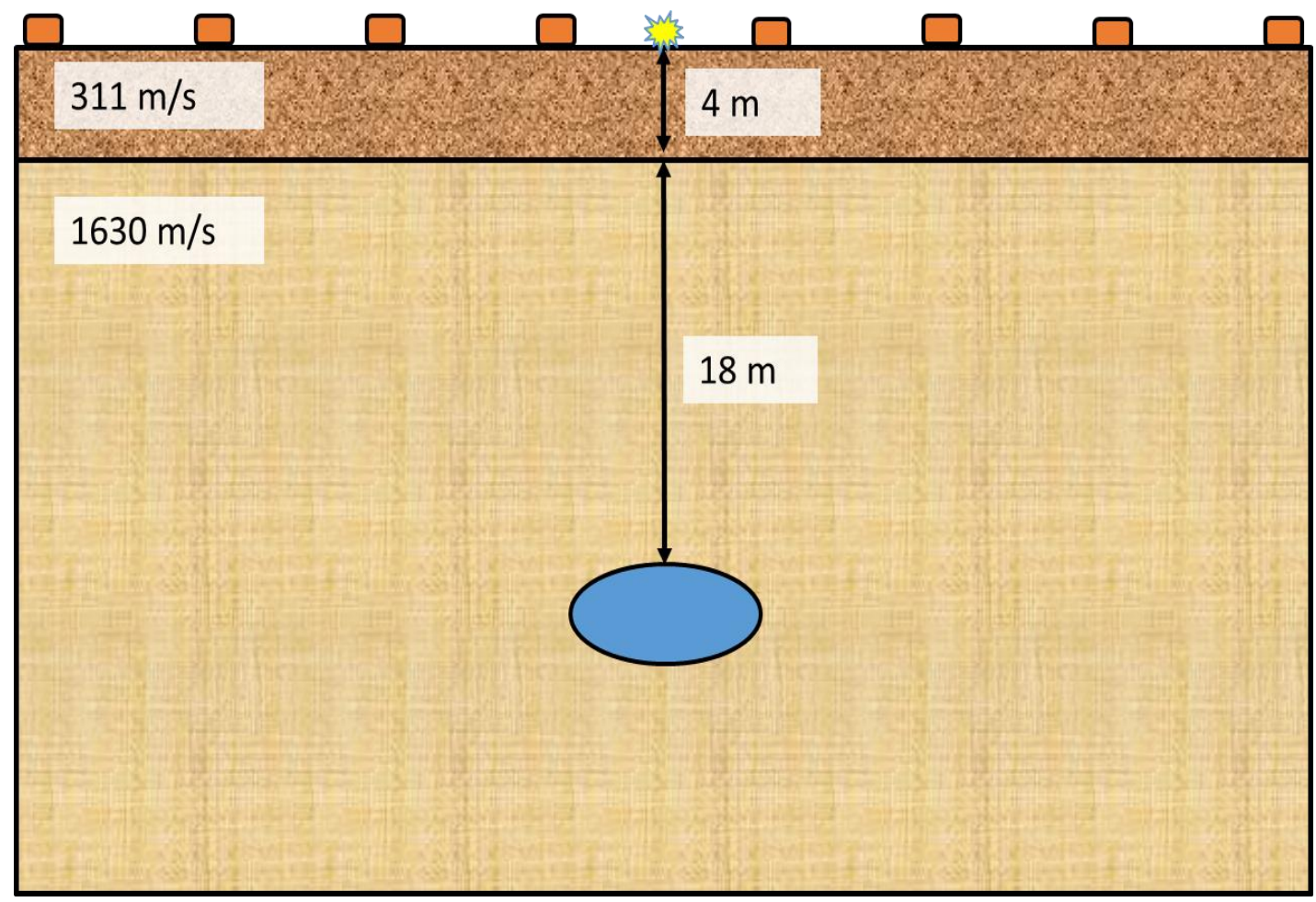

Figure 12: Incident reflection model. The conduit will generate a reflection with a negative polarity and the polarity will change each time as it is reflected off the free surface and the conduit. The velocities used are average velocities from all of the refraction analysis. Given this model the conduit would have a depth of approximately 22 meters. 
Table 1: Multiple reflection times and polarity

\begin{tabular}{|c|c|c|}
\hline Multiple & TWT & Polarity \\
\hline (\#) & (Seconds) & (P/N) \\
\hline $\mathbf{1}$ & 0.05 & $\mathrm{~N}$ \\
\hline $\mathbf{2}$ & 0.10 & $\mathrm{P}$ \\
\hline $\mathbf{3}$ & 0.14 & $\mathrm{~N}$ \\
\hline $\mathbf{4}$ & 0.19 & $\mathrm{P}$ \\
\hline $\mathbf{5}$ & 0.24 & $\mathrm{~N}$ \\
\hline $\mathbf{6}$ & 0.29 & $\mathrm{P}$ \\
\hline $\mathbf{7}$ & 0.33 & $\mathrm{~N}$ \\
\hline $\mathbf{8}$ & 0.38 & $\mathrm{P}$ \\
\hline $\mathbf{9}$ & 0.43 & $\mathrm{~N}$ \\
\hline $\mathbf{1 0}$ & 0.48 & $\mathrm{P}$ \\
\hline
\end{tabular}
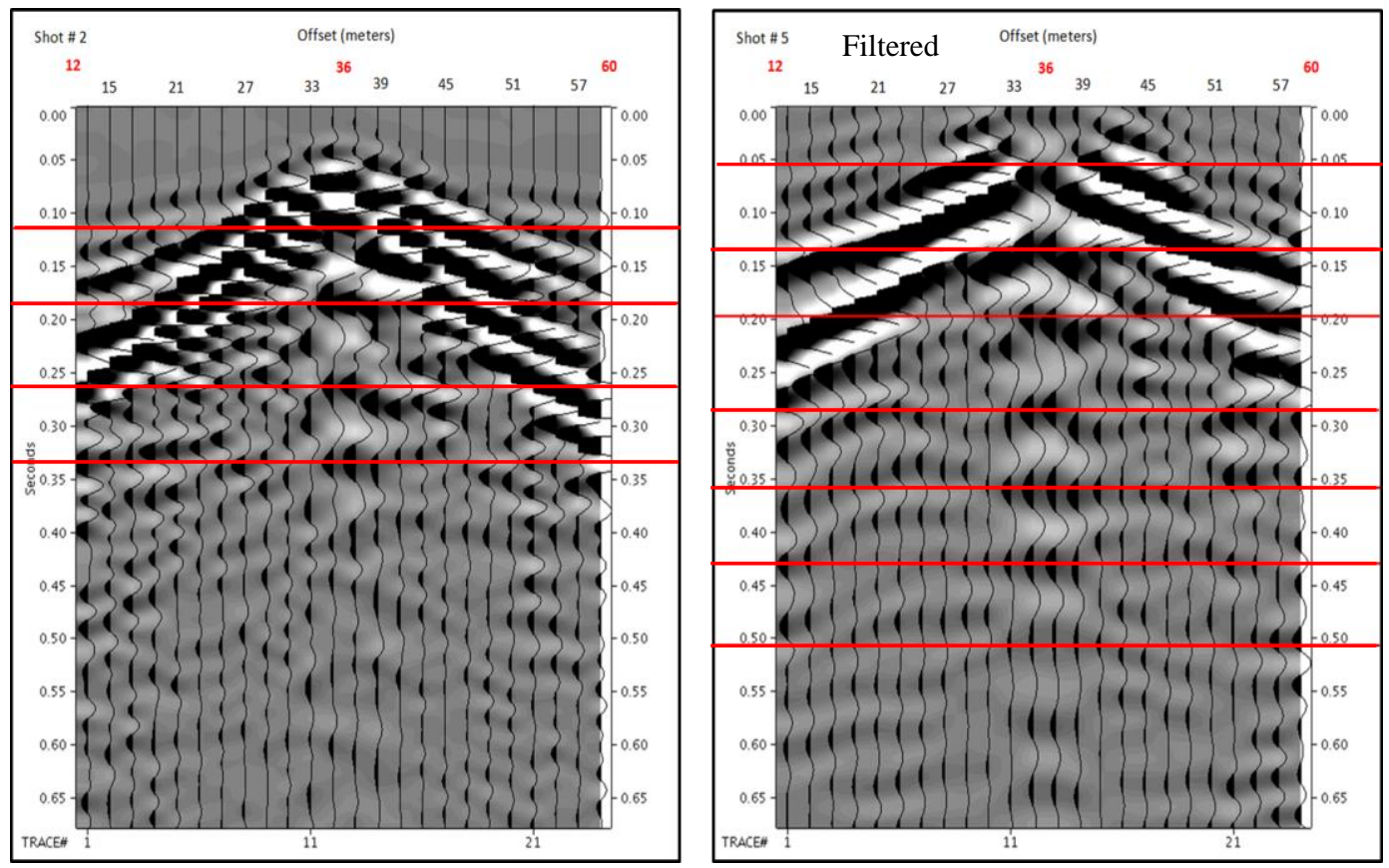

Figure 13: Split shots displaying incident reflections in field data. Notice that shot number 2 has multiple arrivals that coincide with the modeled arrival times for incident reflections in Table 3. Filtering was performed to enhance the multiples in shot 5 by cutting out high frequency noise masking the arrivals. 


\section{Refraction}

We selected first breaks on each of the gathers using a Matlab code called DATAPICKER (Appendix H) and displayed them using the GeoTomo software. First arrivals with the picks highlighted by red dots for both roll along and varying azimuth surveys are seen in Figures 14 and 15. The complete set of first break picks is in Appendix B. We noticed delay times in the first arrivals on the shot gathers; especially those perpendicular to the conduit (Fig. 14). The traces before and after the delays display normal arrival behavior, making it difficult to attribute the delays to dipping or faulted bedrock (Burger et al., 1992). Even more curious is the change in shape of the delay times (Fig. 15).

By plotting the first breaks from the common shot gathers (Fig. 14), we obtained a time vs distance graph (Fig. 16). It is important to note that the delays are all in the same location and of the same magnitude of approximately 8 milliseconds. Because the delays do not correspond to a continuous slope, we excluded them from the velocity calculations (Fig. 17). However, even when excluding them from the calculations we obtain extremely variable velocities depending upon which end of the array we placed the shot. Table 2 shows the velocities and intercept times collected for each shot from the time vs distance graphs. A full catalog of the T-X graphs can be found in Appendices C\&D. When excluding the time delays, these velocity differences can be attributed to a slightly dipping interface. Using the time intercept method, we obtained depth to bedrock of between 4 and 5 meters (elevation of 12.68-13.68 meters). Since the water table is 
estimated to be at an elevation of 12.8 meters, it is likely that the close proximity of the bedrock and water table creates only two observable slopes on the shot records.
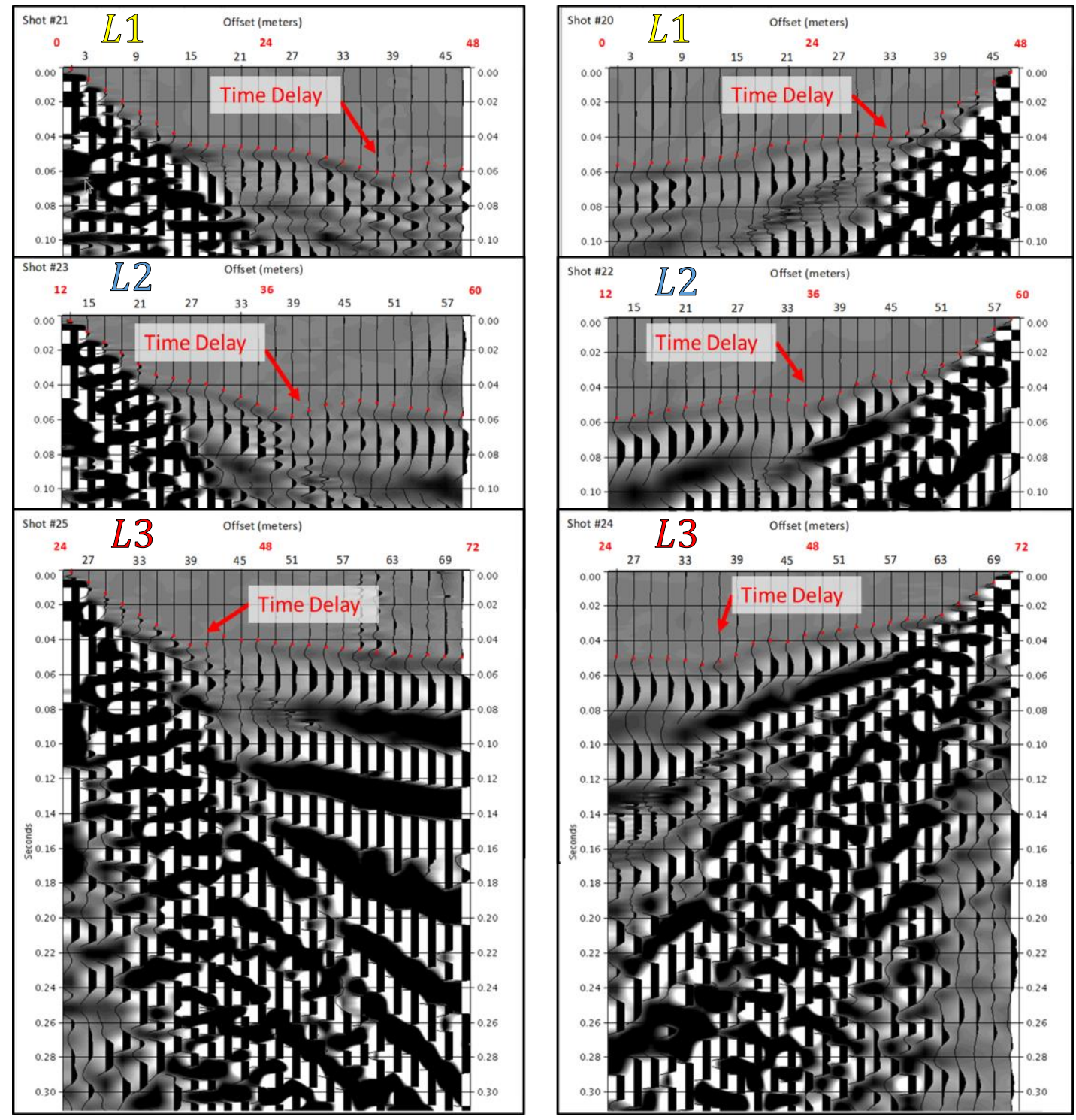

Figure 14: Roll along line common shot gathers. Note the first arrivals indicated by the red dots. First break time delays are indicated with red arrows. Shots 21, 23 and 25 display maximum delay at an offset of 39 meters. Shots 20, 22 and 24 have maximum delay at an offset of 35 meters. 

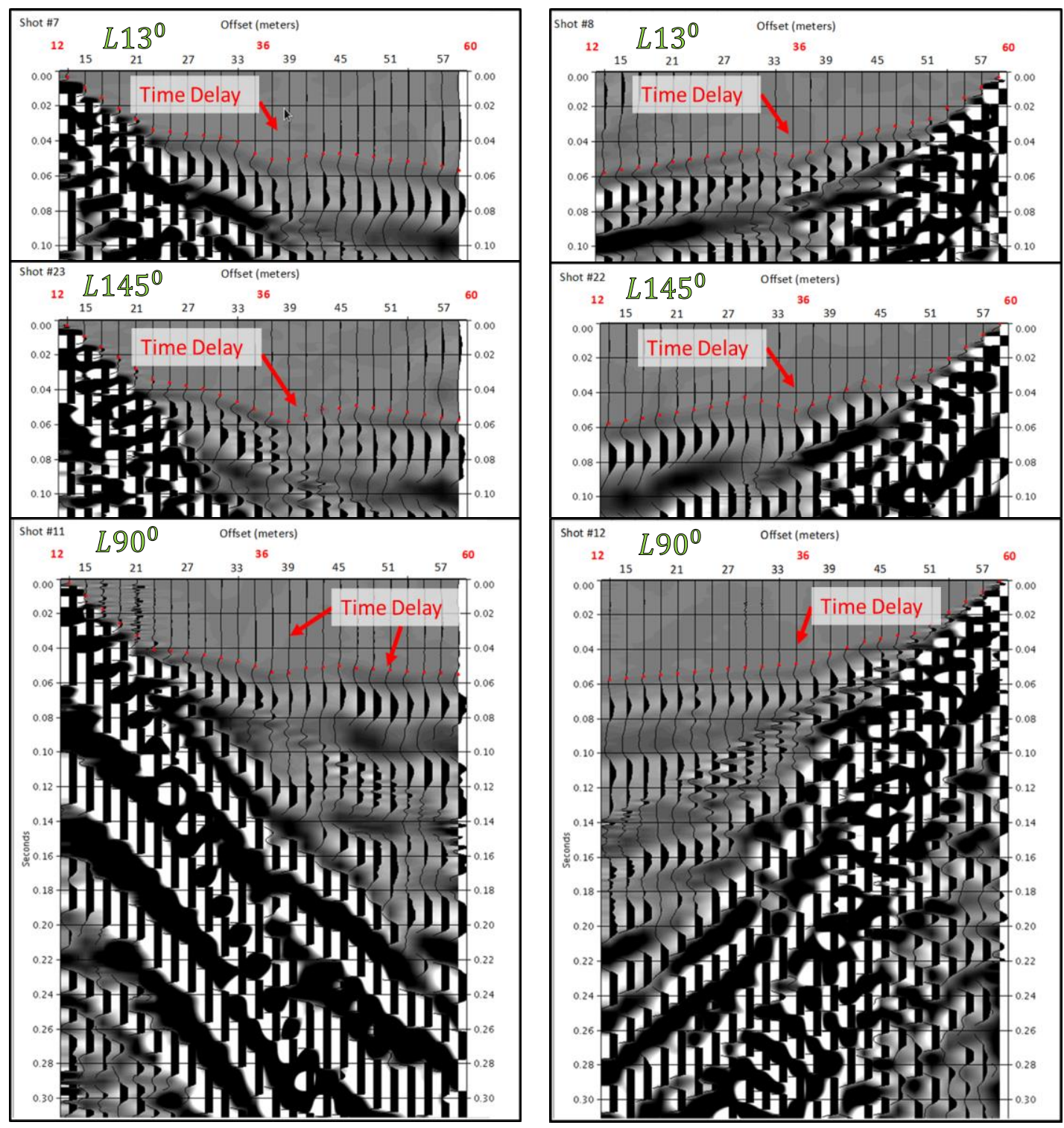

Figure 15: Varying azimuth common shot gathers. Note the first arrivals indicated by the red dots. First break time delays are indicated with red arrows. Shots 7, 11 and 23 display maximum delay at an offset of 37 to 39 meters. Shots 8,12 and 22 have maximum delay at an offset of 35 meters. 

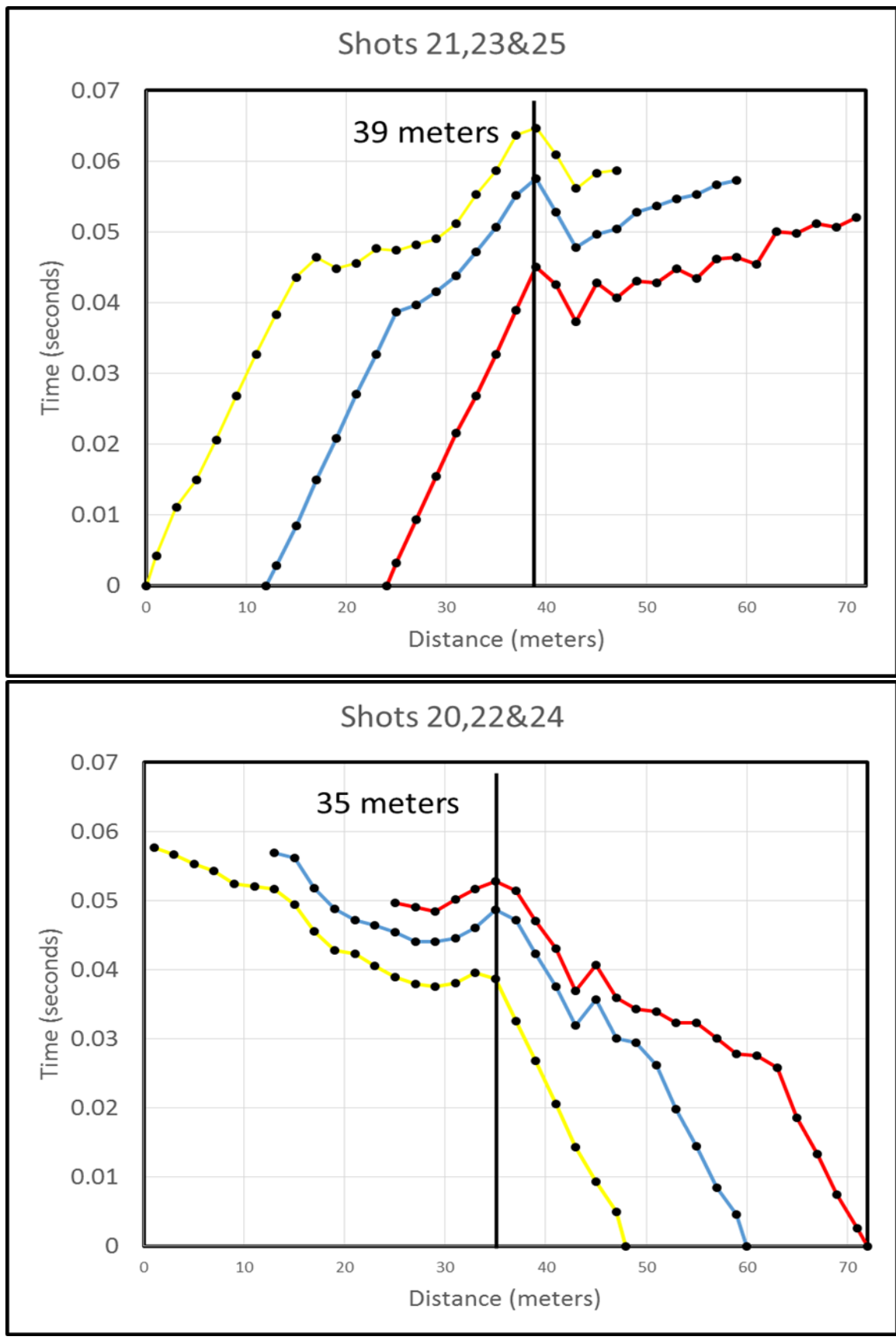

Figure 16: Roll along travel time curves displaying the location of maximum delay time. As indicated on the raw gathers, shots 21,23 and 25 have a max delay at an offset of 39 meters, while shots 20, 22 and 24 have a max delay at an offset of 35 meters. 

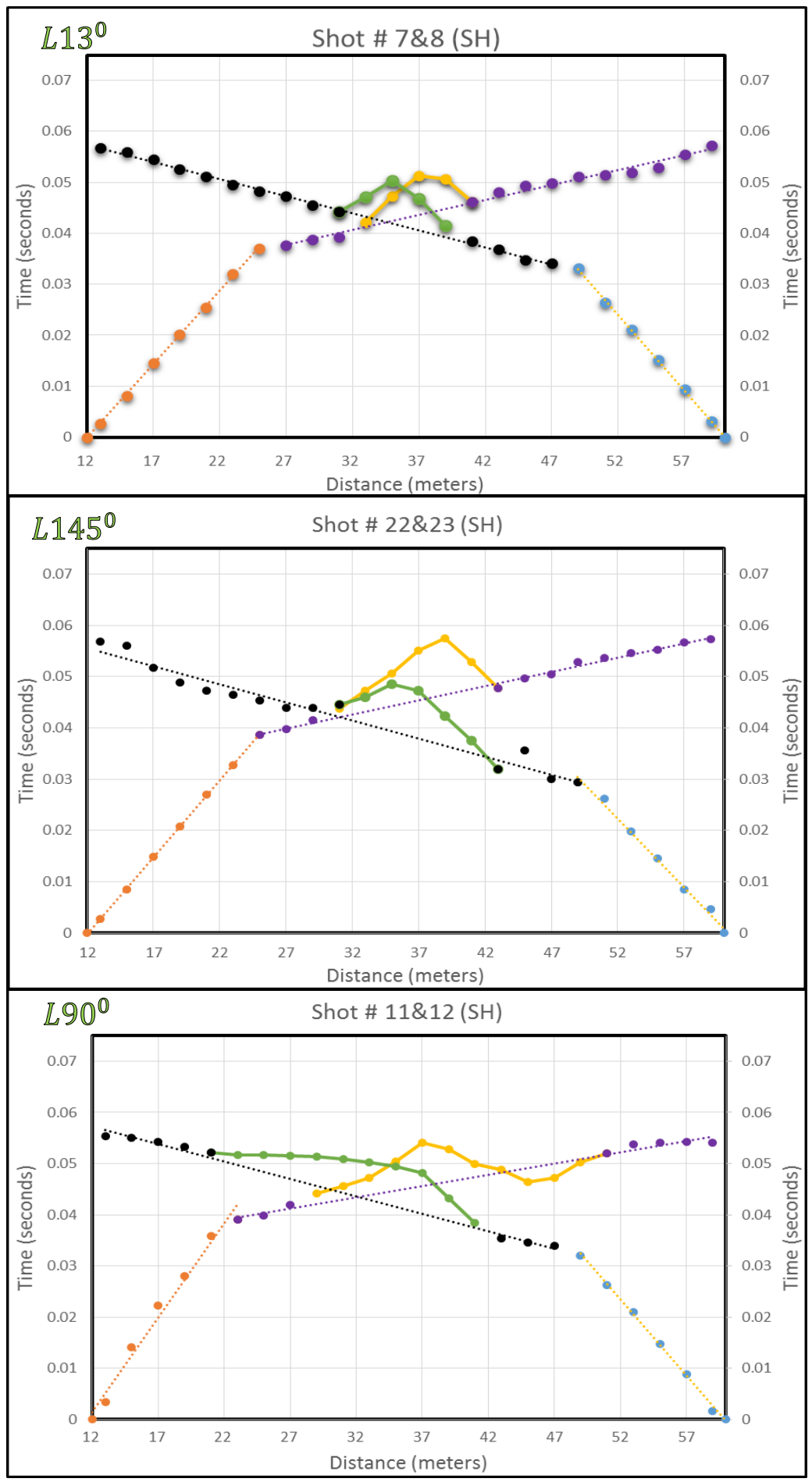

Figure 17: Varying Azimuth T-X curves. Note the change in shape of the delay times with changing azimuth. 
Table 2: Velocities and intercept times from all shots.

\begin{tabular}{|c|c|c|c|}
\hline shot & $\mathrm{V}_{1}$ & $\mathrm{~V}_{2}$ & $\mathrm{t}_{\mathrm{i}}$ \\
\hline $\mathbf{( \# )}$ & $\mathbf{( m / s )}$ & $\mathbf{( m / s )}$ & $\mathbf{( s )}$ \\
\hline $\mathbf{1 F}$ & 330 & 1886 & 0.03129 \\
\hline $\mathbf{1 R}$ & 350 & 909 & 0.0213 \\
\hline $\mathbf{2 F}$ & 344 & 2500 & 0.0361 \\
\hline $\mathbf{2 R}$ & 357 & 833 & 0.0236 \\
\hline $\mathbf{3}$ & 303 & 2000 & 0.0375 \\
\hline $\mathbf{5 F}$ & 178 & 1111 & 0.0296 \\
\hline $\mathbf{5 R}$ & 169 & 1000 & 0.0293 \\
\hline $\mathbf{6 F}$ & 204 & 1666 & 0.035 \\
\hline $\mathbf{6 R}$ & 208 & 1000 & 0.0288 \\
\hline $\mathbf{7}$ & 344 & 1666 & 0.0289 \\
\hline $\mathbf{8}$ & 333 & 1428 & 0.0251 \\
\hline $\mathbf{9 F}$ & 322 & 2000 & 0.0349 \\
\hline $\mathbf{9 R}$ & 312.5 & 1666 & 0.0365 \\
\hline $\mathbf{1 0 F}$ & 344 & 2500 & 0.0361 \\
\hline $\mathbf{1 0 R}$ & 344 & 909 & 0.0276 \\
\hline $\mathbf{1 1}$ & 270 & 2500 & 0.0347 \\
\hline $\mathbf{1 2}$ & 333 & 1428 & 0.0246 \\
\hline $\mathbf{2 0}$ & 344 & 1250 & 0.0207 \\
\hline $\mathbf{2 1}$ & 344 & 2000 & 0.0307 \\
\hline $\mathbf{2 2}$ & 370 & 1428 & 0.0217 \\
\hline $\mathbf{2 3}$ & 312 & 1666 & 0.0315 \\
\hline $\mathbf{2 4}$ & 344 & 1666 & 0.0191 \\
\hline $\mathbf{2 5}$ & 336 & 2500 & 0.0324 \\
\hline $\mathbf{2 6}$ & 344 & 1742 & 0.0281 \\
\hline $\mathbf{2 7}$ & 338 & 1497 & 0.0175 \\
\hline $\mathbf{A v e r a g e}$ & 311.1 & 1630.04 & $\sim$ \\
\hline & & & \\
\hline
\end{tabular}




\section{Engelsfeld}

Using the previously described Engelsfeld method, the depth, diameter, and position of the conduit were estimated as seen in Table 3. The lateral position of the conduit centered around 36 meters with a depth of 4 to 5 meters on the shot records perpendicular to the conduit. However, on shots 11 and 12 we obtain a depth of 16 to 39 meters indicating that the method is only valid when perpendicular to the strike of the feature. Results from this method are not comparable to our original estimation for depth of the conduit.

Table 3: Engelsfeld results.

\begin{tabular}{|c|c|c|c|c|c|c|}
\hline shot & $V_{1}$ & $V_{2}$ & $\theta$ & Diameter & $x_{p}$ & depth \\
\hline (\#) & $(\mathrm{m} / \mathrm{s})$ & $(\mathrm{m} / \mathrm{s})$ & (degrees) & (meters) & (meters) & (meters) \\
\hline 7 & 344 & 1666 & 11.91 & 7.82 & 35 & \multirow[t]{2}{*}{4 to 5} \\
\hline 8 & 333 & 1428 & 13.48 & 7.77 & 37 & \\
\hline 11 & 270 & 2500 & 6.20 & 21.87 & 37 & \multirow[t]{2}{*}{16 to 39} \\
\hline 12 & 333 & 1428 & 13.48 & 21.39 & 37 & \\
\hline 22 & 312 & 1428 & 12.62 & 9.75 & 36 & \multirow[t]{2}{*}{4 to 5} \\
\hline 23 & 344 & 1666 & 11.91 & 9.78 & 35 & \\
\hline 26 & 344 & 1742 & 11.38 & 7.84 & 36 & \multirow[t]{2}{*}{4 to 5} \\
\hline 27 & 338 & 1497 & 13.04 & 7.79 & 36 & \\
\hline
\end{tabular}

\section{Attenuation Analysis of Rayleigh Waves (AARW)}

Each of the 20 shots collected at Madison Blue Springs were examined in both the time and frequency domains. In the frequency domain, we observed amplitude anomalies that were attributed to partitioning wave interactions with the conduit (Moghaddam 2006). Shot 2 which was discussed in the reflection section can be seen below (Fig. 18). Each trace has been converted to the frequency domain using the Fourier transform and 
plotted against offset to create a surface. The amplitude of these frequencies should be greatest near the shot and diminish logarithmically with offset in each direction from the source (Putnam et al., 2008). In shot number 2, however, we observe anomalously high amplitudes for frequencies between 20 and 50 hertz to the right of the shot (located at 36 meters), but not to the left. The large amplitudes present at these receivers can be attributed to both multiple reflections off the conduit, and the reverberation of the conduit due to waves trapped inside its boundaries (Moghaddam 2006).

A similar trend to the one described above is observed but with the shot location at greater offsets from the conduit (Fig. 19). Shot 23 contains anomalously high amplitudes at frequencies between 20 and 40 hertz and an offset of 39 meters. Shot 22 contains an anomaly at an offset of 45 meters. The roll along survey with each of the energy spikes at offsets of either 39 or 45 meters is displayed below (Fig. 20). These shots also display attenuation behavior that can been attributed to the presence of voids (Moghaddam 2006). All of the CSGs show that the surface wave amplitudes are attenuated much faster after passing through the conduit location. Shot 20 is a stark example of the energy reduction caused by the shot being directly above the conduit. A dramatic reduction in amplitude can be seen in profile 22 (Fig. 20). From the AARW analysis we estimated that the conduit location is centered at an offset of 42 meters; however, no depth could be calculated using this technique. The complete set of frequency domain images can be seen in Appendices F\&G. 


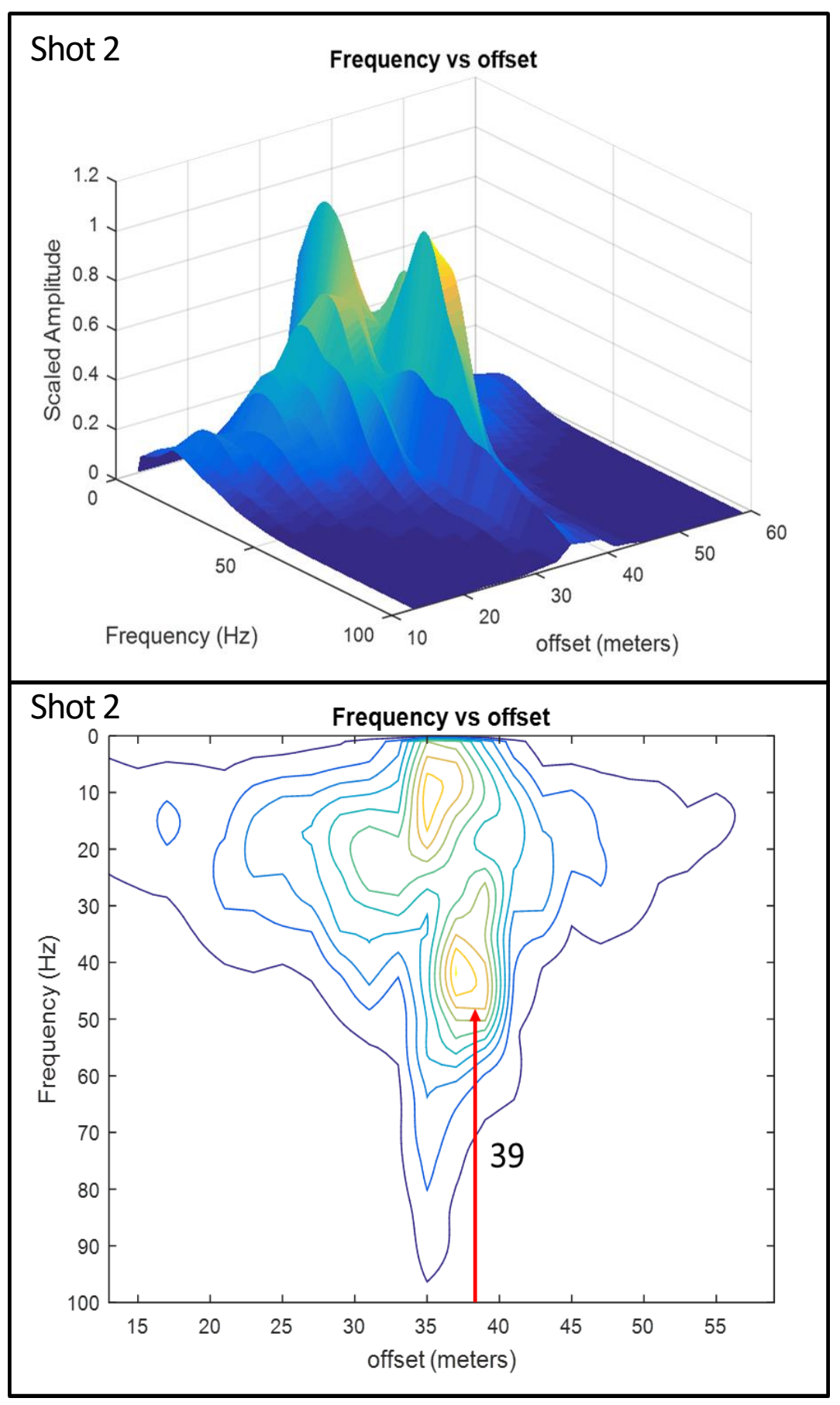

Figure 18: $2 D$ \& 3D common shot gathers in the frequency domain. A high amplitude event appears to the right of the shot but not to the left. This in interpreted to be multiple reflections off the top of the conduit at an offset of 39 meters. 


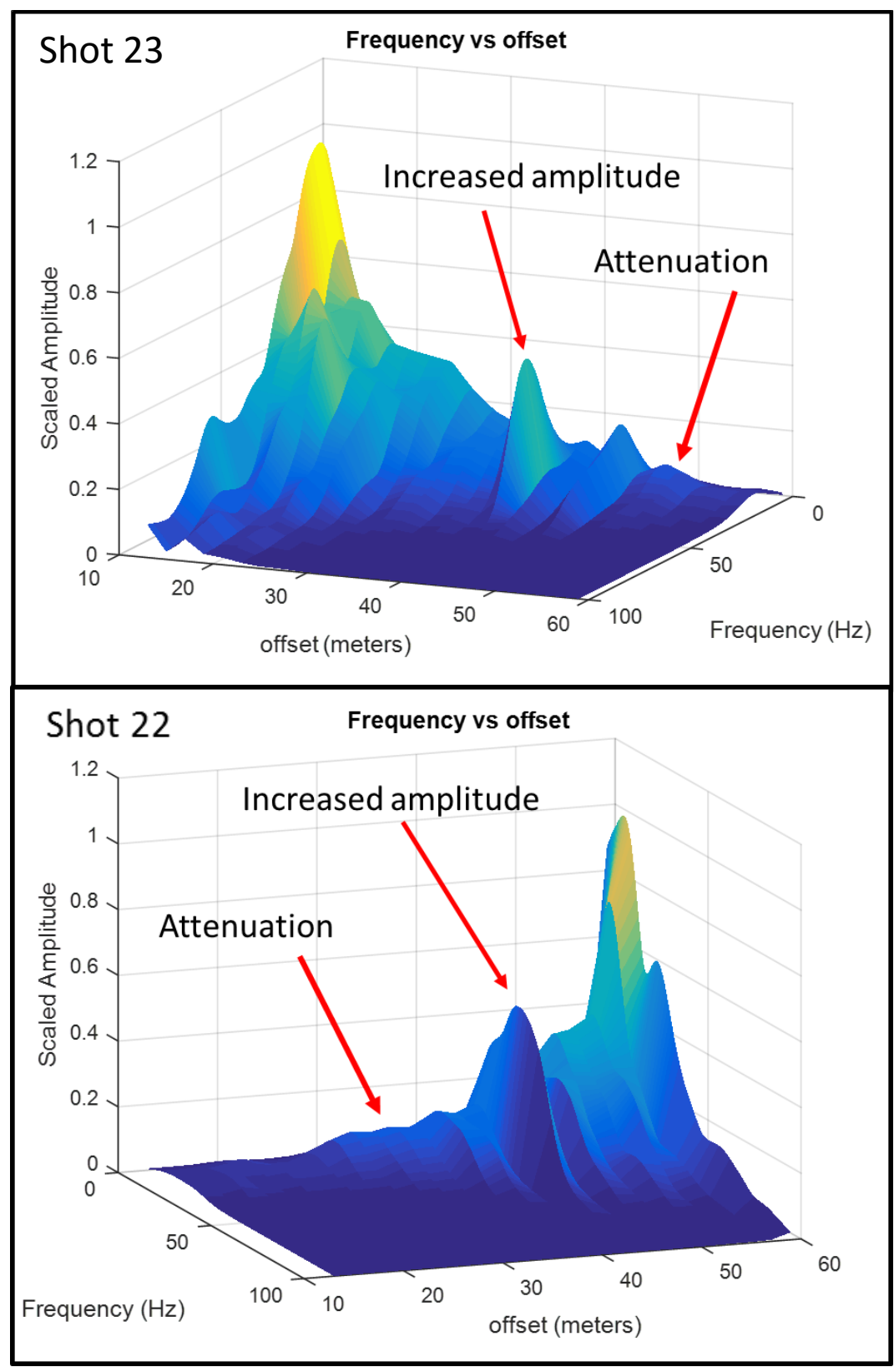

Figure 19: $3 \mathrm{D}$ common shot gathers displayed in the frequency domain. At an offset of 39 and 45 meters, shots 22 and 23 experience increases in amplitude immediately followed by attenuation. This increase in amplitude is interpreted to be focused energy scattered from the conduit. These are likely the same events observable as hyperbolas in the time domain. 

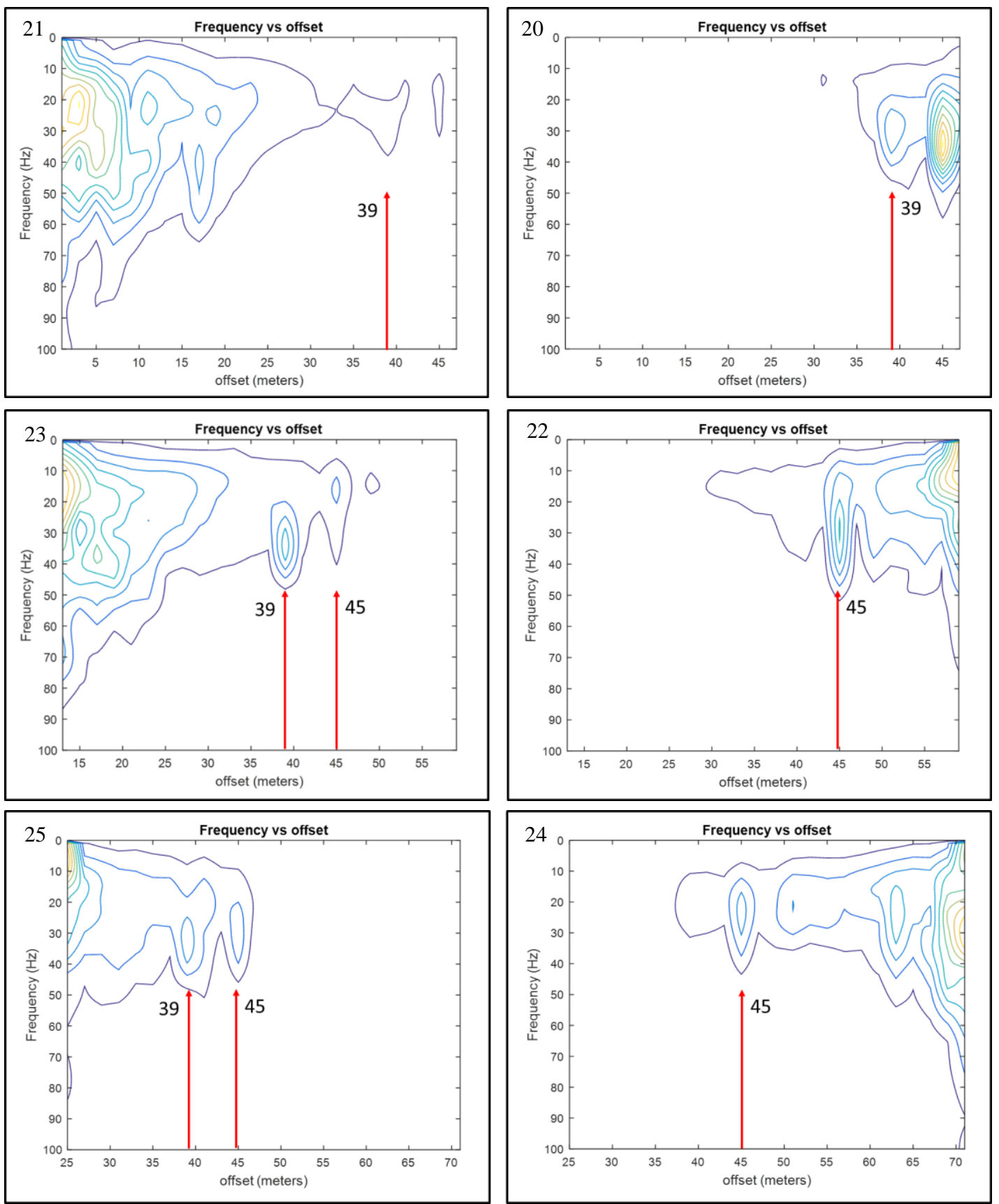

Figure 20: 2D common shot gathers in the frequency domain. Again at an offset of 39 and 45 meters in each shot there is a higher amplitude. This would not be expected especially at greater offsets. Also note that the amplitude diminishes much faster after passing by the conduit offset of 39-41 meters. 


\section{Multichannel Analysis of Surface Waves (MASW)}

Backscatter analysis was the most quantitative approach applied to these data. Figure 21 shows Shots 22 through 25 but excludes shots 20 and 21 as no clear diffraction hyperbolas were present. The phase velocity, Apex arrival, Apex offset, and depth to the conduit for the shots containing diffractions are displayed in Table 4. Using the frequency plots from the previous section, we filtered the CSGs to the frequency range of the amplitude anomalies at 39 and 45 meters. Most of these anomalies fell between 10 and 50 hertz so we designed a bandpass filter with those bounds and balanced the traces (Fig. 22\&23). Some shots do not contain diffraction hyperbolas but still show signs of being affected by the conduit. Shots 22 and 24 have no clear hyperbolas even after being filtered, however, attenuation is visible in traces 41,39 and 37.

The depth to the conduit is best estimated from shots 3, 23 and 25 as they contained the clearest diffraction hyperbolas (Fig. 21). By taking the average depth from the three shots, we get a depth of 25 meters which corresponds well with the initial estimated depth of 23.5 meters (Tab. 4). Varying azimuth shots 7 and 8 cross the conduit in approximately the same location as shots 23 and 22 and indicate the conduit at 27 meters below the surface (Fig. 22). However, shots 11 and 12 cross the conduit at a completely different location (Fig. 4) but yield reasonable depths of 19 and 23 meters to the conduit at their location of intersection. 


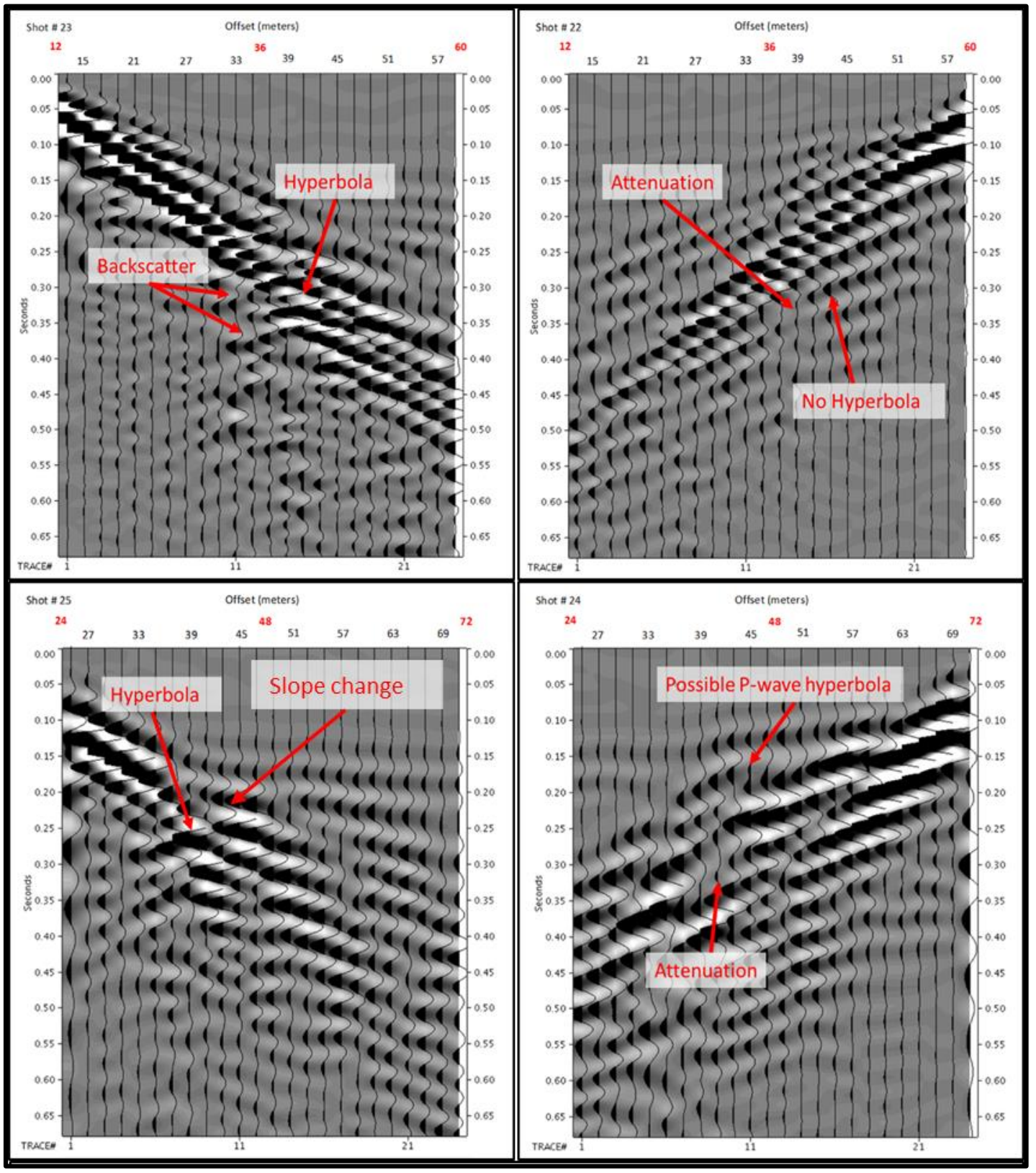

Figure 21: Roll along processed common shot gathers. Note that shots 23 and 25 have clear diffraction hyperbolas while shots 22 and 24 exhibit attenuation at an offsets of 37 to 41 . The diffractions have phase velocities of $160-250 \mathrm{~m} / \mathrm{s}$ and correspond to the location of the conduit on the cave map. Notice the slope change in shot 25 directly after the diffraction. Shots 20 and 21 have no diffractions present. 


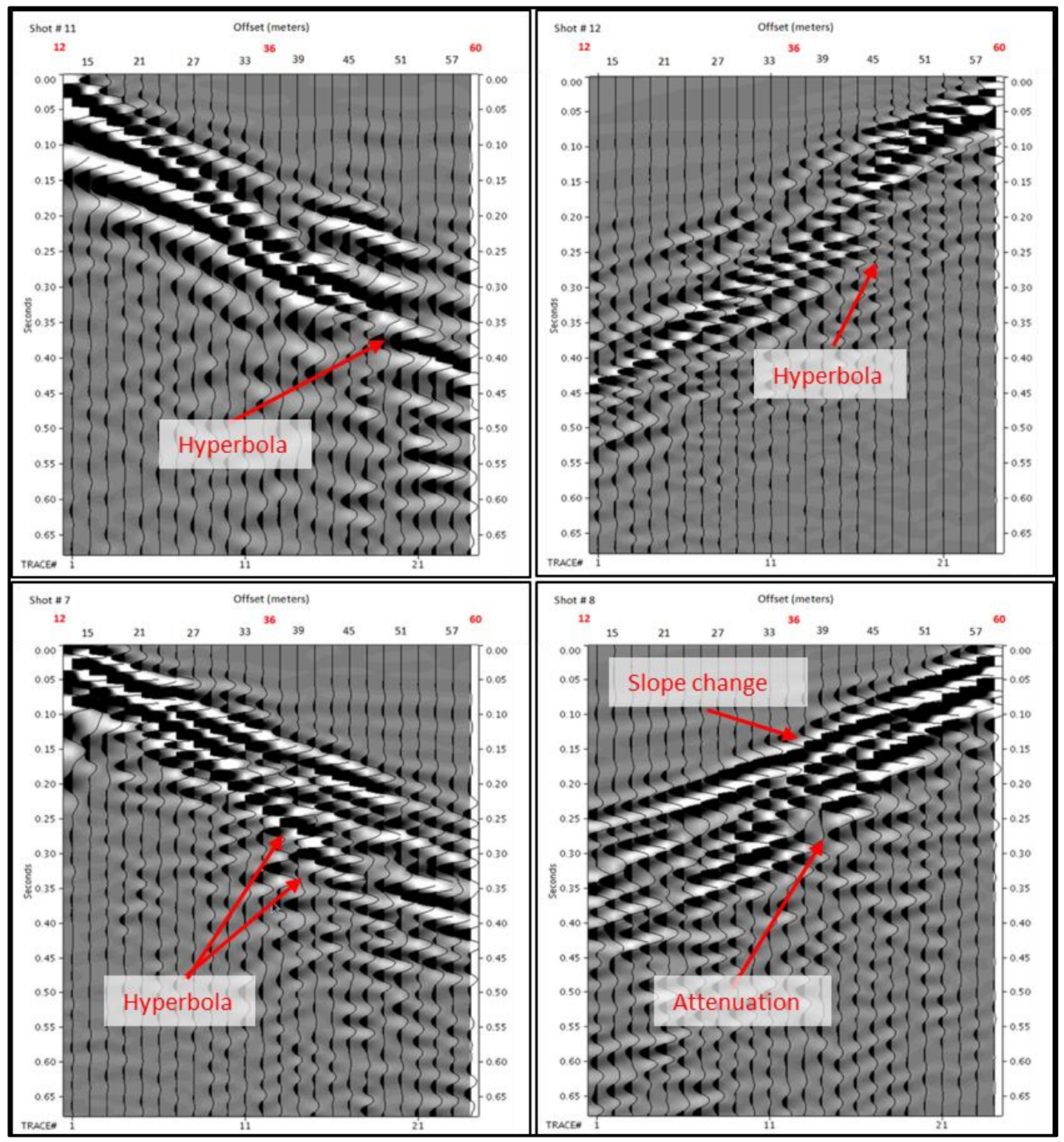

Figure 22: Varying Azimuth processed common shot gathers. Shots 7 and 8 closely resemble shots 22 and 23 due to their similar orientation to the conduit. However notice that shots 11 and 12 have diffractions corresponding to the eastern end of the line where they cross over a larger part of the conduit 
Table 4: Backscatter results

\begin{tabular}{|c|c|c|c|c|}
\hline Shot & Apex time & Apex Offset & $\begin{array}{c}\text { Phase } \\
\text { Velocity }\end{array}$ & Depth \\
\hline $\mathbf{( \# )}$ & (seconds) & (meters) & (m/s) & (meters) \\
\hline $\mathbf{3}$ & 0.353 & 29 & 154 & 25 \\
\hline $\mathbf{7}$ & 0.247 & 29 & 229 & 27 \\
\hline $\mathbf{1 1}$ & 0.362 & 39 & 250 & 23 \\
\hline $\mathbf{1 2}$ & 0.225 & 15 & 152 & 19 \\
\hline $\mathbf{2 1}$ & 0.362 & 44 & 182 & 22 \\
\hline $\mathbf{2 2}$ & 0.351 & 24 & 147 & 28 \\
\hline $\mathbf{2 3}$ & 0.329 & 29 & 157 & 23 \\
\hline $\mathbf{2 5}$ & 0.261 & 15 & 160 & 27 \\
\hline $\mathbf{2 6}$ & 0.309 & 23 & 154 & 25 \\
\hline
\end{tabular}

\section{Numerical Modeling of Seismic Wave Propagation}

Using the GeoTomo software we generated synthetic traces with a Rayleigh velocity of $180 \mathrm{~m} / \mathrm{s}$. Utilizing the previously described model we achieved a diffraction time due to the conduit of 0.32 seconds, correlating well to the apex time of 0.33 seconds observed on shot 23 (Fig. 23). Notice that the diffraction and its multiples in the synthetic section are much stronger than in these data. This again is because the software does not include attenuation so all of the amplitudes are erroneously high.

A match between the synthetic traces and field data was obtained by overlaying and bandpass filtering to different frequency ranges (Fig. 24). In an attempt to isolate the diffracted waves in these data we filtered to the frequencies on which amplitude 
anomalous occurred in the AARW section. Notice that these filtered data matches

extremely well at 10-40 hertz. The image at 20-30 hertz is nearly a perfect match but may not be the best representation because of the narrow frequency range. There was no attempt to match other components of the shot, such as the head waves, because we were only interested in observing the Rayleigh wave diffraction. Using this method, a match is achieved, indicating another reasonable conduit depth of between 20 and 24 meters.
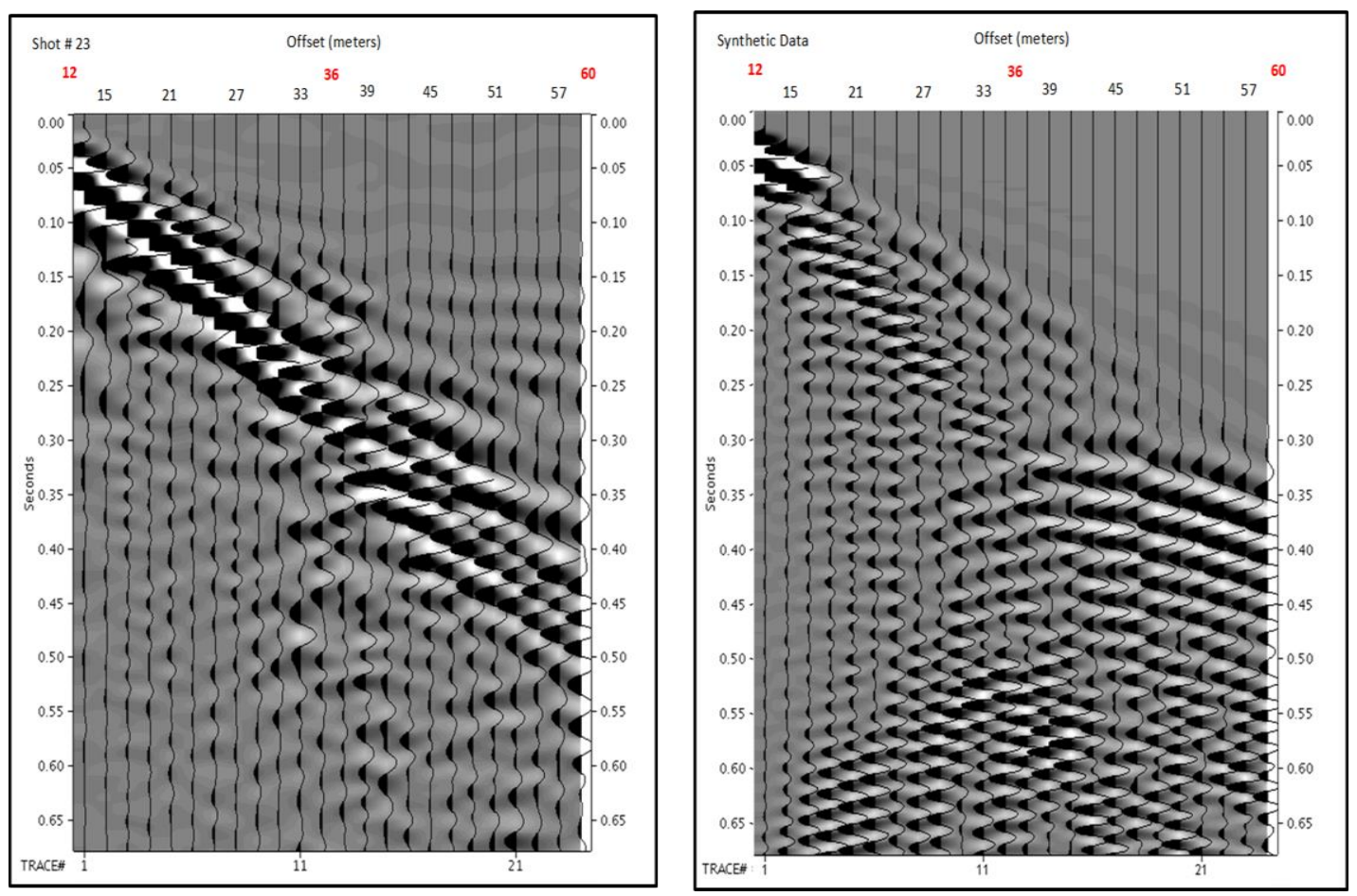

Figure 23: Comparison of real data to synthetic data. The synthetic data was shot using the same relative elevations and a velocity of $180 \mathrm{~m} / \mathrm{s}$. Keep in mind this model is only being used to observe the diffraction behavior of a wave with a phase velocity matching that of the diffraction in the real data in shot 23 . This synthetic match confirms that the arrival time of the diffraction is caused by an object at a depth of approximately 20-24 feet. 

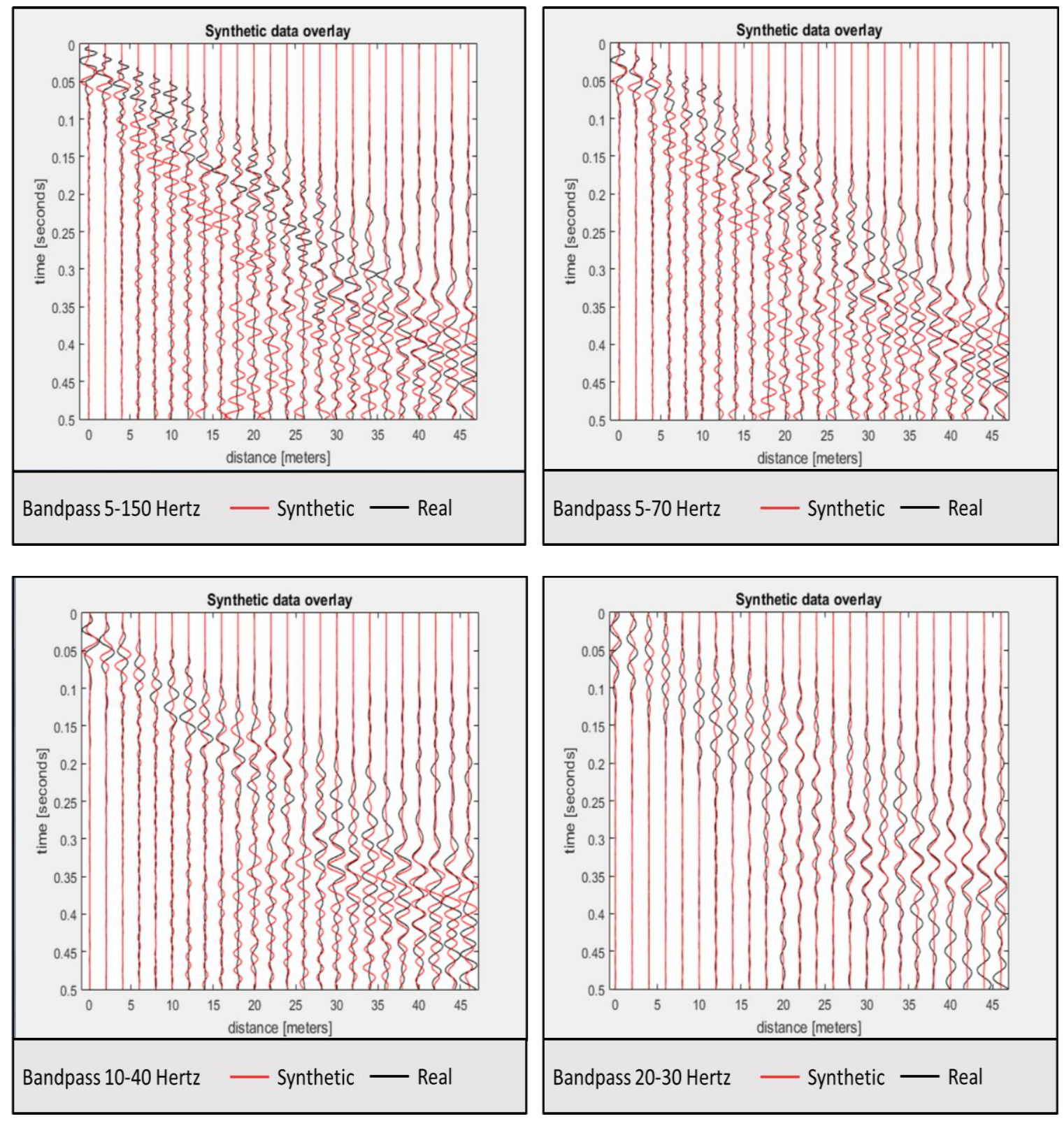

Figure 24: Data and Synthetic traces overlay. Synthetic traces are displayed in red while data are in black. As these data are filtered closer to the frequency range of the diffractions, we achieve a better match between the synthetic traces and data. This confirms a scattering object at a depth of approximately 20-24 meters and an offset of 39 to 41 meters, or directly above the conduit location on the cave map. 


\section{Discussion}

Of the six seismic analyses performed, five yielded results that could be validated with the conduit map. Using the water table elevation and calculating overburden thickness using refraction, our original depth estimation to the conduit was 23.5 meters. We then compared the results from 5 methods to the conduit map to determine their effectiveness for cave detection.

Attenuation analysis of Rayleigh waves proved to be the most effective method in locating the conduit. The high amplitude anomalies are easy to identify in the frequency domain. Even shots that did not contain diffraction hyperbolas in the time domain had frequency anomalies indicating the cave location. Shots $22 \& 24$ do not contain visible diffraction hyperbolas but the frequency anomalies clearly indicate the cave location (Fig. 20). AARW may be able to give an indication of cave width. Notice that the anomaly offsets are at 39 and 45 meters, the difference being approximately the conduit diameter of 7 meters (Fig. 20).

The frequency anomalies provide parameters for the design of the bandpass filter used by the MASW technique as well. MASW proved to be the most practical method for determining the depth to the conduit. By matching the frequency band of the AARW anomalies in a bandpass filter, we were able to observe diffraction hyperbolas to calculate depth. We were able to confirm the depths obtained by MASW using the synthetic model to generate surface wave diffractions to match these data. 
Seismic refraction data were particularly useful in combination with reflection data. The refraction method defined the velocity structure and layer thicknesses used in the reflection model to observe multiple incident arrivals from the conduit. Reflection yielded results similar to MASW with depths to the conduit of 20-24 meters. However, the reflection method as applied in this study requires the location of the feature to be known which makes it less flexible than MASW.

The Engelsfeld method yielded results that were geologically unreasonable for depth but the lateral position of the time delays corresponded well to the cave location. Depths of 4-5 meters were obtained for lines perpendicular to the strike of the conduit but varied greatly when the azimuth of the line was changed. Because the Engelsfeld method operates on the principles of refraction, it may be affected by low velocity layers which did not produce first breaks on the shot record (hidden layers). This could possibly play a role in the discrepancy between the calculated and known depth of the conduit. The Engelsfeld method is likely inadequate for this application because it is designed for a two layer model with the void in the first layer, where our conduit is in the second layer making the incident angles used to calculate depth no longer valid (Engelsfeld et al., 2008).

One of the distinct benefits of seismic methods is that several analyses can be performed on a single data set. Each of the methods utilized in this study took advantage of different aspects of the same common shot gathers to extract as much information about the subsurface as possible. We used AARW to locate the cave offset by identifying anomalies in the frequency domain. Information from these anomalies were used to filter 
CSGs and identify backscatter hyperbolas in the time domain. Seismic refraction was used to determine layer velocities and thicknesses to generate model parameters for correlating incident reflections. Synthetic data were used to confirm backscatter result by matching the waveform of the diffraction hyperbola.

The disadvantage of this data set, and of nearly all data sets used for cavity or tunnel detection studies, is that frequency content is very low and all data are recorded on the surface. However, the complementary nature of these techniques, allows for more targeted and practical applications in the field. Because we knew the orientation and approximate depth of the conduit at Madison Blue Spring, we were able to design our

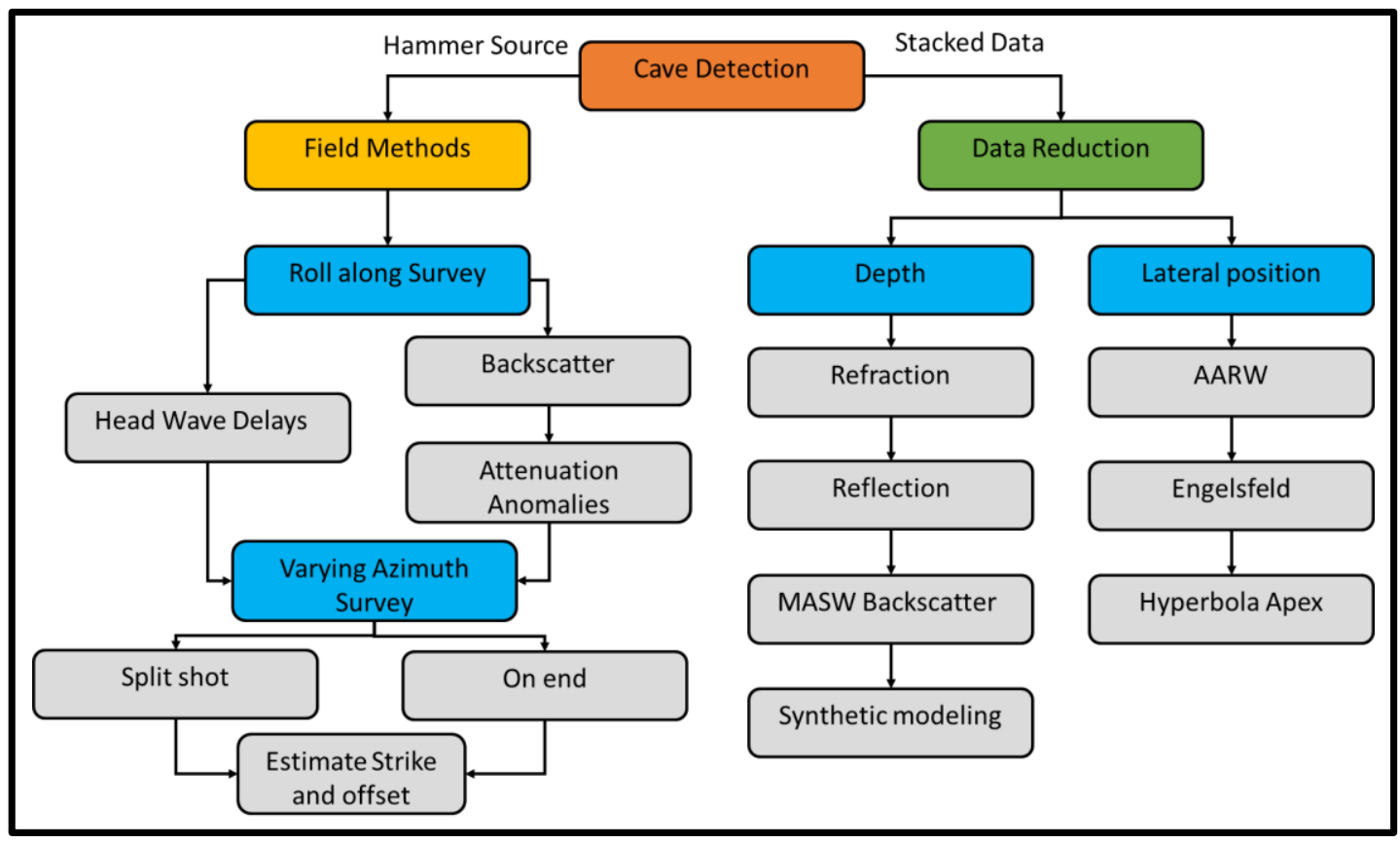

Figure 25: Cave detection workflow for acquisition and processing. A roll along survey is applied to search for backscatter, time delays and attenuation. When these anomalies are detected, a varying azimuth survey is centered on these anomalies and rotated in an attempt to determine the strike of the feature. Each CSG generated is stacked 20 times to ensure a better signal to noise ratio. These data are then analyzed to determine the lateral position and depth of the feature. 
acquisition parameters to best detect the cave. In a true exploration scenario where cave depths, diameters, and strikes are unknown, detection is less straightforward. However, as a result of this study a workflow for cave detection can be used to increase the likelihood of detecting caves (Fig. 25). By applying these procedures, and using computationally simple processing techniques, cave exploration can be performed entirely in the field. This reduces the time and cost of exploration while increasing the flexibility of the acquisition and thus the resolution of the seismic data set.

\section{Conclusion}

Cave detection remains one of the biggest challenges for geophysics. Natural and anthropogenic interference such as soil conditions, salt water and utilities often render popular methods like GPR and Resistivity ineffective for cave detection. Seismic methods, however, have proven effective in detection of several shallow voids (Dobecki and Upchurch 2006), tunnels (Sloan et al., 2013), and caves (Xia, et al., 2007) up to 17 meters in depth. Using a cave of known size and depth at Madison Blue Spring State Park, we demonstrated that seismic methods are effective for the detection of water filled karst features even at depths of up to 25 meters. Using attenuation analysis of Rayleigh waves (AARW), multichannel analysis of surface waves (MASW), the Engelsfeld method, seismic refraction and reflection, and synthetic modeling, we were able to detect a water-filled cave with a depth of approximately 25 meters.

Using this test site, we developed a workflow (Fig. 25) that can be performed completely in the field, minimizing time and cost of cave detection. We showed that rollalong surveys can be used for initial cave detection, and varying azimuth surveys can 
indicate cave geometries. AARW, MASW, and the Engelsfeld methods were used to determine the offset of the conduit from roll along CSGs. MASW, refraction, reflection, and synthetic models were used to determine depth and infer the width and strike of the cave. Our original estimation for the conduit depth from data collected by cave divers was 23.5 meters below the ground surface. AARW, MASW, and the Engelsfeld method indicated the conduit offset at 42,41 and 39 meters from the northern end of line 1 (Fig. 4). MASW, synthetic data, and the combination of refraction and reflection indicated a conduit depth of between 20 and 25 meters. These results confirm the location of the void and validate the use of these methods for the detection of water filled karst conduits. 


\section{References}

Ashcroft, William. 2011. A Petroleum Geologist's Guide to Seismic Reflection. West Sussex: Wiley-Blackwell. doi:10.1111/j.1468-8123.2011.00359.x.

Burger, H. Robert, anne F. Sheehan, and Craig H. Jones. 1992. Introduction to Applied Geophysics. New York: W.W. Norton \& Company, Inc.

C. Hickey, D. Schmitt, J. sabatier. Grey Riddle. 2009. "Seismic Measurements for Detecting Underground High-Contrast Voids." Symposium on the Application of Geophysics to Engineering and Enviornmental Problems 929-936.

Chalikakis, Konstantinos, Valerie Plagnes, Roger Guerin, Remi Valois, and Frank P. Bosch. 2011. "Contribution of geophysical methods to karst-system exploration: an overview." Hydrogeology Journal (19): 1169-1180.

District, Saint Johns River Water Managment. n.d. Hydrogeologic Information System. Accessed 4 18, 2016. www.SJRWMD.com.

Dobecki, T., and S. Upchurch. 2006. "Geophysical Application to detect sinkholes and ground subsidence." The leading Edge 25 (3): 336.

Doll, W.E., B.J. Carr, J.R. Sheenhan, and W.A. Mandell. 2005. Overview of Karst Effects and Karst Detection in Seismic Data from the Oak Ridge Reservation, Tennessee. U.S. Geological Survey.

Engelsfeld, Tihomir, Franjo Sumanovac, and Nenad Pavin. 2008. "Investigation of underground cavities in a two-layer model using the refraction seismic method." Near Surface Geophysics (Near Surface Geophysics) 221-231.

Ford, Derek, and Paul Williams. 2007. Karst Hydrology and Geomorphology. Chichester: John Wiley \& sons.

Grandjean, Gilles, and Donatienne Leparoux. 2004. "The potential of seismic methods for detecting cavities and buried objects: experimentation at a test site." Journal of Applied Geophysics (56): 93-106.

Gulley, Jason, Jonathan B. Martin, Elizabeth J. Screaton, and Paul J. Moore. 2011. "River Reversals into karst springs: A model for cave enlargement in eogenetic karst aquifers." Geological Society of America 123: 457-467. doi:10.1130/B30254.1.

Harmankaya, U., A. Kaslilar, J. Thorbecke, K. Wapenaar, and D. Dragnov. 2013. "Locating near-surface scatterers using non-physical scattered waves resulting from seismic interferometry." Jornal of Applied Geophysics (91): 66-81.

Hiltunen, Dennis R, Nick Hudyma, Timothy p. Quigley, and Chandra Samakur. 2006. "Ground Proofing Three Seismic Refraction Tomography Programs." Gainsville. 
Meinzer, E.O. 1927. Large Springs in the United States. Water-Supply Paper 557, U.S. Gelologica Survey.

Miller, James A. 1982. Hydrogeologic Framework of the Floridan Aquifer System in Florida and in parts of Georgia, Alabamam and South Carolina. Professional Paper 1403-B, U.S. Geological Society.

Moghaddam, Nasseri. 2006. Study of lateral Inhomogeneities on the Propogation of Rayleigh Waves in an Elastic Medium. Ph.D. Thesis, University of Waterloo.

Palmer, Arthur N. 1991. "Origin and morphology of limesone caves." Geological Society of Americs Bulletin 103: 1-21. doi:10.1130/00167606(1991)103<0001:OAMOLC>2.3CO;2.

Park, Choon B., and Jianghai Xia Richard D. Miller. 1999. "Multichannel analysis of surface waves." Geophysics 64 (3): 800-8008.

Putnam, Niklas H., Ali nasseri Moghaddam, Oleg Kovin, Evgeniy Torgashov, and Neil L. Anderson. 2008. Analysis Using Surface Wave Methods To Detect Shallow Manmade Tunnels. Technical Report, Rolla, Missouri: Department of Geological Sciences Missouri University of Science \& Technology.

Sheehan, Jacob R., William E. Doll, David B. Watson, and Wayne A. Mandell. 2005. Applitcation of Seismic Refraction Tomography to Karst Cavities. Karst Interest Group, Rapid City: United States Geological Survey.

Sloan, Steve D., Shelby L. Peterie, Richard D. Miller, Julian Ivanov, Jason R. McKenna, and Seth W. Broadfoot. 2013. "Tunnel detection using near-surface seismic methods." Geophysical Society of Houston (November): 13-16.

Sowers, George F. 1996. Building on Sinkholes- Design and Construction of Foundations in Karst Terrain. New York: ASCE Press.

Stein, Seth, and Michael Wysession. 2003. An Introduction to seismology. Earthquakes. and Earth Structure. Blackwell Publishing.

Vesper, Dorothy J., Caroline M. Loop, and William B. White. 2001. "Contaminant transport in Karst aquifers." Theiretical and Applied Karstology 13-14 (2): 101111.

Wilson, William L., and Barry F. Beck. 1992. "Hydrogeologic Factors Affecting New Sinkhole Development in the Orlando Area Florida." Ground Water 30 (6): 918930.

Xia, Jianghai, Chen Chao, Tian Gang, Miller D. Richard, and Julian Ivanov. 2005. "Resolution of High-frequency Rayleigh-wave Data." Journal of Enviornmental \& Engineering Geophysics 10 (2): 99-110. 
Xia, Jianghai, Jonathan E Nyquist, Yixian Xu, Mary J.S. Roth, and Richard D. Miller. 2007. "Feasibility of detecting near-surface feature with Rayleigh-wave diffraction." Journal of Applied Geophysics (62): 244-253.

Xia, Jianghai; Miller, Richard D.; Park, Choon B. 1999. "Estimation of near-surface shear-wave velocity by inversion of Rayleigh waves." Geophysics 64 (3): 691700. 


\section{Appendices}

Appendix A: Survey Line Elevations \& Coordinates ...............................51

Appendix B: CSGs \& First Breaks .....................................................................55

Appendix C: First Break Tables .....................................................................75

Appendix D: T-X Graphs.....................................................................................81

Appendix E: Processed \& Filtered Images .................................................90

Appendix F: 3D Frequency Images ..................................................................111

Appendix G: Frequency Contour Plots...................................................123

Appendix H: Matlab Codes ................................................................................135 


\section{Appendix A: Survey Line Elevations \& Coordinates}


Table 5: Survey line elevation and coordinates

\begin{tabular}{|c|c|c|c|c|c|}
\hline L1 & MSL & Zone & $17 \mathrm{~N}$ & & \\
\hline Distance & Elevation & Easting & Northing & Latitude & Longitude \\
\hline (meters) & (meters) & (meters) & (meters) & (degrees) & (degrees) \\
\hline 0 & 62.0 & 284511.0 & 3374157.0 & 30.480359 & -83.244869 \\
\hline 1 & 61.9 & 284510.2 & 3374158.7 & 30.480374 & -83.244878 \\
\hline 3 & 61.7 & 284509.3 & 3374160.3 & 30.480389 & -83.244887 \\
\hline 5 & 61.6 & 284508.5 & 3374162.0 & 30.480404 & -83.244896 \\
\hline 7 & 61.5 & 284507.7 & 3374163.7 & 30.480419 & -83.244905 \\
\hline 9 & 61.4 & 284506.8 & 3374165.3 & 30.480434 & -83.244914 \\
\hline 11 & 61.4 & 284511.0 & 3374157.0 & 30.480359 & -83.244869 \\
\hline 13 & 61.4 & 284511.8 & 3374155.3 & 30.480344 & -83.24486 \\
\hline 15 & 61.3 & 284512.7 & 3374153.7 & 30.48033 & -83.244851 \\
\hline 17 & 61.4 & 284513.5 & 3374152.0 & 30.480315 & -83.244841 \\
\hline 19 & 61.4 & 284514.3 & 3374150.3 & 30.4803 & -83.244832 \\
\hline 21 & 61.5 & 284515.2 & 3374148.7 & 30.480285 & -83.244823 \\
\hline 23 & 61.3 & 284516.0 & 3374147.0 & 30.48027 & -83.244814 \\
\hline 25 & 61.1 & 284516.8 & 3374145.3 & 30.480255 & -83.244805 \\
\hline 27 & 61.0 & 284517.7 & 3374143.7 & 30.48024 & -83.244796 \\
\hline 29 & 60.9 & 284518.5 & 3374142.0 & 30.480225 & -83.244787 \\
\hline 31 & 60.8 & 284519.3 & 3374140.3 & 30.48021 & -83.244778 \\
\hline 33 & 60.5 & 284520.2 & 3374138.7 & 30.480196 & -83.244769 \\
\hline 35 & 60.2 & 284521.0 & 3374137.0 & 30.480181 & -83.24476 \\
\hline 37 & 60.2 & 284521.8 & 3374135.3 & 30.480166 & -83.244751 \\
\hline 39 & 60.2 & 284522.7 & 3374133.7 & 30.480151 & -83.244742 \\
\hline 41 & 60.2 & 284523.5 & 3374132.0 & 30.480136 & -83.244733 \\
\hline 43 & 60.2 & 284524.3 & 3374130.3 & 30.480121 & -83.244724 \\
\hline 45 & 60.2 & 284525.2 & 3374128.7 & 30.480106 & -83.244715 \\
\hline 47 & 60.3 & 284526.0 & 3374127.0 & 30.480091 & -83.244706 \\
\hline
\end{tabular}


Survey line elevation and coordinates continued

\begin{tabular}{|c|c|c|c|c|c|}
\hline L2 & MSL & Zone & $17 \mathrm{~N}$ & & \\
\hline Distance & Elevation & Easting & Northing & Latitude & Longitude \\
\hline (meters) & (meters) & (meters) & (meters) & (degrees) & (degrees) \\
\hline 12 & 61.4 & 284511.0 & 3374157.0 & 30.480359 & -83.244869 \\
\hline 13 & 61.4 & 284511.8 & 3374155.3 & 30.480344 & -83.24486 \\
\hline 15 & 61.3 & 284512.7 & 3374153.7 & 30.48033 & -83.244851 \\
\hline 17 & 61.4 & 284513.5 & 3374152.0 & 30.480315 & -83.244841 \\
\hline 19 & 61.4 & 284514.3 & 3374150.3 & 30.4803 & -83.244832 \\
\hline 21 & 61.5 & 284515.2 & 3374148.7 & 30.480285 & -83.244823 \\
\hline 23 & 61.3 & 284516.0 & 3374147.0 & 30.48027 & -83.244814 \\
\hline 25 & 61.1 & 284516.8 & 3374145.3 & 30.480255 & -83.244805 \\
\hline 27 & 61.0 & 284517.7 & 3374143.7 & 30.48024 & -83.244796 \\
\hline 29 & 60.9 & 284518.5 & 3374142.0 & 30.480225 & -83.244787 \\
\hline 31 & 60.8 & 284519.3 & 3374140.3 & 30.48021 & -83.244778 \\
\hline 33 & 60.5 & 284520.2 & 3374138.7 & 30.480196 & -83.244769 \\
\hline 35 & 60.2 & 284521.0 & 3374137.0 & 30.480181 & -83.24476 \\
\hline 37 & 60.2 & 284521.8 & 3374135.3 & 30.48 & -83.244751 \\
\hline 39 & 60.2 & 284522.7 & 3374133.7 & 30.480151 & -83.244742 \\
\hline 41 & 60.2 & 284523.5 & 3374132.0 & 30.480136 & -83.244733 \\
\hline 43 & 60.2 & 284524.3 & 3374130.3 & 30.480121 & -83.244724 \\
\hline 45 & 60.2 & 284525.2 & 3374128.7 & 30.480106 & -83.244715 \\
\hline 47 & 60.3 & 284526.0 & 3374127.0 & 30.480091 & -83.244706 \\
\hline 49 & 60.4 & 284526.8 & 3374125.3 & 30.480077 & -83.244697 \\
\hline 51 & 60.5 & 284527.7 & 3374123.7 & 30.480062 & -83.244688 \\
\hline 53 & 61.3 & 284528.5 & 3374122.0 & 30.480047 & -83.244679 \\
\hline 55 & 62.1 & 284529.3 & 3374120.3 & 30.480032 & -83.24467 \\
\hline 57 & 62.4 & 284530.2 & 3374118.7 & 30.480017 & -83.244661 \\
\hline 59 & 62.7 & 284531.0 & 3374117.0 & 30.480002 & -83.244652 \\
\hline
\end{tabular}


Survey line elevation and coordinates continued

\begin{tabular}{|c|c|c|c|c|c|}
\hline L3 & MSL & Zone & 17 N & & \\
\hline Distance & Elevation & Easting & Northing & Latitude & Longitude \\
\hline (meters) & (meters) & (meters) & (meters) & (degrees) & (degrees) \\
\hline 24 & 61.3 & 284516.0 & 3374147.0 & 30.48027 & -83.244814 \\
\hline 25 & 61.1 & 284516.8 & 3374145.3 & 30.480255 & -83.244805 \\
\hline 27 & 61.0 & 284517.7 & 3374143.7 & 30.48024 & -83.244796 \\
\hline 29 & 60.9 & 284518.5 & 3374142.0 & 30.480225 & -83.244787 \\
\hline 31 & 60.8 & 284519.3 & 3374140.3 & 30.48021 & -83.244778 \\
\hline 33 & 60.5 & 284520.2 & 3374138.7 & 30.480196 & -83.244769 \\
\hline 35 & 60.2 & 284521.0 & 3374137.0 & 30.480181 & -83.24476 \\
\hline 37 & 60.2 & 284521.8 & 3374135.3 & 30.480166 & -83.244751 \\
\hline 39 & 60.2 & 284522.7 & 3374133.7 & 30.480151 & -83.244742 \\
\hline 41 & 60.2 & 284523.5 & 3374132.0 & 30.480136 & -83.244733 \\
\hline 43 & 60.2 & 284524.3 & 3374130.3 & 30.480121 & -83.244724 \\
\hline 45 & 60.2 & 284525.2 & 3374128.7 & 30.480106 & -83.244715 \\
\hline 47 & 60.3 & 284526.0 & 3374127.0 & 30.480091 & -83.244706 \\
\hline 49 & 60.4 & 284526.8 & 3374125.3 & 30.480077 & -83.244697 \\
\hline 51 & 60.5 & 284527.7 & 3374123.7 & 30.480062 & -83.244688 \\
\hline 53 & 61.3 & 284528.5 & 3374122.0 & 30.480047 & -83.244679 \\
\hline 55 & 62.1 & 284529.3 & 3374120.3 & 30.480032 & -83.24467 \\
\hline 57 & 62.4 & 284530.2 & 3374118.7 & 30.480017 & -83.244661 \\
\hline 59 & 62.7 & 284531.0 & 3374117.0 & 30.480002 & -83.244652 \\
\hline 61 & 62.8 & 284531.6 & 3374115.8 & 30.479991 & -83.244645 \\
\hline 63 & 62.9 & 284532.3 & 3374114.5 & 30.47998 & -83.244639 \\
\hline 65 & 63.0 & 284532.9 & 3374113.3 & 30.479969 & -83.244632 \\
\hline 67 & 62.9 & 284533.5 & 3374112.0 & 30.479958 & -83.244625 \\
\hline 69 & 62.8 & 284534.1 & 3374110.8 & 30.479946 & -83.244618 \\
\hline 71 & 62.7 & 284534.8 & 3374109.5 & 30.479935 & -83.244611 \\
\hline & & & & & \\
\hline 5 & & & & \\
\hline 5 & & & & & \\
\hline 5 & & & & &
\end{tabular}


Appendix B: CSGs \& First Breaks 


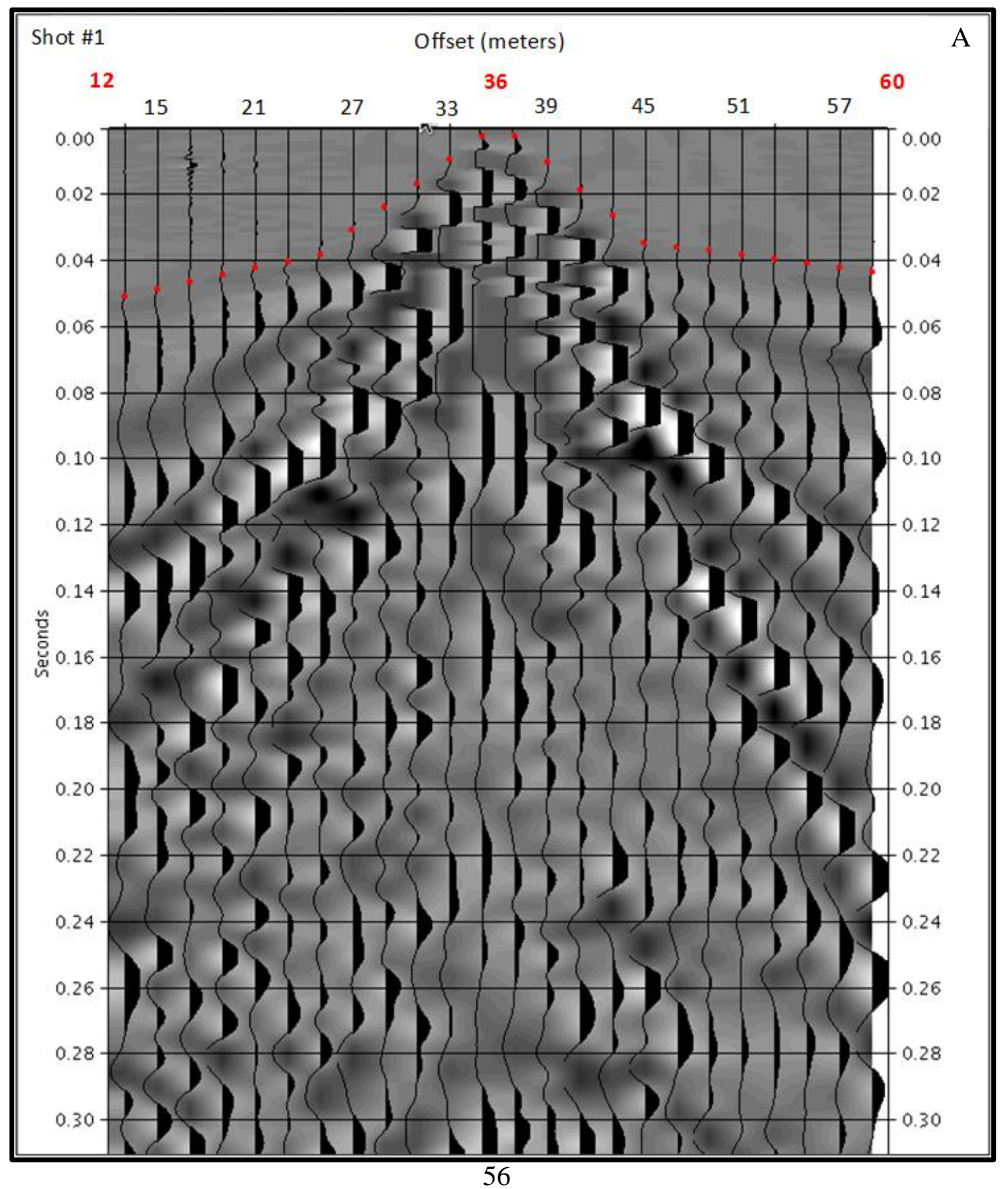




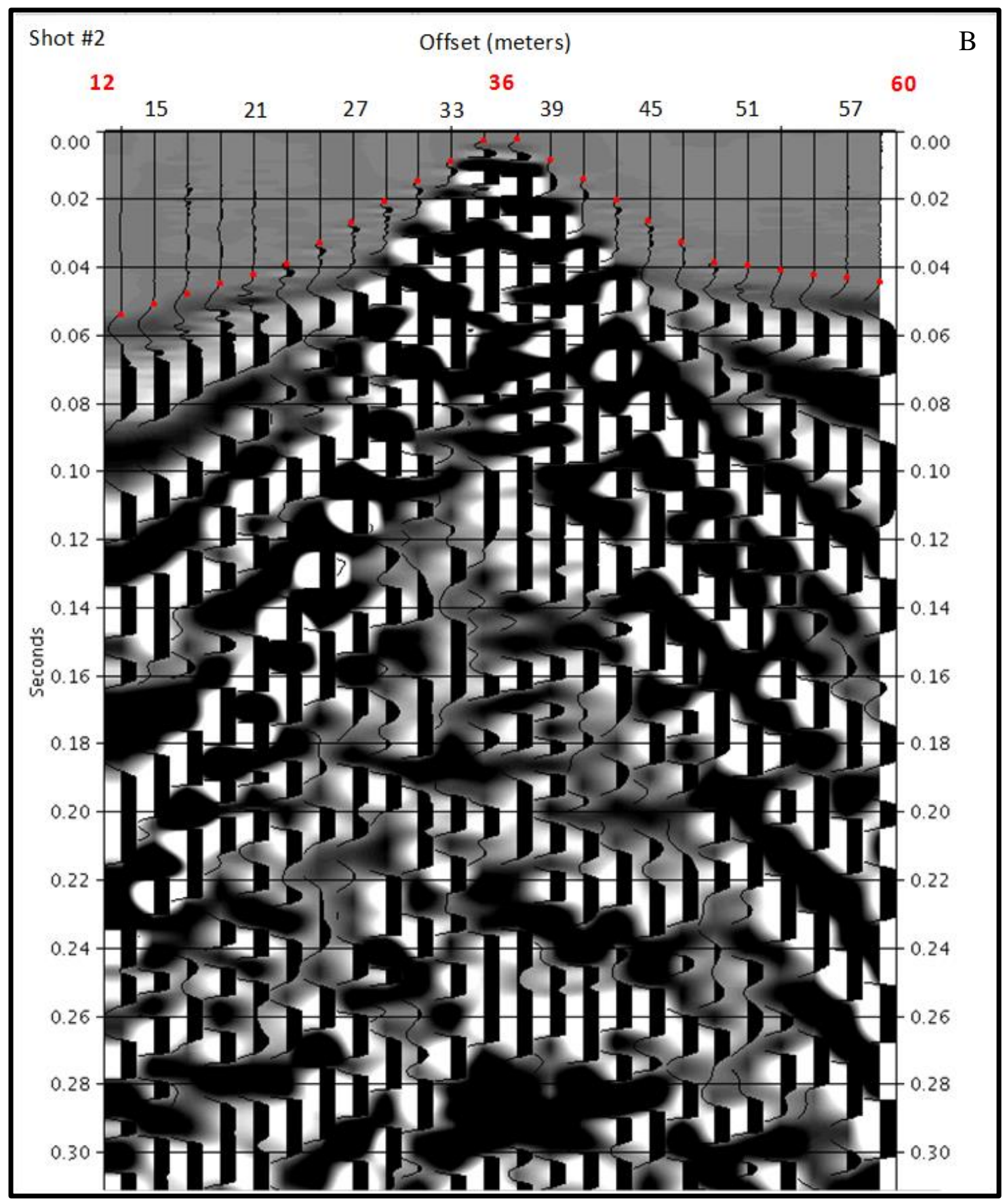




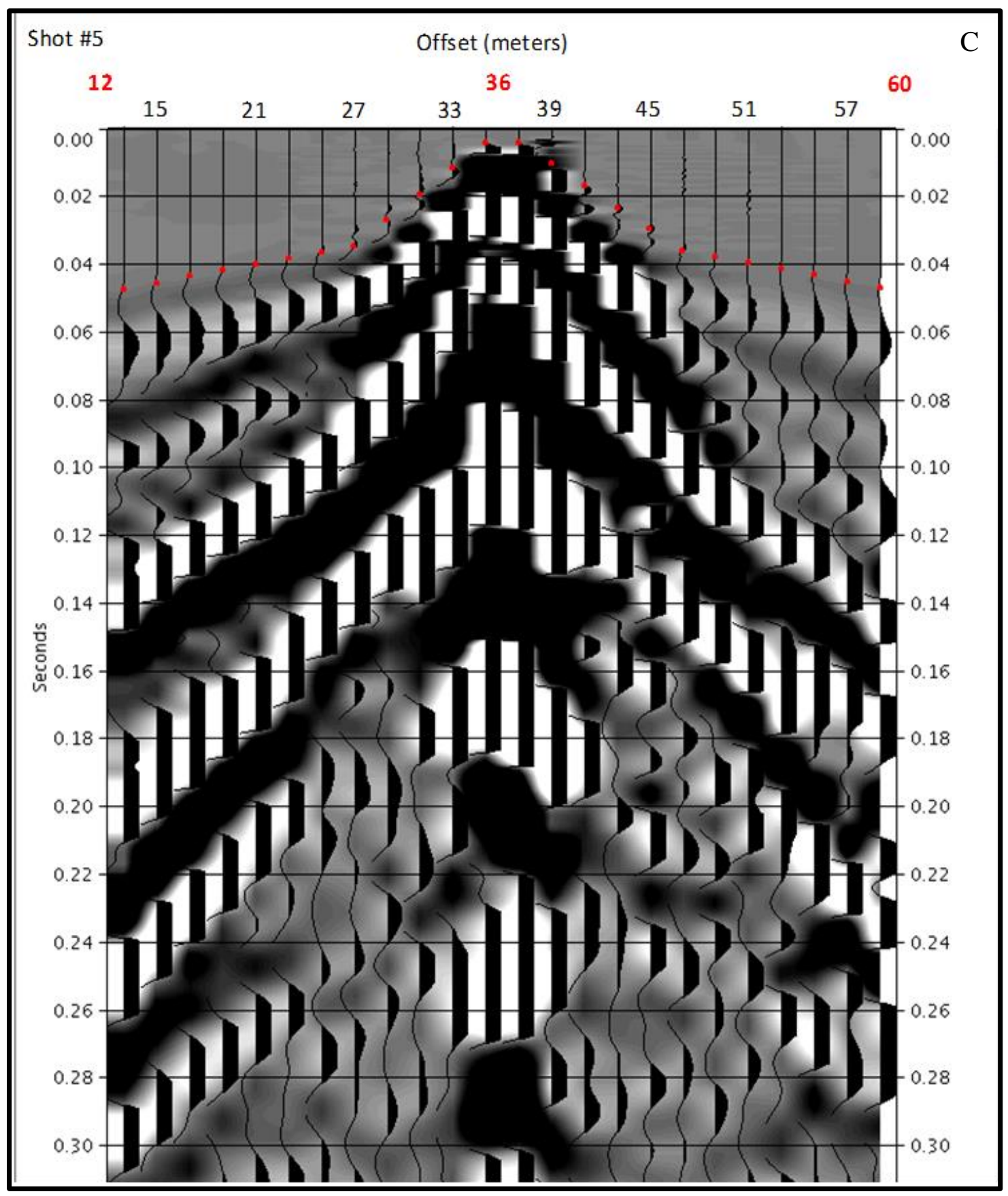




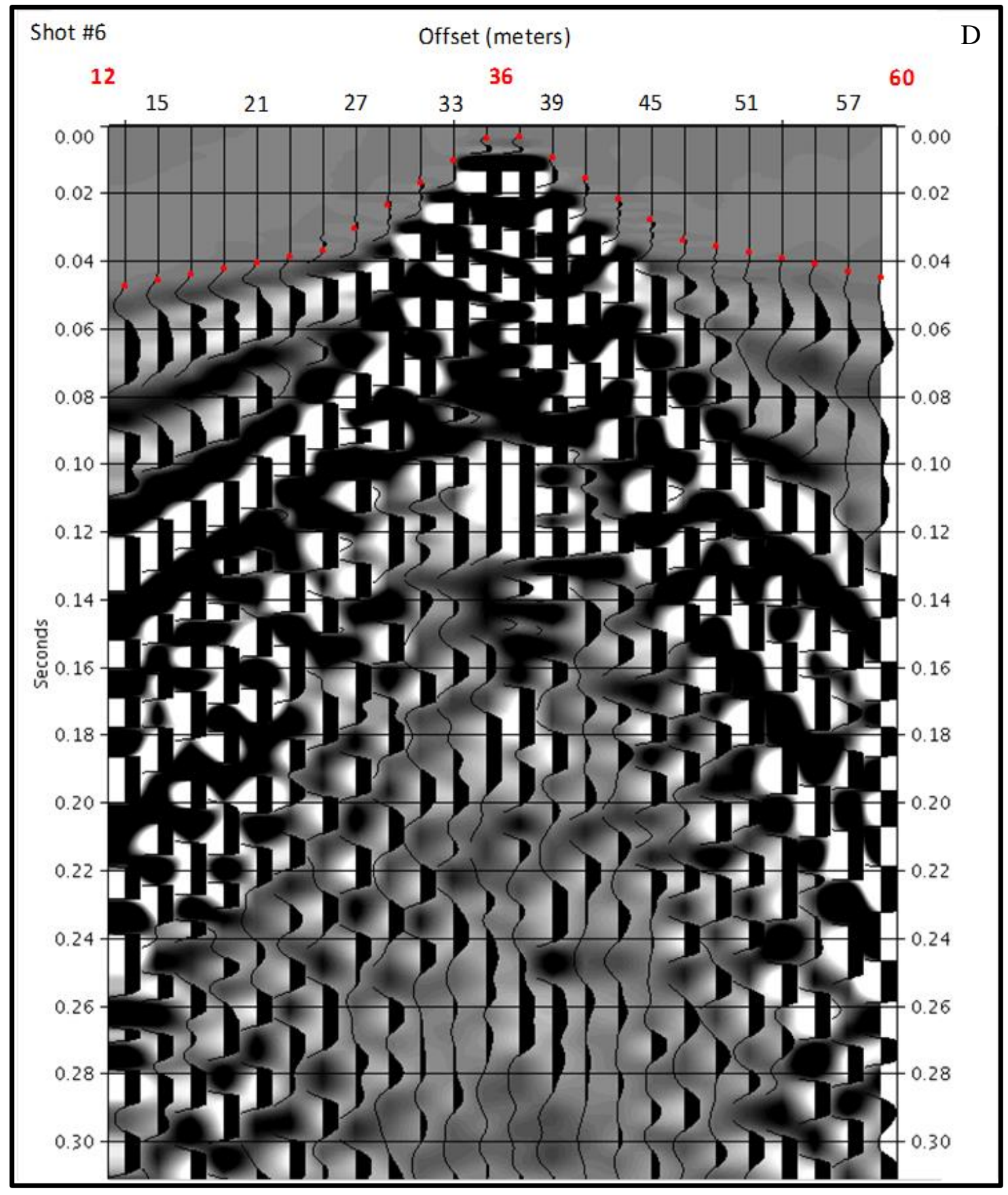




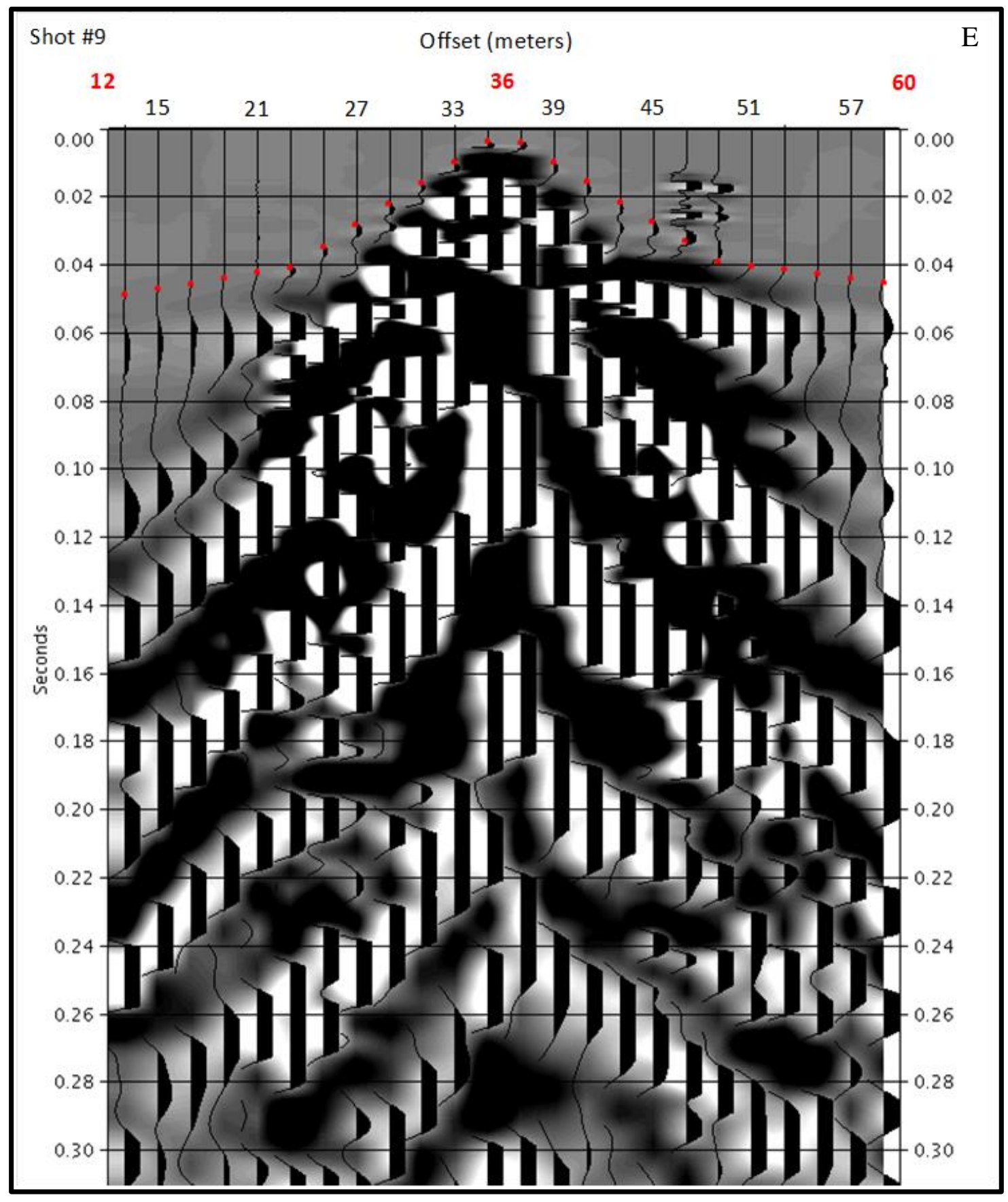




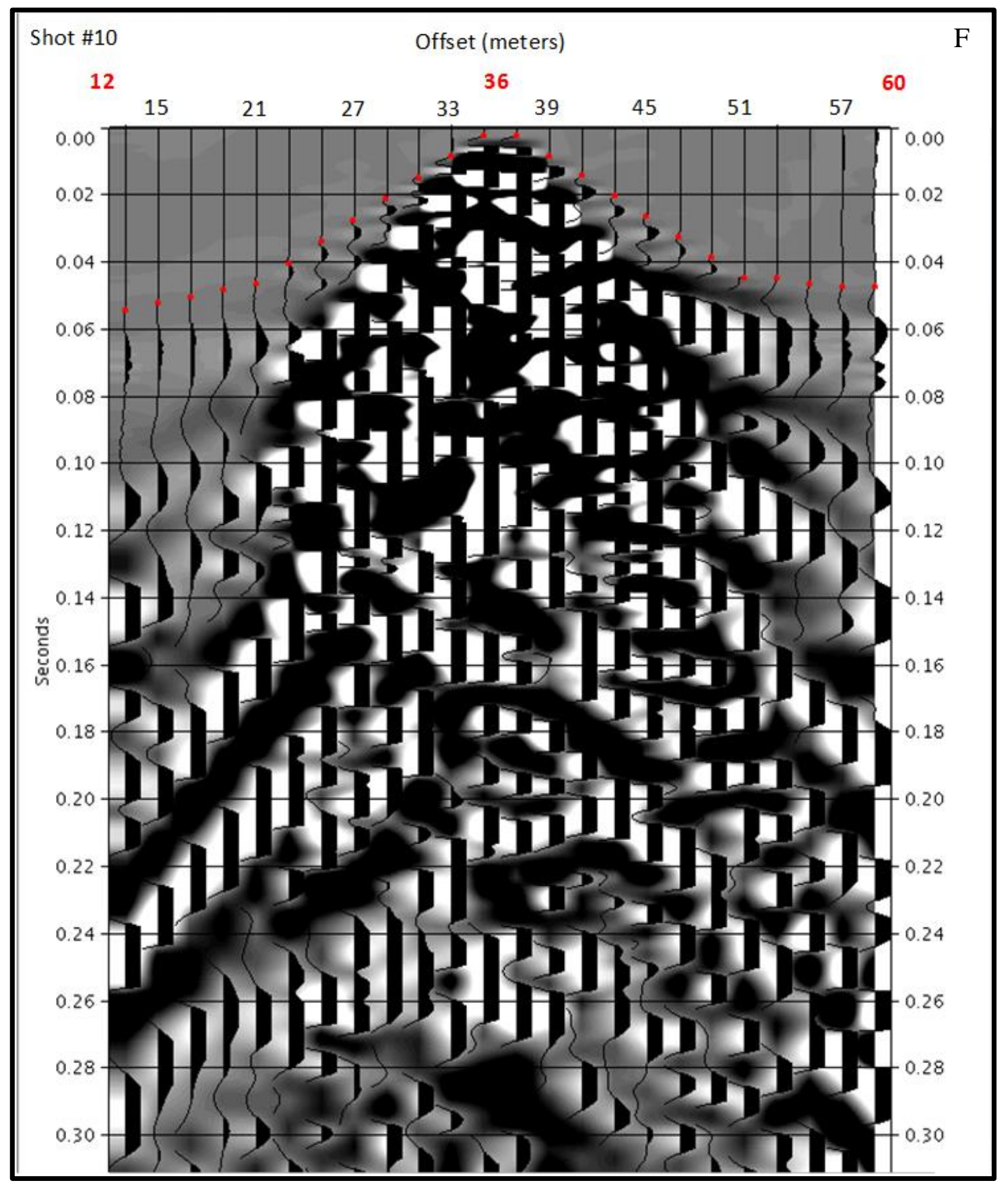




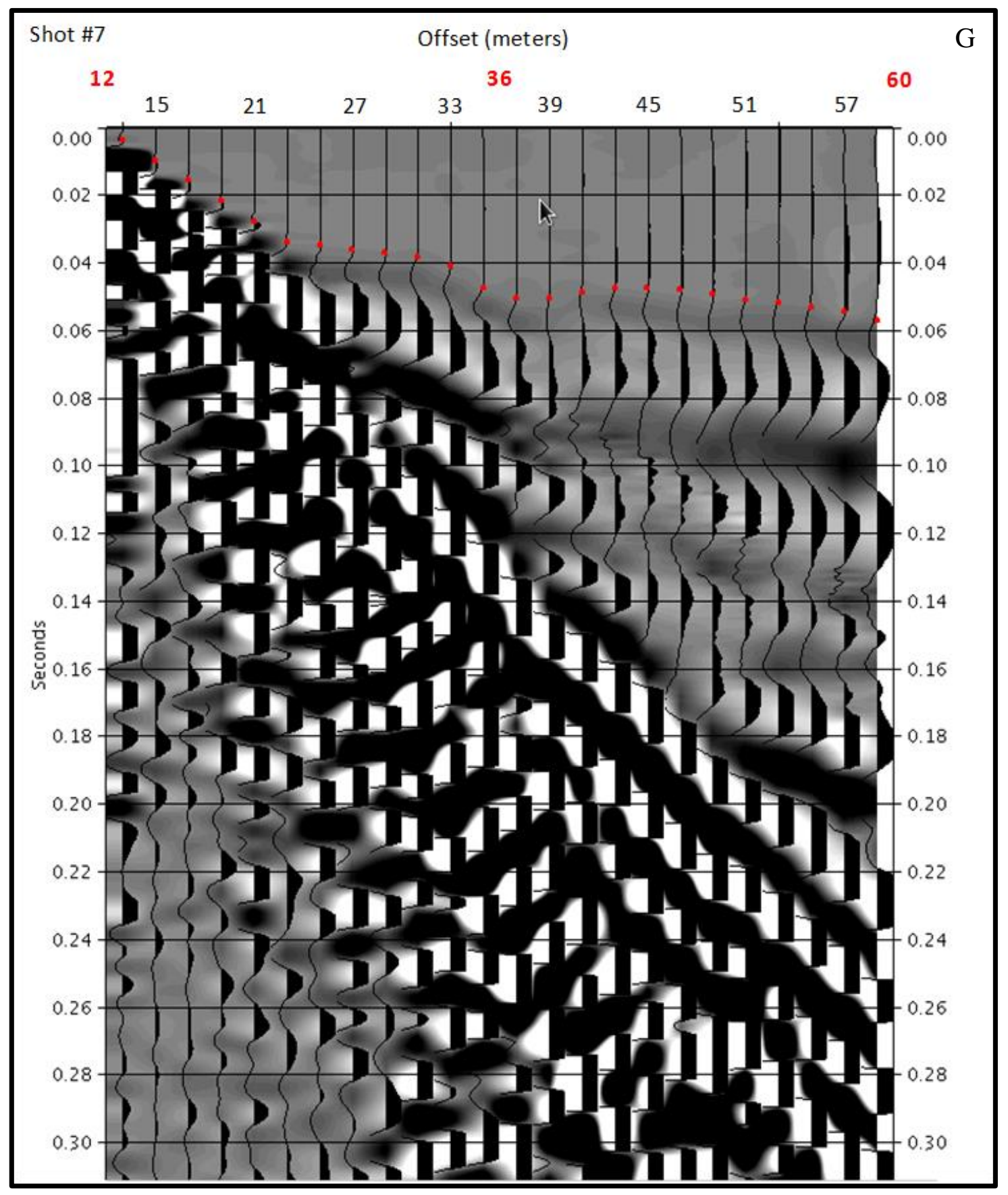




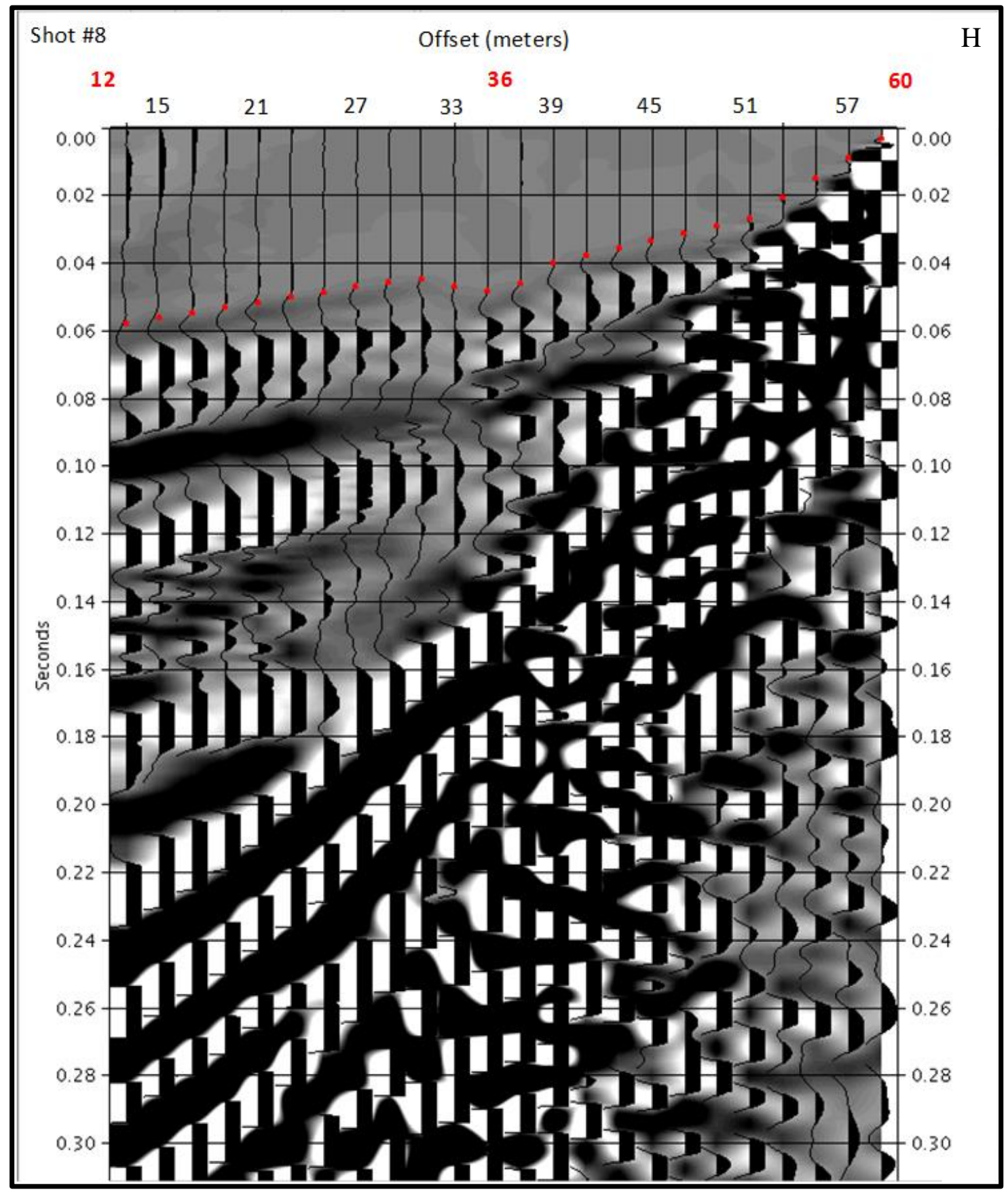




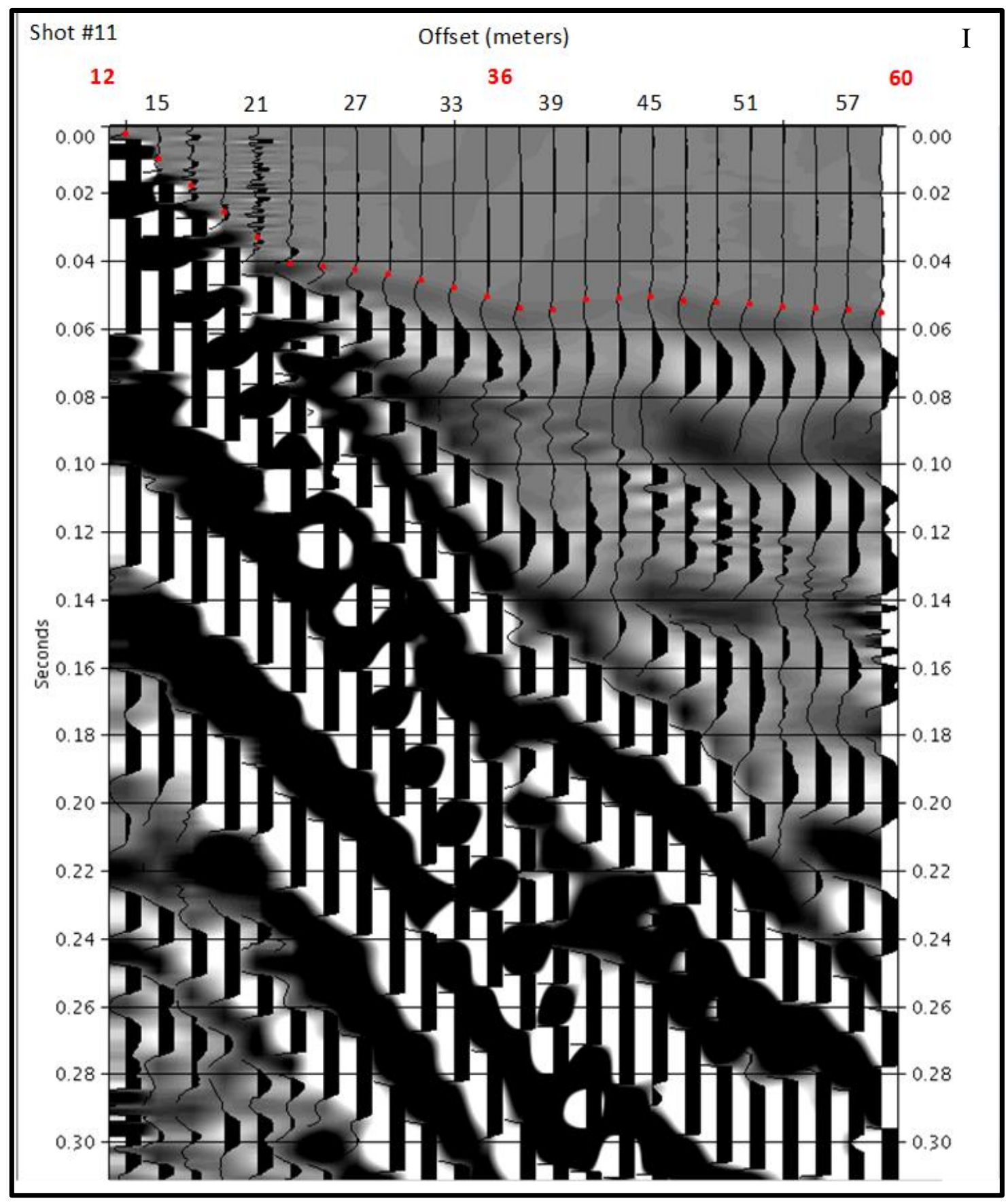




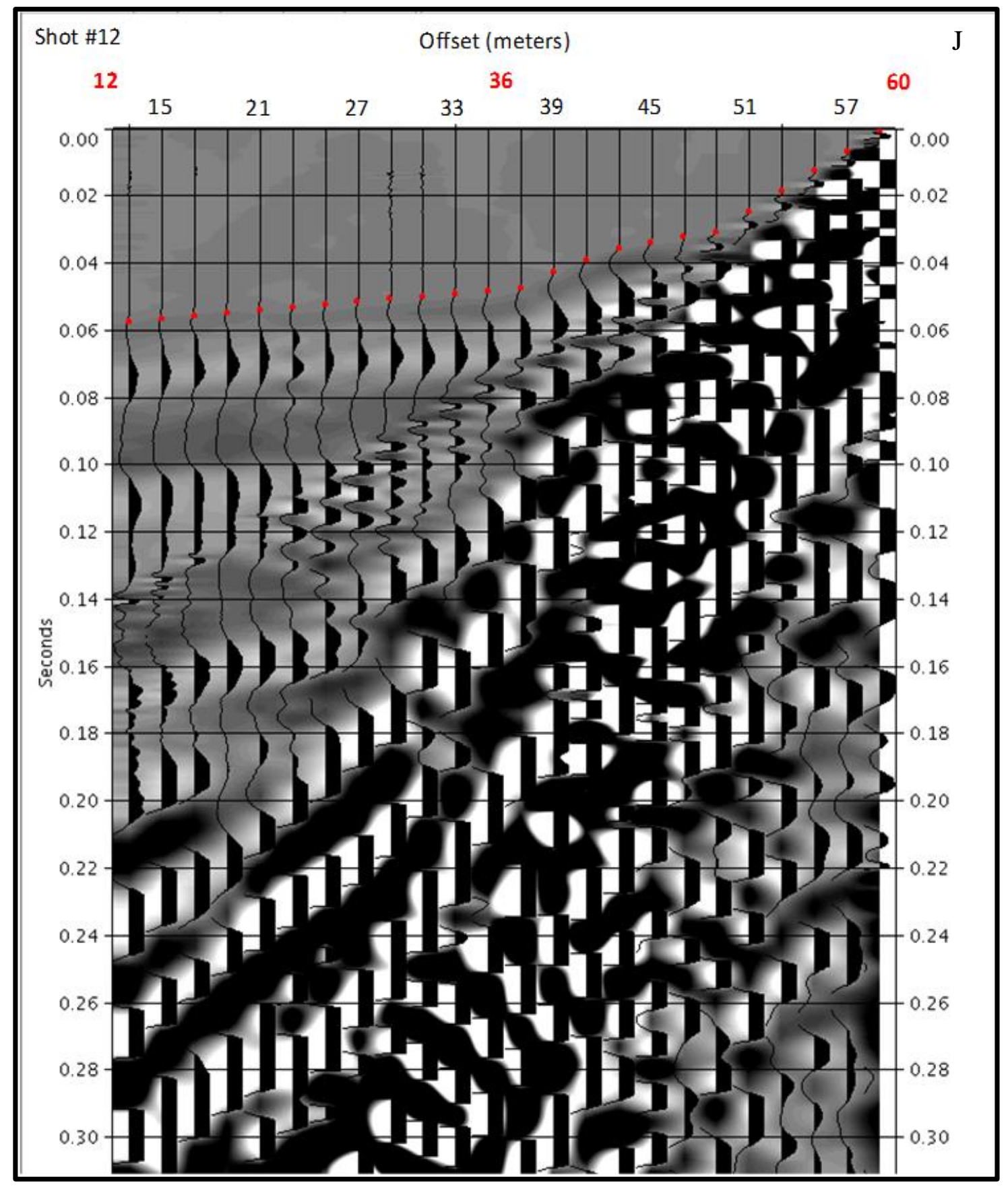




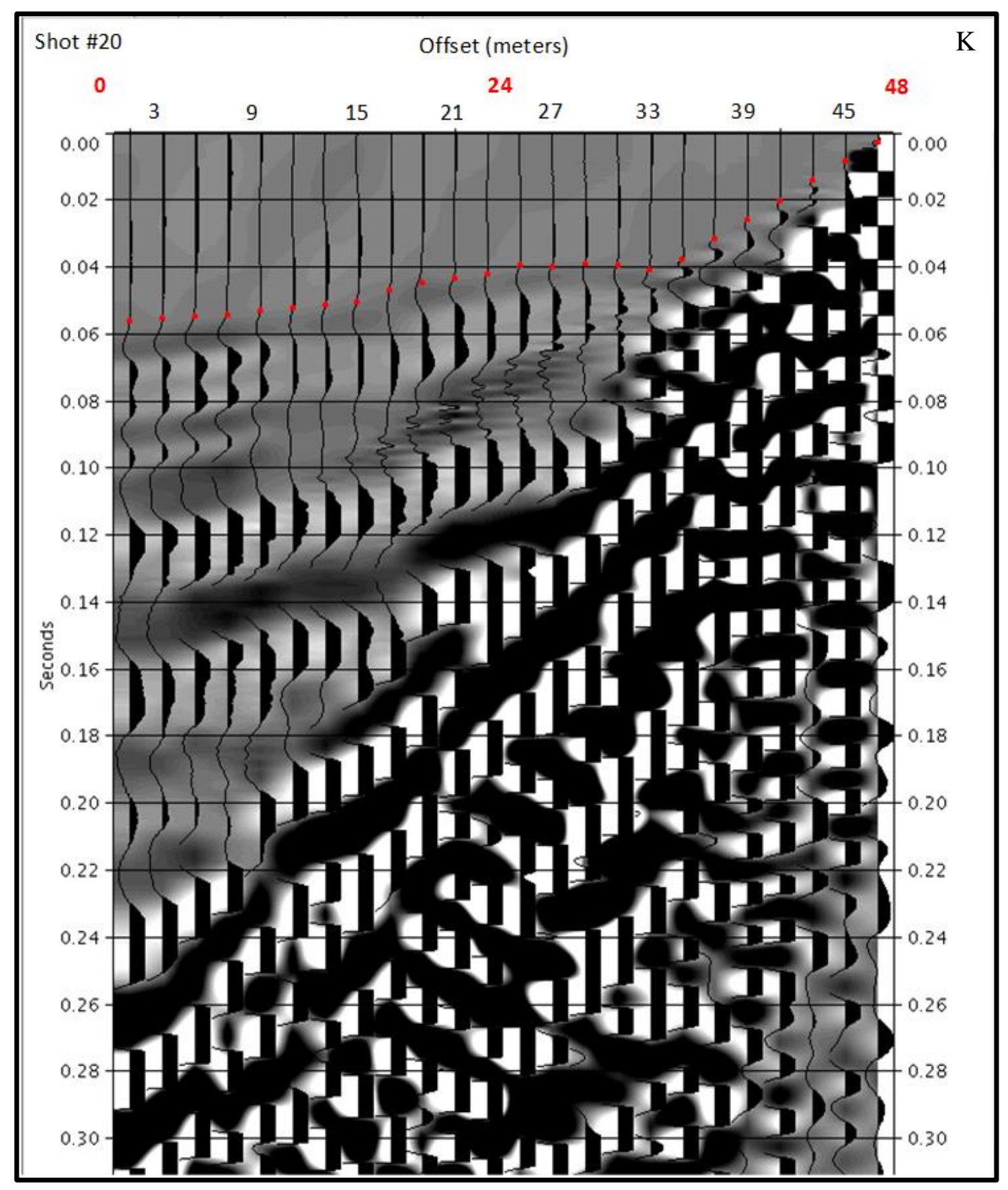




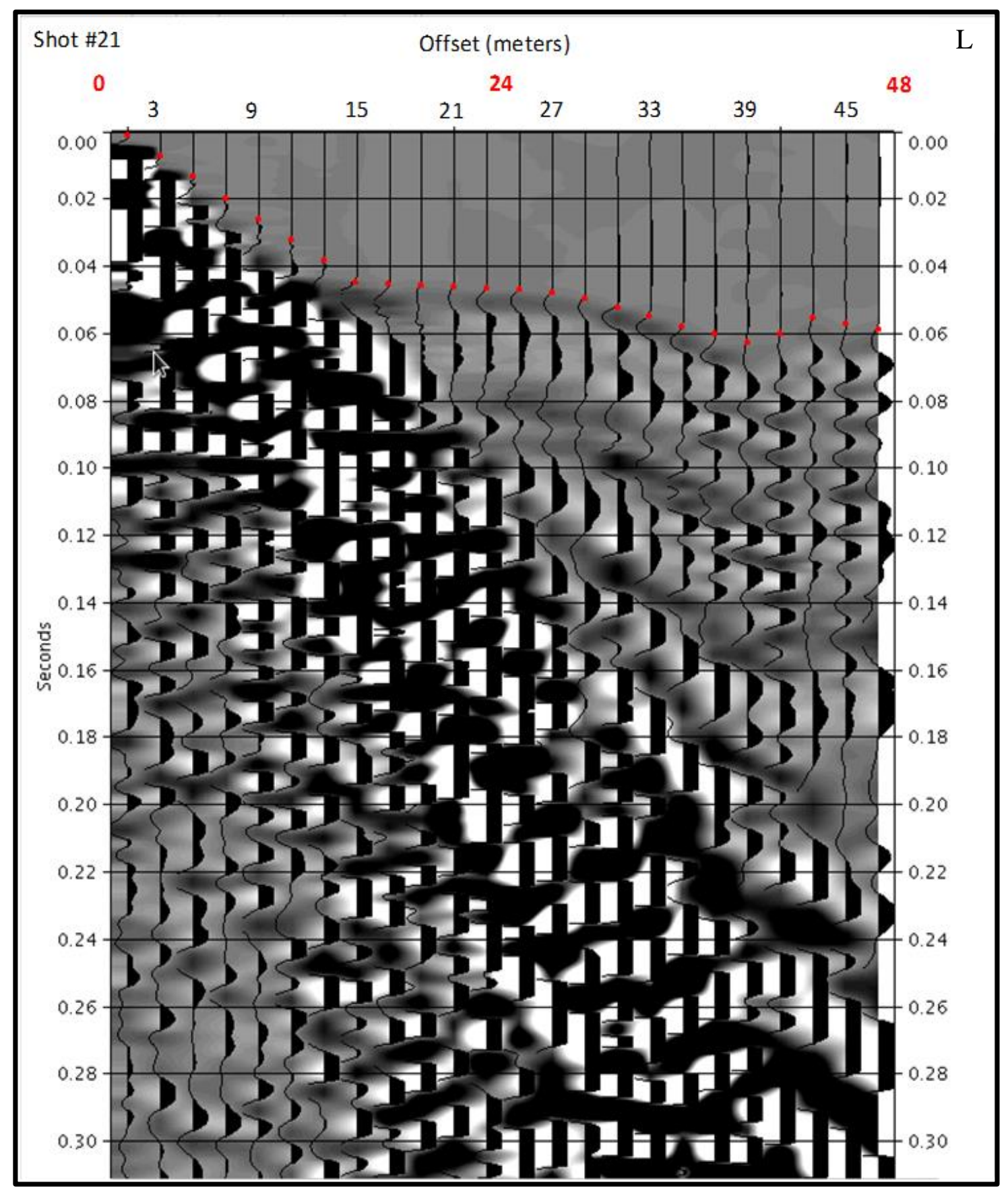




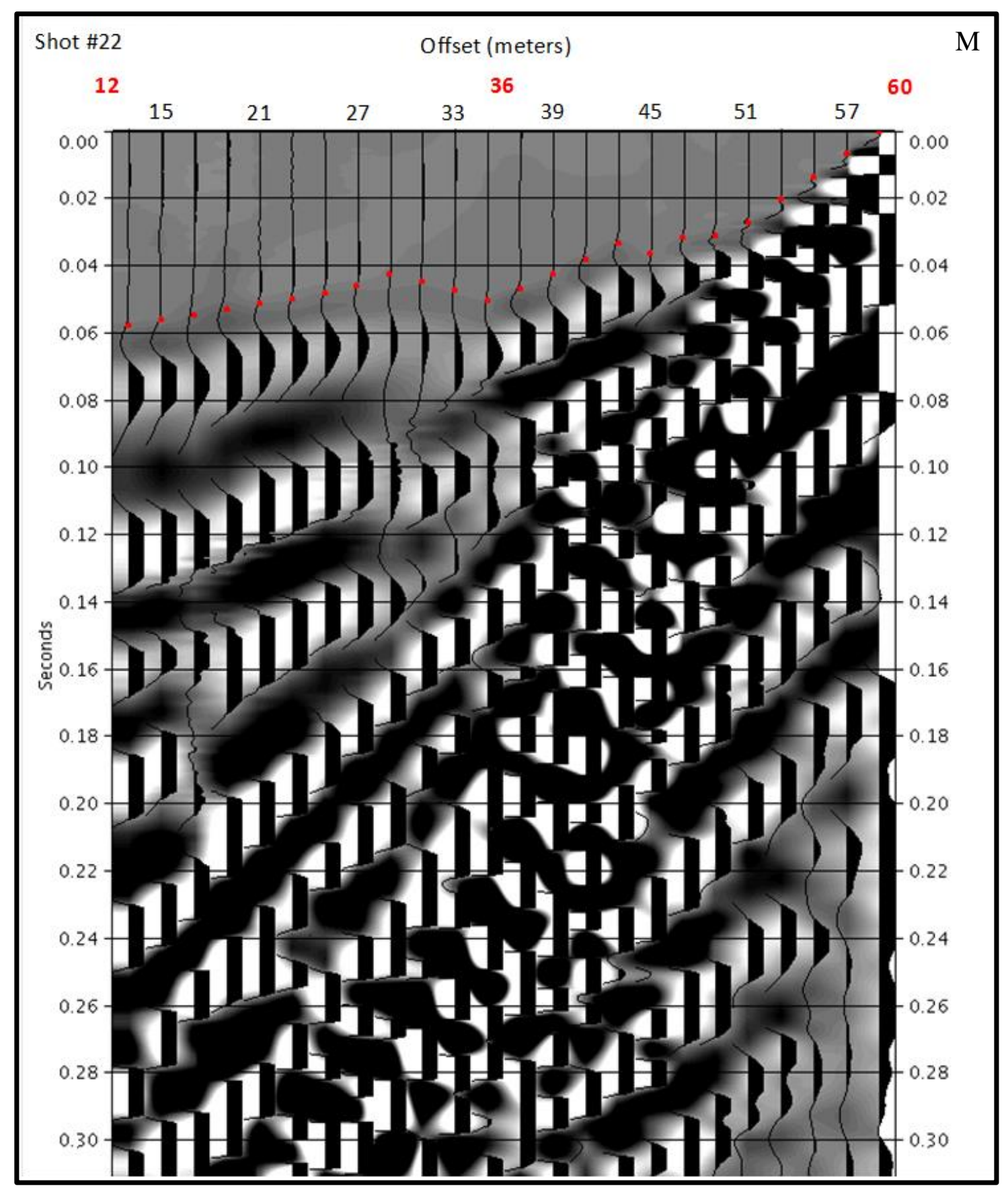




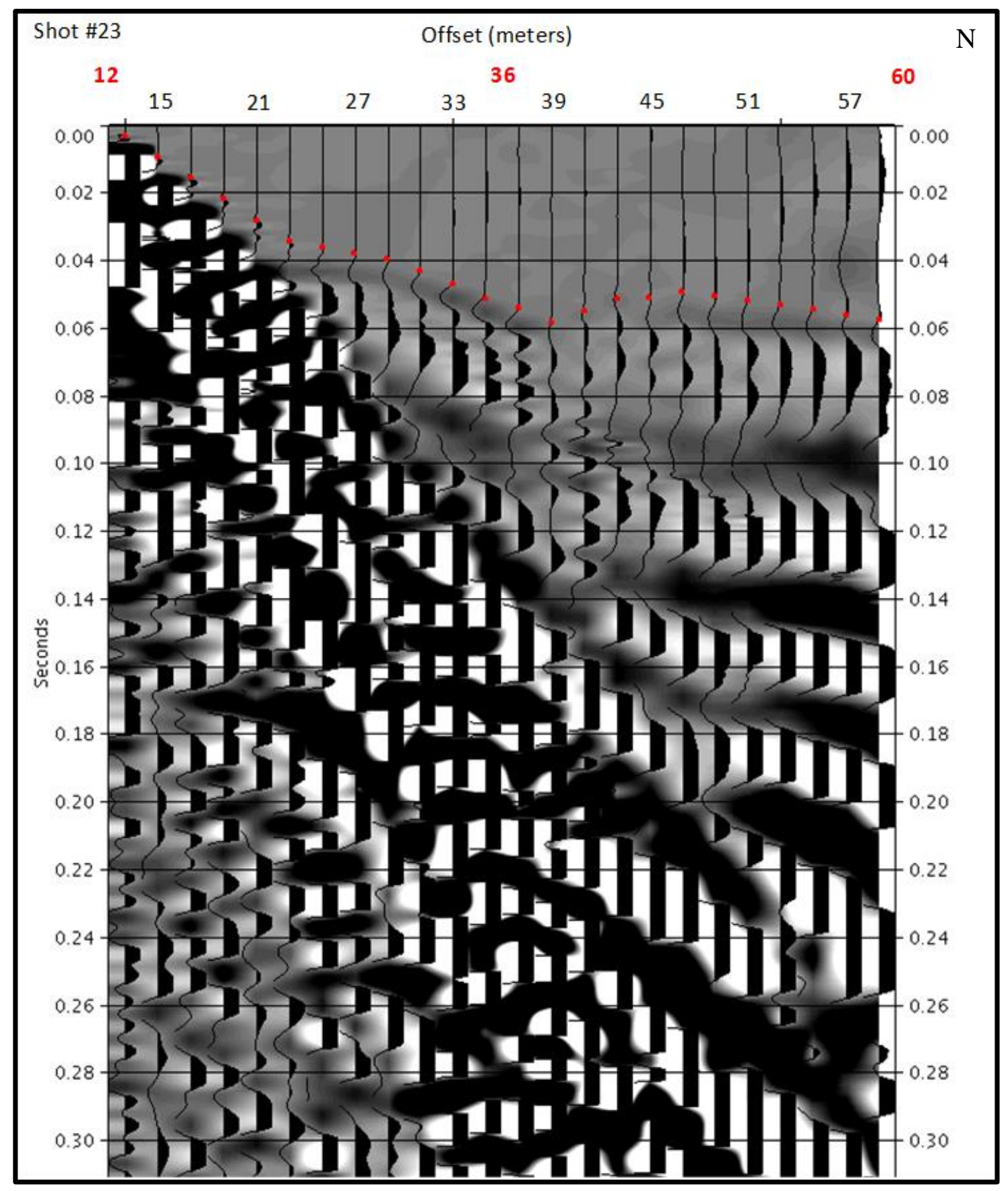




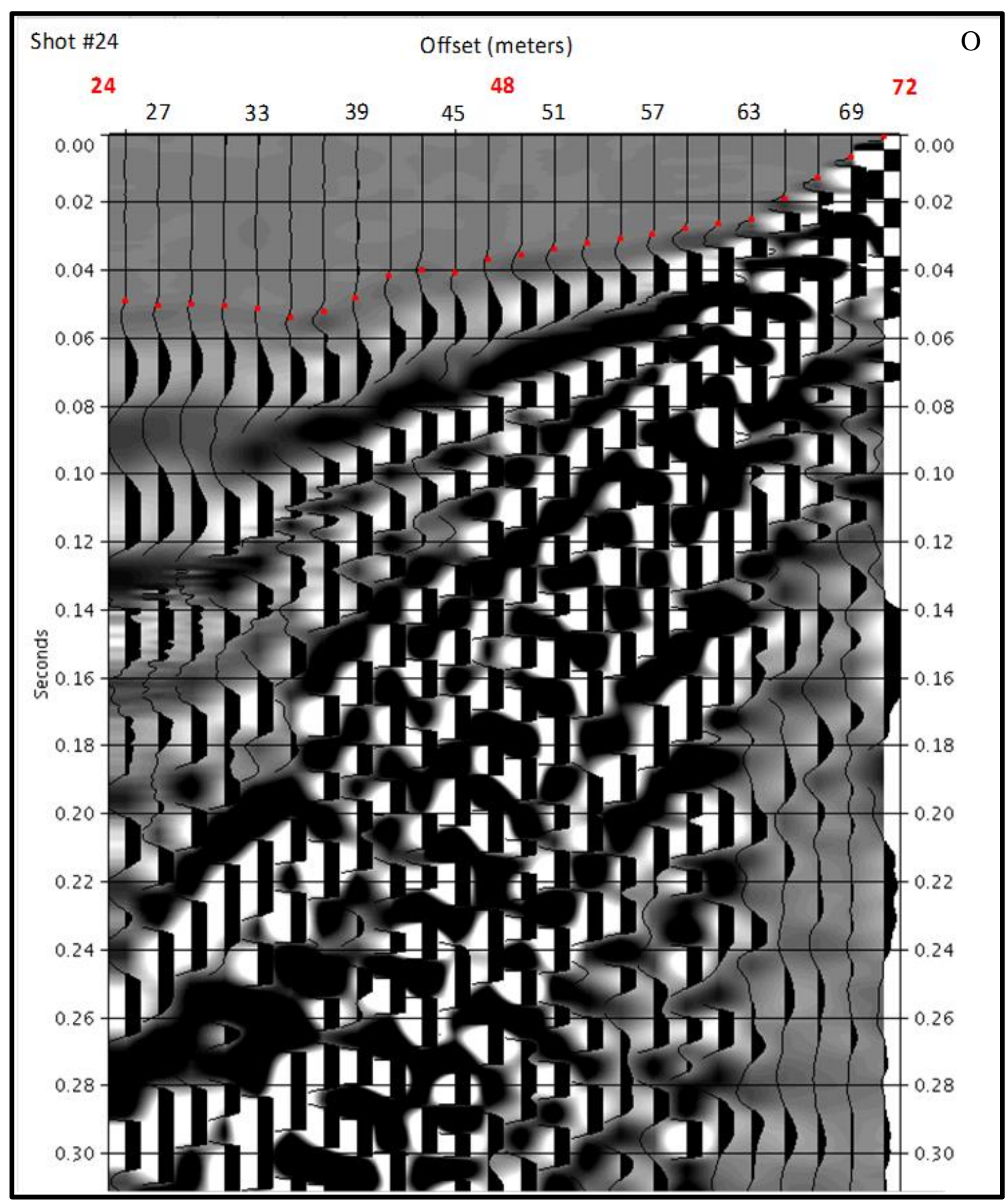




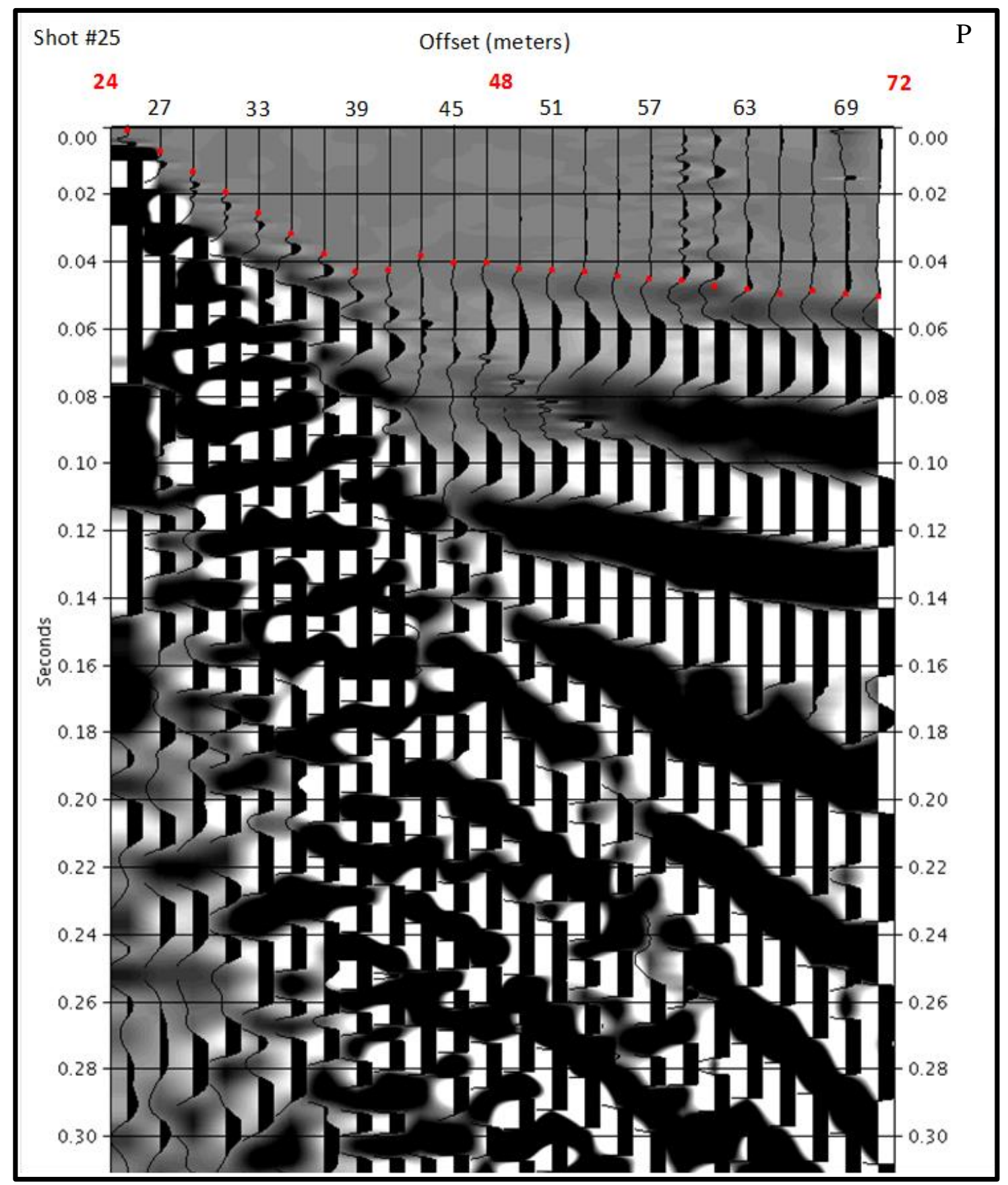




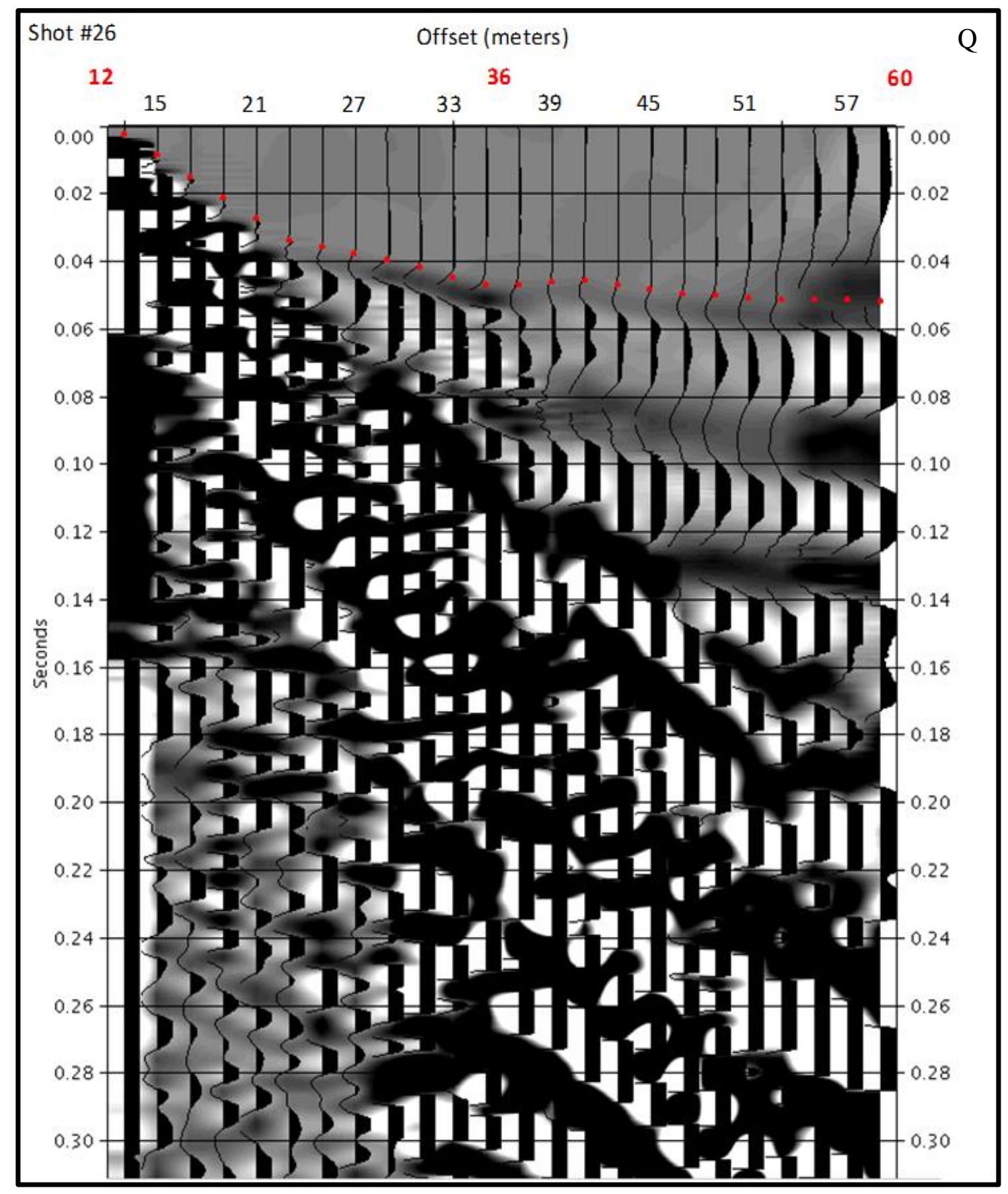




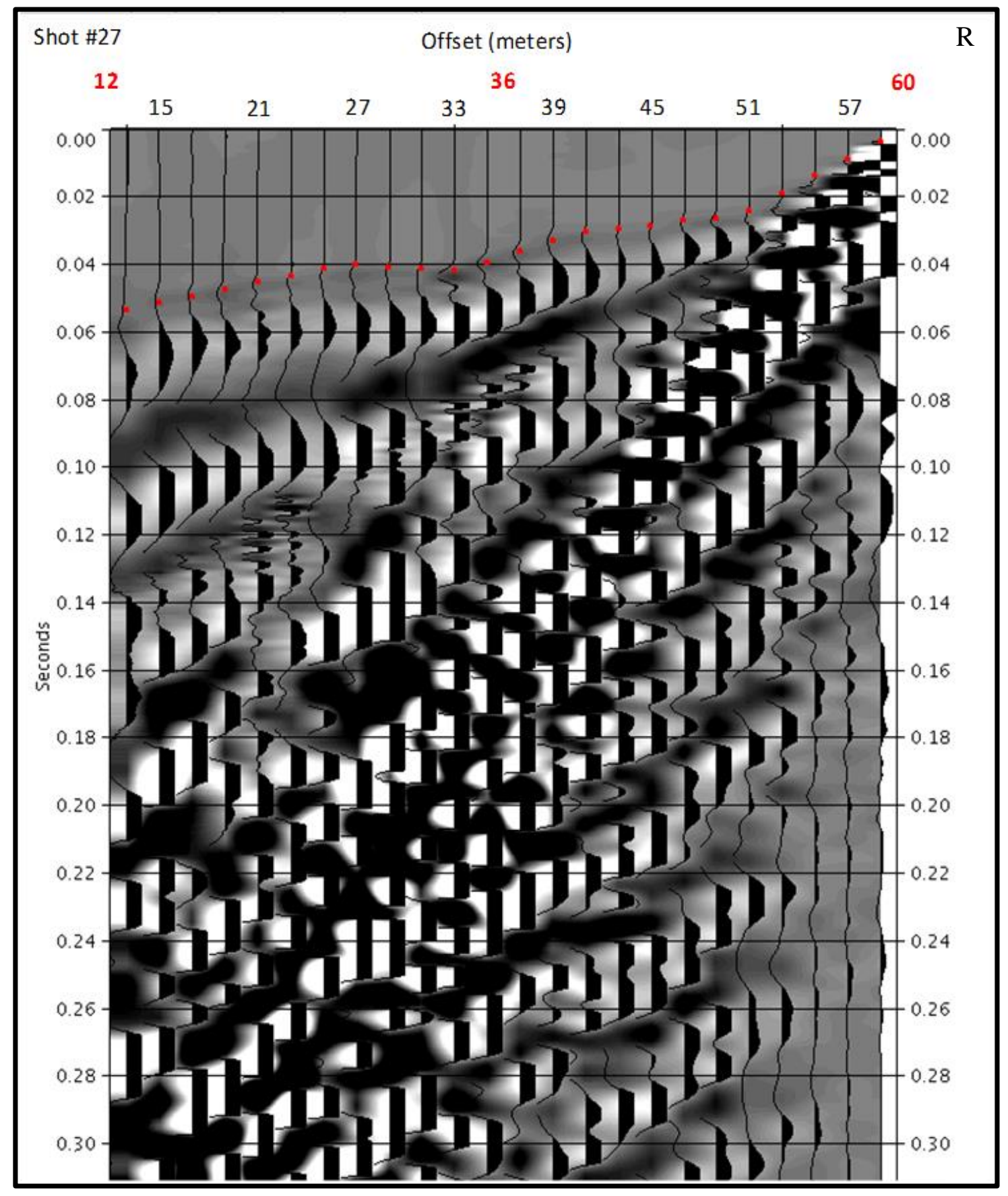


Figure 26 A-R: Complete set of common shot gathers with first breaks selected. Each of the following 18 images is labeled from A-R and the shot number displayed in the upper left corner. The shot number can be correlated with the location map in figure 4 . Images for line 1 ( $\mathrm{K}$ and $\mathrm{L}$ ), line 2 (A,B,M,N,O and R), Line 2 at $13^{\circ}(\mathrm{C}, \mathrm{D}, \mathrm{G}$ and $\mathrm{H})$, line 2 at $90^{\circ}(\mathrm{E}, \mathrm{F}, \mathrm{I}$ and $\mathrm{J})$, and line $3(\mathrm{O}$ and $\mathrm{P}$ ) were used to generate the T-X graphs seen in Appendix D. Each image was generated using a 2 meter geophone interval and stacked data from a hammer source. The red dots on each of the traces indicates the first breaks. 


\section{Appendix C: First Break Tables}


Table 6: Complete set of first break times vs offset

\begin{tabular}{|c|c|c|c|c|c|c|c|}
\hline \multicolumn{2}{|c|}{ SS $145^{\circ}$} & \multicolumn{2}{|c|}{ SS $145^{\circ}$} & \multicolumn{2}{|c|}{ OE $145^{\circ}$} & \multicolumn{2}{|c|}{ OE $145^{\circ}$} \\
\hline L2 & Betsy & L2 & Sledge & L2 & Sledge & L2 & Sledge \\
\hline File \# & Stacks & File \# & Stacks & File \# & Stacks & File \# & Stacks \\
\hline 1 & 2 & 2 & 20 & 3 & 20 & 4 & 20 \\
\hline Time & Offset & Time & Offset & Time & Offset & Time & Offset \\
\hline (s) & (meters) & (s) & (meters) & (s) & (meters) & (s) & (meters) \\
\hline 0.0489 & 13 & 0.0529 & 13 & 0.0598 & 13 & 0 & 12 \\
\hline 0.0469 & 15 & 0.0509 & 15 & 0.06 & 15 & 0.0051 & 13 \\
\hline 0.0436 & 17 & 0.0474 & 17 & 0.059 & 17 & 0.0134 & 15 \\
\hline 0.0409 & 19 & 0.0461 & 19 & 0.0587 & 19 & 0.0207 & 17 \\
\hline 0.0406 & 21 & 0.0444 & 21 & 0.0572 & 21 & 0.026 & 19 \\
\hline 0.0386 & 23 & 0.0383 & 23 & 0.0562 & 23 & 0.0318 & 21 \\
\hline 0.0325 & 25 & 0.0323 & 25 & 0.0545 & 25 & 0.0383 & 23 \\
\hline 0.0277 & 27 & 0.0267 & 27 & 0.0532 & 27 & 0.0439 & 25 \\
\hline 0.0217 & 29 & 0.0209 & 29 & 0.0517 & 29 & 0.0446 & 27 \\
\hline 0.0146 & 31 & 0.0151 & 31 & 0.0547 & 31 & 0.0456 & 29 \\
\hline 0.0116 & 33 & 0.0091 & 33 & 0.0592 & 33 & 0.0482 & 31 \\
\hline 0.0018 & 35 & 0.003 & 35 & 0.0595 & 35 & 0.0507 & 33 \\
\hline 0 & 36 & 0 & 36 & 0.0557 & 37 & 0.0552 & 35 \\
\hline 0.0008 & 37 & 0.0028 & 37 & 0.0489 & 39 & 0.0592 & 37 \\
\hline 0.0109 & 39 & 0.0088 & 39 & 0.0469 & 41 & 0.0585 & 39 \\
\hline 0.0157 & 41 & 0.0149 & 41 & 0.0436 & 43 & 0.0547 & 41 \\
\hline 0.0217 & 43 & 0.0207 & 43 & 0.0416 & 45 & 0.0517 & 43 \\
\hline 0.0275 & 45 & 0.0262 & 45 & 0.0398 & 47 & 0.0537 & 45 \\
\hline 0.0328 & 47 & 0.0323 & 47 & 0.0358 & 49 & 0.054 & 47 \\
\hline 0.0388 & 49 & 0.0383 & 49 & 0.0288 & 51 & 0.0555 & 49 \\
\hline 0.0388 & 51 & 0.0424 & 51 & 0.0221 & 53 & 0.0565 & 51 \\
\hline 0.0398 & 53 & 0.0429 & 53 & 0.0164 & 55 & 0.0572 & 53 \\
\hline 0.0409 & 55 & 0.0436 & 55 & 0.0112 & 57 & 0.058 & 55 \\
\hline 0.0431 & 57 & 0.0451 & 57 & 0.006 & 59 & 0.059 & 57 \\
\hline 0.0434 & 59 & 0.0454 & 59 & 0 & 60 & 0.0603 & 59 \\
\hline
\end{tabular}


Complete set of first break times vs offset continued

\begin{tabular}{|c|c|c|c|c|c|c|c|}
\hline \multicolumn{2}{|c|}{ SS $13^{\circ}$} & \multicolumn{2}{|c|}{ SS $13^{\circ}$} & \multicolumn{2}{|c|}{$\mathrm{OE} 13^{\circ}$} & \multicolumn{2}{|c|}{ OE $13^{\circ}$} \\
\hline L2 & Betsy & L2 & Sledge & L2 & Sledge & L2 & Sledge \\
\hline File \# & Stacks & File \# & Stacks & File \# & Stacks & File \# & Stacks \\
\hline 5 & 2 & 6 & 20 & 7 & 20 & 8 & 20 \\
\hline Time & Offset & Time & Offset & Time & Offset & Time & Offset \\
\hline (s) & (meters) & (s) & (meters) & (s) & (meters) & (s) & (meters) \\
\hline 0.0514 & 13 & 0.0522 & 13 & 0.0568 & 13 & 0 & 12 \\
\hline 0.0497 & 15 & 0.0499 & 15 & 0.0559 & 15 & 0.0026 & 13 \\
\hline 0.0482 & 17 & 0.0484 & 17 & 0.0545 & 17 & 0.0081 & 15 \\
\hline 0.0461 & 19 & 0.0456 & 19 & 0.0526 & 19 & 0.0145 & 17 \\
\hline 0.0441 & 21 & 0.0444 & 21 & 0.0511 & 21 & 0.0202 & 19 \\
\hline 0.0416 & 23 & 0.0421 & 23 & 0.0496 & 23 & 0.0255 & 21 \\
\hline 0.0401 & 25 & 0.0403 & 25 & 0.0483 & 25 & 0.032 & 23 \\
\hline 0.0383 & 27 & 0.0376 & 27 & 0.0473 & 27 & 0.0371 & 25 \\
\hline 0.0358 & 29 & 0.0343 & 29 & 0.0456 & 29 & 0.0377 & 27 \\
\hline 0.0295 & 31 & 0.028 & 31 & 0.0443 & 31 & 0.0388 & 29 \\
\hline 0.0189 & 33 & 0.0184 & 33 & 0.0471 & 33 & 0.0392 & 31 \\
\hline 0.0066 & 35 & 0.0093 & 35 & 0.0504 & 35 & 0.0422 & 33 \\
\hline 0 & 36 & 0 & 36 & 0.0468 & 37 & 0.0473 & 35 \\
\hline 0.0061 & 37 & 0.0091 & 37 & 0.0415 & 39 & 0.0513 & 37 \\
\hline 0.0209 & 39 & 0.0194 & 39 & 0.0384 & 41 & 0.0507 & 39 \\
\hline 0.0272 & 41 & 0.0277 & 41 & 0.0369 & 43 & 0.0462 & 41 \\
\hline 0.0348 & 43 & 0.0358 & 43 & 0.0348 & 45 & 0.0481 & 43 \\
\hline 0.0383 & 45 & 0.0401 & 45 & 0.0341 & 47 & 0.0494 & 45 \\
\hline 0.0396 & 47 & 0.0414 & 47 & 0.0331 & 49 & 0.0498 & 47 \\
\hline 0.0419 & 49 & 0.0424 & 49 & 0.0265 & 51 & 0.0511 & 49 \\
\hline 0.0436 & 51 & 0.0434 & 51 & 0.0212 & 53 & 0.0515 & 51 \\
\hline 0.0449 & 53 & 0.0446 & 53 & 0.0151 & 55 & 0.0519 & 53 \\
\hline 0.0464 & 55 & 0.0456 & 55 & 0.0094 & 57 & 0.053 & 55 \\
\hline 0.0482 & 57 & 0.0469 & 57 & 0.0032 & 59 & 0.0555 & 57 \\
\hline 0.0502 & 59 & 0.0482 & 59 & 0 & 60 & 0.0572 & 59 \\
\hline
\end{tabular}


Complete set of first break times vs offset continued

\begin{tabular}{|c|c|c|c|c|c|c|c|}
\hline \multicolumn{2}{|c|}{ SS $90^{\circ}$} & \multicolumn{2}{|c|}{ SS $90^{\circ}$} & \multicolumn{2}{|c|}{ OE $90^{\circ}$} & \multicolumn{2}{|c|}{ OE $90^{\circ}$} \\
\hline L2 & Betsy & L2 & Sledge & L2 & Sledge & L2 & Sledge \\
\hline File \# & Stacks & File \# & Stacks & File \# & Stacks & File \# & Stacks \\
\hline 9 & 2 & 10 & 20 & 11 & 20 & 12 & 20 \\
\hline Time & Offset & Time & Offset & Time & Offset & Time & Offset \\
\hline (s) & (meters) & (s) & (meters) & (s) & (meters) & (s) & (meters) \\
\hline 0.0507 & 13 & 0.0529 & 13 & 0.0553 & 13 & 0 & 12 \\
\hline 0.0494 & 15 & 0.0509 & 15 & 0.0551 & 15 & 0.0034 & 13 \\
\hline 0.0484 & 17 & 0.0474 & 17 & 0.0542 & 17 & 0.0141 & 15 \\
\hline 0.0472 & 19 & 0.0461 & 19 & 0.0532 & 19 & 0.0222 & 17 \\
\hline 0.0456 & 21 & 0.0444 & 21 & 0.0521 & 21 & 0.028 & 19 \\
\hline 0.0436 & 23 & 0.0383 & 23 & 0.0517 & 23 & 0.0359 & 21 \\
\hline 0.0376 & 25 & 0.0323 & 25 & 0.0517 & 25 & 0.0391 & 23 \\
\hline 0.0318 & 27 & 0.0267 & 27 & 0.0515 & 27 & 0.0399 & 25 \\
\hline 0.0265 & 29 & 0.0209 & 29 & 0.0513 & 29 & 0.0419 & 27 \\
\hline 0.0237 & 31 & 0.0151 & 31 & 0.0509 & 31 & 0.0442 & 29 \\
\hline 0.0126 & 33 & 0.0091 & 33 & 0.0502 & 33 & 0.0456 & 31 \\
\hline 0.0061 & 35 & 0.003 & 35 & 0.0494 & 35 & 0.0472 & 33 \\
\hline 0 & 36 & 0 & 36 & 0.0481 & 37 & 0.0504 & 35 \\
\hline 0.0056 & 37 & 0.0028 & 37 & 0.0432 & 39 & 0.054 & 37 \\
\hline 0.0126 & 39 & 0.0088 & 39 & 0.0384 & 41 & 0.0528 & 39 \\
\hline 0.0184 & 41 & 0.0149 & 41 & 0.0354 & 43 & 0.05 & 41 \\
\hline 0.025 & 43 & 0.0207 & 43 & 0.0346 & 45 & 0.0488 & 43 \\
\hline 0.032 & 45 & 0.0262 & 45 & 0.0339 & 47 & 0.0464 & 45 \\
\hline 0.0366 & 47 & 0.0323 & 47 & 0.032 & 49 & 0.0472 & 47 \\
\hline 0.0406 & 49 & 0.0383 & 49 & 0.0263 & 51 & 0.0502 & 49 \\
\hline 0.0416 & 51 & 0.0424 & 51 & 0.021 & 53 & 0.052 & 51 \\
\hline 0.0431 & 53 & 0.0429 & 53 & 0.0147 & 55 & 0.0538 & 53 \\
\hline 0.0429 & 55 & 0.0436 & 55 & 0.0089 & 57 & 0.054 & 55 \\
\hline 0.0446 & 57 & 0.0451 & 57 & 0.0017 & 59 & 0.0543 & 57 \\
\hline 0.0454 & 59 & 0.0454 & 59 & 0 & 60 & 0.054 & 59 \\
\hline
\end{tabular}


Complete set of first break times vs offset continued

\begin{tabular}{|c|c|c|c|c|c|c|c|}
\hline \multicolumn{2}{|c|}{ OE $145^{\circ}$} & \multicolumn{2}{|c|}{ OE $145^{\circ}$} & \multicolumn{2}{|c|}{ OE $145^{\circ}$} & \multicolumn{2}{|c|}{ OE $145^{\circ}$} \\
\hline L1 & Sledge & L1 & Sledge & L2 & Sledge & L2 & Sledge \\
\hline File \# & Stacks & File \# & Stacks & File \# & Stacks & File \# & Stacks \\
\hline 20 & 20 & 21 & 20 & 22 & 20 & 23 & 20 \\
\hline Time & Offset & Time & Offset & Time & Offset & Time & Offset \\
\hline (s) & (meters) & (s) & (meters) & (s) & (meters) & (s) & (meters) \\
\hline 0.0577 & 1 & 0 & 0 & 0.0569 & 13 & 0 & 12 \\
\hline 0.0567 & 3 & 0.0042 & 1 & 0.0561 & 15 & 0.0028 & 13 \\
\hline 0.0553 & 5 & 0.0111 & 3 & 0.0518 & 17 & 0.0085 & 15 \\
\hline 0.0543 & 7 & 0.0149 & 5 & 0.0488 & 19 & 0.0149 & 17 \\
\hline 0.0524 & 9 & 0.0206 & 7 & 0.0472 & 21 & 0.0208 & 19 \\
\hline 0.052 & 11 & 0.0268 & 9 & 0.0464 & 23 & 0.027 & 21 \\
\hline 0.0516 & 13 & 0.0327 & 11 & 0.0454 & 25 & 0.0327 & 23 \\
\hline 0.0494 & 15 & 0.0383 & 13 & 0.044 & 27 & 0.0387 & 25 \\
\hline 0.0456 & 17 & 0.0436 & 15 & 0.044 & 29 & 0.0397 & 27 \\
\hline 0.0428 & 19 & 0.0464 & 17 & 0.0446 & 31 & 0.0415 & 29 \\
\hline 0.0423 & 21 & 0.0448 & 19 & 0.046 & 33 & 0.0438 & 31 \\
\hline 0.0405 & 23 & 0.0456 & 21 & 0.0486 & 35 & 0.0472 & 33 \\
\hline 0.0389 & 25 & 0.0476 & 23 & 0.0472 & 37 & 0.0506 & 35 \\
\hline 0.0379 & 27 & 0.0474 & 25 & 0.0423 & 39 & 0.0551 & 37 \\
\hline 0.0375 & 29 & 0.0482 & 27 & 0.0375 & 41 & 0.0575 & 39 \\
\hline 0.0381 & 31 & 0.049 & 29 & 0.0319 & 43 & 0.0528 & 41 \\
\hline 0.0395 & 33 & 0.0512 & 31 & 0.0357 & 45 & 0.0478 & 43 \\
\hline 0.0387 & 35 & 0.0553 & 33 & 0.03 & 47 & 0.0496 & 45 \\
\hline 0.0325 & 37 & 0.0587 & 35 & 0.0294 & 49 & 0.0504 & 47 \\
\hline 0.0268 & 39 & 0.0637 & 37 & 0.0262 & 51 & 0.0528 & 49 \\
\hline 0.0206 & 41 & 0.0647 & 39 & 0.0198 & 53 & 0.0536 & 51 \\
\hline 0.0143 & 43 & 0.0609 & 41 & 0.0145 & 55 & 0.0547 & 53 \\
\hline 0.0093 & 45 & 0.0561 & 43 & 0.0085 & 57 & 0.0553 & 55 \\
\hline 0.005 & 47 & 0.0583 & 45 & 0.0046 & 59 & 0.0567 & 57 \\
\hline 0 & 48 & 0.0587 & 47 & 0 & 60 & 0.0573 & 59 \\
\hline
\end{tabular}


Complete set of first break times vs offset continued

\begin{tabular}{|c|c|c|c|c|c|c|c|}
\hline \multicolumn{2}{|c|}{ OE $145^{\circ}$} & \multicolumn{2}{|c|}{ OE $145^{\circ}$} & \multicolumn{2}{|c|}{ OE $145^{\circ}$} & \multicolumn{2}{|c|}{ OE $145^{\circ}$} \\
\hline L3 & Sledge & L3 & Sledge & L2 & Sledge & L2 & Sledge \\
\hline File \# & Stacks & File \# & Stacks & File \# & Stacks & File \# & Stacks \\
\hline 24 & 20 & 25 & 20 & 26 & 20 & 27 & 20 \\
\hline Time & Offset & Time & Offset & Time & Offset & Time & Offset \\
\hline (s) & (meters) & (s) & (meters) & (s) & (meters) & (s) & (meters) \\
\hline 0.0496 & 25 & 0 & 24 & 0 & 12 & 0.0496 & 13 \\
\hline 0.049 & 27 & 0.0032 & 25 & 0.004 & 13 & 0.0462 & 15 \\
\hline 0.0484 & 29 & 0.0093 & 27 & 0.0093 & 15 & 0.0456 & 17 \\
\hline 0.0502 & 31 & 0.0155 & 29 & 0.0147 & 17 & 0.0448 & 19 \\
\hline 0.0516 & 33 & 0.0216 & 31 & 0.0206 & 19 & 0.0438 & 21 \\
\hline 0.0528 & 35 & 0.0268 & 33 & 0.0268 & 21 & 0.0419 & 23 \\
\hline 0.0514 & 37 & 0.0327 & 35 & 0.0327 & 23 & 0.0407 & 25 \\
\hline 0.047 & 39 & 0.0389 & 37 & 0.0351 & 25 & 0.0395 & 27 \\
\hline 0.043 & 41 & 0.045 & 39 & 0.0365 & 27 & 0.0395 & 29 \\
\hline 0.0369 & 43 & 0.0426 & 41 & 0.0387 & 29 & 0.0391 & 31 \\
\hline 0.0407 & 45 & 0.0373 & 43 & 0.0391 & 31 & 0.0401 & 33 \\
\hline 0.0359 & 47 & 0.0428 & 45 & 0.0428 & 33 & 0.0359 & 35 \\
\hline 0.0343 & 49 & 0.0407 & 47 & 0.0462 & 35 & 0.0335 & 37 \\
\hline 0.0339 & 51 & 0.043 & 49 & 0.0472 & 37 & 0.0294 & 39 \\
\hline 0.0323 & 53 & 0.0428 & 51 & 0.044 & 39 & 0.0286 & 41 \\
\hline 0.0323 & 55 & 0.0448 & 53 & 0.0438 & 41 & 0.0284 & 43 \\
\hline 0.03 & 57 & 0.0434 & 55 & 0.0464 & 43 & 0.028 & 45 \\
\hline 0.0278 & 59 & 0.0462 & 57 & 0.0472 & 45 & 0.0252 & 47 \\
\hline 0.0276 & 61 & 0.0464 & 59 & 0.0488 & 47 & 0.0246 & 49 \\
\hline 0.0258 & 63 & 0.0454 & 61 & 0.0488 & 49 & 0.0244 & 51 \\
\hline 0.0185 & 65 & 0.05 & 63 & 0.0504 & 51 & 0.0208 & 53 \\
\hline 0.0133 & 67 & 0.0498 & 65 & 0.052 & 53 & 0.0151 & 55 \\
\hline 0.0074 & 69 & 0.0512 & 67 & 0.0536 & 55 & 0.0091 & 57 \\
\hline 0.0026 & 71 & 0.0506 & 69 & 0.0536 & 57 & 0.0034 & 59 \\
\hline 0 & 72 & 0.052 & 71 & 0.0545 & 59 & 0 & 60 \\
\hline
\end{tabular}




\section{Appendix D: T-X Graphs}



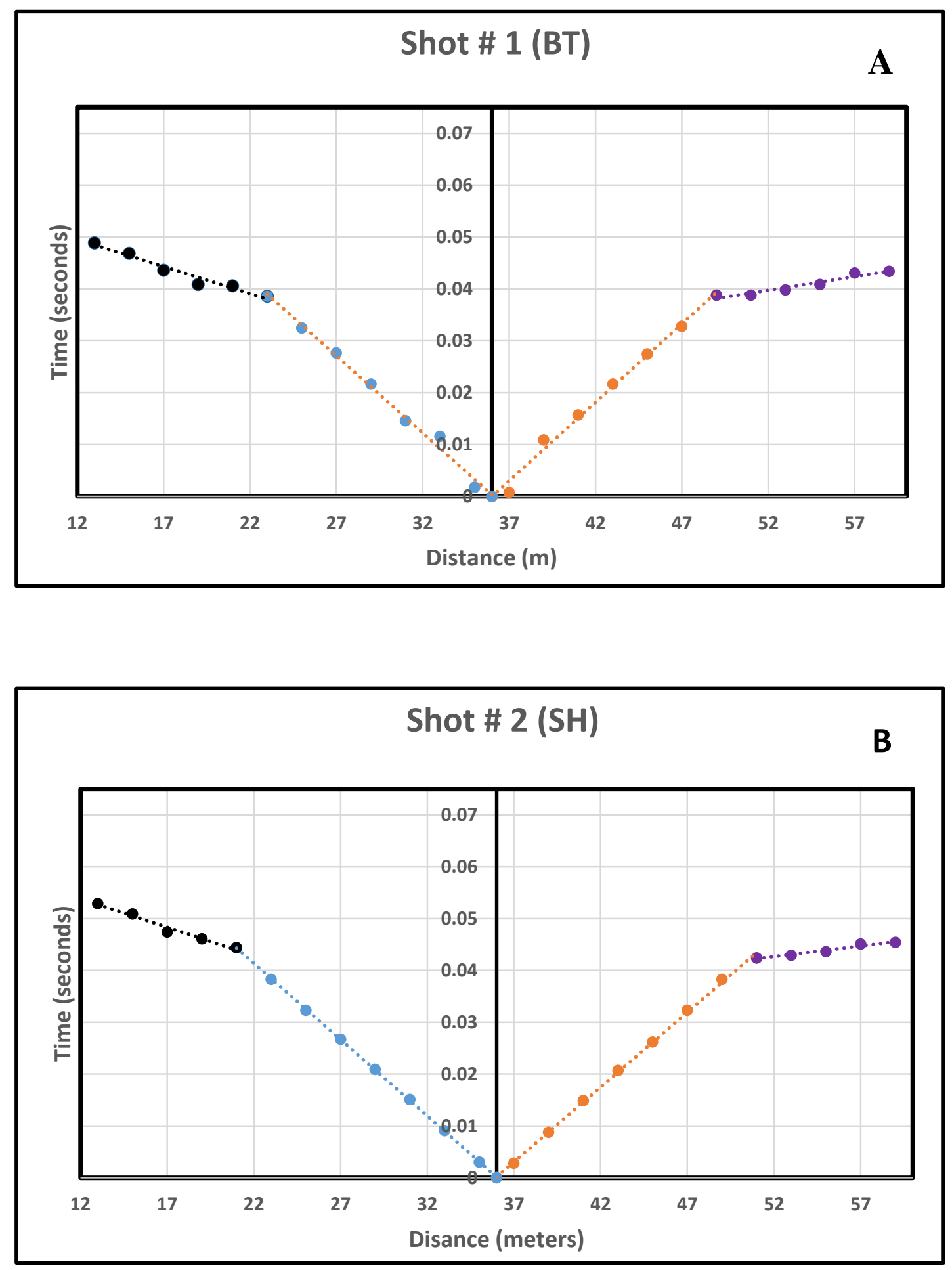

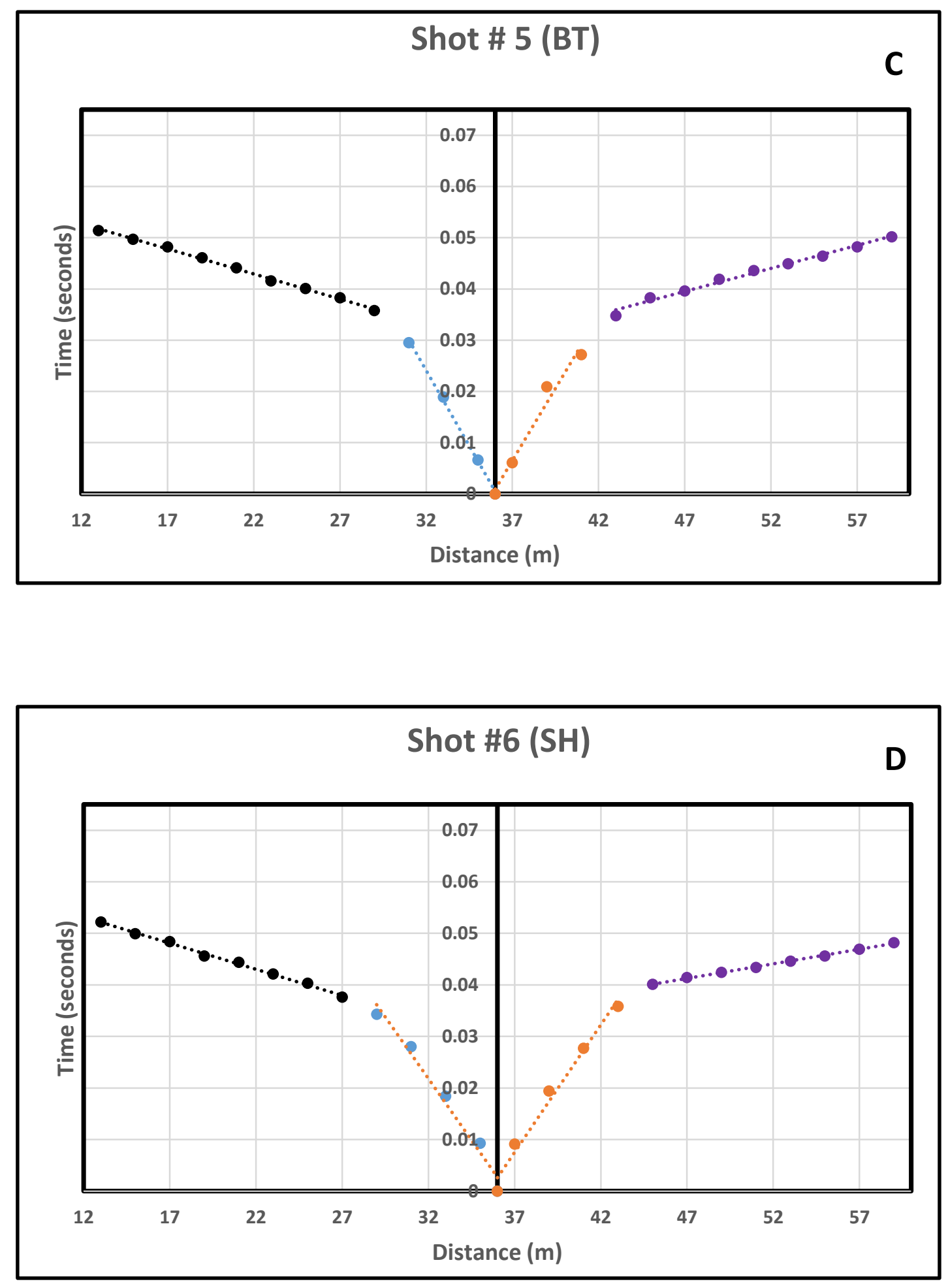

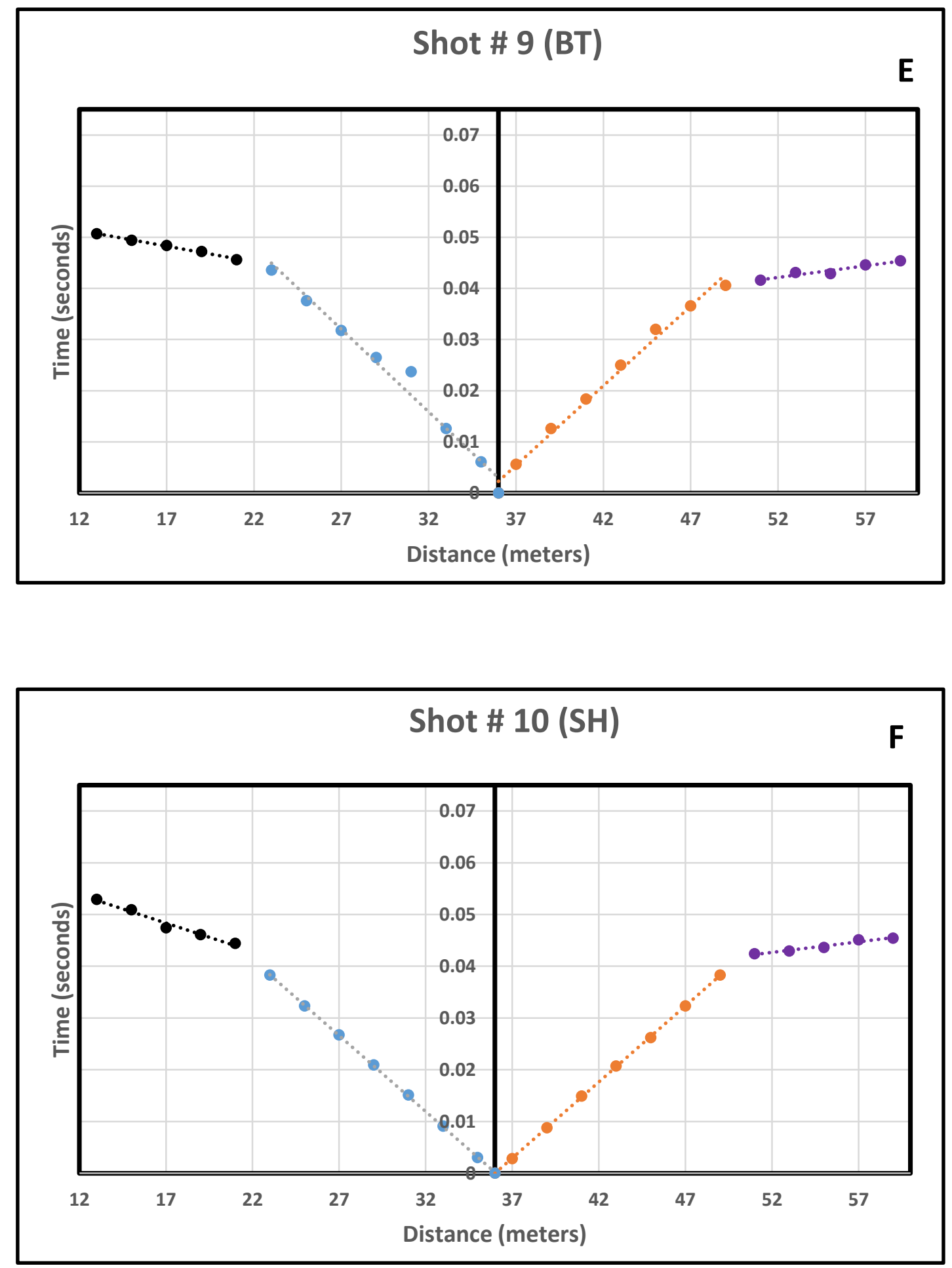

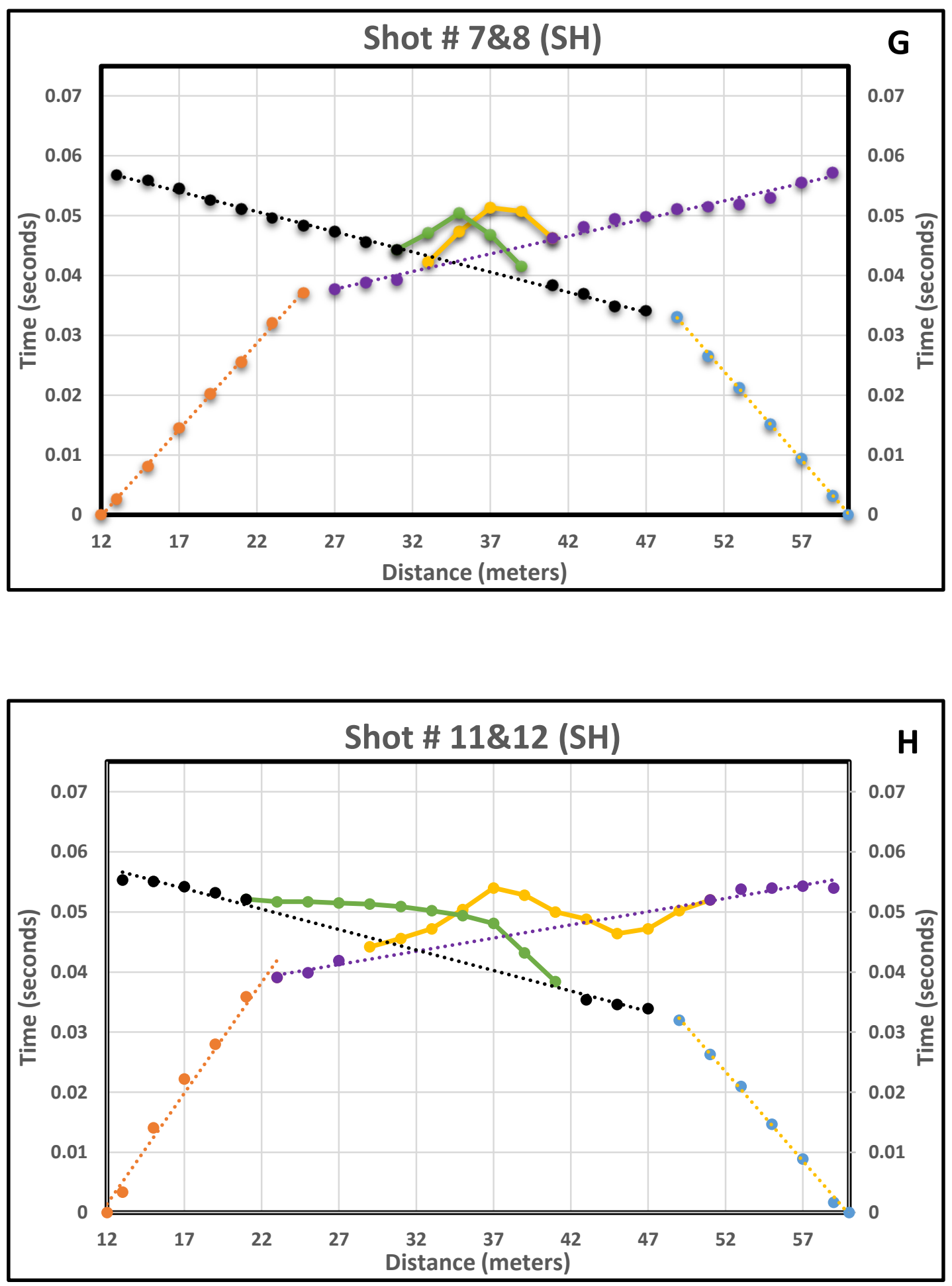

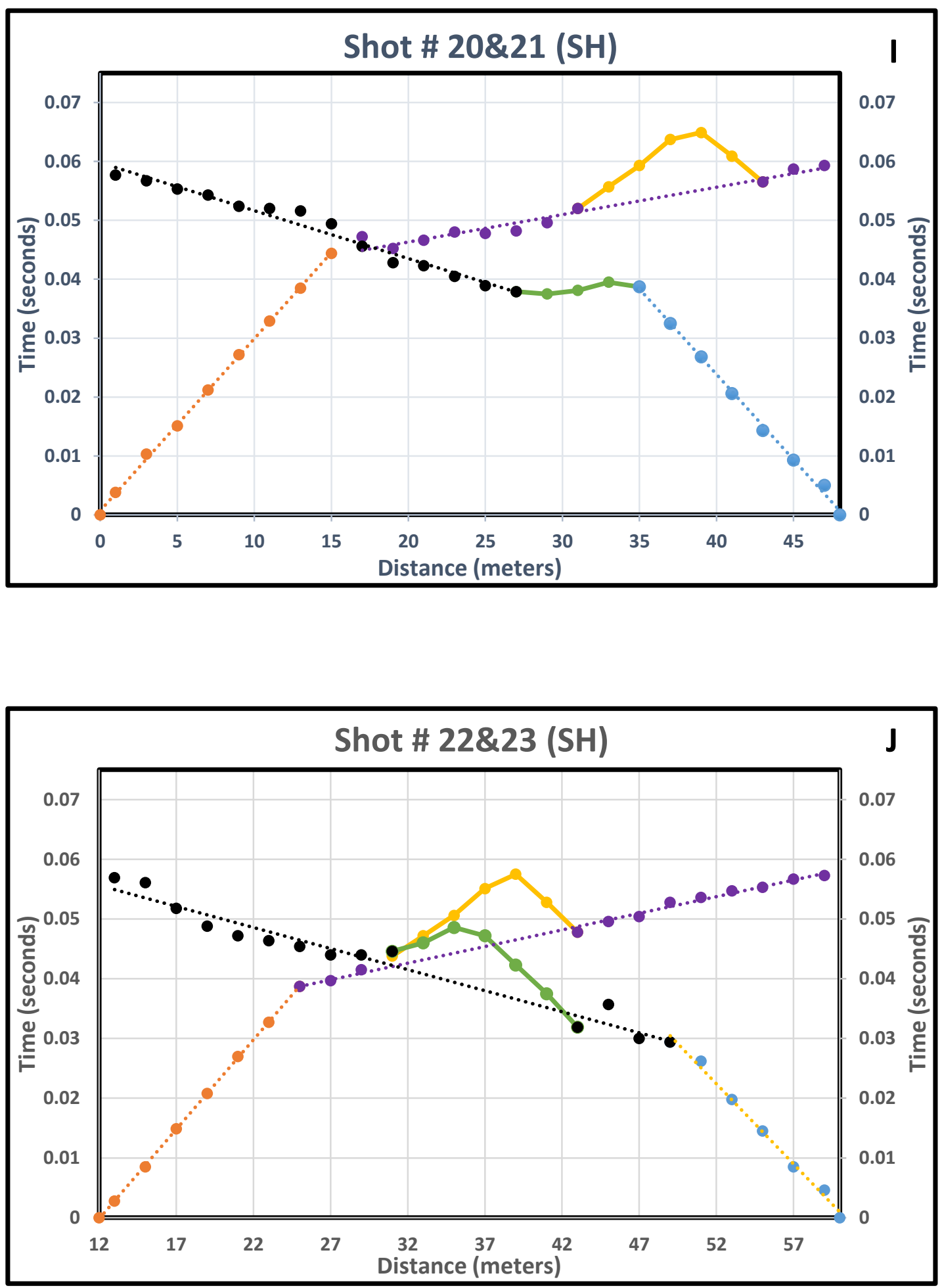

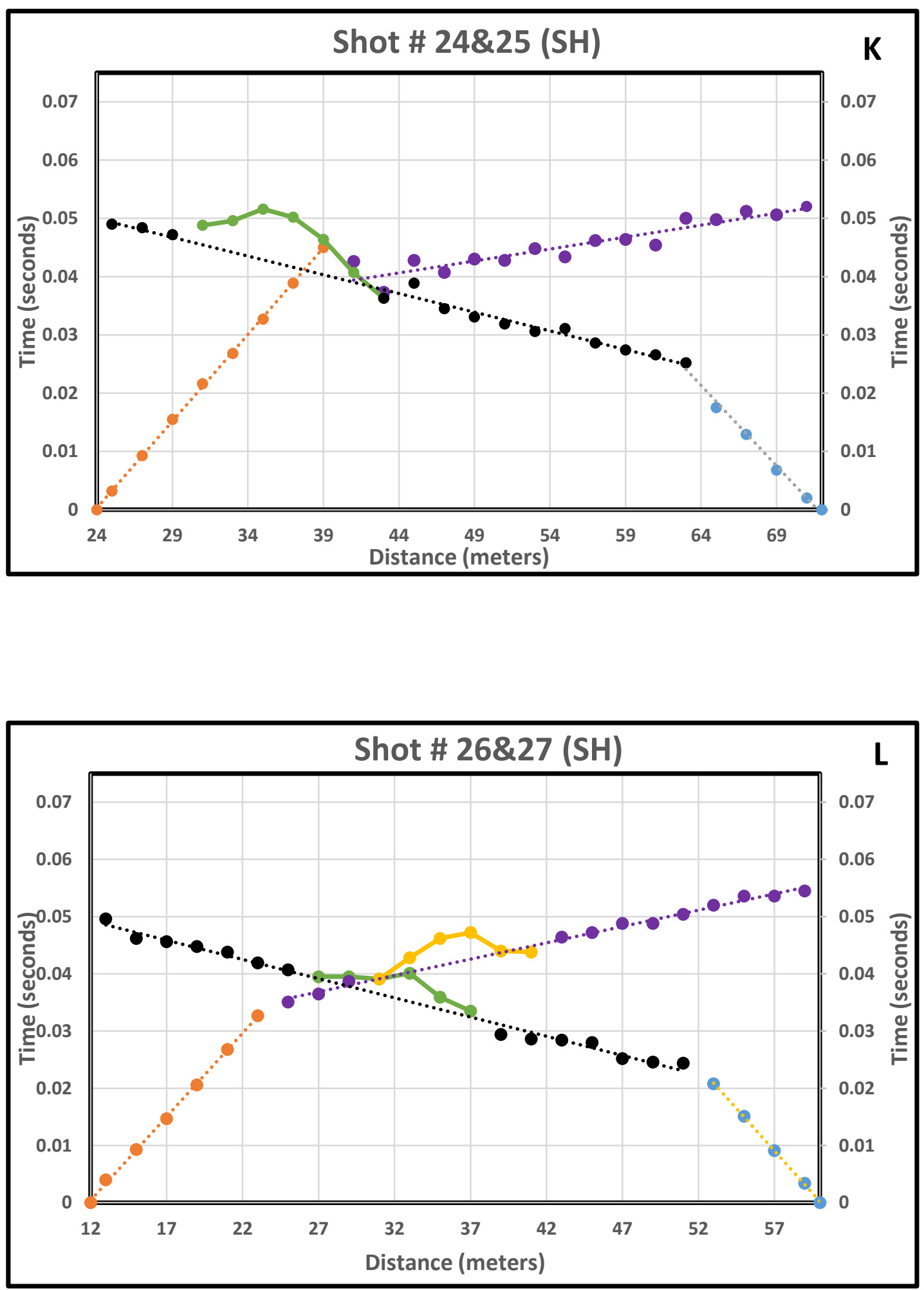


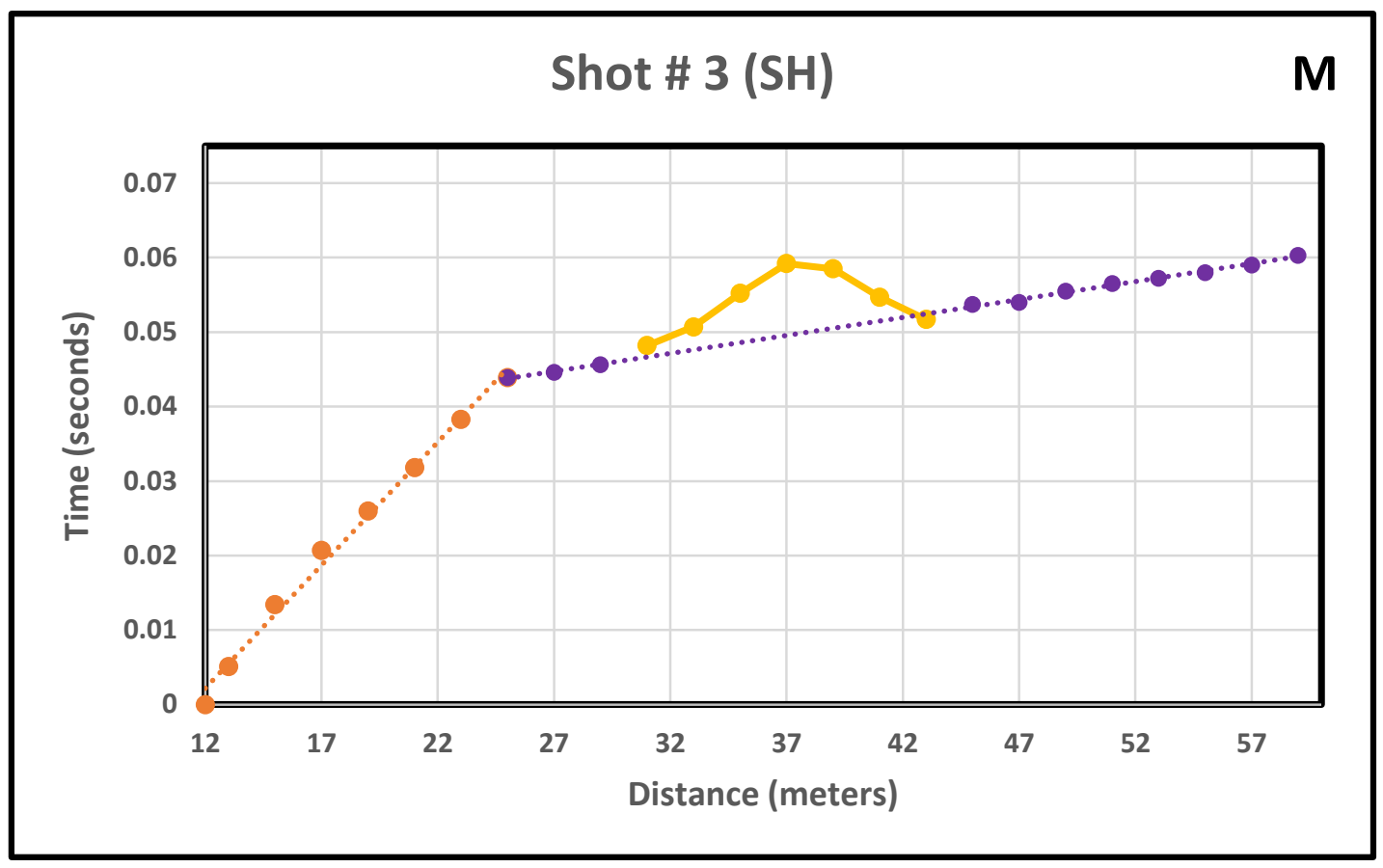


Figure 28 A-S: Complete set of filtered common shot gathers. Each of the following 19 graphs displays the filtered shot gathers used to observe the surface wave diffractions and incident reflections from the cave. Images for line 1 ( $\mathrm{K}$ and L), line 2 (A,B,M,N,O, R and S), Line 2 at $13^{\circ}$ (C,D,G and H), line 2 at $90^{\circ}$ (E, F, I and $\mathrm{J}$ ), and line 3 ( $\mathrm{O}$ and $\mathrm{P}$ ) were bandpass filtered to highlight these diffractions based on their response in the frequency domain. Images A-F were used to estimate the incident reflections from the cave roof while images G-S were used to find diffraction hyperbolas from backscatter off the cave. Each image is individually filtered based on the range of the frequency anomalies seen in appendix F. 
Appendix E: Processed \& Filtered Images 


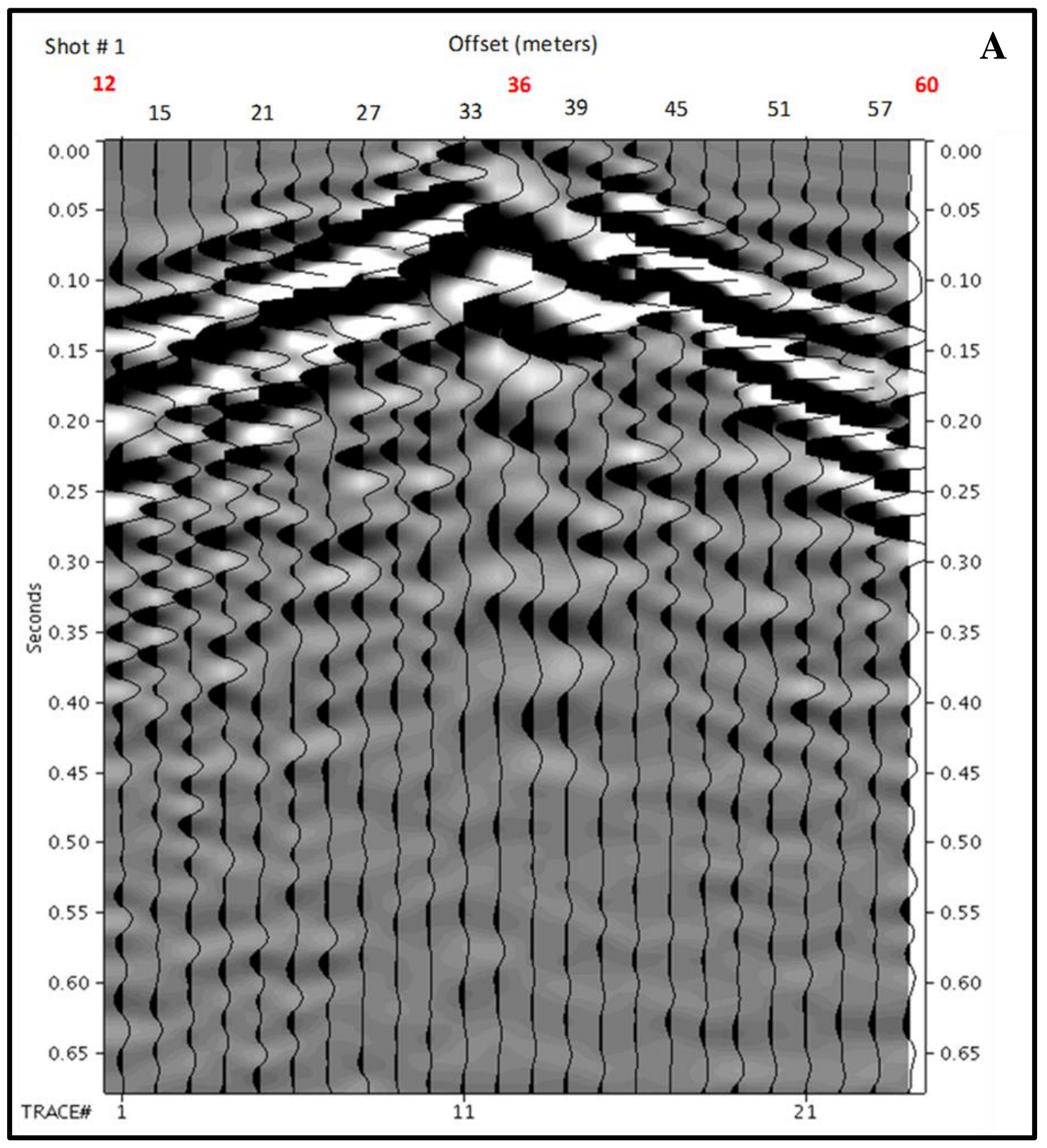




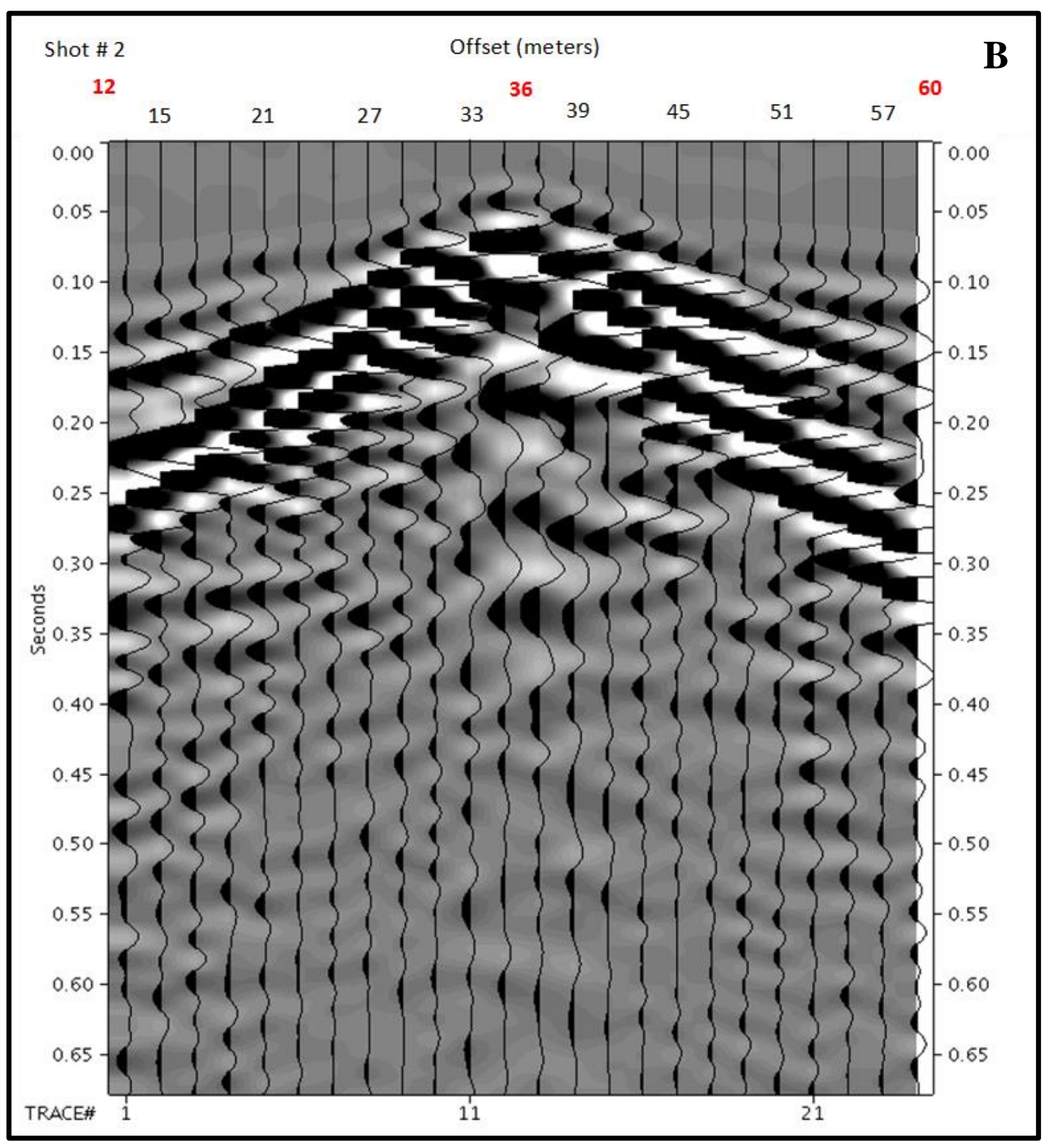




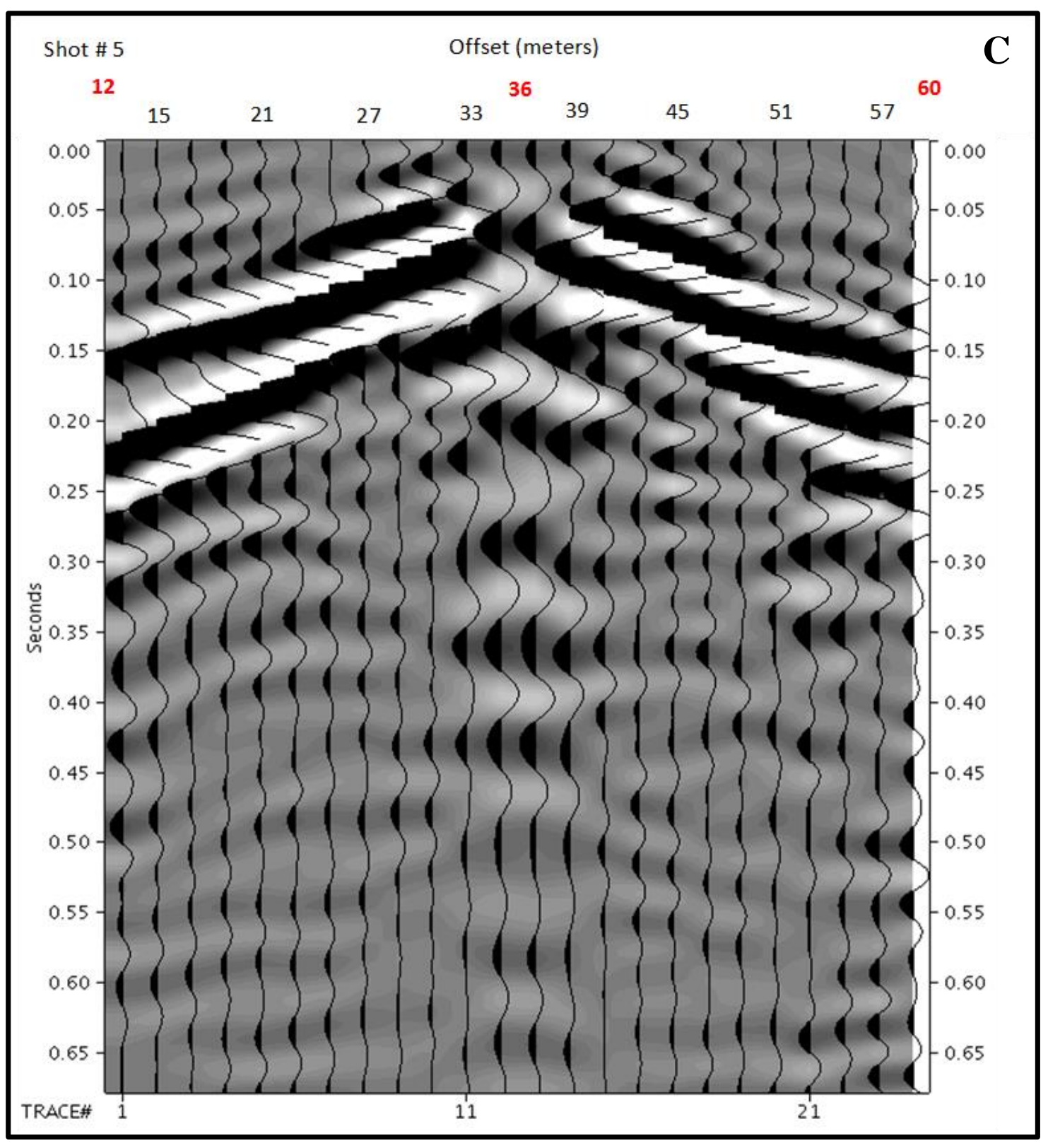




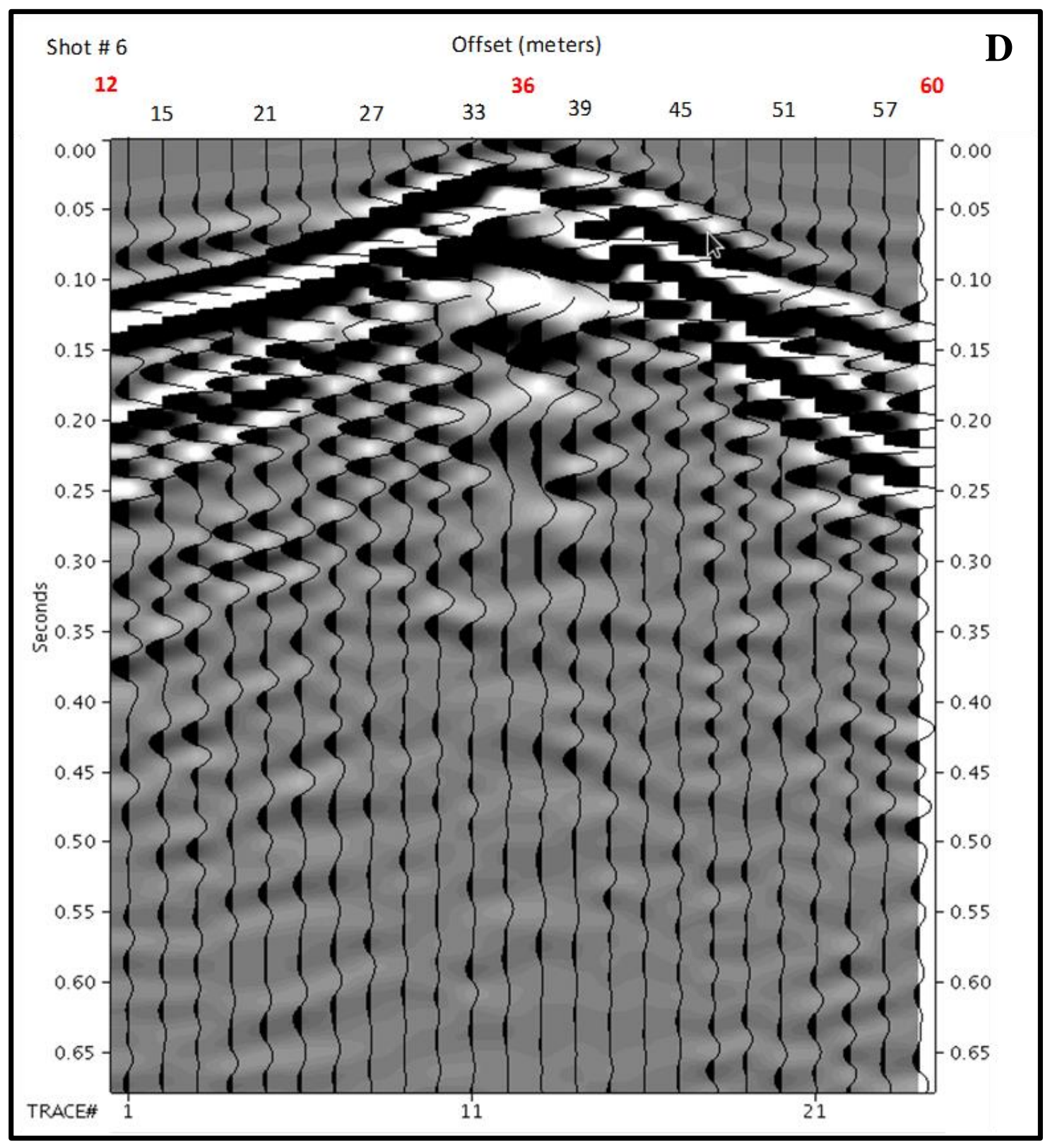




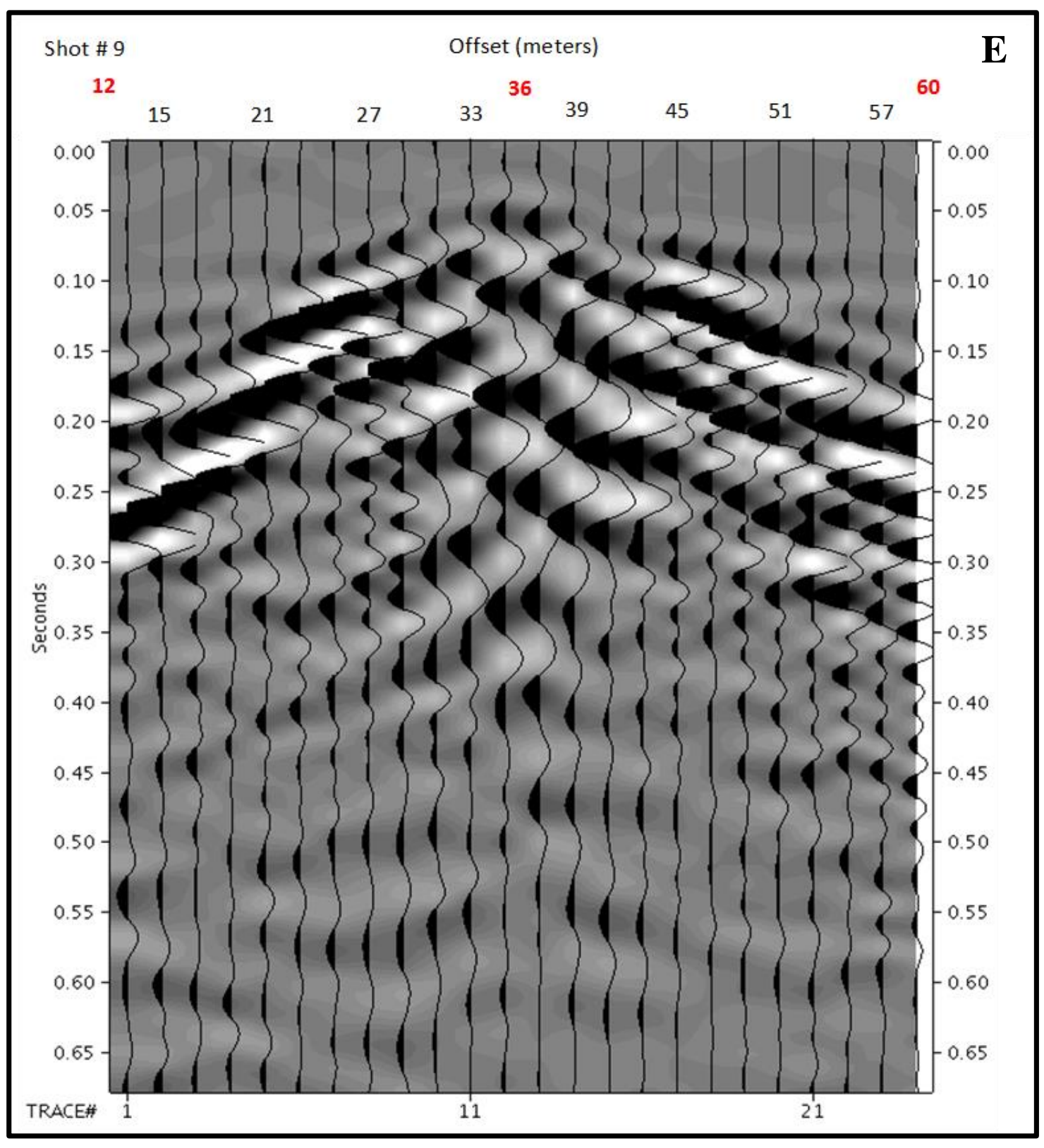




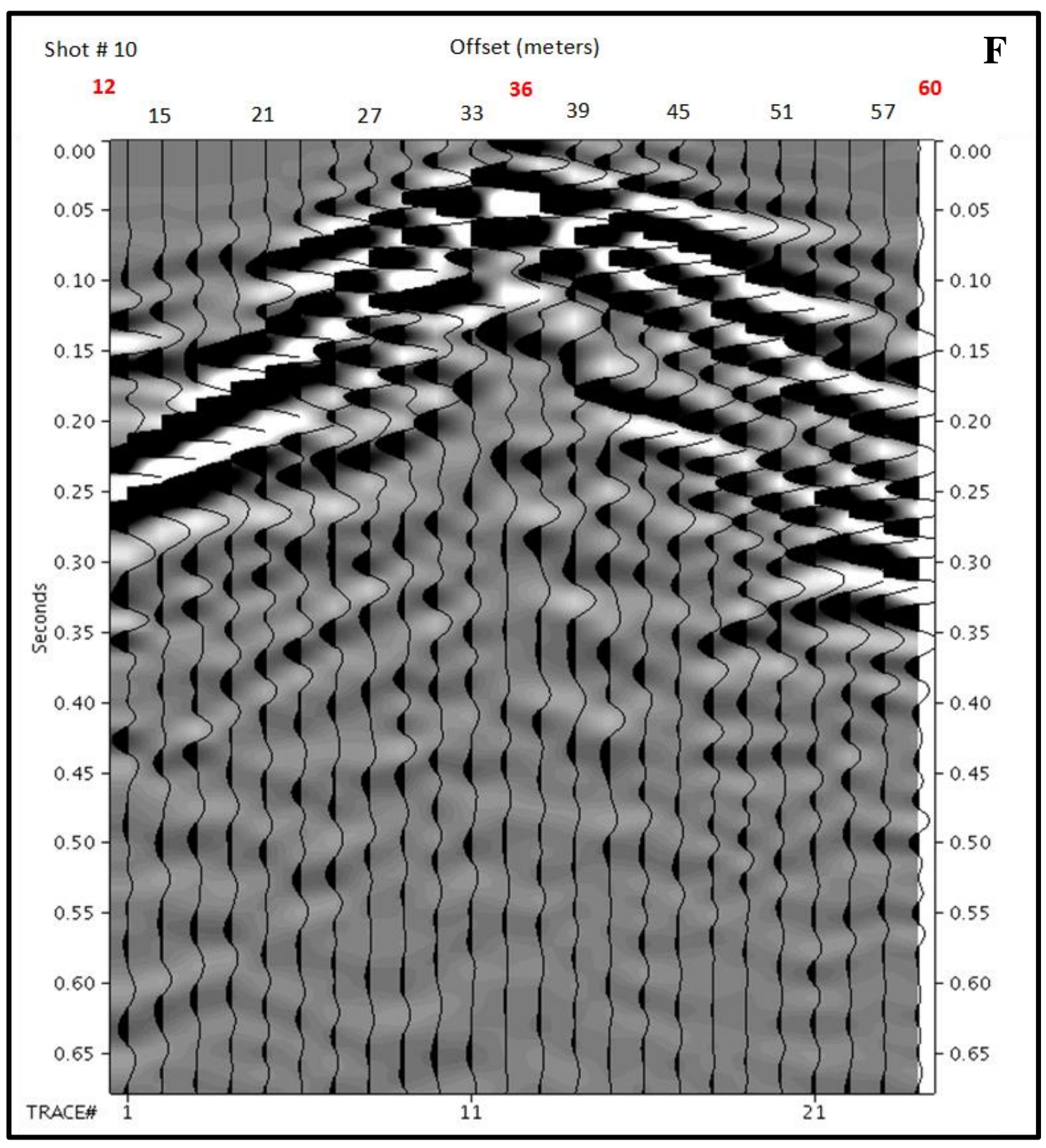




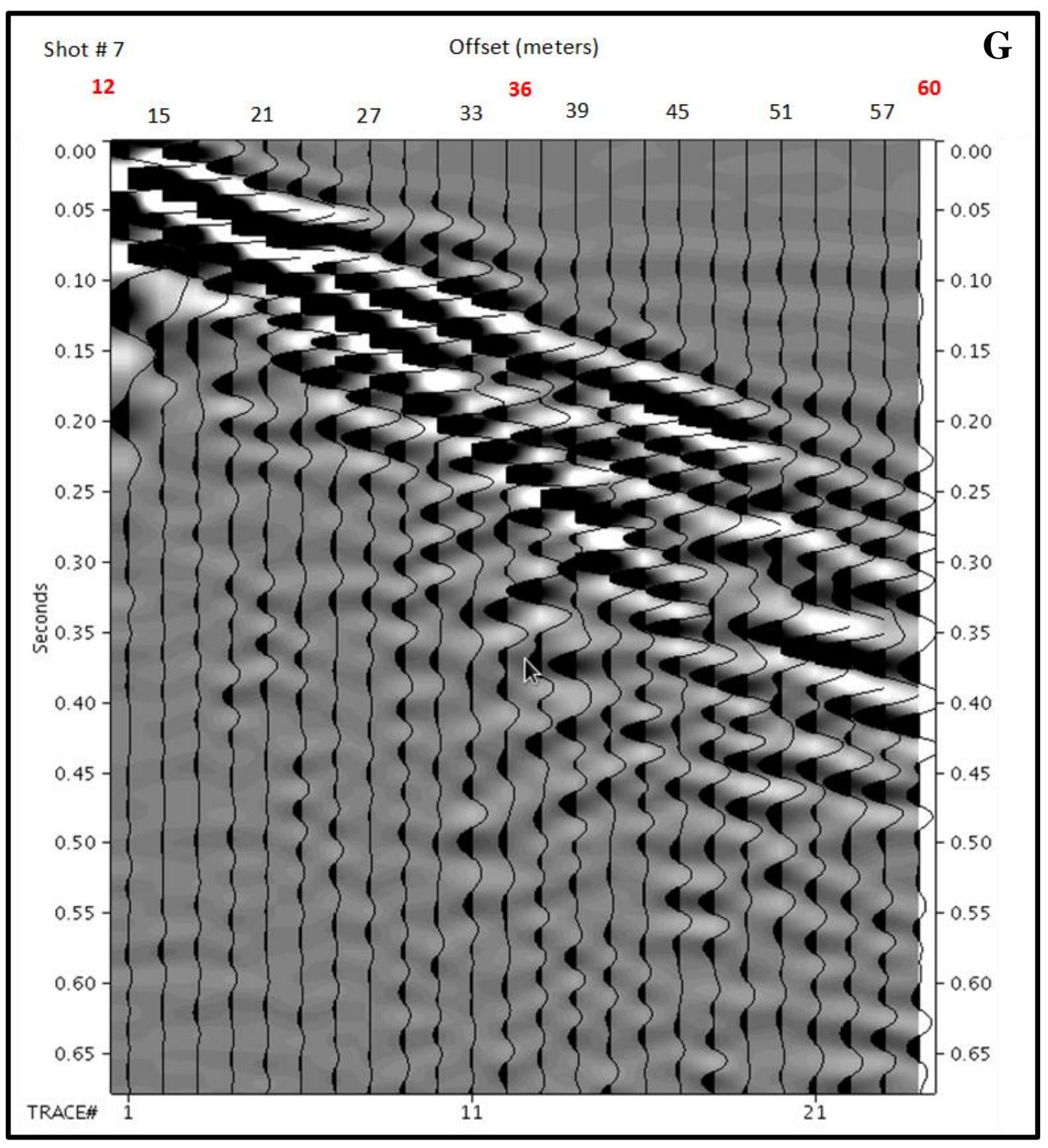




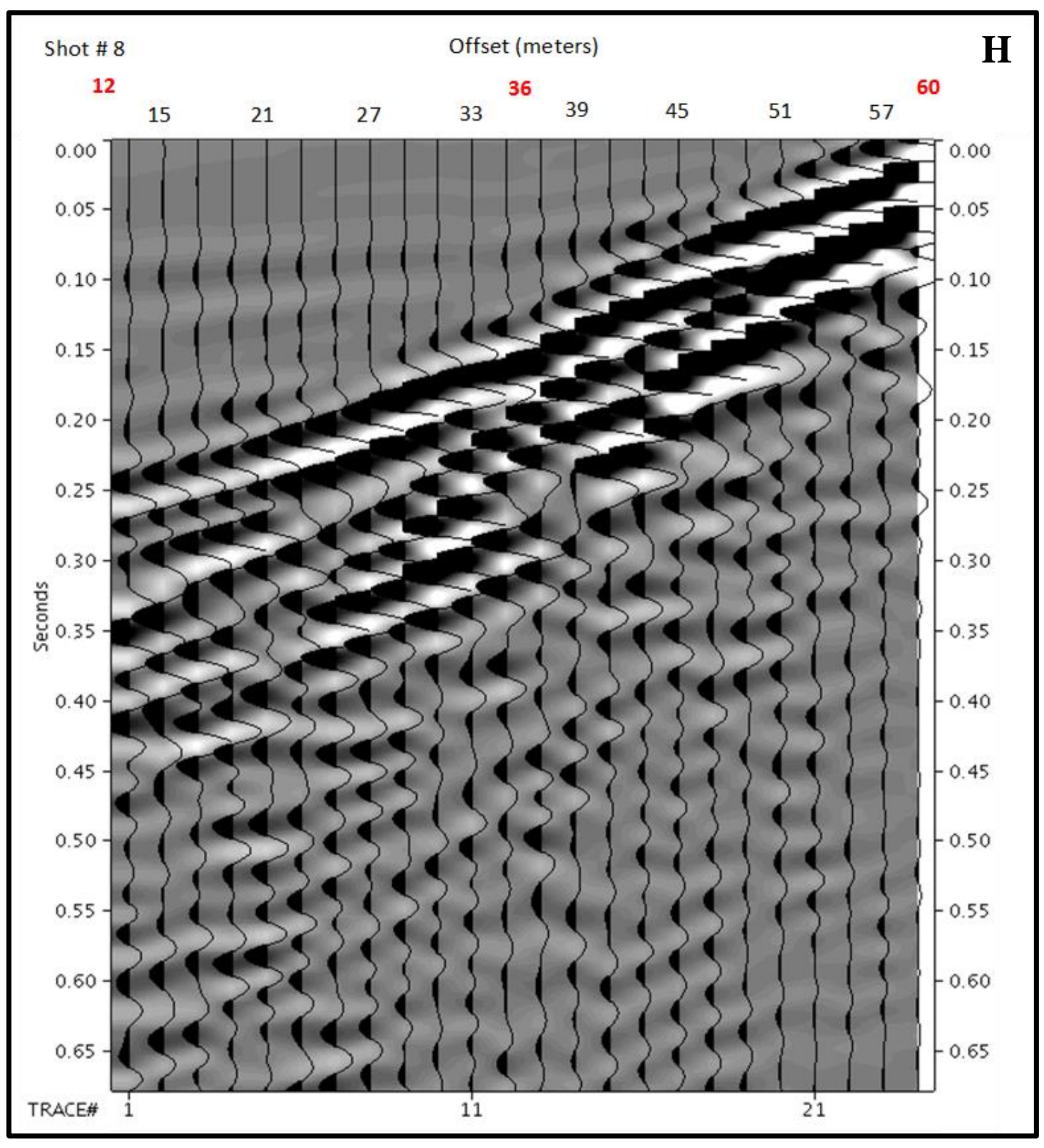




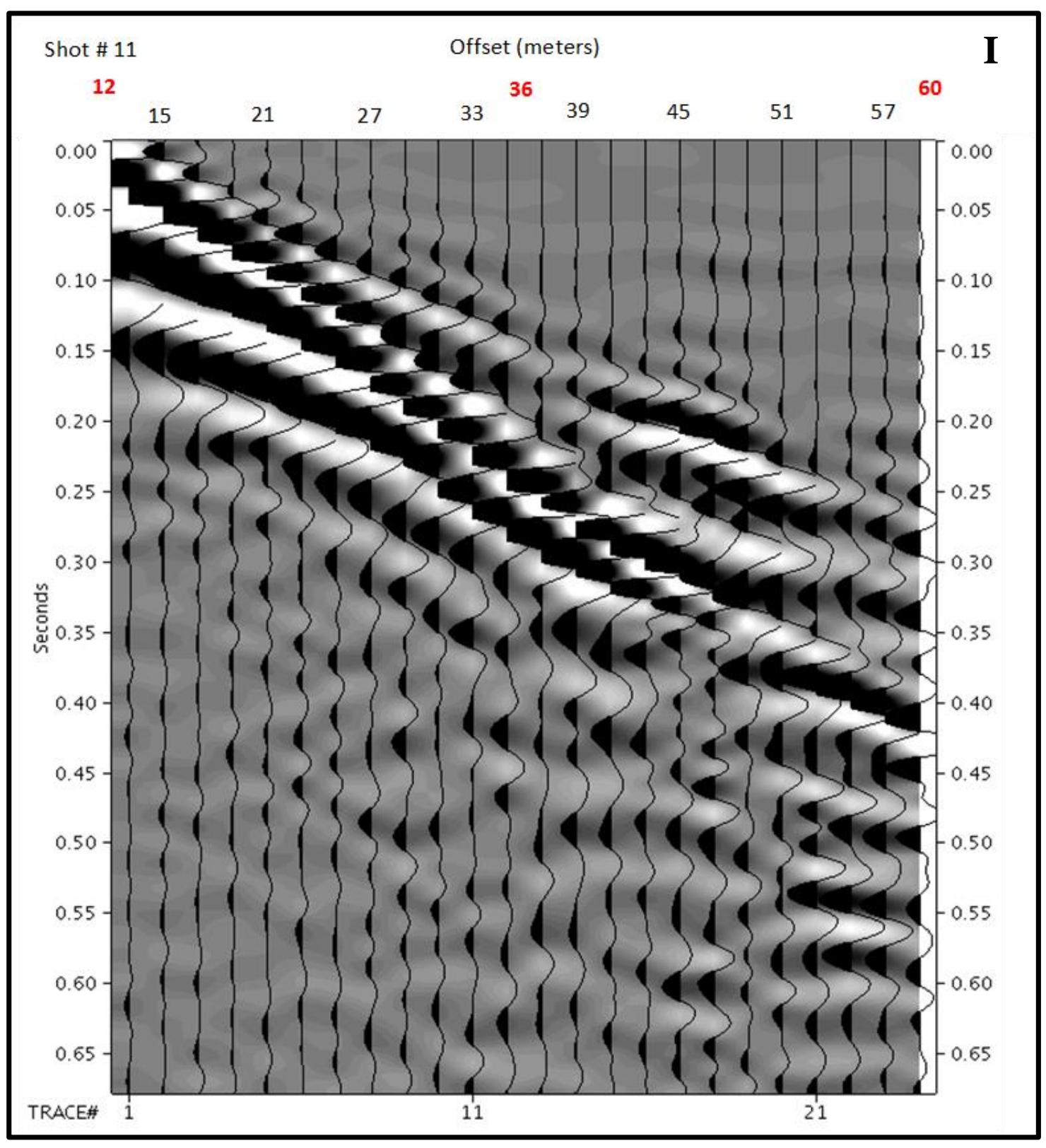




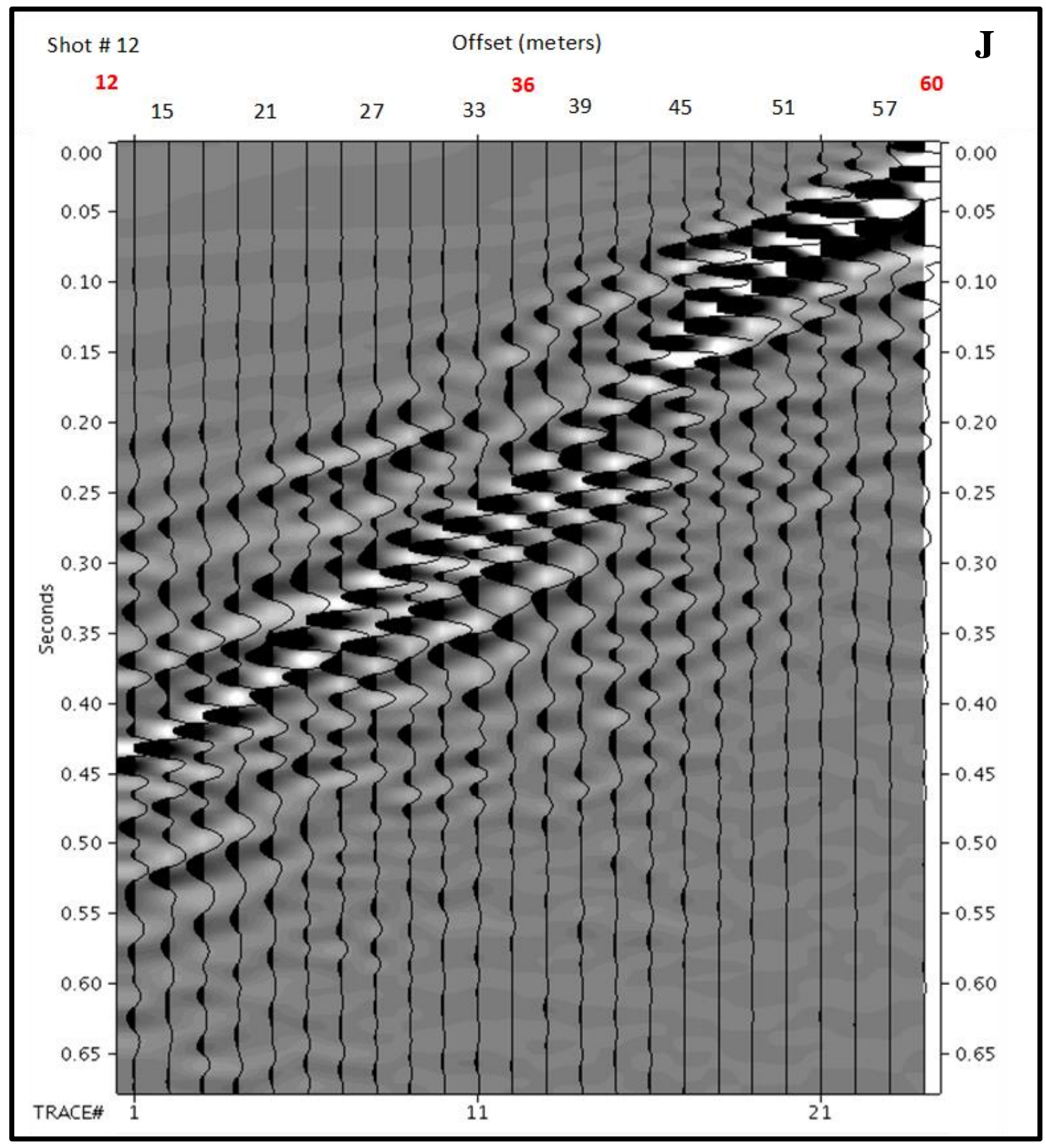




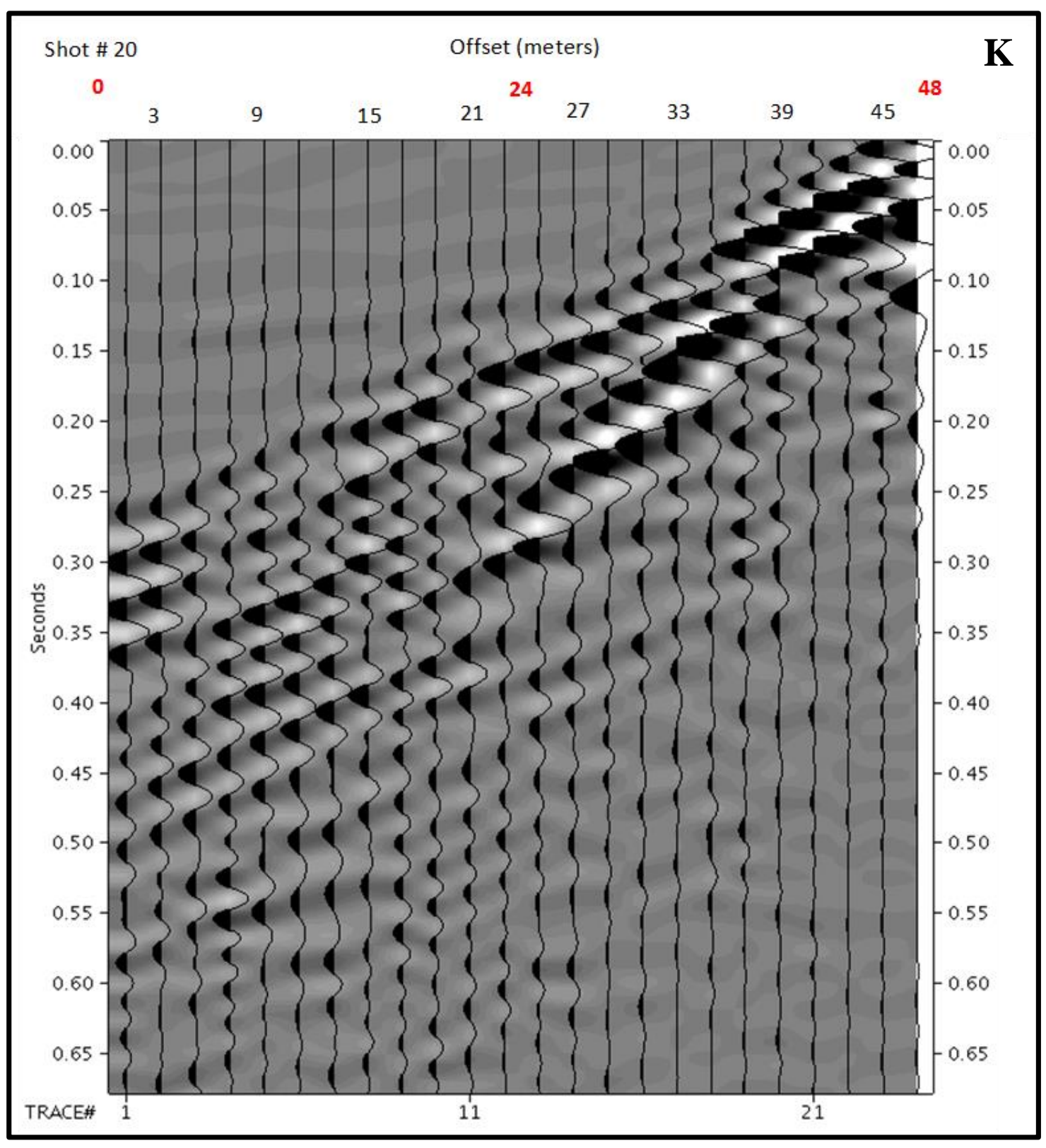




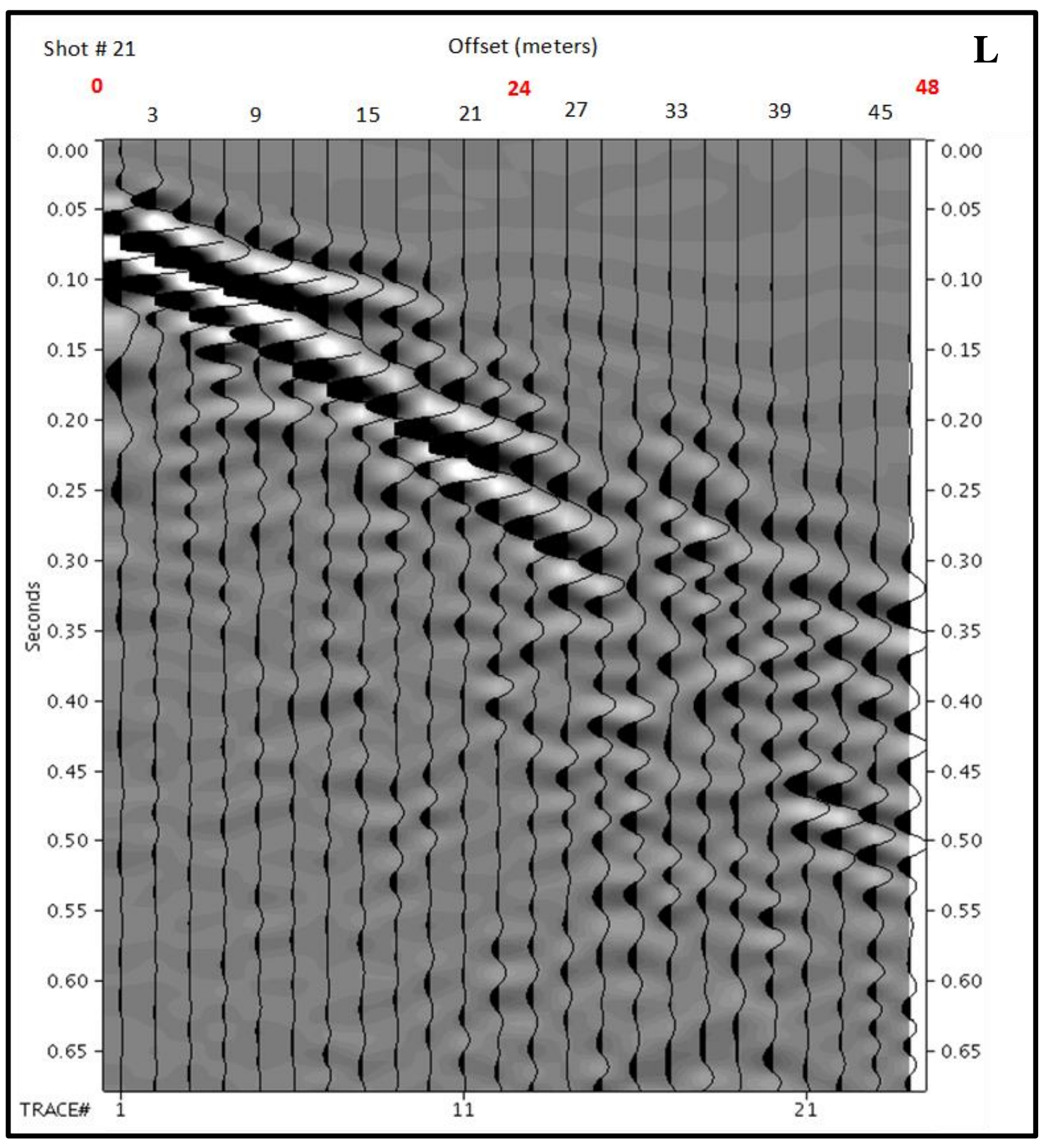




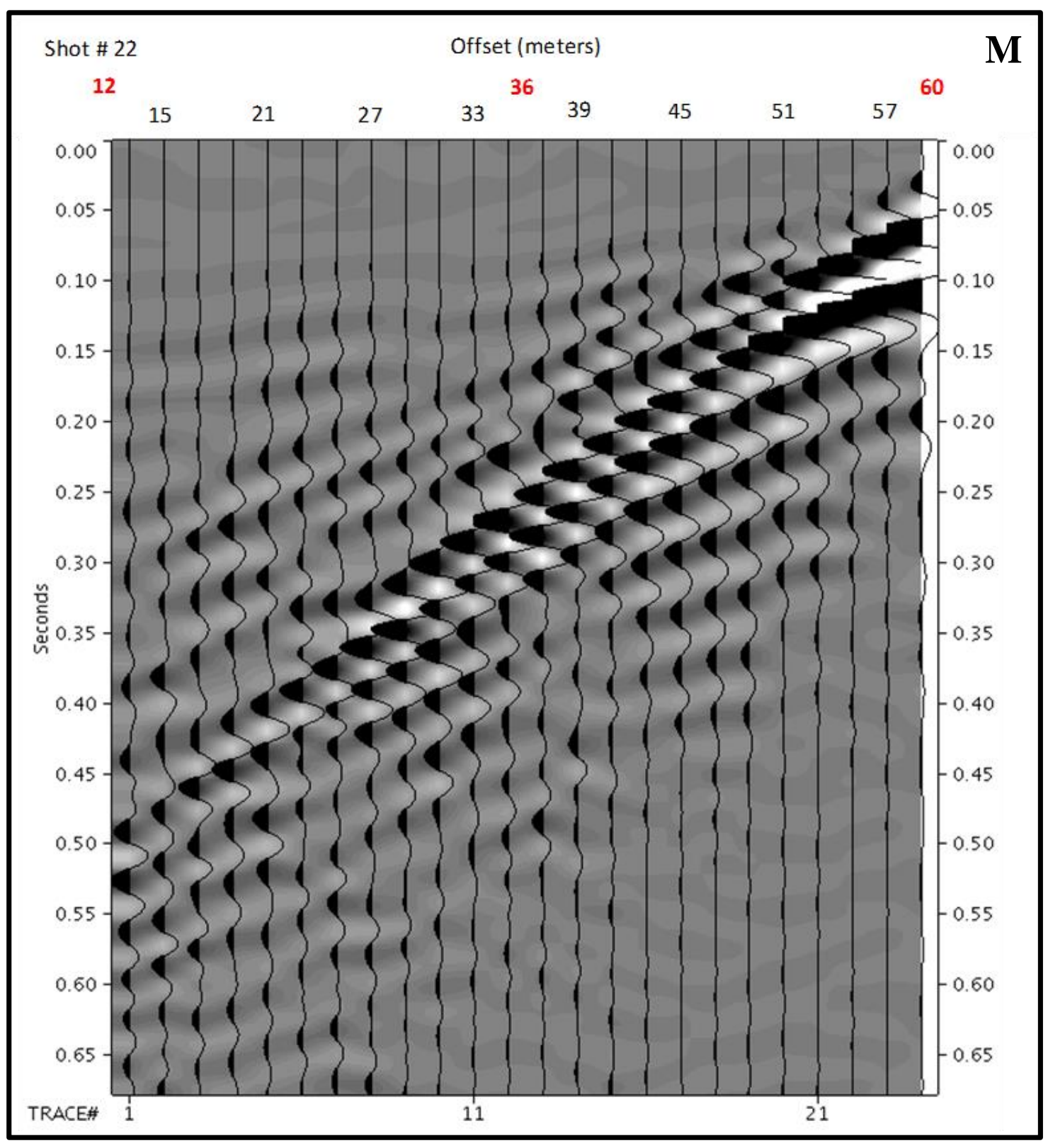




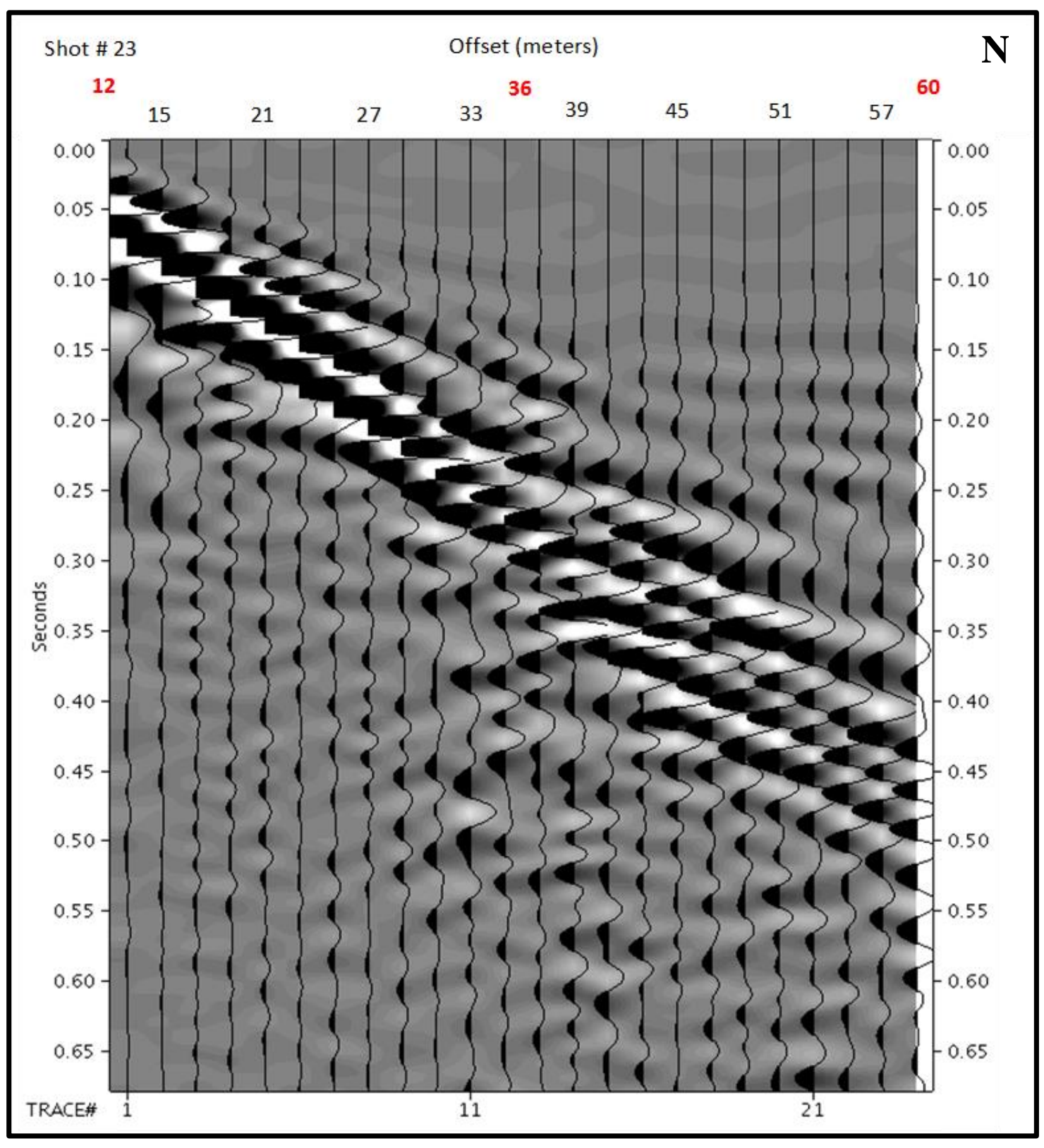




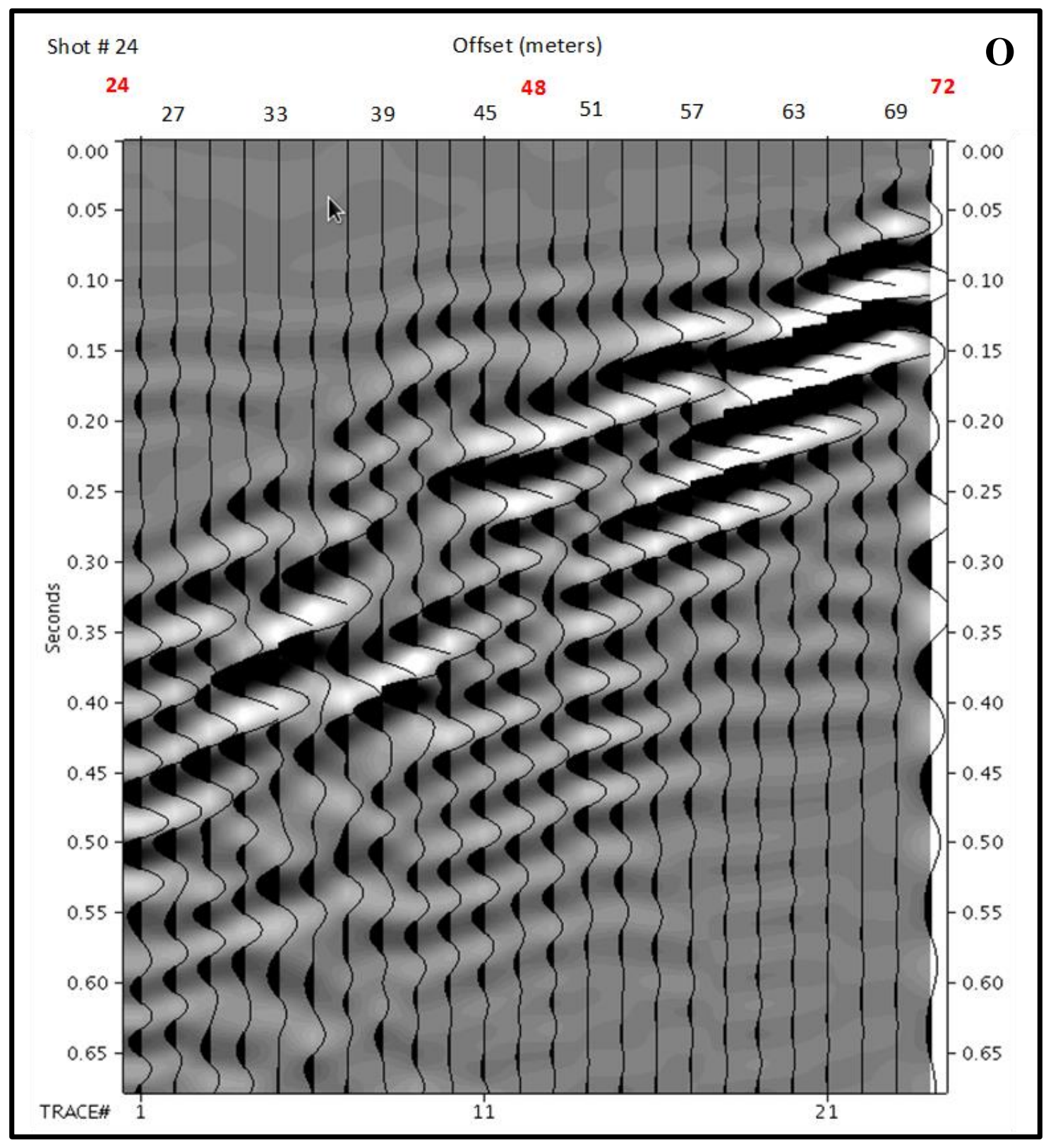




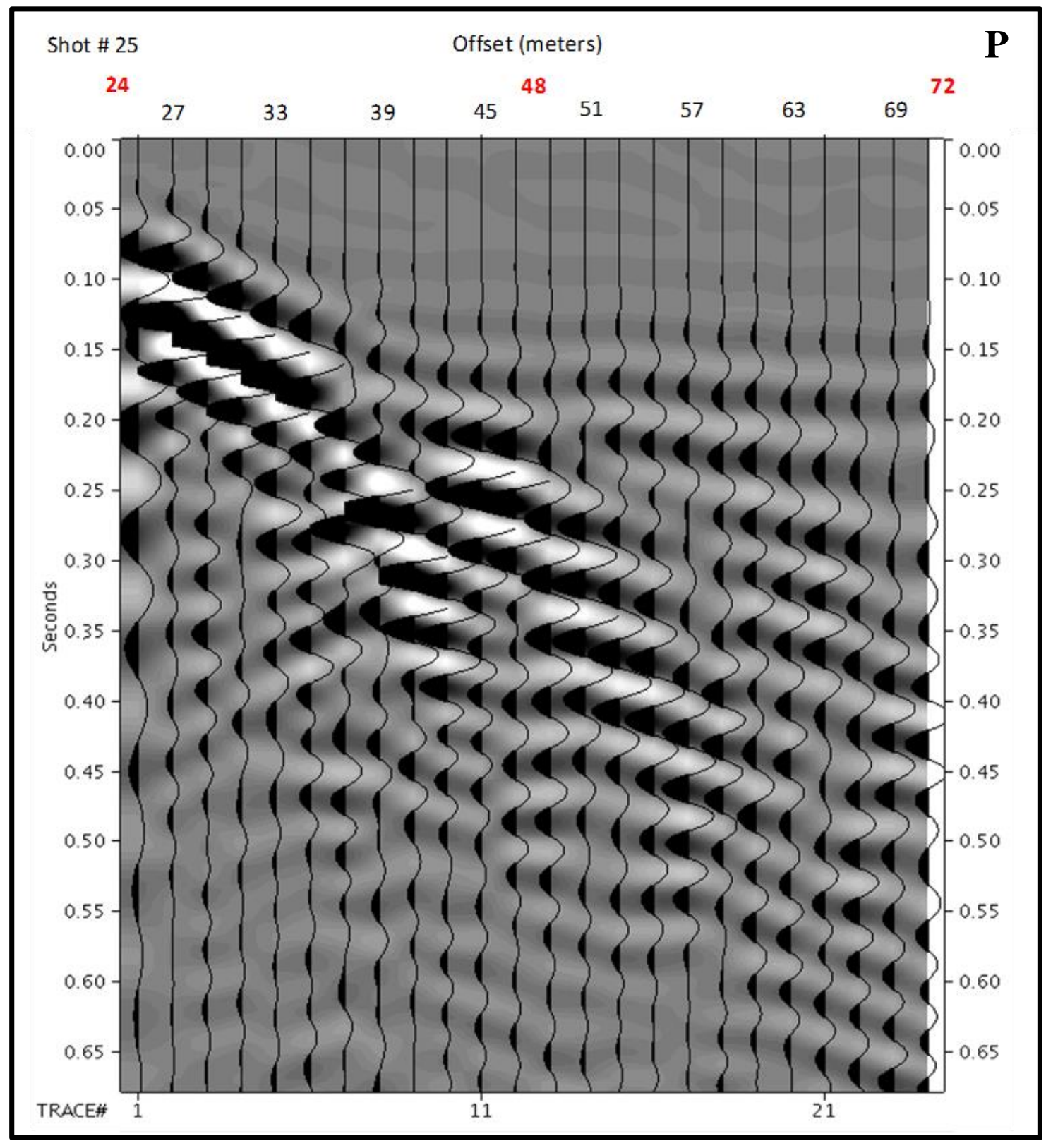




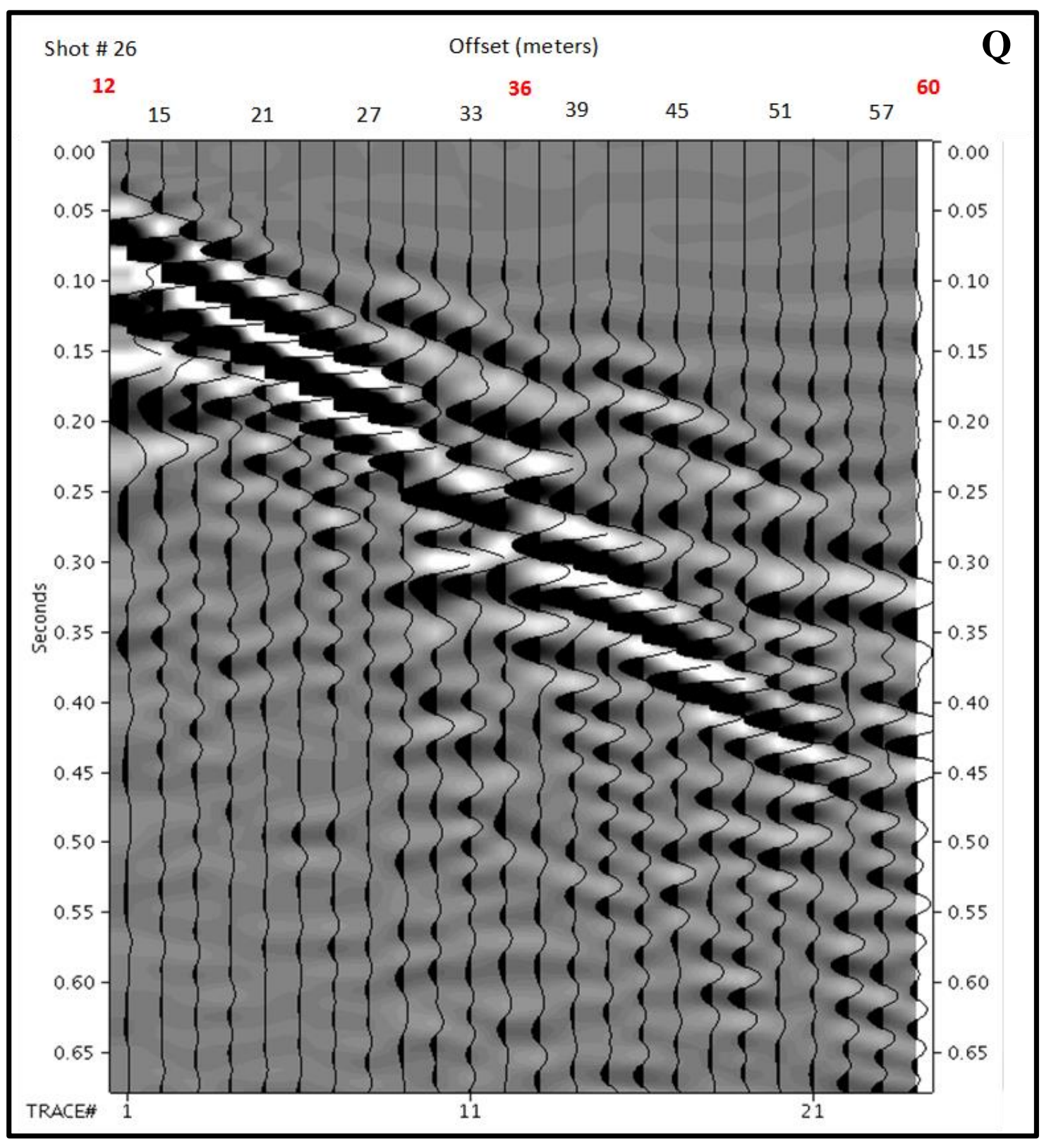




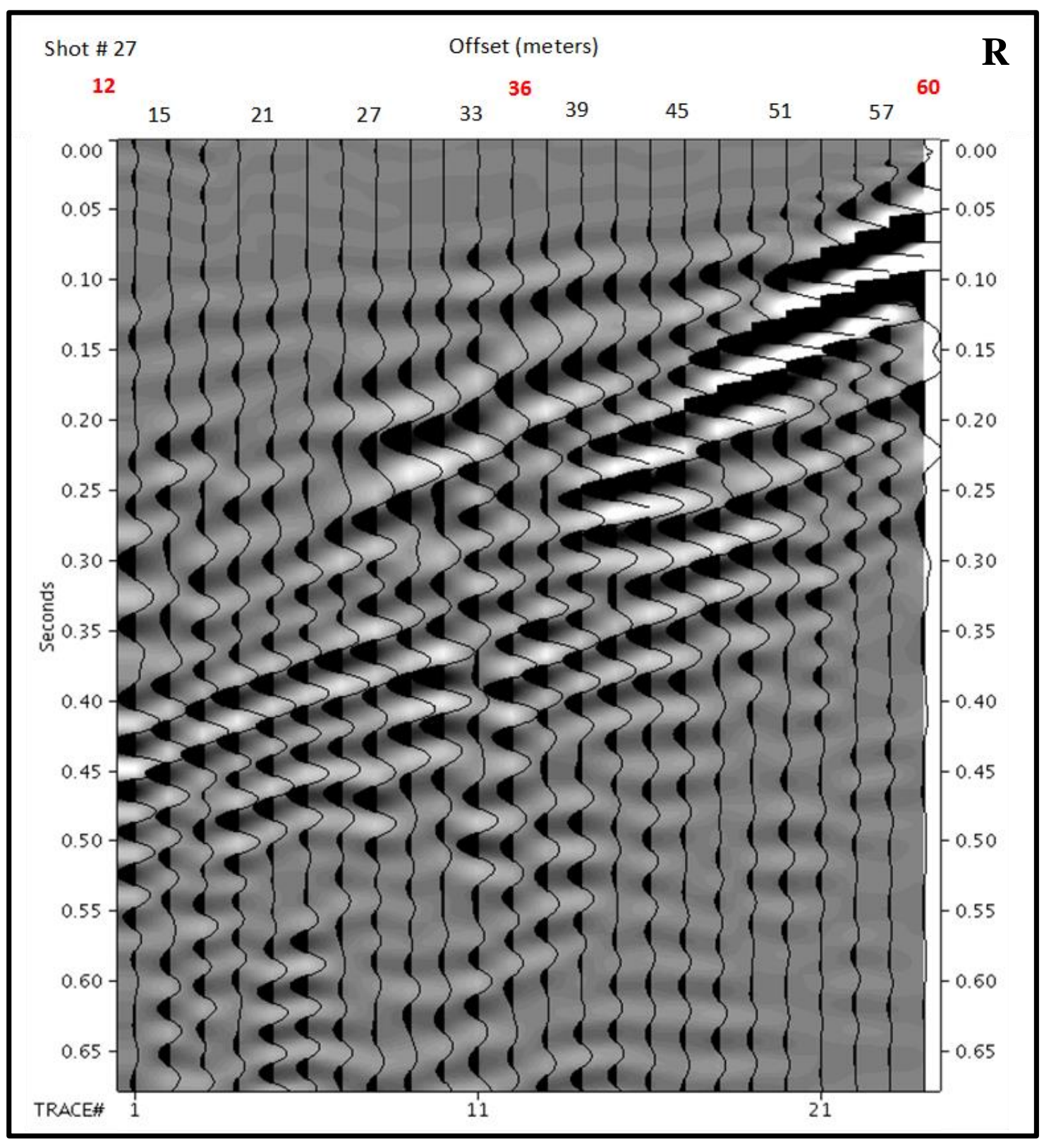




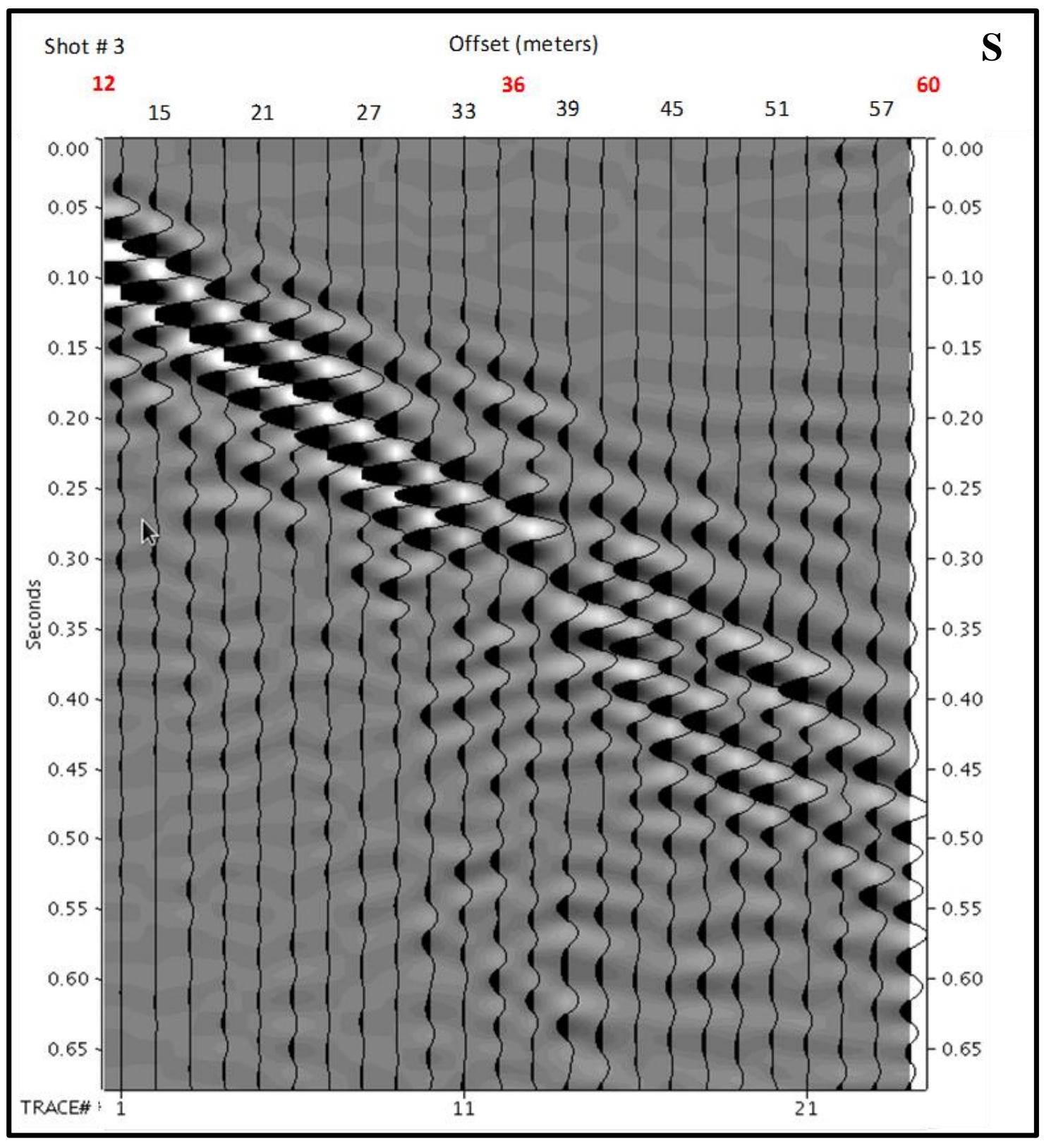


Figure 28 A-S: Complete set of filtered common shot gathers. Each of the following 19 graphs displays the filtered shot gathers used to observe the surface wave diffractions and incident reflections from the cave. Images for line 1 ( $\mathrm{K}$ and L), line 2 (A,B,M,N,O, R and S), Line 2 at $13^{\circ}$ (C,D,G and H), line 2 at $90^{\circ}$ (E, F, I and $\mathrm{J})$, and line $3(\mathrm{O}$ and $\mathrm{P})$ were bandpass filtered to highlight these diffractions based on their response in the frequency domain. Images A-F were used to estimate the incident reflections from the cave roof while images G-S were used to find diffraction hyperbolas from backscatter off the cave. Each image is individually filtered based on the range of the frequency anomalies seen in appendix F. 


\section{Appendix F: 3D Frequency Images}



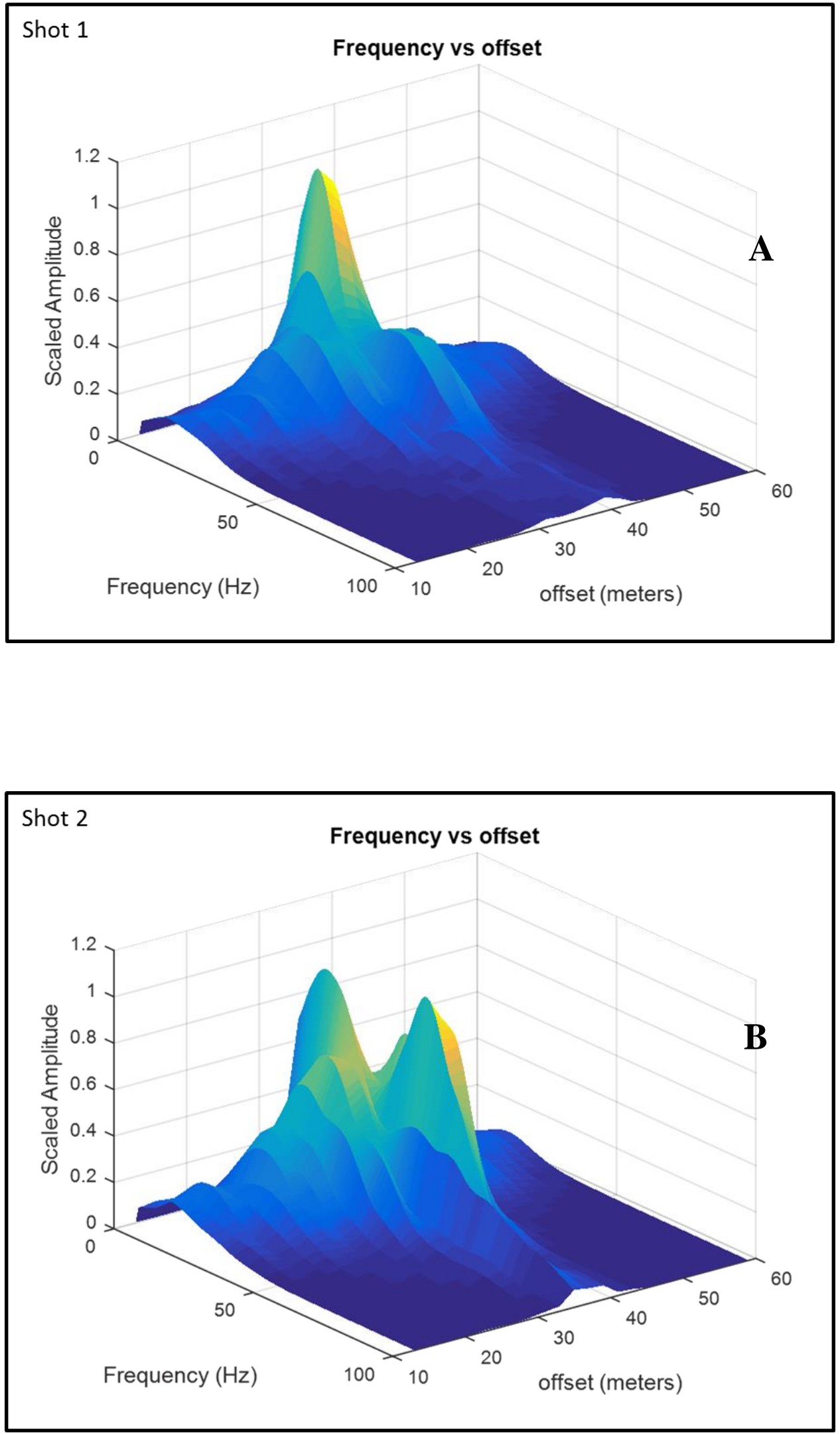

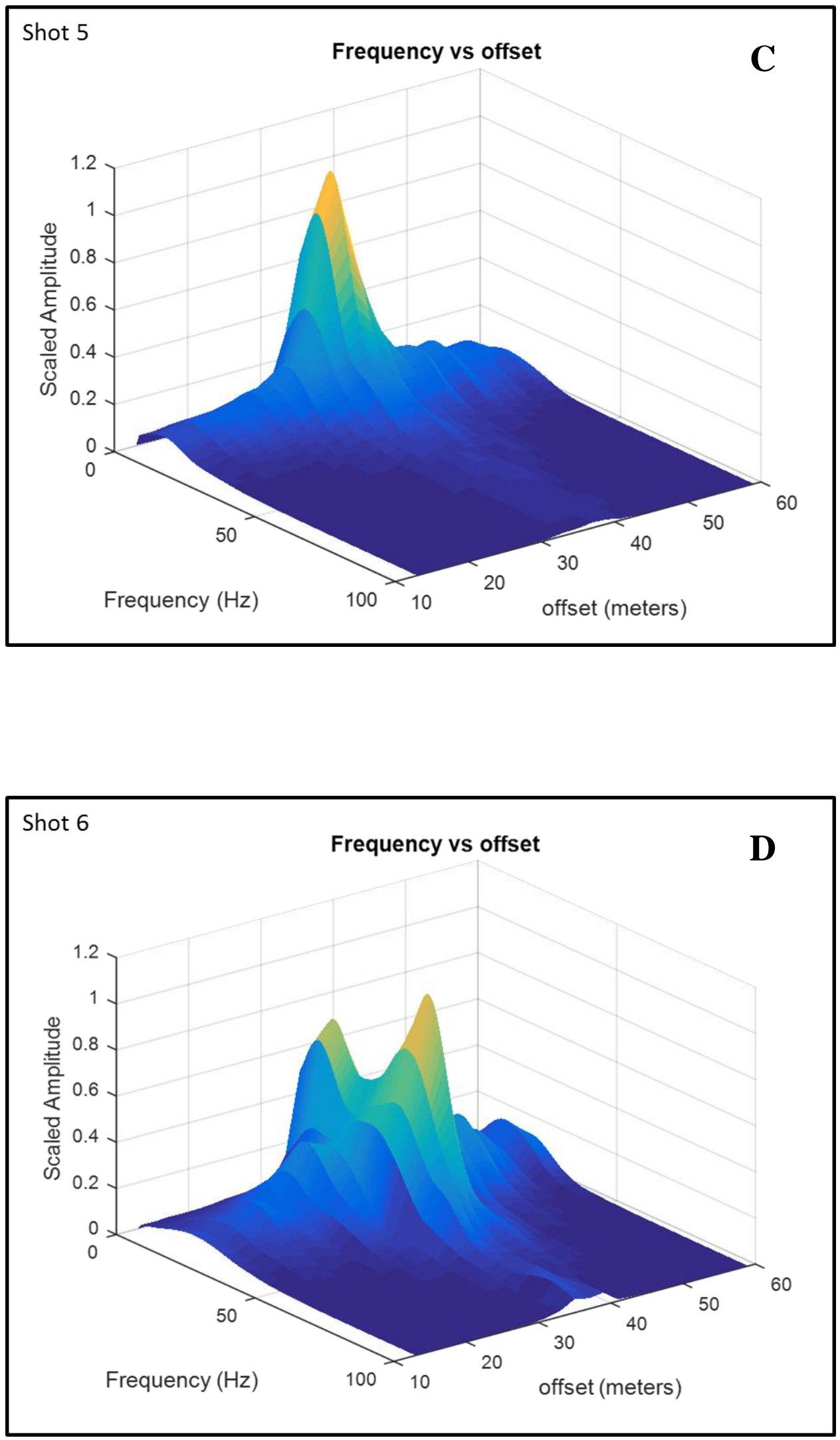

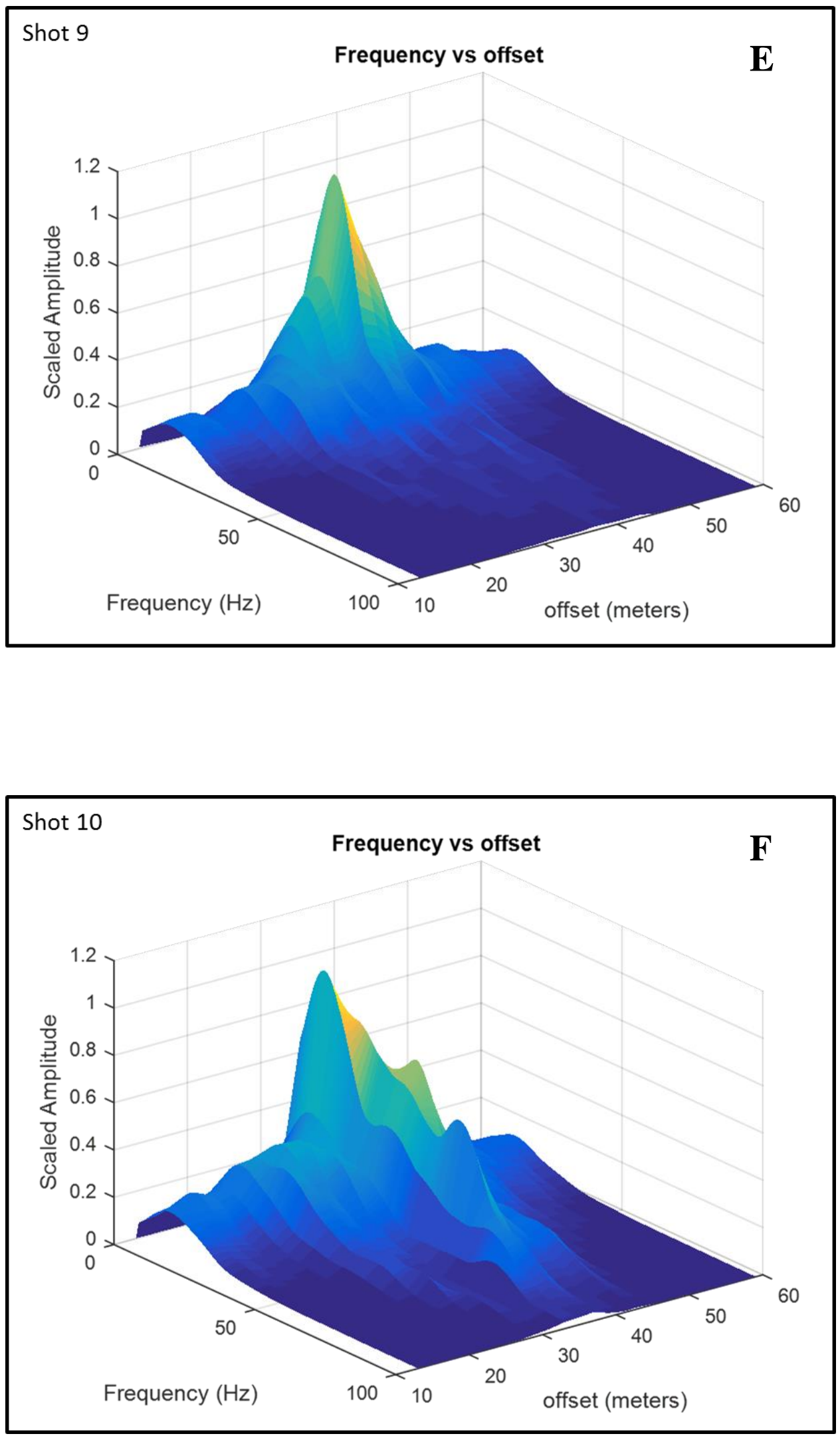

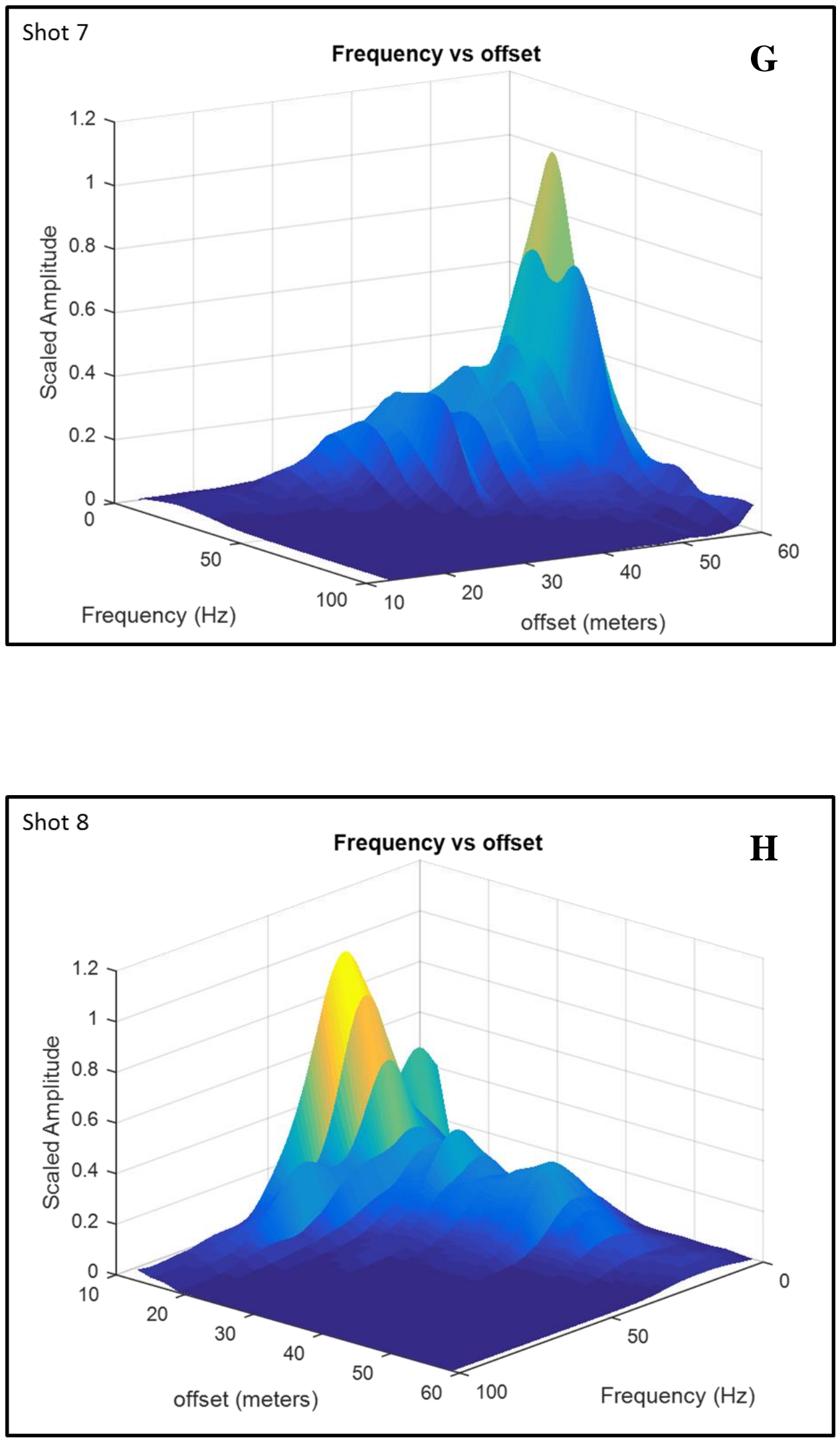

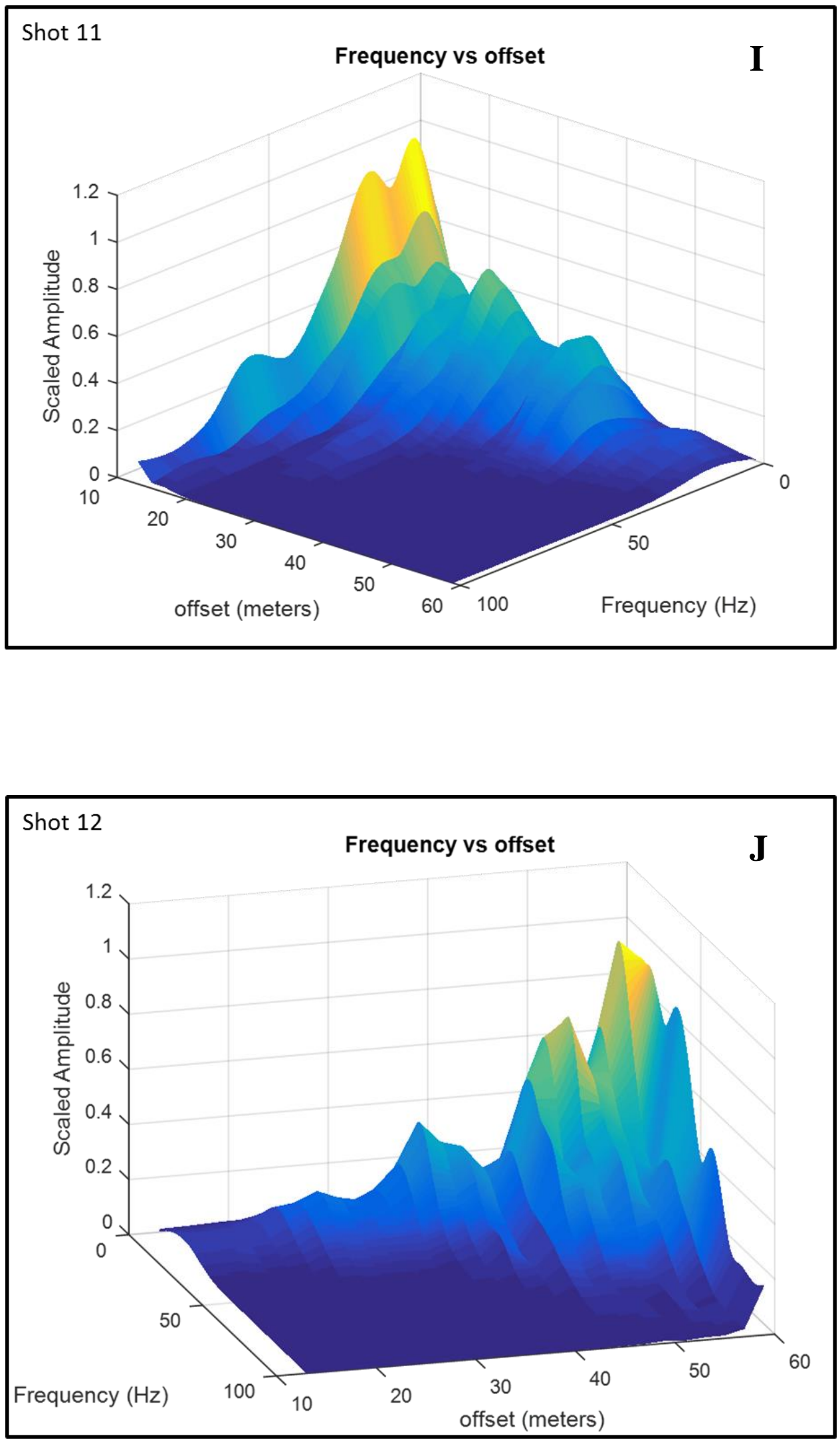

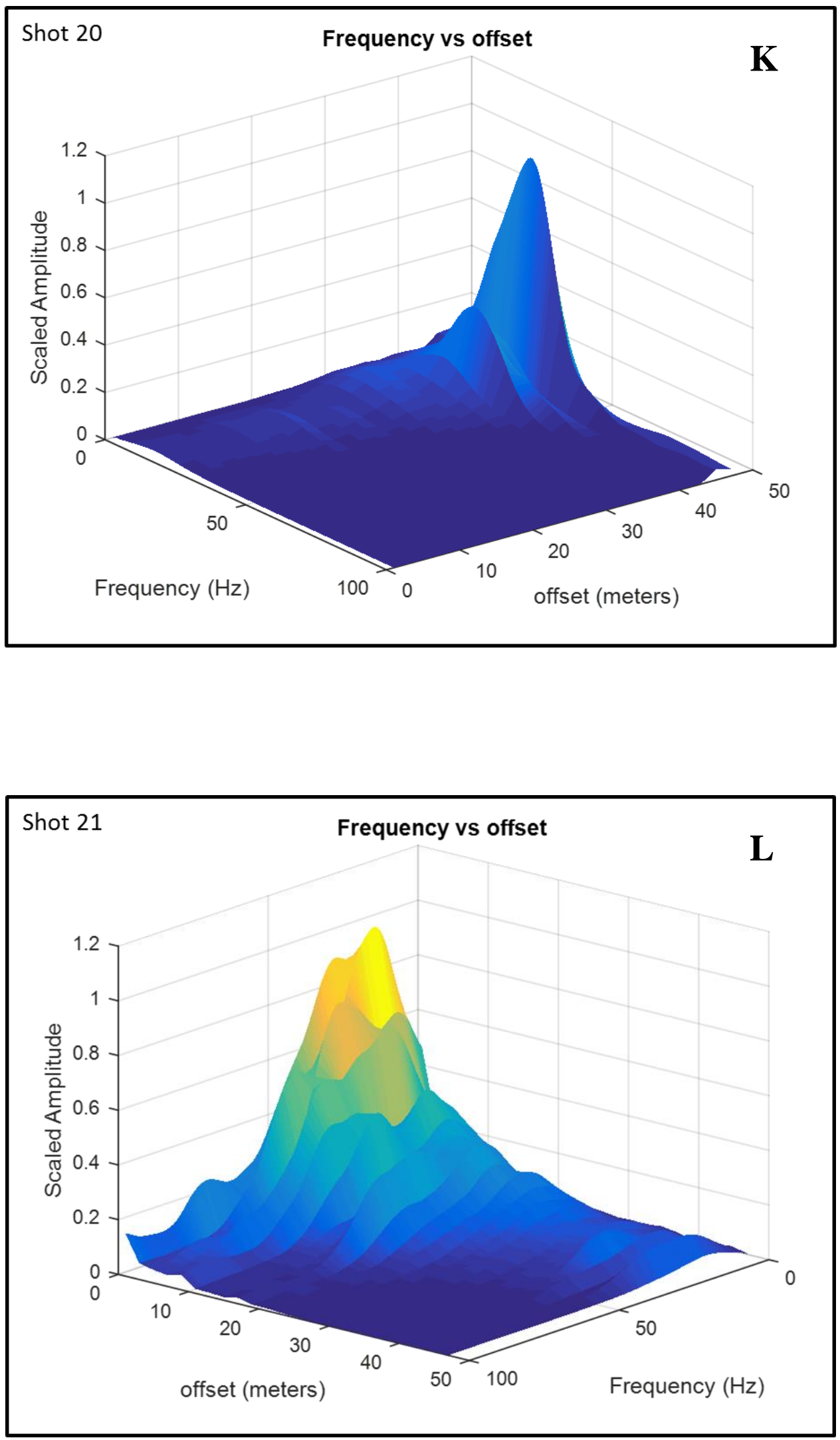

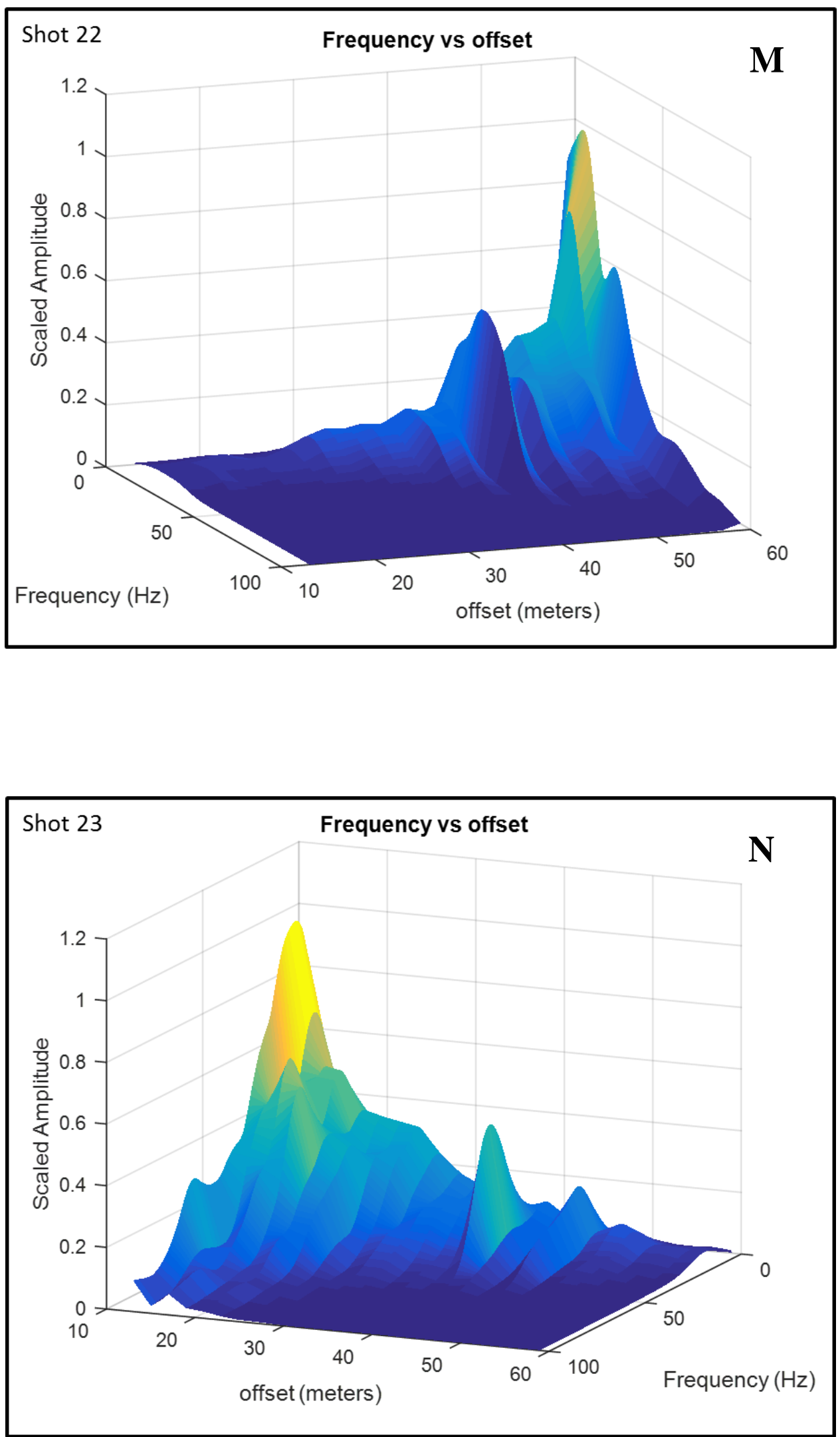

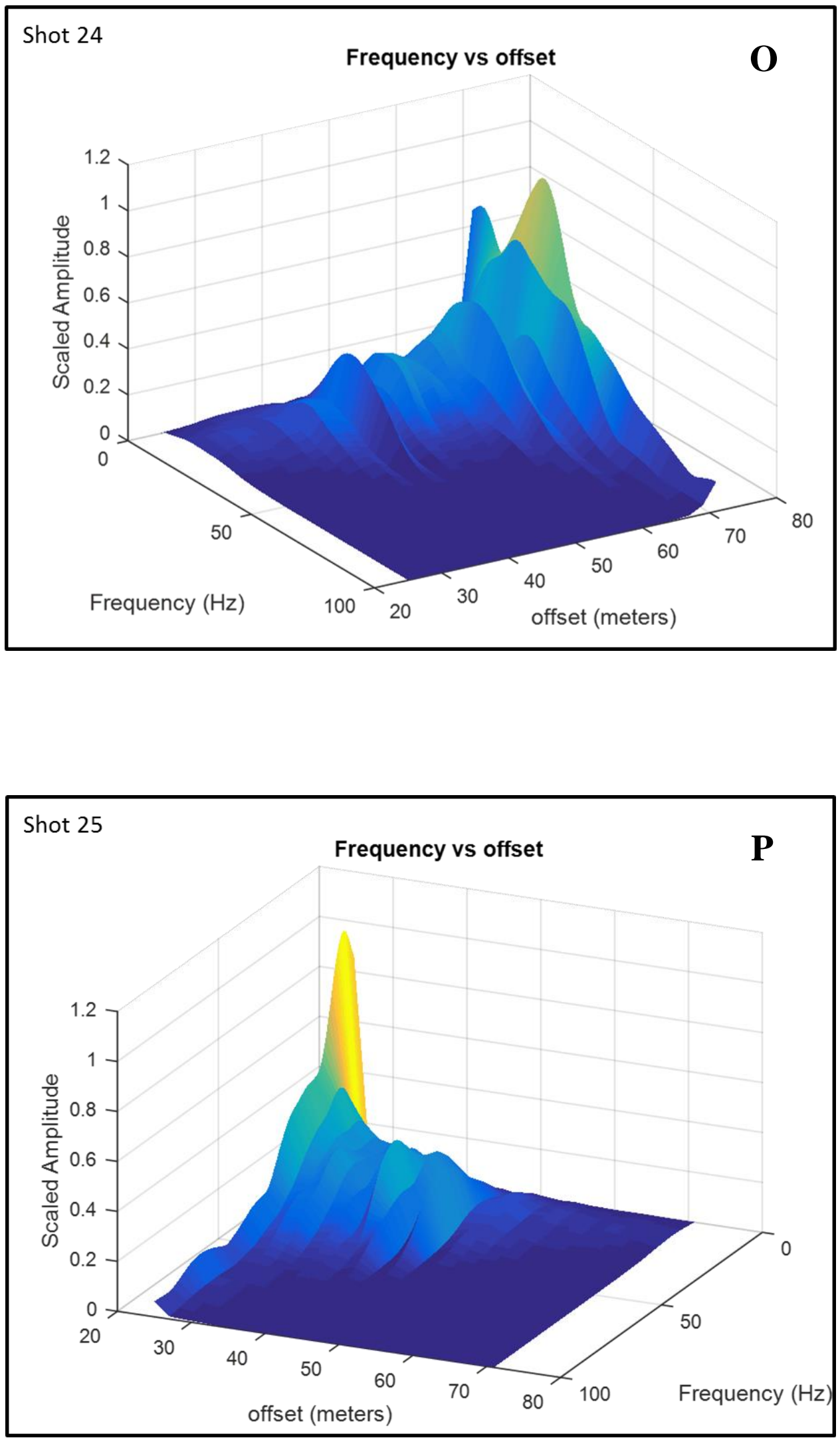

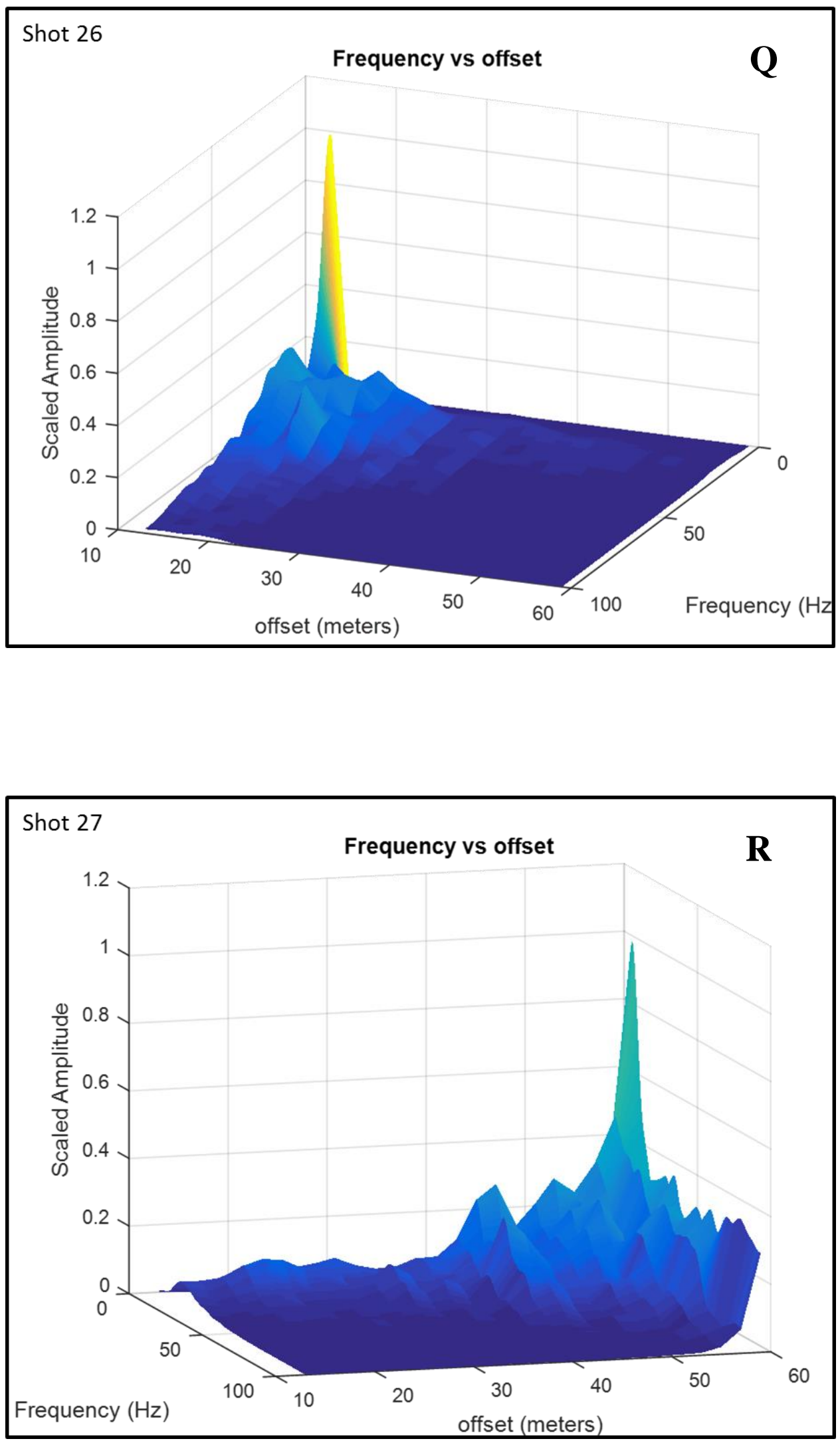


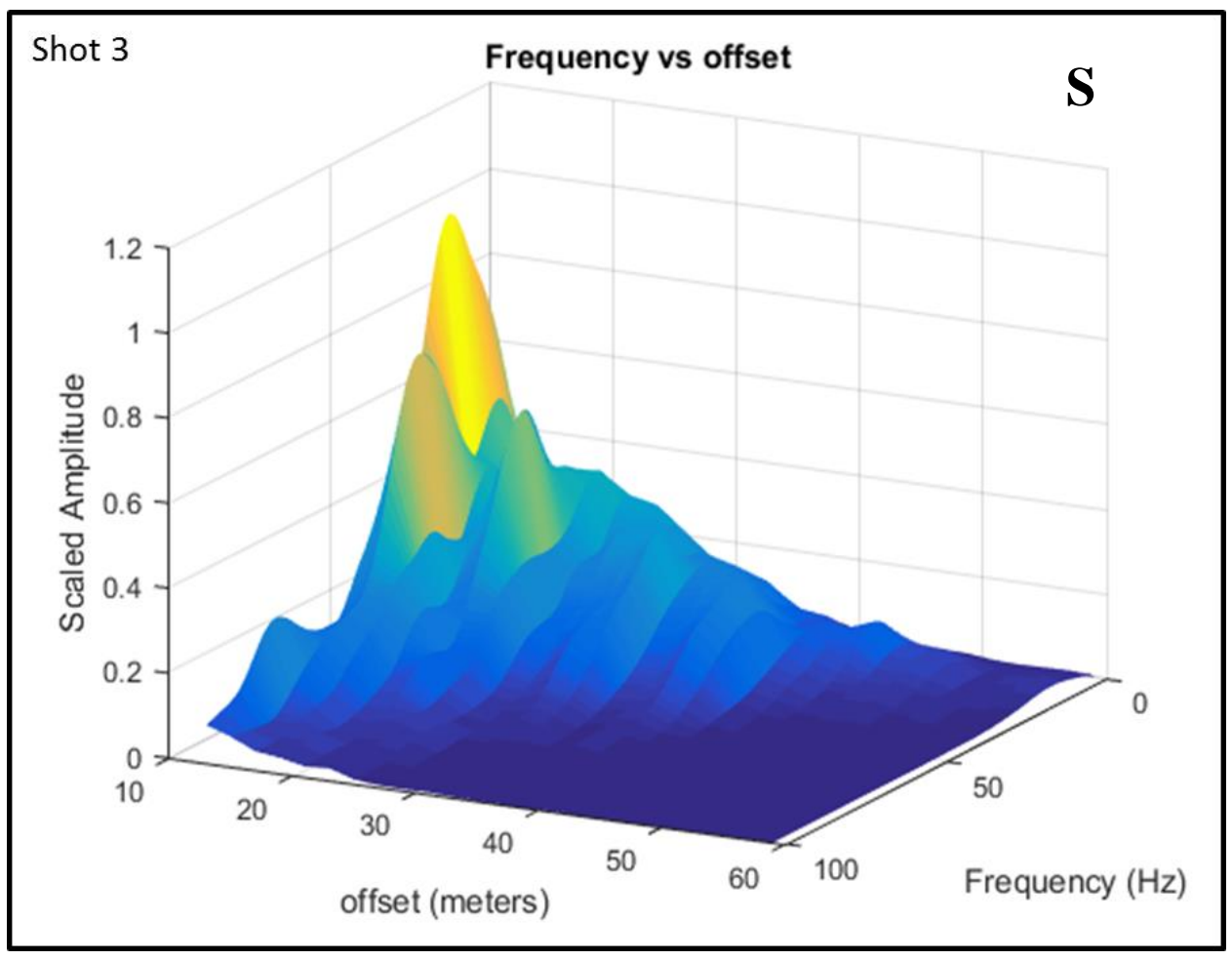


Figure 29 A-S: Complete set of frequency vs offset plots. Each of the following 19 graphs displays the frequency domain of the common shot gathers. Images for line $1(\mathrm{~K}$ and $\mathrm{L})$, line $2(\mathrm{~A}, \mathrm{~B}, \mathrm{M}, \mathrm{N}, \mathrm{O}, \mathrm{R}$ and $\mathrm{S})$, Line 2 at $13^{\circ}(\mathrm{C}, \mathrm{D}, \mathrm{G}$ and $\mathrm{H})$, line 2 at $90^{\circ}(\mathrm{E}, \mathrm{F}, \mathrm{I}$ and $\mathrm{J})$, and line $3(\mathrm{O}$ and $\mathrm{P})$ were used to bandpass filtered the common shot gathers in the time domain to highlight surface wave diffractions. Image $\mathrm{M}$ and $\mathrm{N}$ show the clearest amplitude anomalies caused by the cave. Other images such as $\mathrm{K}$ and $\mathrm{L}$ show how the attenuation properties change depending on the location of the shot point with respect to the cave. 


\section{Appendix G: Frequency Contour Plots}



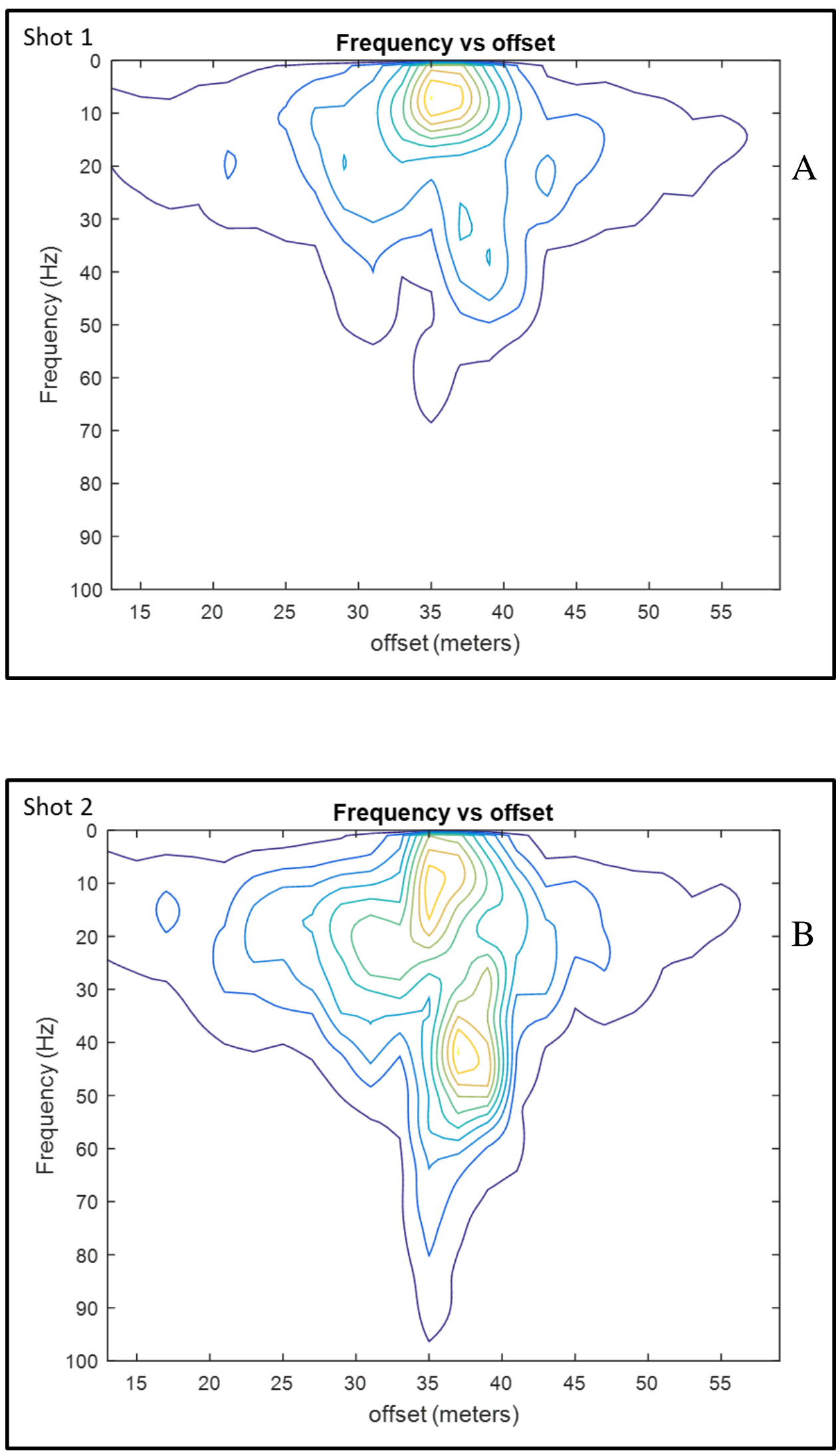

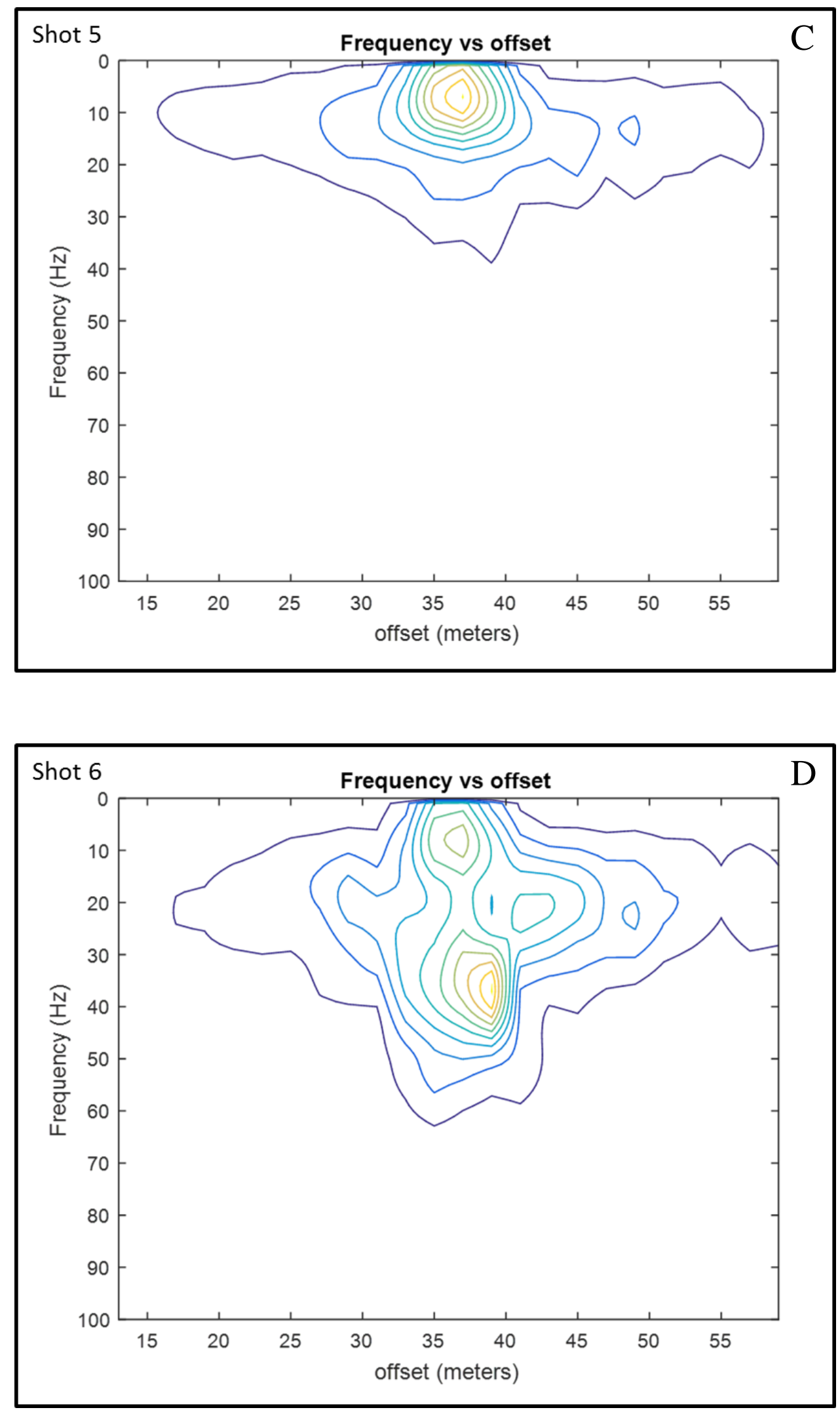

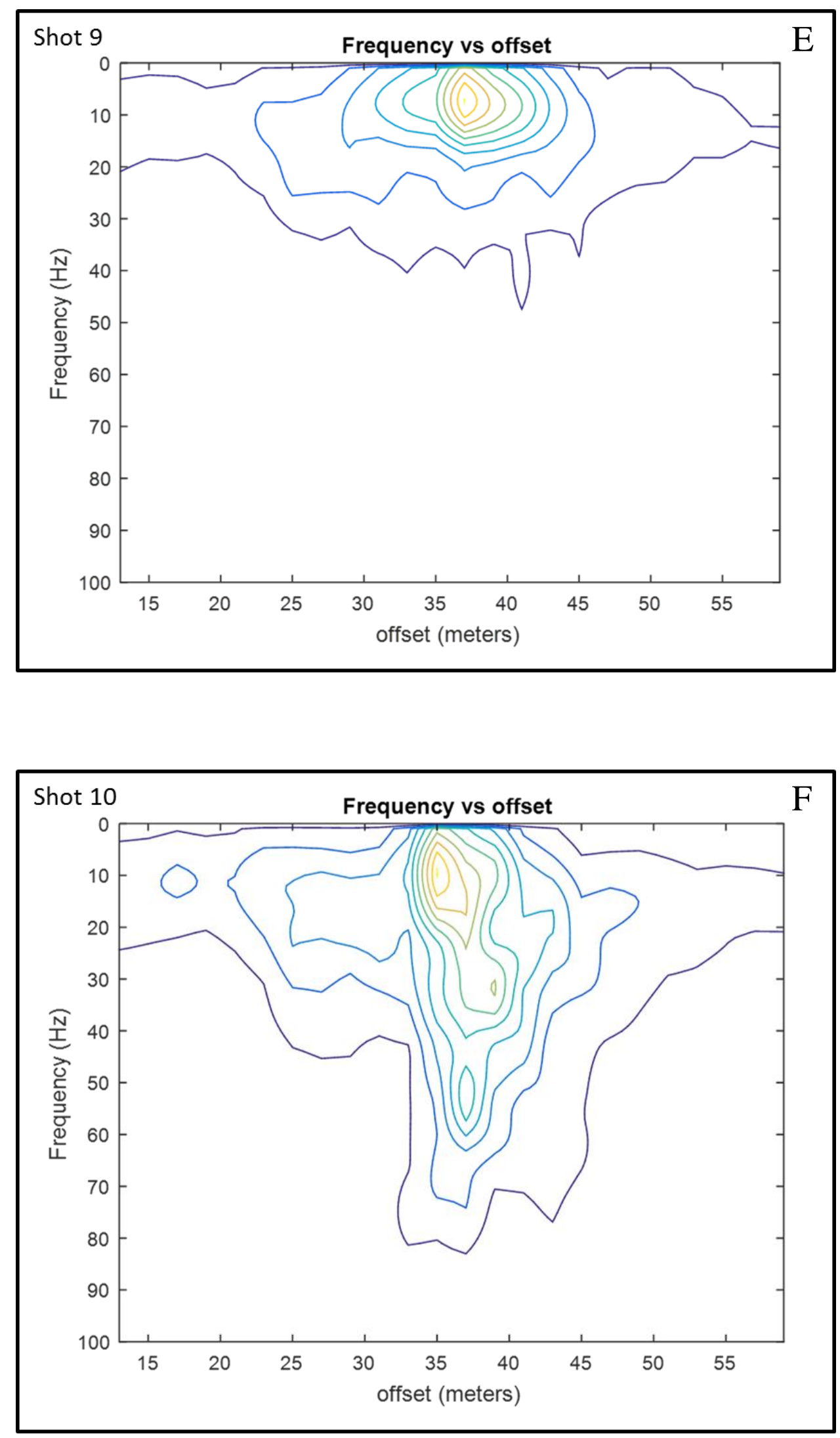

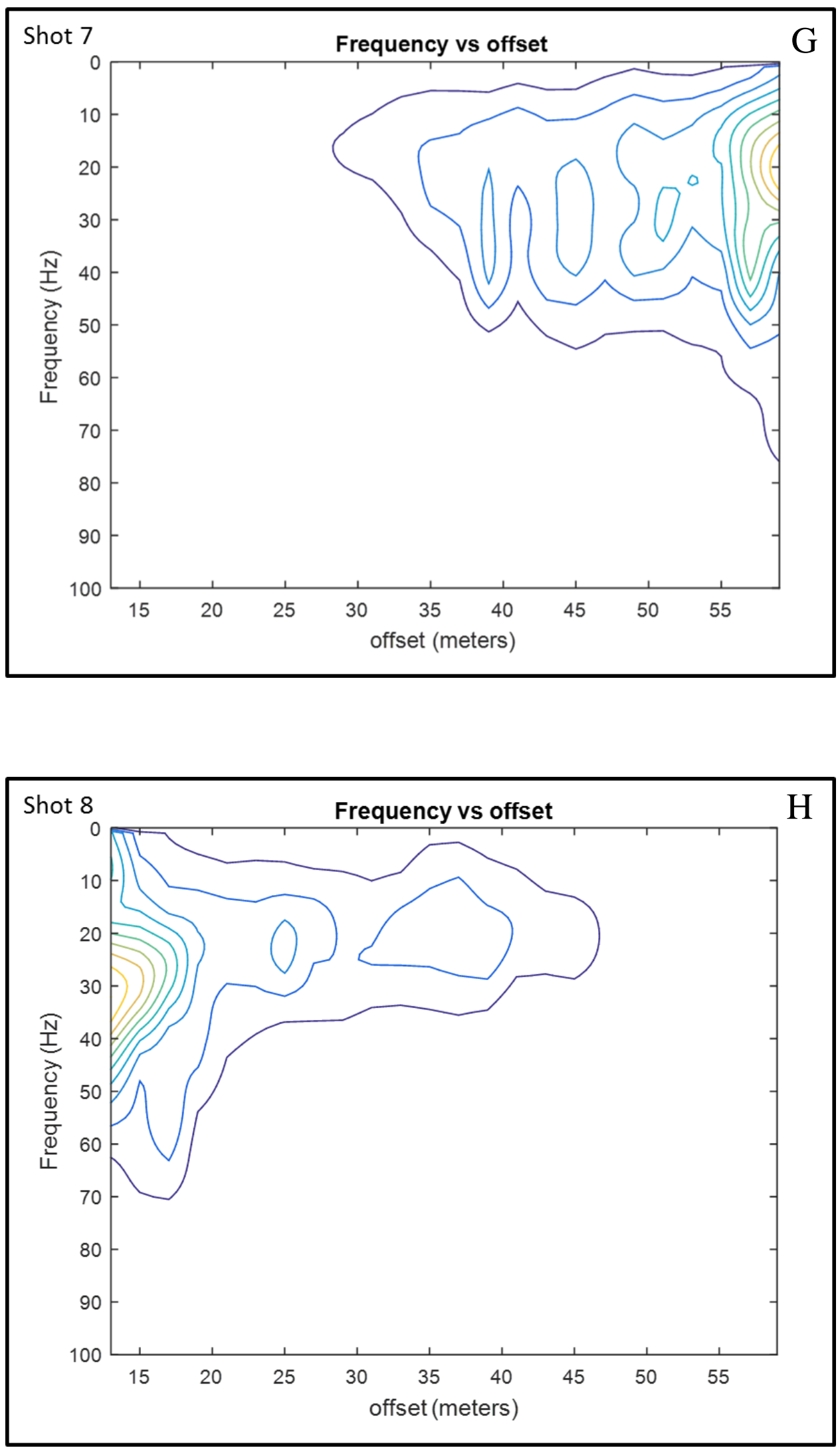

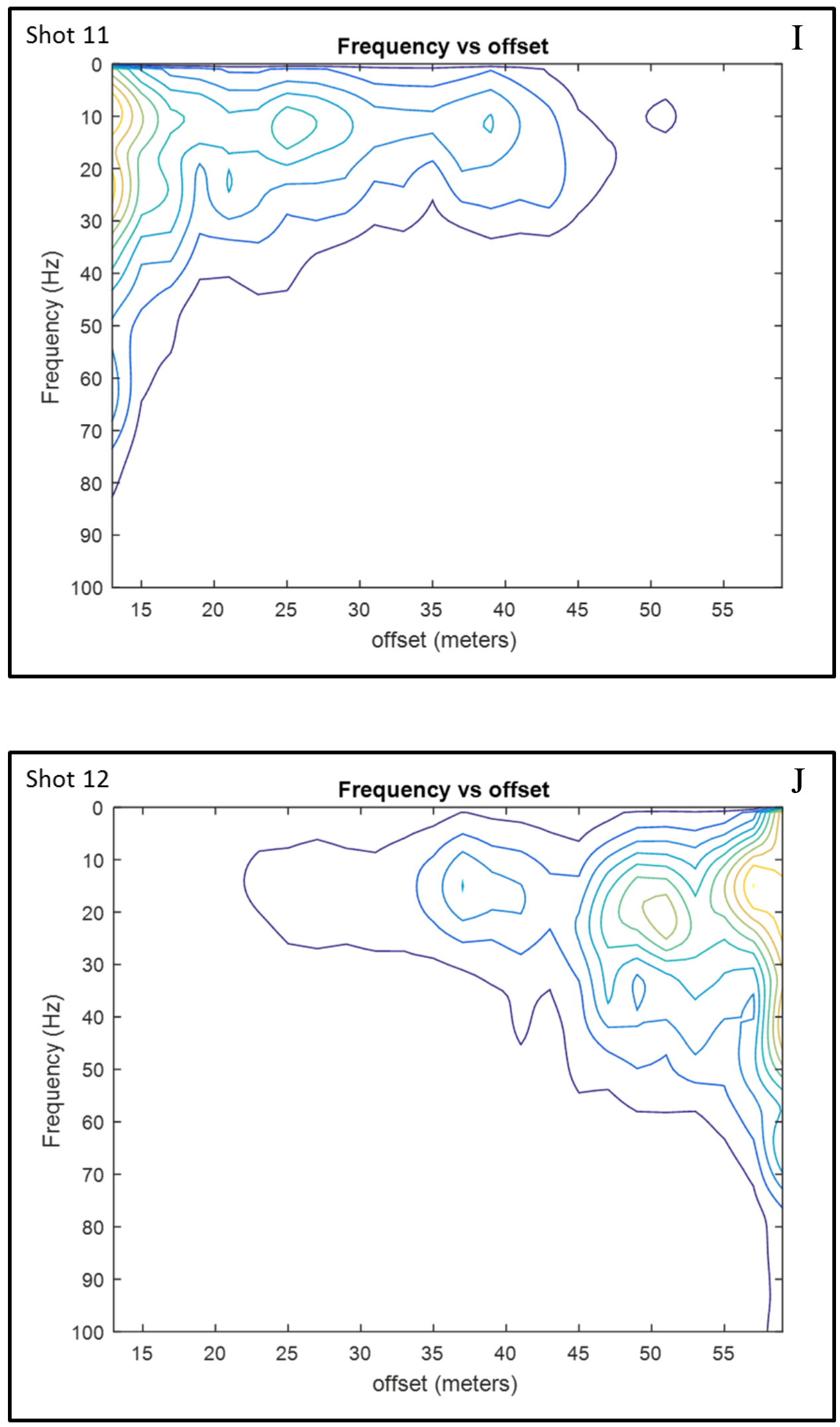

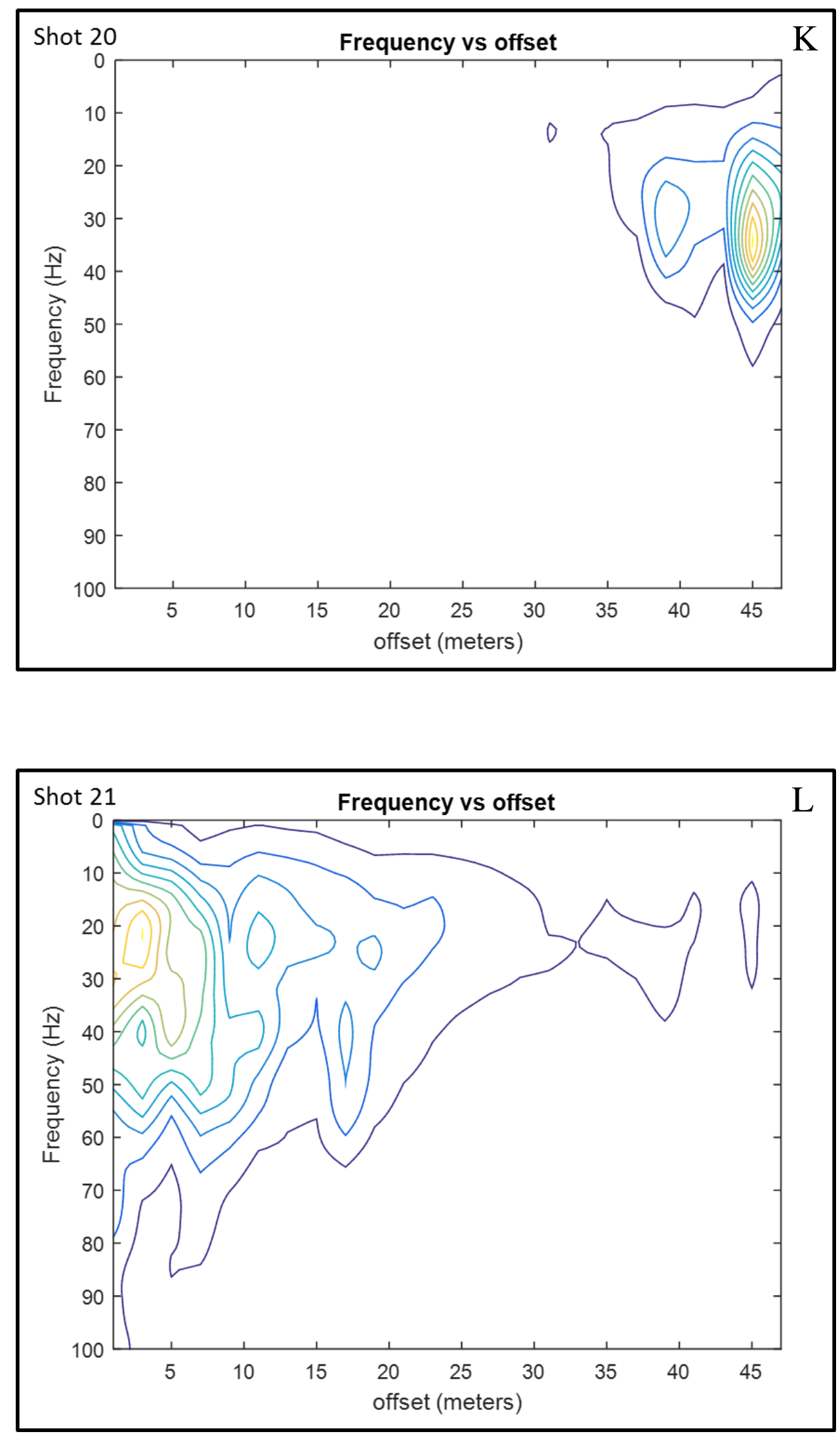

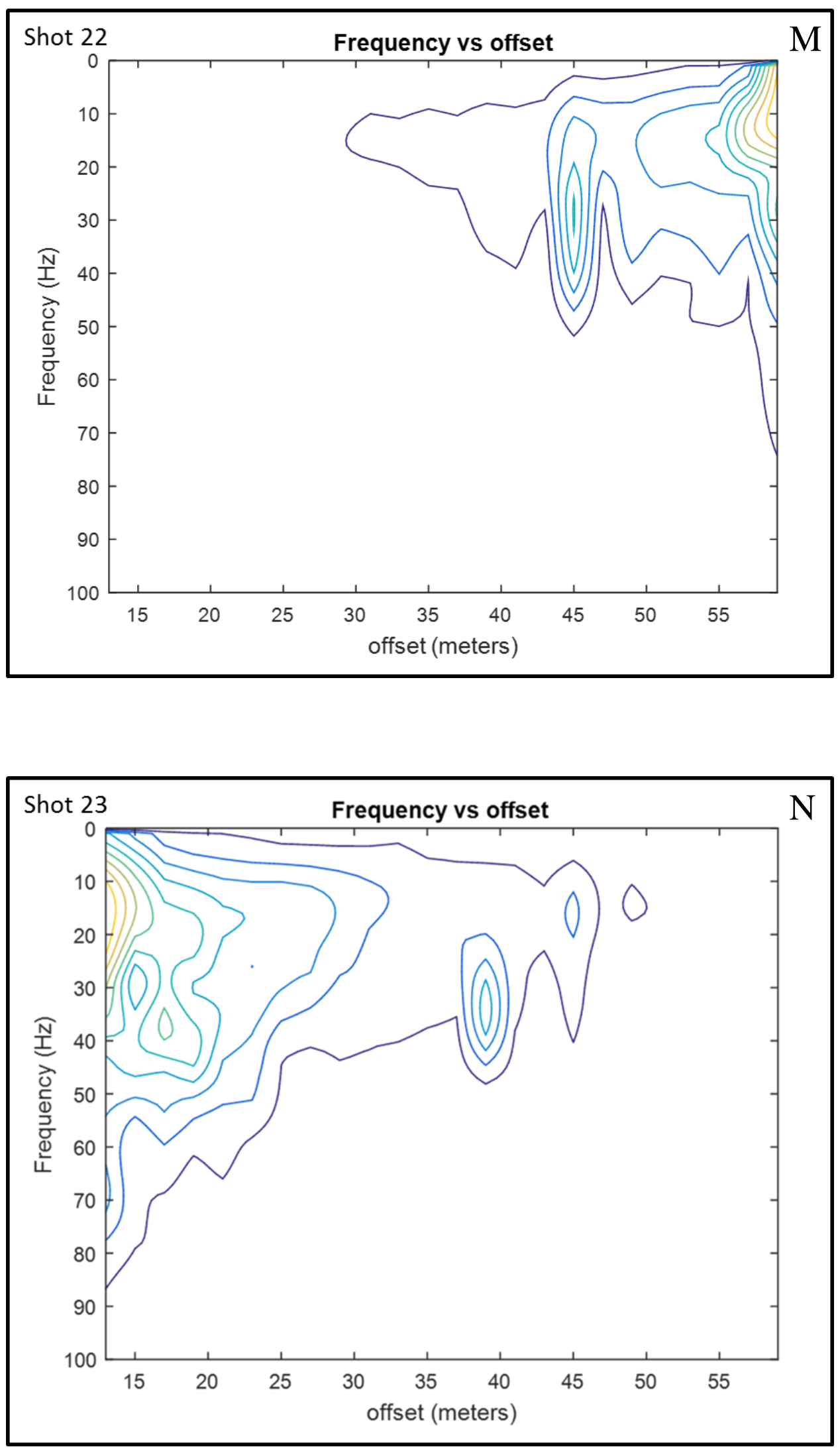

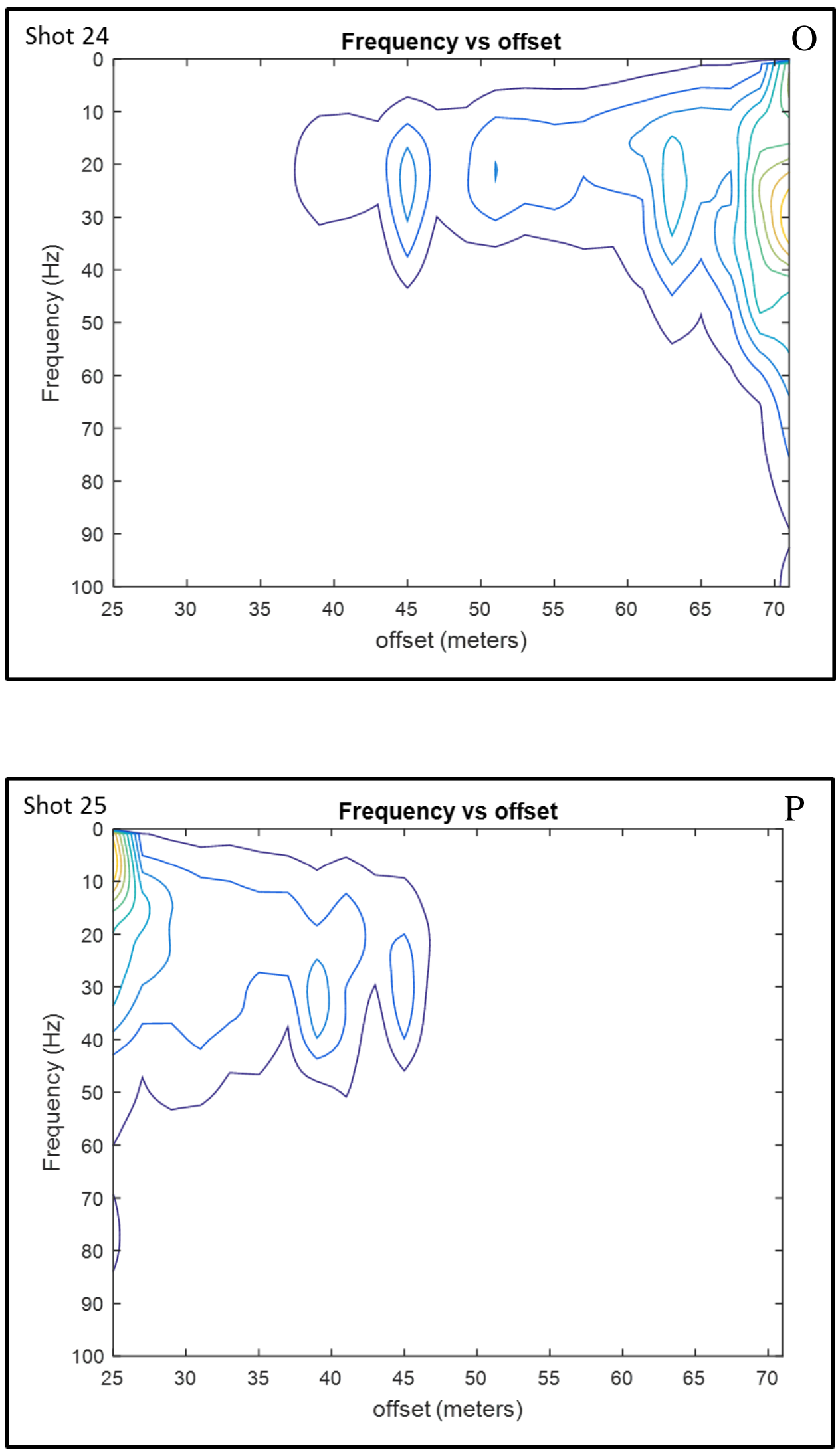

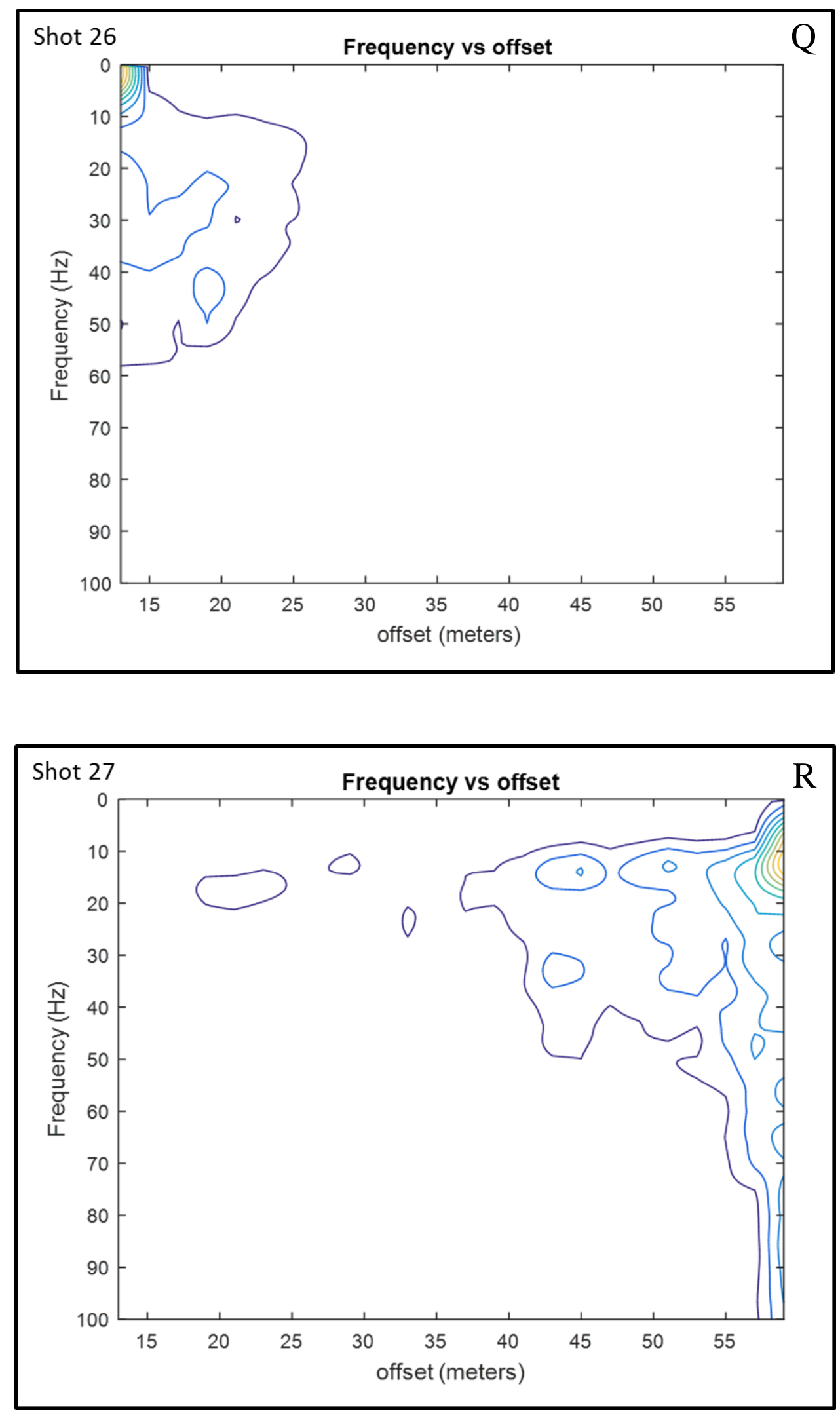


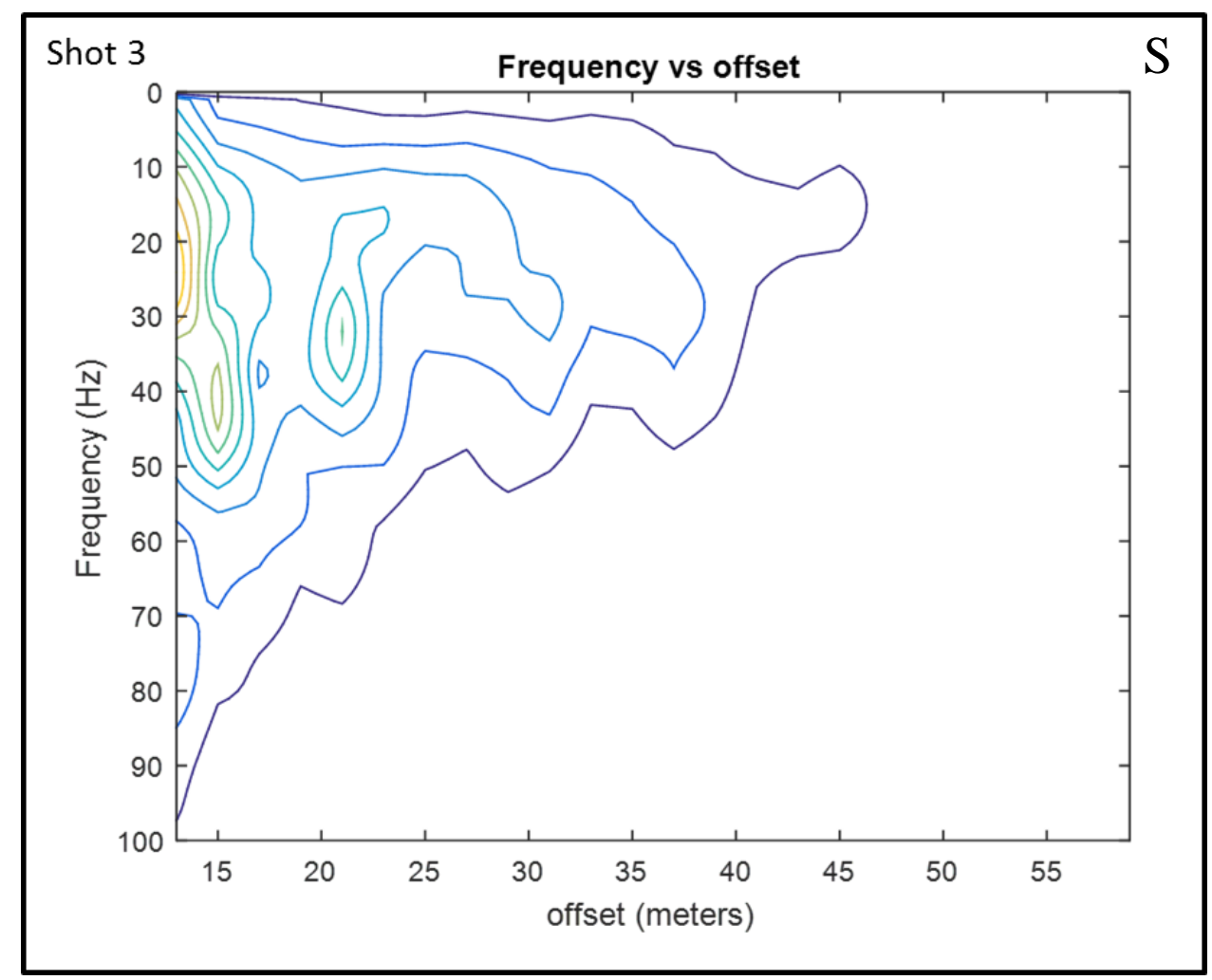


Figure 30 A-S: Complete set of frequency vs offset plots. Each of the following 19 graphs displays the frequency domain of the common shot gathers in contour plots. These plots were generated for better visualization of the anomaly offsets and frequency range.. Images for line 1 (K and L), line 2 (A,B,M,N,O, R and S), Line 2 at $13^{\circ}(\mathrm{C}, \mathrm{D}, \mathrm{G}$ and $\mathrm{H})$, line 2 at $90^{\circ}(\mathrm{E}, \mathrm{F}, \mathrm{I}$ and $\mathrm{J})$, and line $3(\mathrm{O}$ and $\mathrm{P}$ ) were used to bandpass filtered the common shot gathers in the time domain to highlight surface wave diffractions. Images $\mathrm{K}, \mathrm{L}, \mathrm{M}, \mathrm{N}, \mathrm{O}$, and $\mathrm{P}$ show the clearest amplitude anomalies and yield the most compelling evidence for the cave location. 
Appendix H: Matlab Codes 


\section{"Simpleoverlayplot"}

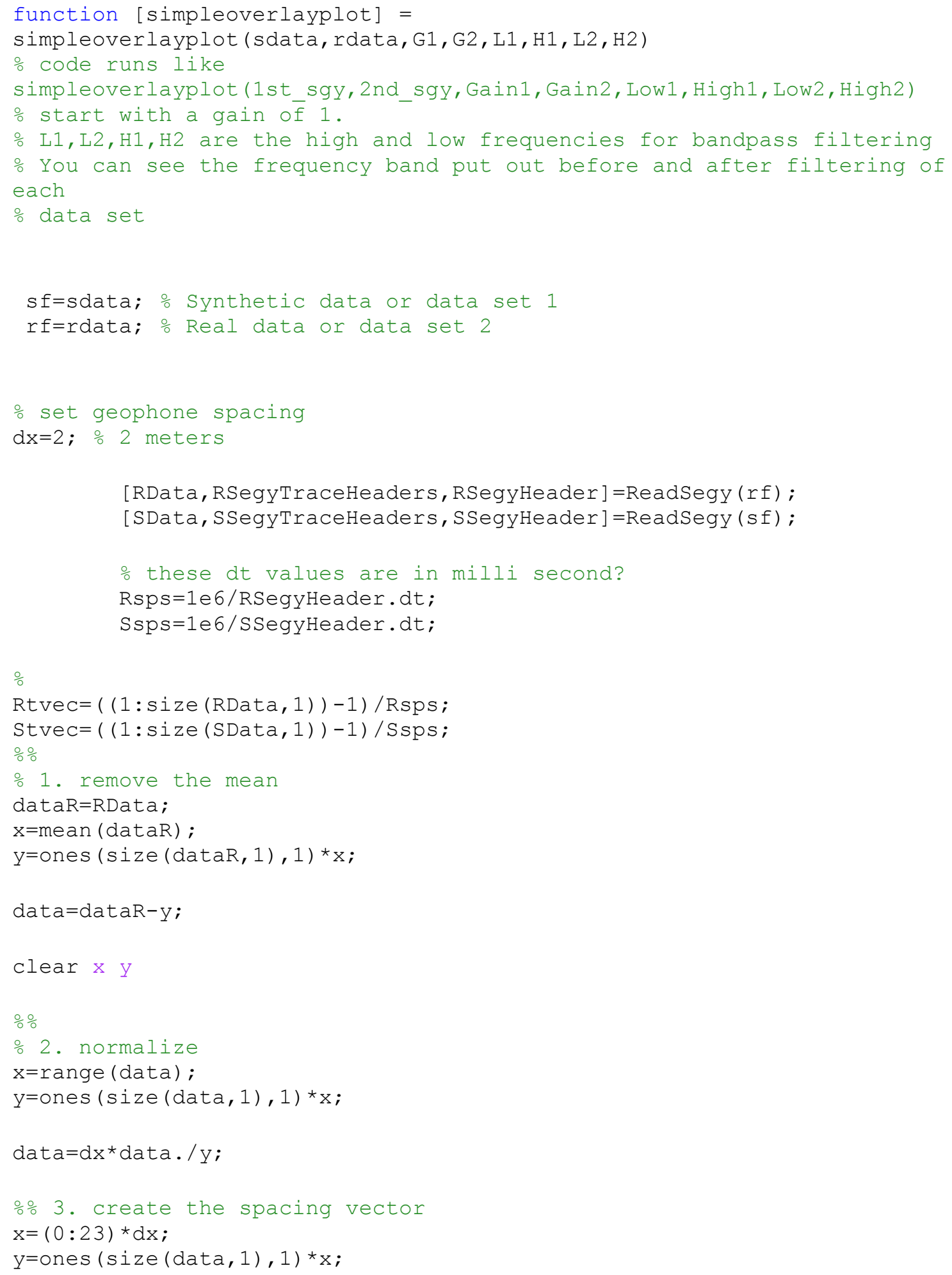




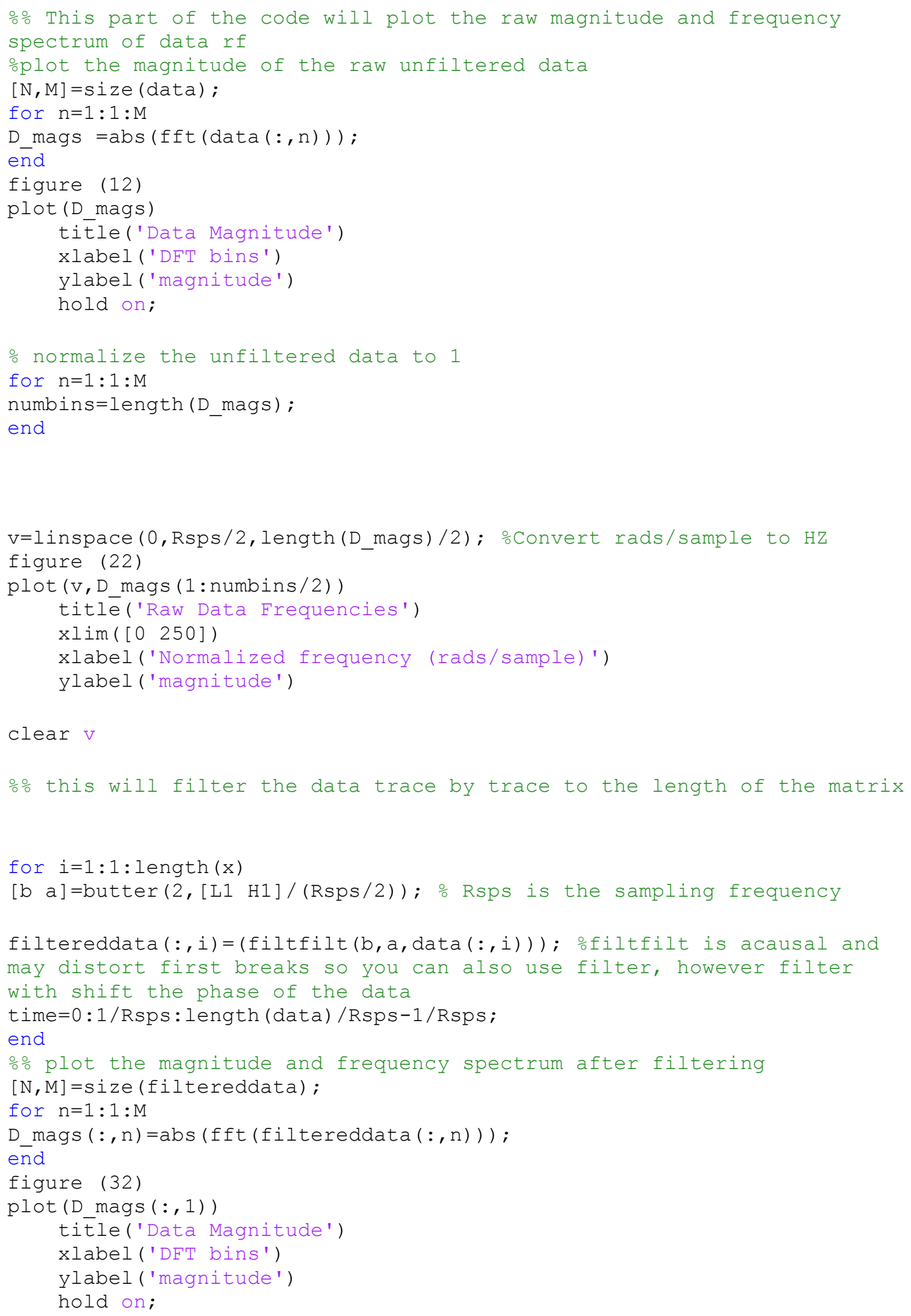




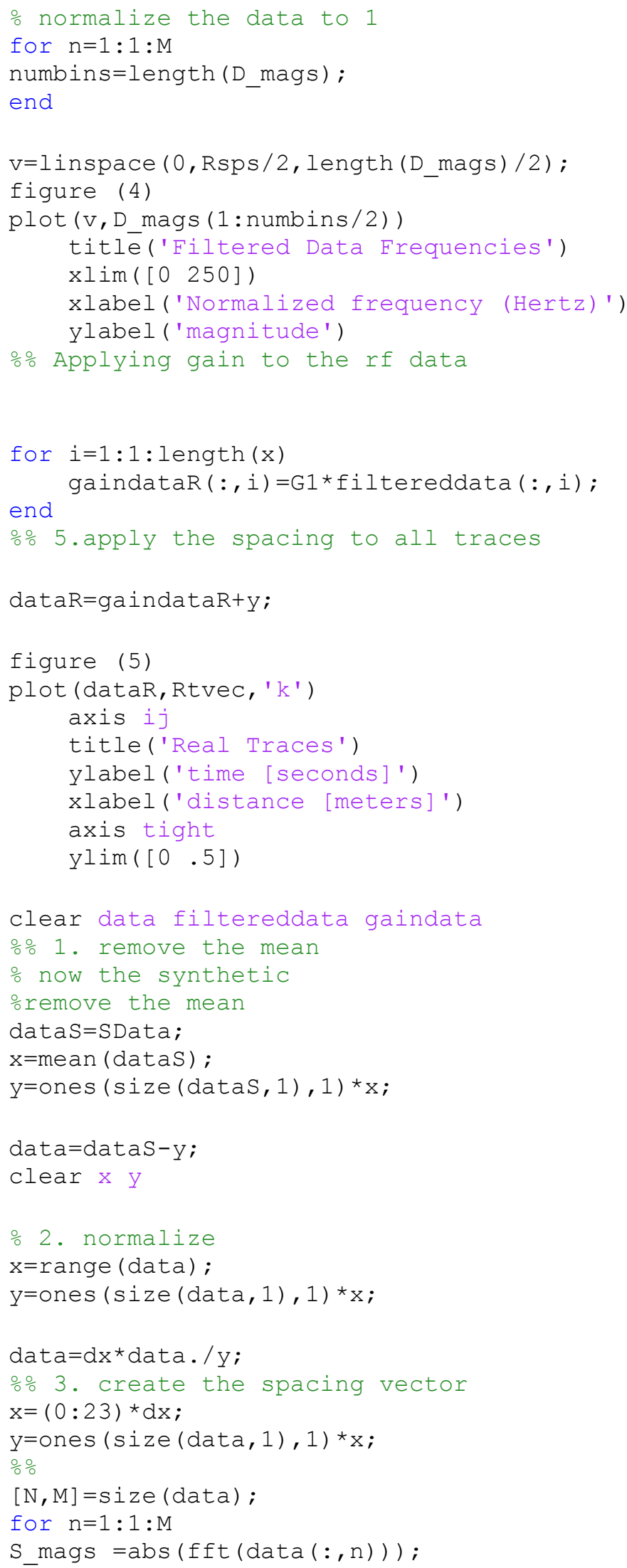




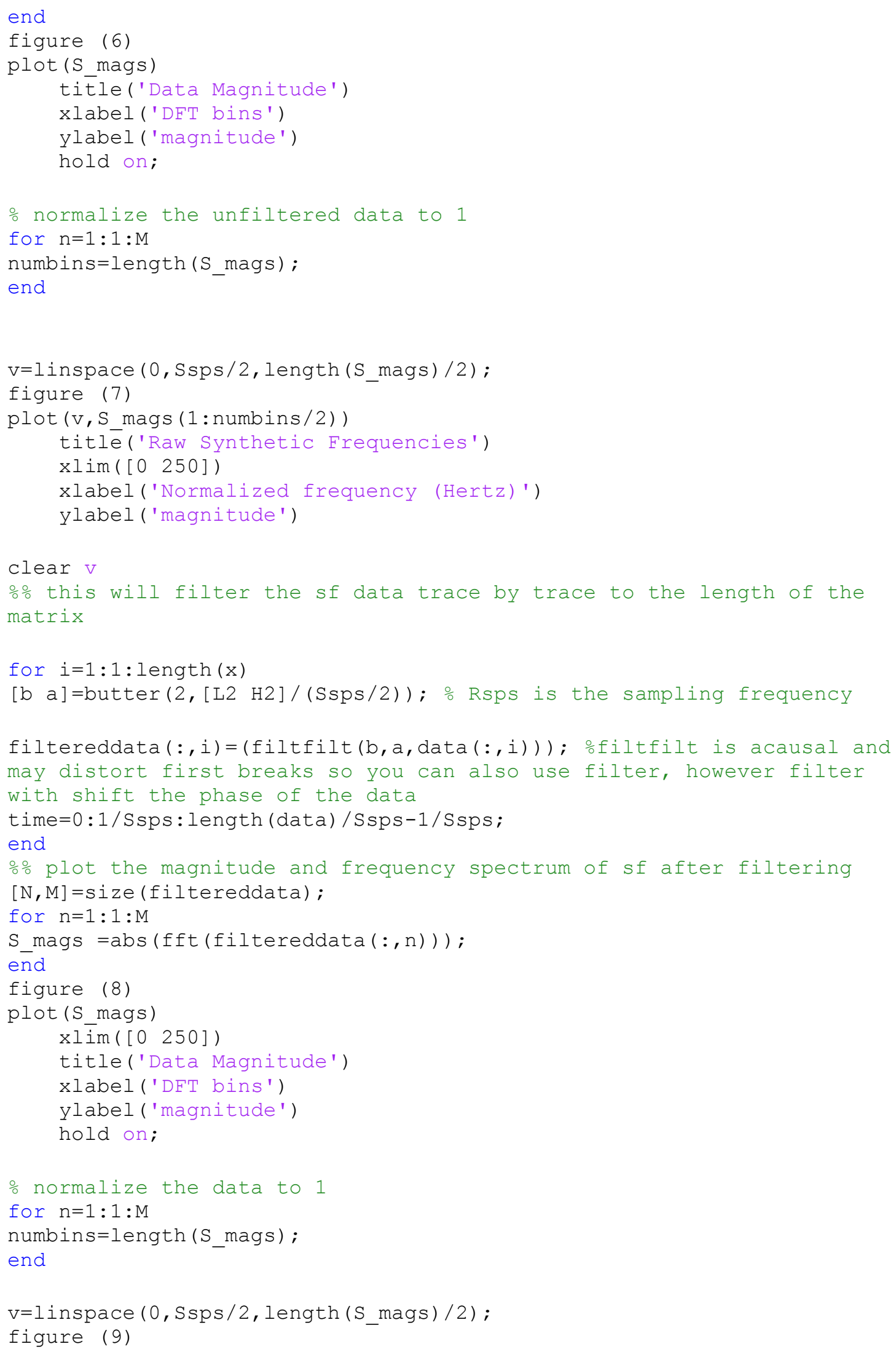




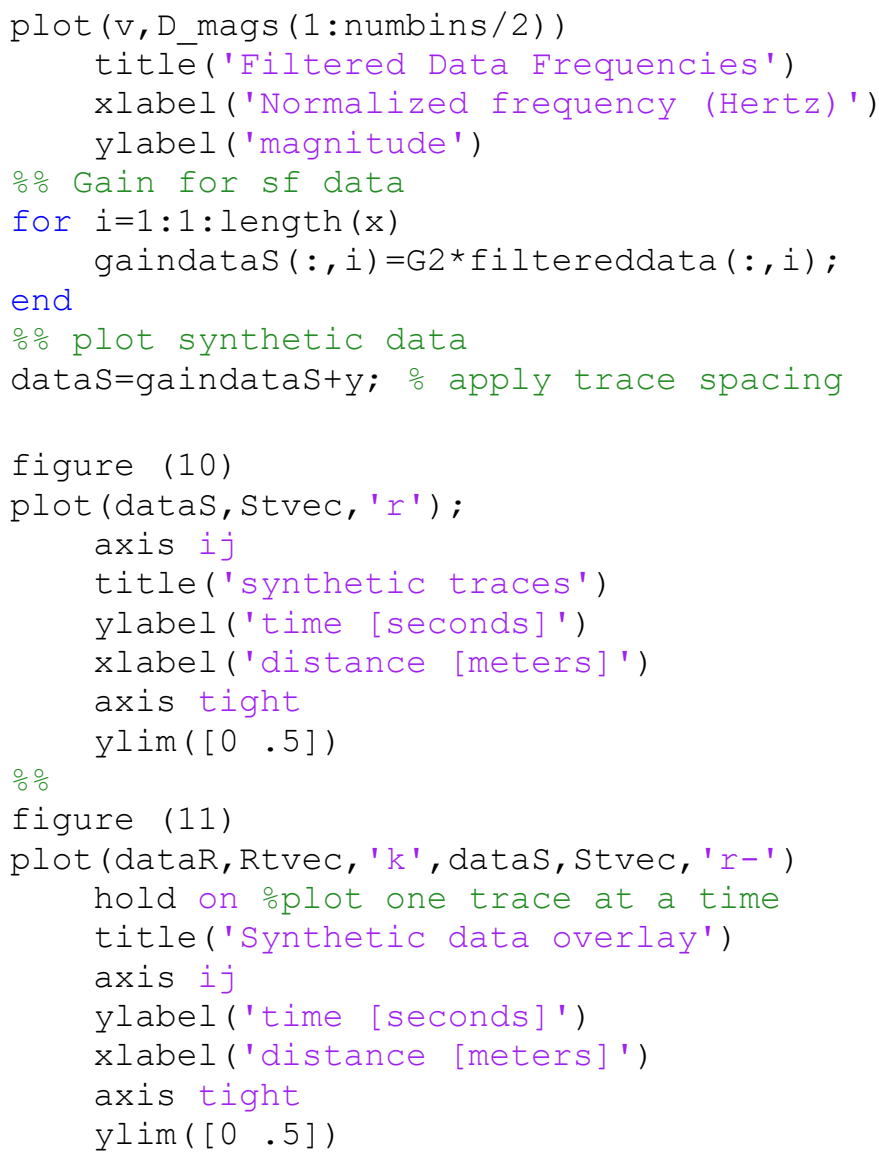




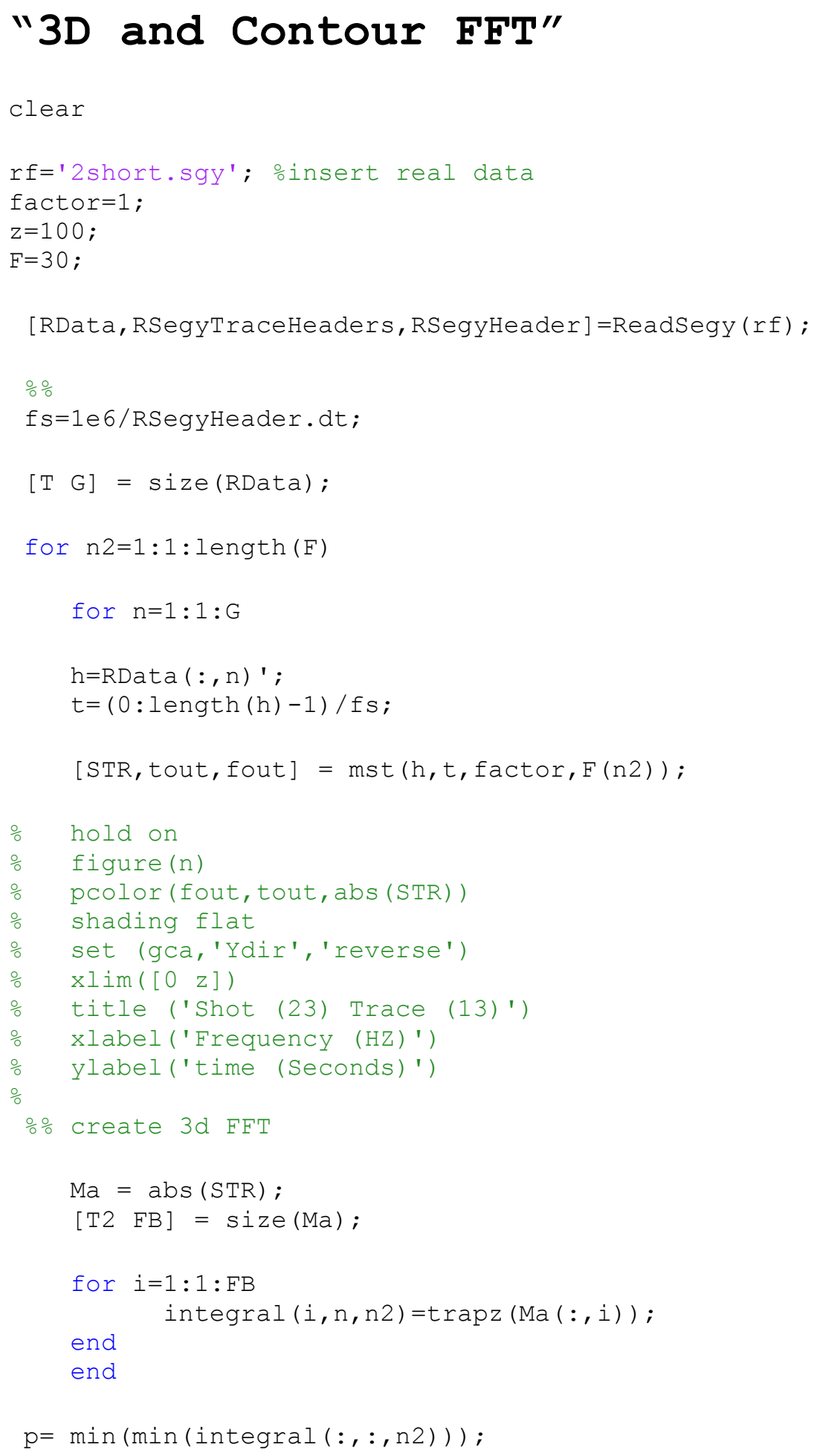




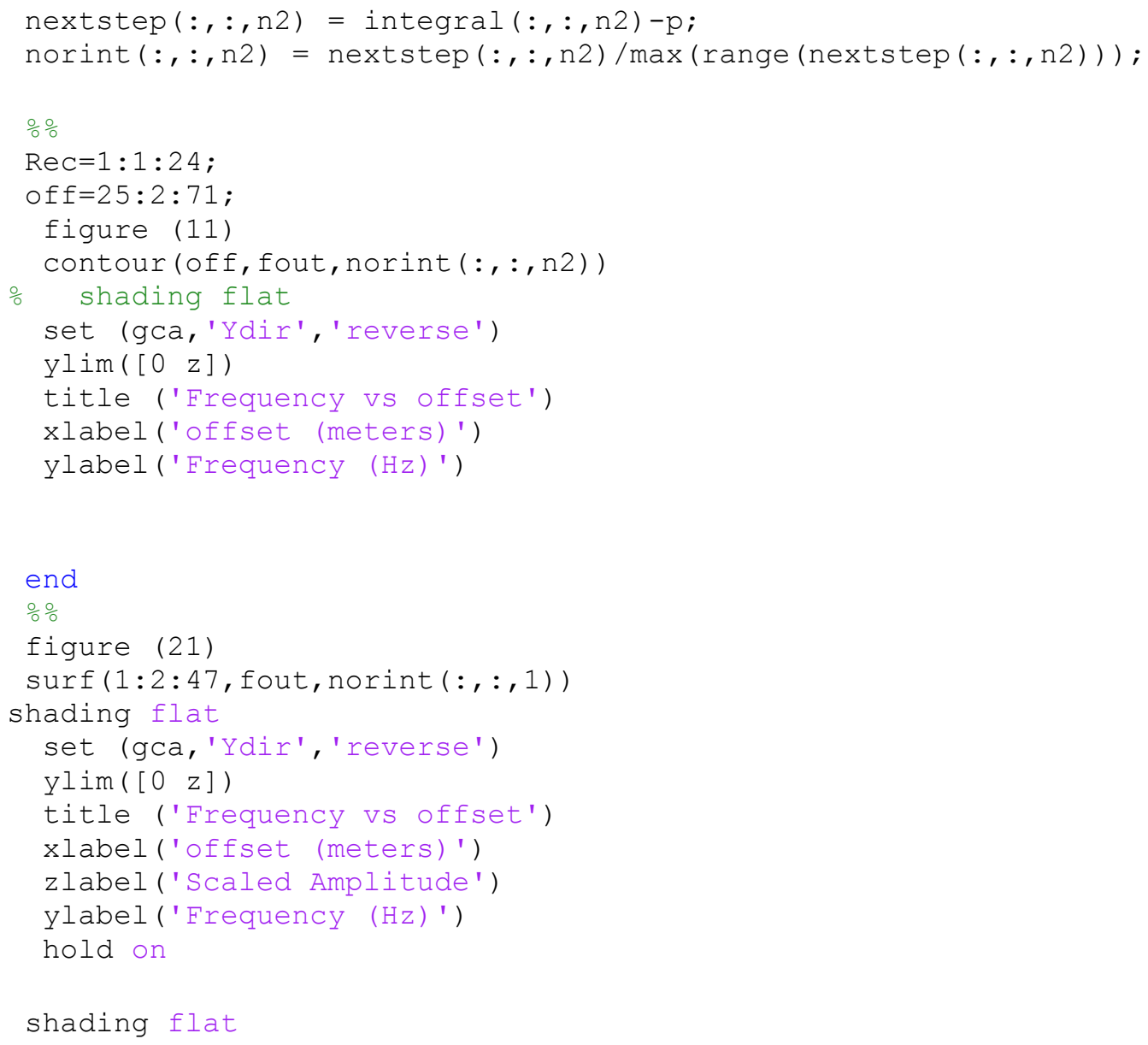




\section{"Data Picker"}

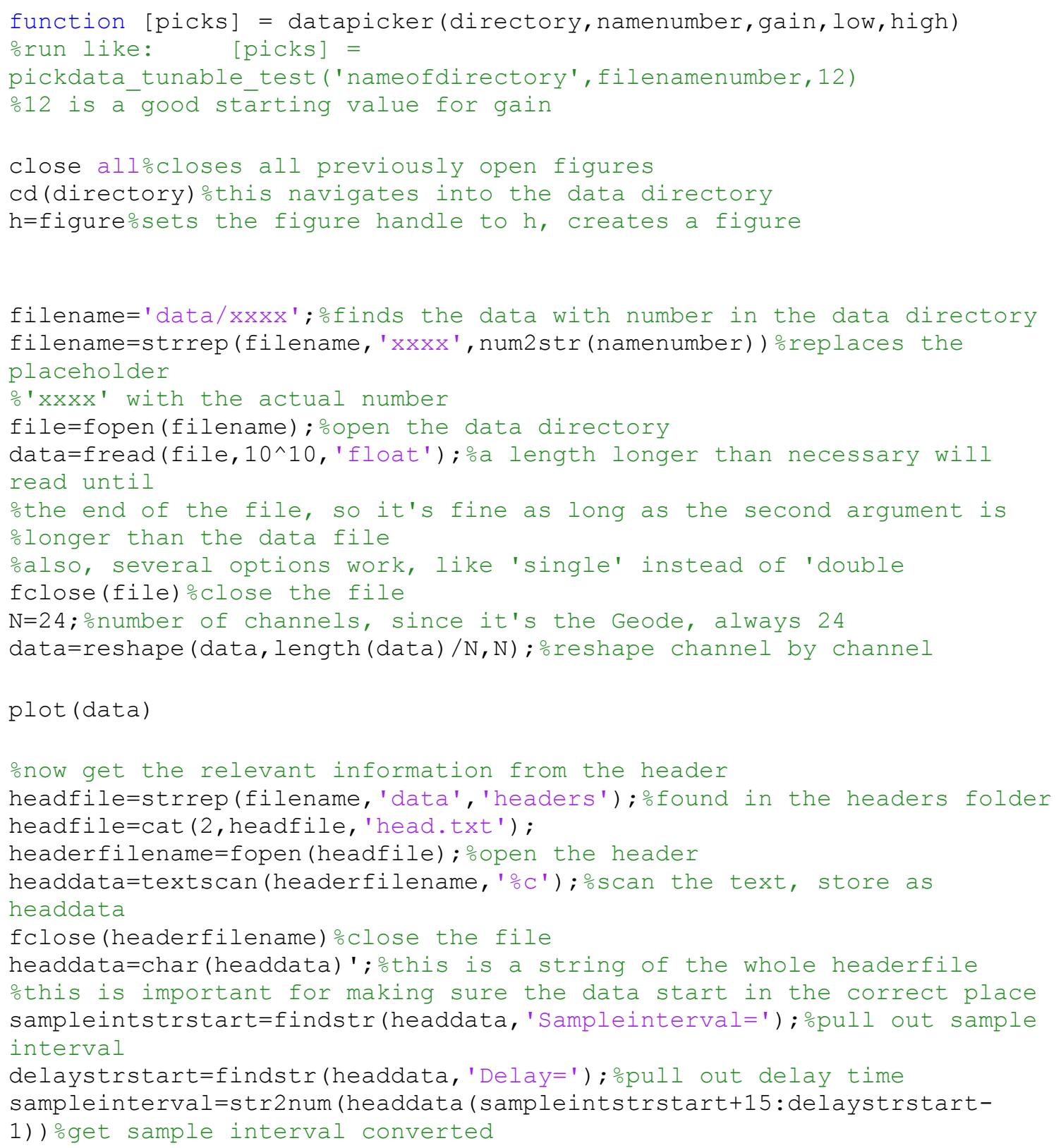


oto a number; it resides in the file as a character string

delay=str 2 num (headdata (delaystrstart+6: length (headdata)) ) \%same for delay

endtime=size (data,1)*sampleinterval+delay; $\%$ find what the end time

should be

ostrings occur in this fashion

o' Sampleinterval=0.0005Delay=-0.2'

owithin the header

oThis part doesn't do anything now, but if it were uncommented, could be

omade to filter with these two lines:

oxample:

o[ba]=butter (4, [high]/(1/(sampleinterval*0.5)), 'high'); \%100 Hz high pass filter

[b a ] =butter (2, [low high] / (1/(sampleinterval*0.5)), 'bandpass') ; $0100-$

$300 \mathrm{~Hz}$ band pass filter

\%[b a ] =butter (4, [low]/(1/(sampleinterval*0.5)), 'low'); ㅇow pass filter

odata=filter (b, a, data) ;

onow this part just decides the starting gain for the traces

for $i=1: N$

gaindata=gain*data $(:, i) / \max (\operatorname{data}(:, i))$;

startinggain $(i)=g a i n / \max (\operatorname{data}(:, i))$;

oclip data at .9 of the full trace width to emphasize first breaks

toohigh=find (gaindata>.9);

toolow=find (gaindata<-.9);

gaindata $($ toolow $)=-.9$;

gaindata (toohigh) $=.9$;

oplot the data with the appropriate timing

plot (delay: sampleinterval:endtime-sampleinterval, gaindata+(i), 'k')

hold onoplot one trace at a time

end

title(num2str(namenumber)) \%title of the traces from the input file xlim([-.01 .5]) \%window to zoom in on the most important of the traces oif data are cut off before first breaks, this can be lengthened to osomething like xlim([-.05.3]) etc, where currently, the traces is odisplayed from zero time -0.05 seconds to 0.2 seconds

xlabel('Time (s)') \%add time label to the x-axis

ylabel ('Arbitrary Amplitude') amplitude, not uniformly scaled

othis part now allows an interactive gain change portion

disp('use the arrow keys as numbers to change between channels and adjust gain')

channum=1; ㅇtart always at channel one, which only is assigned

depending on geode location

chan=0 ;

disp('up/down for channel, left right for gain, 1 on numpad to quit'); hold off

while chan =49\%49 is actually \#1 on the num pad

$\mathrm{w}=$ waitforbuttonpress; ㅇats for something to get hit

if $\mathrm{w}$ 


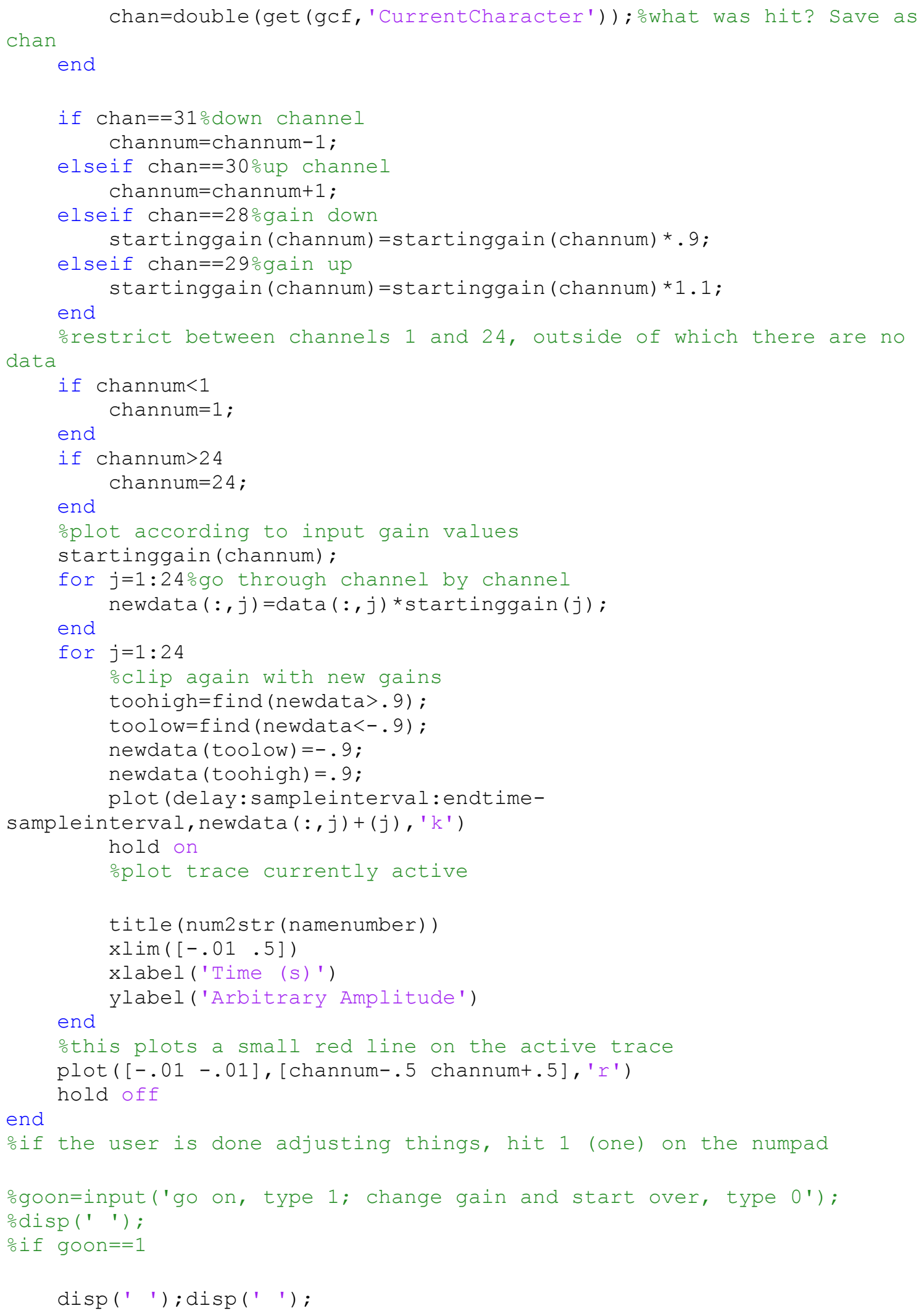




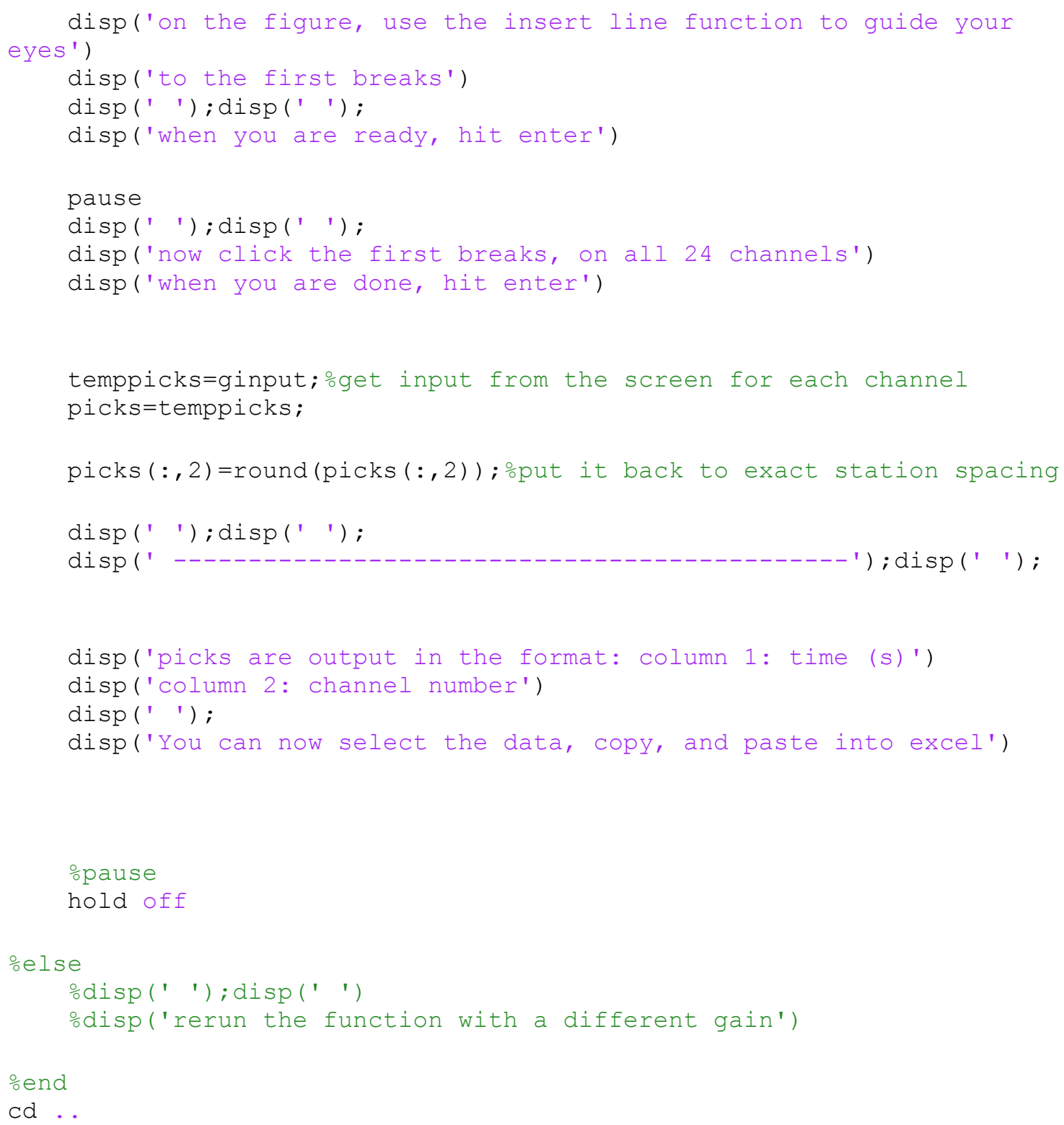

